\title{
WestVirginiaUniversity
}

THE RESEARCH REPOSITORY @ WVU

Graduate Theses, Dissertations, and Problem Reports

2017

\section{Civil Religion and Ontological Threat}

Matthew R. Arp

Follow this and additional works at: https://researchrepository.wvu.edu/etd

\section{Recommended Citation}

Arp, Matthew R., "Civil Religion and Ontological Threat" (2017). Graduate Theses, Dissertations, and Problem Reports. 5126.

https://researchrepository.wvu.edu/etd/5126

This Dissertation is protected by copyright and/or related rights. It has been brought to you by the The Research Repository @ WVU with permission from the rights-holder(s). You are free to use this Dissertation in any way that is permitted by the copyright and related rights legislation that applies to your use. For other uses you must obtain permission from the rights-holder(s) directly, unless additional rights are indicated by a Creative Commons license in the record and/ or on the work itself. This Dissertation has been accepted for inclusion in WVU Graduate Theses, Dissertations, and Problem Reports collection by an authorized administrator of The Research Repository @ WVU.

For more information, please contact researchrepository@mail.wvu.edu. 


\title{
Civil Religion and Ontological Threat
}

\author{
Matthew R. Arp \\ Dissertation submitted \\ to the Eberly College of Arts and Sciences \\ at West Virginia University \\ in partial fulfillment of the requirements for the degree of \\ Doctor of Philosophy in \\ Political Science \\ Joe D. Hagan, Ph.D, Chair \\ R. Scott Crichlow, Ph.D \\ Robert D. Duval, Ph.D \\ David M. Hauser, Ph.D \\ Philip A. Michelbach, Ph.D \\ Department of Political Science \\ Morgantown, West Virginia \\ 2017
}

Keywords: International Crisis Behavior, Ontological Threat Perception, Dyadic Conflict, Cultural and Normative Differences, Civil Religion and Conflict.

Copyright 2017 Matthew Arp 


\section{ABSTRACT \\ Civil Religion and Ontological Threat}

\section{Matthew R. Arp}

Dyadic conflict research within international relations is largely reliant on the analysis of differences in regime or leadership characteristics as a catalyst for conflict. This dissertation challenges traditional scholarship through the introduction of a unique approach that examines more fundamental differences between states. These fundamental historical and cultural differences, which are enshrined in a states' civil religion, offer insights into the behavior of states during crisis. The three primary questions of this dissertation are the following: What role does societal norms and cultural values have in threat perception? Why do states practice restraint in some crises and escalation of belligerence in others? Why do some conflicts result in brutal wars and others in limited wars? The theoretical expectation is that greater cultural and historical differences between states reduces the bargaining range for states to resolve crises, resulting in the escalation of tensions. In order to demonstrate empirical support for these claims, a mixedmethods approach is utilized. The quantitative analysis will be conducted to determine the generalizability and applicability of differences in civil religion on hostilities and escalation of crisis between dyads. The qualitative analysis will expound on the historical narratives of three pairs of dyads, which include the same state involved in two crises. These case studies will demonstrate how crises between certain dyads are escalated because of ontological threat perception. Furthermore, these case studies also demonstrate how the severity and brutality of war can vary dramatically between different dyads. 


\section{Table of Contents}

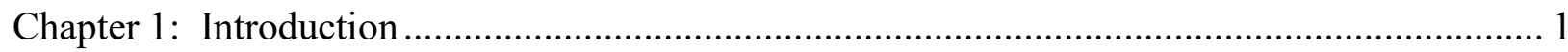

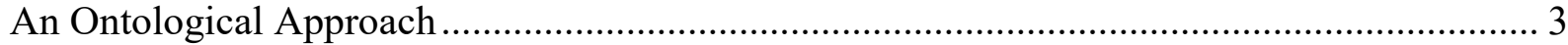

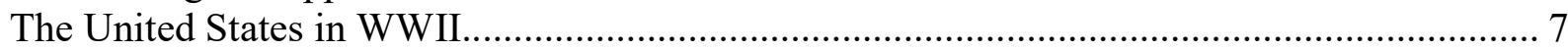

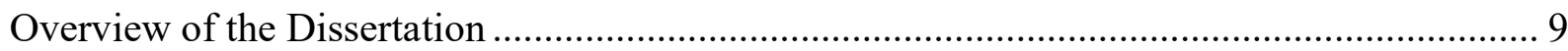

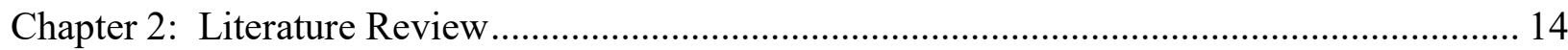

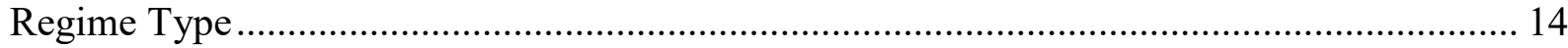

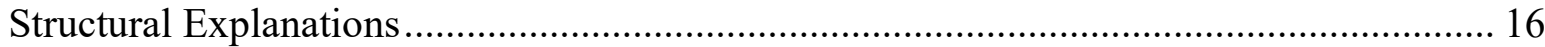

Normative Explanations........................................................................................ 17

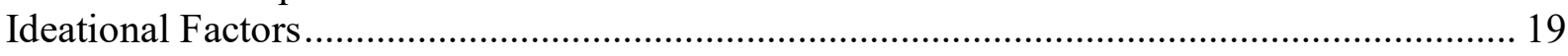

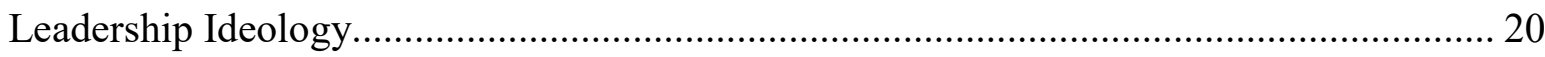

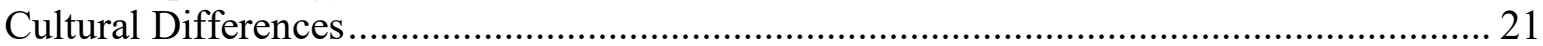

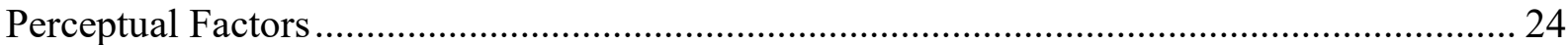

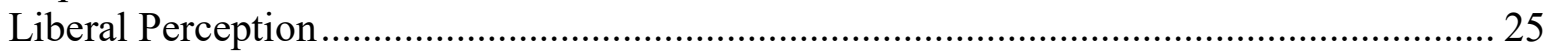

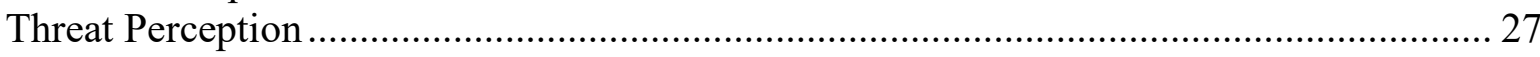

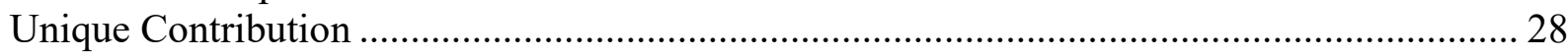

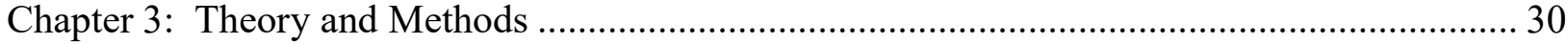

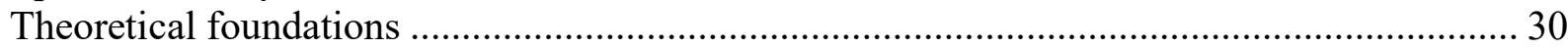

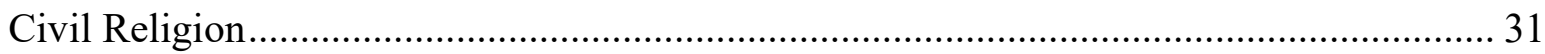

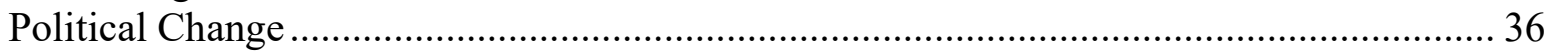

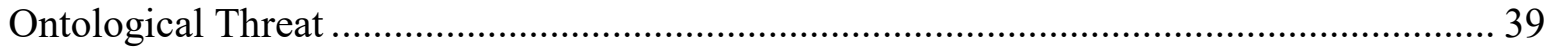

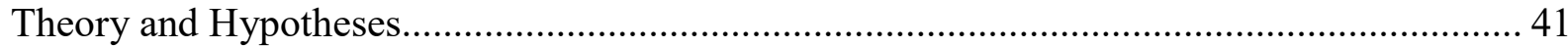

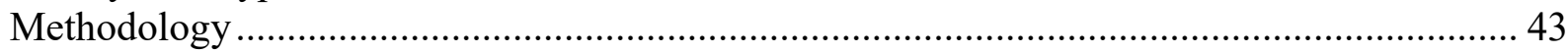

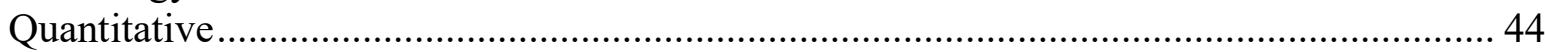

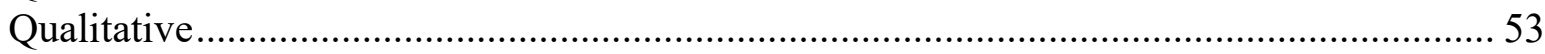

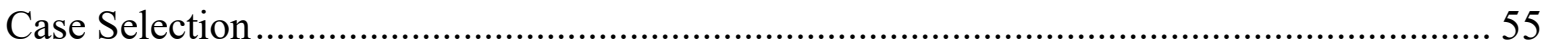

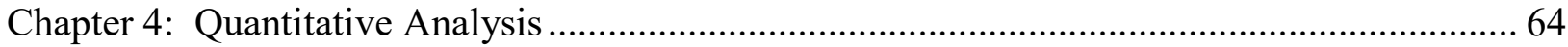

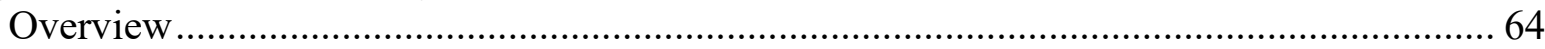

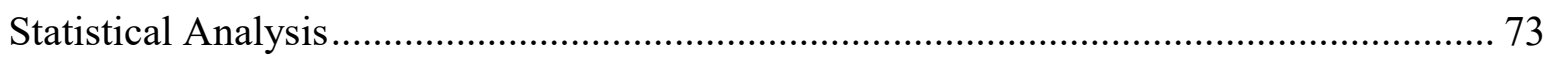

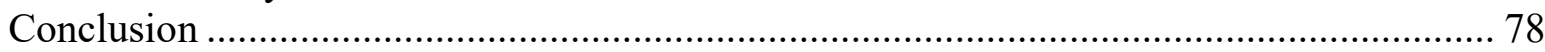

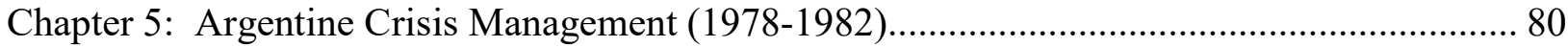

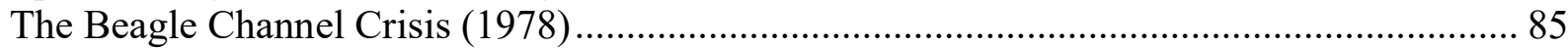

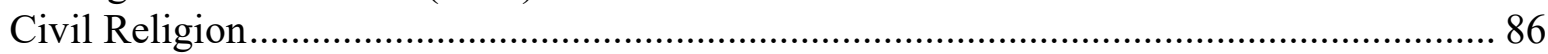

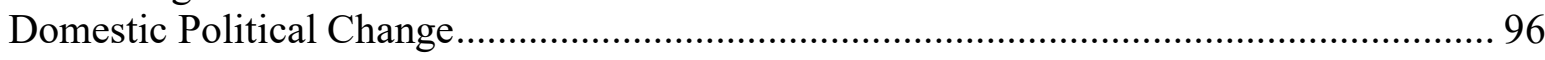

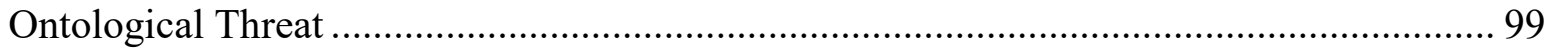

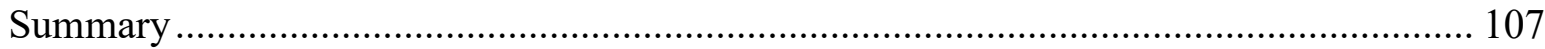

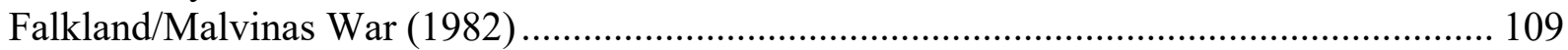

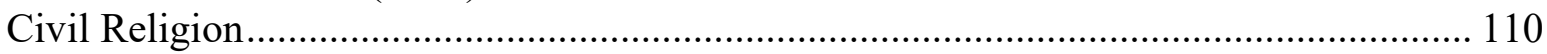

Domestic Political Change........................................................................................... 118

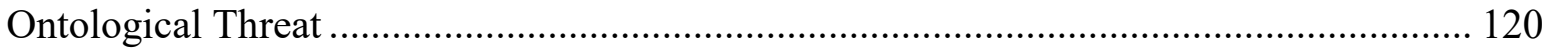

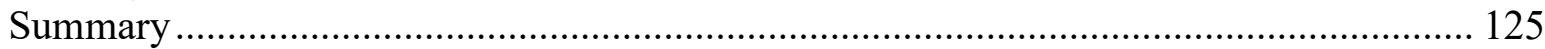

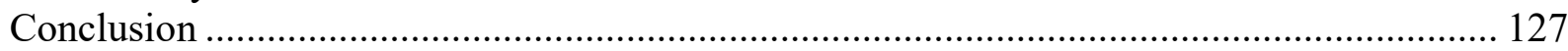

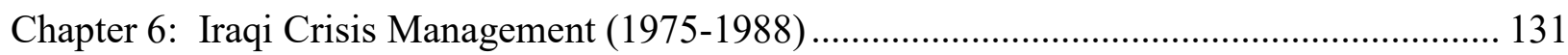

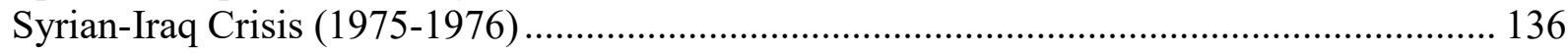

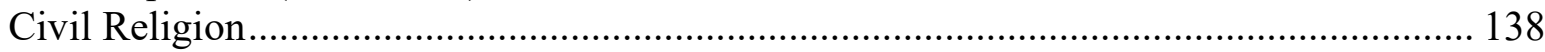

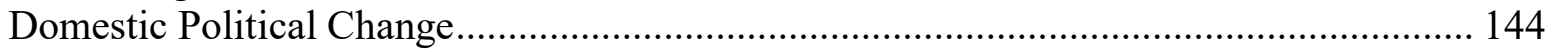




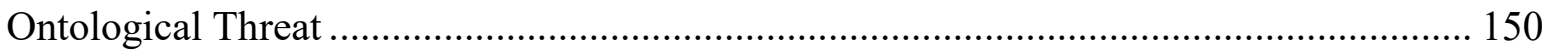

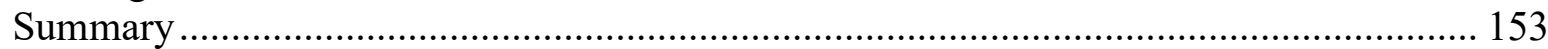

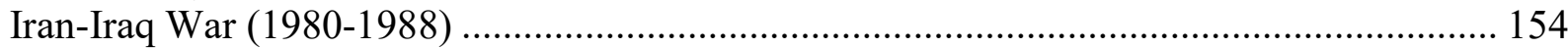

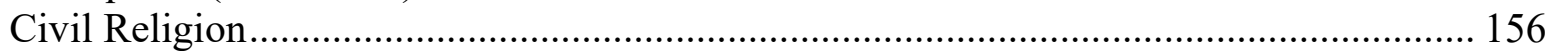

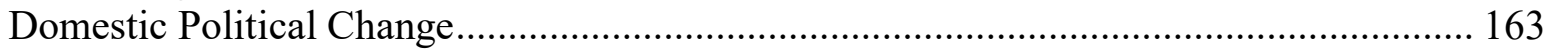

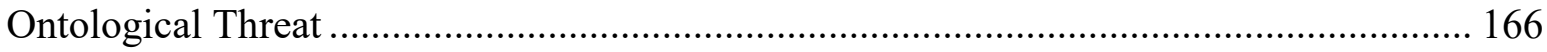

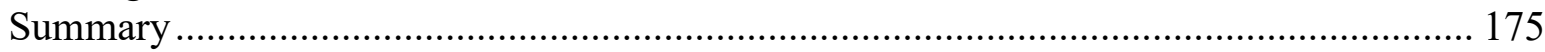

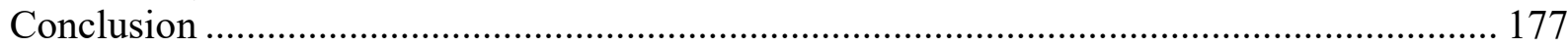

Chapter 7: Vietnamese Crisis Management (1964-1979)...................................................... 180

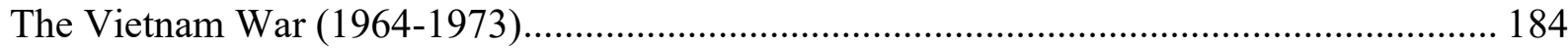

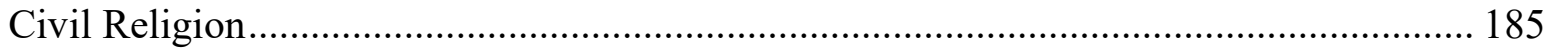

Domestic Political Change ......................................................................................... 190

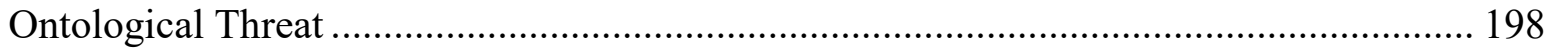

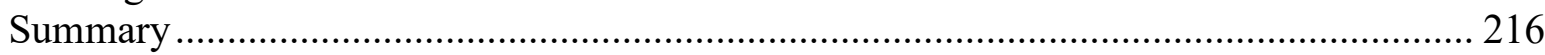

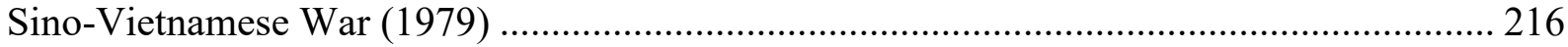

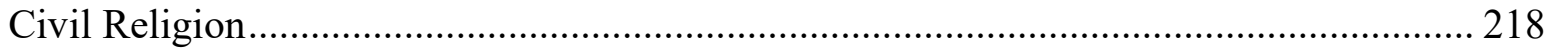

Domestic Political Change.......................................................................................... 223

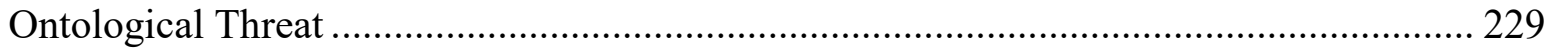

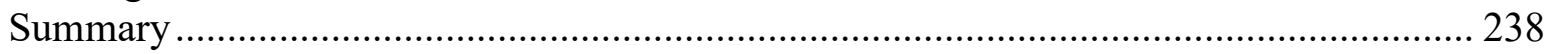

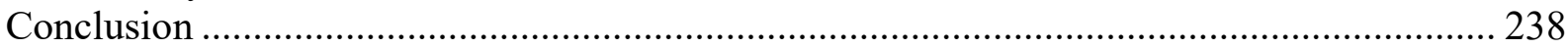

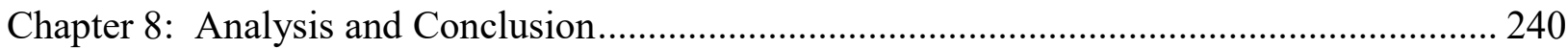

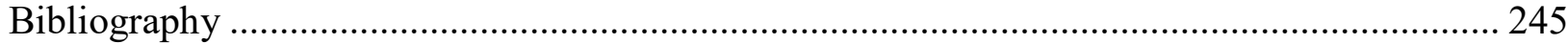

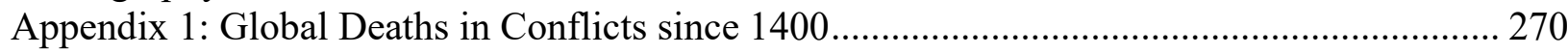

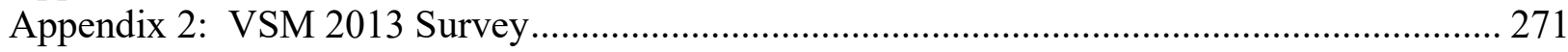




\section{Chapter 1: Introduction}

'War is not a primordial biological 'curse.' It is a cultural innovation, an especially vicious, persistent meme, which culture can help us transcend" - John Horgan ${ }^{1}$

Over the past 500 years, the number of global deaths (military and civilian) in conflicts have ebbed and flowed. Periods of conflict between great powers was immediately followed by peaceful epochs, which are subsequently followed by an uptick in global conflicts. ${ }^{2}$ Since the conclusion of World War II, the number of global interstate wars and casualties has been steadily falling. ${ }^{3}$ There was no single explanation for this phenomenon; It has been hailed by neo-liberal scholars as the result of global cooperation between major powers, which has created a system of interdependence, making wars much costlier. ${ }^{4}$ Neo-realists have attributed the downturn in conflicts and casualties to bi-polar alignment ${ }^{5}$ (during the Cold War), hegemonic stability ${ }^{6}$ (after the Cold War) and multi-polar balancing ${ }^{7}$ (Prior to WWII). In actuality, we are currently living in one of the most peaceful eras in human history since the 1880s.

However, while the number of global conflicts and casualties was on the decline, war is not a relic of the past, as between 4.4 and 19.7 million soldiers and civilians were killed during combat operations since the conclusion of World War II (1945-2008). ${ }^{8}$ Several significant wars involving a major power that resulted in over a million deaths occurred since 1945, including the Vietnam, Korean, Iran-Iraq, and Afghanistan Wars. One of the common features of these conflicts

\footnotetext{
${ }^{1}$ John Horgan, "No, War is not inevitable," Discover (June 2012), http://discovermagazine.com/2012/jun/02-nowar-is-not-inevitable (accessed July 1, 2017).

${ }^{2}$ Appendix 1 illustrates the global trends in conflict since 1400.

${ }^{3}$ Bethany Lacina and Nils Petter Gleditsch, "Monitoring trends in global combat: A new dataset of battle deaths," European Journal of Population 21, no. 2 (2005): 145-166.

${ }^{4}$ Robert O. Keohane and Joseph S. Nye, Power and interdependence (Boston: Longman, 1977), 3-19. See also Robert Keohane, After Hegemony: Cooperation and Discord in the World Political Economy (Princeton: Princeton University Press, 1984) and Robert Axelrod, The Evolution of Cooperation (New York: Basic Books, 1984).

${ }^{5}$ Kenneth Waltz, Theory of International Politics (Reading, MA: Addison-Wesley, 1979), 102-128.

${ }^{6}$ Robert Gilpin, War and change in world politics (Cambridge University Press, 1983), 9-50.

${ }^{7}$ John Mearsheimer, The Tragedy of Great Power Politics (New York: Norton Publishers, 2001), 338-344.

${ }^{8}$ Lacina and Gleditsch, "Monitoring trends in global combat: A new dataset of battle deaths," 145-166.
} 
was brutal and total warfare, featuring indiscriminate civilian targeting, which resulted in higher than average death rates of civilians. Given the economic and human costs of war, it is as important as ever to investigate the causes of interstate conflict.

In an effort to better understand conflictual relations between states, this dissertation aims to develop a better understanding of conflict intensity and frequency. This research project attempts to answer the following questions: What role does societal norms and cultural values have in threat perception? Why do states practice restraint in some crises and escalation of belligerence in others? Why do some conflicts result in brutal total wars and others in limited wars? In order to answer these questions, this dissertation will examine fundamental cultural and historical differences between states - which are codified in their respective civil religion. Unlike the neo-liberal and neo-realist explanations of dyadic conflict, this dissertation will move beyond regime and ideological differences between states. In doing so, this research will develop a new paradigm for examining conflicts, which can be used by future researchers to predict (and hopefully circumvent) such calamities in the future. Myriads of international relations literature has been written on this subject, which established a solid framework of understanding the dynamics of the international system. These questions build upon a realist-constructivist literature that accept the assumptions of material capabilities, while acknowledging the role of norms and ideas in understanding threat perception. In addressing these questions, this dissertation aims to augment traditional explanations for understanding of state behavior as a reaction to basal differences in societal norms and cultural values.

This approach of examining dyadic relationships through differences in foundational value structures is a novel within international relations, with even fewer attempts to test empirically. State behavior cannot be observed in a vacuum, as state behavior towards different states can vary 
depending on an assortment of factors. Previous literature has identified a multitude of dyadic factors, including shared regime type, ideology, interdependence and alliances, which can result in a state behaving differently towards different states. This dissertation will examine the role of moral and belief structures (codified in the civil religion of the state) on varying patterns of behavior of different dyads. The behavior of a state is reflected in the similarities and differences in moral and belief structures. This begs the question: why do cultural differences matter? The short answer is that states are less likely to escalate a conflict against an opponent that is a reflection of themselves.

This dissertation has established a theoretical framework for understanding these dyadic relationships. This dissertation will flesh out the two different ways in which normative differences effect decision-making during crisis. The two primary effects of normative differences are the following: (1) The decision to wage war against a particular opponent, while practicing restraint against another and (2) The decision to limit the scope, collateral damage or goals of the crisis, while engaging in brutal wars against another opponent. This logic can be applied to a variety of conflicts, but is most effective when focused on the decision making of an individual state, with respect to multiple crises.

\section{An Ontological Approach}

It is reasonable to dispute the importance of ontology as a relevant concept within international relations. Ontology is a branch of metaphysics, focused on the examination of phenomena that transcends the physical or natural. This approach is usually reserved for philosophical questions, due to the abstract and squishy nature of inquiry. These include such questions as "Is there a God?", "How should I live?", and "What is the good?". The answers to these fundamental questions of existence may seem trivial, but they constitute a certain worldview 
through which all information is filtered and categorized. Two notable recent pieces of international relations scholarship embody this approach: Phillips' War, Religion and Empire and Carleton's Russia: Story of War. This section will explore the causal logic of each manuscript, noting how this ontological approach will be utilized throughout this dissertation.

The thesis of War, Religion and Empire is that great powers construct international orders, which establish normative and institutional paradigms for all other states in the international system. International orders are forged through shared ontological assumptions, which define the collective identity, shared understanding and common ethical framework. Throughout history, several notable examines of these orders - including Latin Christendom, Sinosphere and the Global State System - transform the way in which states interact with one another. International orders are transformed through great power conflicts, formulation of new legitimizing principles and hegemonic establishment of international norms. ${ }^{9}$ Growing resistance to these organizing principles usher in new eras of international orders, which are constituted through competing norms, institutions and material capabilities. These orders establish a normative complex, institutions and material context for all states in the international system. The normative complex is of great interest to this dissertation, as it "provides actors with the 'maps of meaning' necessary to navigate social life, conferring upon them a shared collective identity, as well as a common ethical system and a framework for recognizing and legitimizing political authority". ${ }^{10}$

The assumption regarding the normative complex in differing international orders is a cornerstone of this dissertation. However, rather than examining the normative complex from the perspective of international orders, this dissertation will examine dyadic relationships between

\footnotetext{
${ }^{9}$ Mlada Bukovansky, Legitimacy and power politics: the American and French Revolutions in international political culture (Princeton University Press, 2010), 10-11.

${ }^{10}$ Andrew Phillips, War, religion and empire: The transformation of international orders (Cambridge University Press, 2010), 24.
} 
states. Similar ontological belief structures between states create linkages that offer collective identities and shared moral values. Just as the international order provides 'maps of meaning' to foreign policy relations under certain conditions, dyadic relationships are influenced by similar or different normative complexes. On the other hand, dyads that exhibit dissimilarities in their normative complexes are at an increased risk of misperception and miscommunication. The key difference in my theory is that rather than the international order governing state interactions, I posit that the dyadic differences are the source of compromise and contestation.

While not explicitly using the term ontology, Carlton uses an ontological approach throughout Russia: Story of War. The historical narrative and identity of all states is constructed through their historical experience. Russia is a unique case because their narrative and identity has largely been constructed through their experience with war. ${ }^{11}$ This narrative dates back to the Mongol invasions of Rus, coupled with the betrayal by their eastern European allies in taking advantage of their weakened state. Hundreds of years later, territory was reclaimed from Sweden and the Mongols, which was framed under the guise of a defensive conflict against occupying infidels. $^{12}$ This narrative was only accentuated through the defense of their homeland against both Napoleonic and German invasions. In both cases, Russia was not only successful at repelling invading 'forces of evil', but driving the invaders from eastern Europe. Both of these defensive wars were extremely costly, both economically and in terms of human life. These conflicts clearly demonstrated the historical narrative and ontological beliefs of the Russian people, who exemplified self-sacrifice and self-reliance. Furthermore, the actions of Russia in both of these conflicts directly resulted in the 'liberation' of eastern European states that had previously fallen. The Russian identity and historical narrative, as liberators and protectors of Europe, is a point of

\footnotetext{
${ }^{11}$ Gregory Carleton, Russia: The Story of War (Harvard University Press, 2017), 5-6.

12 Ibid., 8-10.
} 
pride for the Russian people. However, other western powers do not perceive and interpret these actions of Russia in the same way.

Over the past hundred years, other western states have viewed the foreign policy of Russia as bellicose and threatening. Even the occupation of eastern Europe during and after World War II was perceived by the West as aggressive expansion and oppressive to local populations. In more modern times, the narrative surrounding the annexation of Crimea and support for Ukrainian separatists are based on divergent historical narratives. In both cases, the Russian narrative is centered on reclaiming rightful territory that has been unlawfully taken. The West has a different point of view: Russia is a bully. How can the exact same behavior and actions of Russia be interpreted in completely different ways by different parties? This dissertation offers a satisfying answer to this question by unpackaging these historical narratives and identities through the examination of their underlying norms. Every state has a distinct historical narrative and identity which is forged through their unique historical experience. The implication of this experience is the acceptance of certain moral beliefs and rejection of others. This does more than guide the future behavior towards other states, but also the way in which actions are perceived by others. In the case of Russia, other Eastern European states may not share in the same historical beliefs as Russia, but do share in their underlying moral code. The linkages between states only facilitate communications and reduces the chance of misperception.

The scholarship that utilizes an ontological approach within international relations is relatively recent. The previous literature discussed in this section establishes the value of examining divergent identities, narratives and normative complexes in state behavior. This dissertation expands the reach of this approach through its application in dyadic conflict. The theoretical approach developed herein introduces a state-level variable - civil religion - which is 
an institutionalization of moral beliefs and cultural values within a particular state. The next section will introduce an example of this approach as an illustration of the research question and methodological approach.

\section{The United States in WWII}

The United States' involvement in the European and Pacific Theatres during World War II can serve as an illustrative example of this approach. The United States was involved in two different Theatres during World War II: The Pacific (against Japan) and European (against Germany and Italy). While the United States was involved in warfare against three autocratic regimes, the perception of their European opponents was different than the perception of the Japanese. This was reflective in both the strategy of warfare as well as domestic policies directed toward each specific group. This is because Americans were able to relate to their enemy in Europe, some of which were descendants of immigrants from those counties. On the other hand, the Japanese were seen in a much different light, as barbaric and savage, and war (and post-war relations) was conducted according to those beliefs.

Many publications framed the narrative of the pacific theatre as good versus evil. Furthermore, the Japanese were painted as being diabolical, subhuman and untrustworthy. ${ }^{13}$ Feelings of hostility towards the Japanese were not limited to wartime propaganda, to the point that "winning the war became secondary to just killing Japanese" ${ }^{14}$ This manifested itself in the savage and brutal fighting and frequent atrocities that were committed by both Japanese and American soldiers. Neither the Allied nor Japanese soldiers surrendered voluntarily, both adopting

13 see George S. Andrew, Jr., “The 41st Didn't Take Prisoners," Saturday Evening Post (July 27, 1946): 22; Gonald Gask, "Japs Do Surrender," Newsweek (October 30, 1944): 32- 33; William McGuffin, "What the Japanese Civilian Fears Most," Saturday Evening POST (October 14, 1944): 35.

${ }^{14}$ Clayton D. Laurie, "The Ultimate Dilemma of Psychological Warfare in the Pacific: Enemies who don't Surrender, and GIs who don't Take Prisoners." War \& Society 14.1 (1996): 99. 
an attitude of kill or be killed. In total, nearly 2.5 million Germans were prisoners of war, compared to a meager 16,429 Japanese POWs, 11,000 of which were from Okinawa. ${ }^{15}$

Domestically, attitudes towards the Japanese were far more threatening and racist than toward Germans and Italians. Even prior to the attack at Pearl Harbor, Japanese Immigrants were perceived "to present a threat to the American standard of living and to the racial integrity of the nation." $"$ In response to growing numbers of Japanese immigrants, policies were enacted to curb immigration from Asian states. The California Land Law of 1913 prohibited "aliens ineligible for citizenship" from being able to own property, which specifically targeted Asian immigrants. Legislation culminated with the Immigration Restriction Act of 1924, which prohibited the immigration of individuals who were ineligible for naturalization, effectively prohibiting all Asian immigrants. From the turn of the century, a practice of xenophobia toward Asian immigrants was the norm. Because of this latent prejudice towards Asians, it should be no surprise that American war strategy was dehumanizing towards the Japanese.

These attitudes can be contrasted with those towards Europeans. At the turn of the century, Germans were viewed by public opinion as "one of the most assimilable and reputable of immigrant groups". ${ }^{17}$ Public opinion shifted during the First World War, primarily against proGerman groups that supported Germany in the war effort. Efforts were made to censor German names of food, with sauerkraut renamed to liberty cabbage and frankfurter to hot dogs. Once entering the war, this event was formative on the identity of German-Americans, who began to identify themselves as American more than Germany. ${ }^{18}$ By the onset of World War II, select pro-

\footnotetext{
${ }^{15}$ George G. Lewis and John Mehwa, History of Prisoner of War Utilization by the United States Army 1776-1945 (Department of the Army, 1955).

${ }^{16}$ R. Daniels, Prisoners Without Trial: Japanese Americans in World War II (New York: Hill and Wang, 1993 ), 4.

${ }^{17}$ John Higham, Strangers in the Land: Patterns of American Nativism, 1860-1925 (New Brunswick, New Jersey: Rutgers University Press, 1955), 196.

18 Timothy J. Holian, The German-Americans and World War II: An Ethnic Experience (New York: Peter Lang, 1996).
} 
Nazi groups were singled out as examples of anti-American activities, including the Bund Madison Square Garden Rally in 1936 and $1939 .{ }^{19}$ While a minority of German-Americans supported the Nazi regime, the vast majority did not support their war goals, with many German-Americans fighting against them.

The disparity in domestic treatment between Japanese-Americans and German-Americans was fueled by latent prejudices that had existed prior to the War. This also manifested a different attitude towards enemy combatants during operations in the European and Pacific Theatres. Shared historical, ethnic and cultural ties between German and American policymakers created an environment of mutual understanding that did not exist between Japan and American decisionmakers. This anecdote serves as a mere example of how state behavior can differ towards different opponents based on normative differences.

\section{Overview of the Dissertation}

This dissertation will be organized in the following manner. The second chapter is dedicated to exploring the literature related to dyadic conflict. The third chapter will develop the theoretical argument and present the methodology of this dissertation. The fourth chapter will present a quantitative analysis in order to demonstrate generalizability of the theory. Chapters five, six and seven are devoted to the qualitative analysis of three cases - Argentina, Iraq and Vietnam - who each faced two crises with wildly different outcomes. Chapter eight will present the final analysis, conclusions and directions for future research. Each of these chapters will be discussed in further detail.

The literature review, presented in chapter two, will overview the perspectives on which I am building my own theory and causal mechanisms. There is a finite amount of resources

\footnotetext{
${ }^{19}$ La Vern J. Rippley, The German-Americans (Boston: Twayne Publishers, 1976), 204-207.
} 
available on the relationship between civil religion and ontological threat, therefore, I have endeavored to meld mainstream international relations theories with political theory literature. What I will present in the literature review is well-known dyadic international relations literature which is relevant to the research question of this dissertation. These literatures include the democratic peace literature, which was one of the most fruitful bodies of literature on explaining dyadic conflict. Another relevant set of literature is ideational factors, which include differences in leadership ideology and culture in dyadic conflict. Lastly, threat perception is an important component of understanding dyadic conflict and state behavior during crisis. This chapter will also identify shortcomings of the current literature and position my research agenda within the larger body of literature. These three strands of literature will be augmented with political theory literature, which is located in the theory and methods chapter.

Theory and methods, presented in chapter three, will present the causal mechanisms, theory, operationalization and testing of the theory herein. This theory is based on three causal mechanisms - civil religion, political change and ontological threat. All established states have a unique cultural, moral, and historical identity. These factors serve as the basis for the establishment of their respective civil religion, or societal norms and political institutions that are self- replicating. Dyadic differences in the civil religions are latent sources of tension, however, domestic political changes can accentuate these differences and disrupt routinized relations. This can take the form of rapid ideological shifts and/or abrupt regime changes, which pose an ontological threat to other states. Whether or not a state perceives these changes to be an ontological threat is rooted in the latent differences in civil religion. As a result, crises between dyads with greater differences in civil religion are more likely to exhibit the escalation of conflict 
and total war, whereas dyads with greater similarities are more likely to resolve conflicts or engage in limited war.

Quantitative analysis will be conducted in chapter four, with the purpose of establishing generalizability of the theory. In addition to examining cases which may be anomalies, the use of quantitative testing will broadly apply the theory across time and a variety of dyads. This will be accomplished through an empirical test using OLS panel regression. There will be one test for each hypothesis with hostility levels are the dependent variable for both. The first test will encompass the entire MID dataset (1816-2008), whereas the second test will be limited to states in crisis. The use of large-N datasets, including MID, ICB and VSM 2013, is to generalize this theory across a variety of dyads. The remaining empirical chapters (five, six and seven), will focus on the specific causal mechanisms and how these variables result in differing outcomes for different dyads.

The case studies, presented in chapters five, six and seven will offer an in-depth analysis of six different dyadic crises involving three states. The choice of Argentina, Iraq and Vietnam provide a natural case study, as they were faced with multiple crises during the tenure of the same regime. While each pair of crisis had many similarities, the differing outcomes provides a unique opportunity to flesh out the causal mechanisms. Three sets of case studies will be presented in these chapters, which include the following dyads:

\section{Table 1-1: Case Selection}

$\begin{array}{ll}\text { Similar Dyads } & \text { Different Dyads } \\ \text { Argentina - Chile } & \text { Argentina - Great Britain } \\ \text { Iraq - Syria } & \text { Iraq - Iran } \\ \text { Vietnam - China } & \text { Vietnam - United States }\end{array}$

Argentina will be the focal point of chapter five, with different outcomes from the Beagle Channel Crisis and Falkland/Malvinas War. There are numerous commonalities between these 
crisis, including Argentina's international zeal for regaining lost territory and domestic political upheaval under the juntas. One important difference was the national identity of their opponents, with Chile having similar cultural, moral and religious beliefs to Argentina. On the other hand, Great Britain was perceived as a decedent western power that had little in common with Argentina. Iraq will be the focal point of chapter six, with different results from the Syria-Iraq Crisis and IranIraq War. There are numerous commonalities between these crisis, including the struggle for legitimacy, regional hegemony and territorial rights. One important difference was the national identity of their opponents, with Syria having similar attitudes towards Arab nationalism and secular rule. Alternatively, Iran was defined by their Islamic religious character, which stood in opposition to Iraq. Vietnam will be the focal point of chapter seven, engaging in two different wars - The Sino-Vietnamese War and Vietnam War - which were conducted in vastly different ways. The source of contention in Vietnam was much different for the United States and China, which were displayed in different tactics and goals of the wars. The Sino-Vietnamese War was a limited war conducted with limited goals as punishment for Vietnamese foreign policy towards China. This can be contrasted with the American experience in Vietnam, which evolved into a war of attrition, body counts and quotas with the wide sweeping goal of defeating the Communist ideology.

The final chapter will synthesize the quantitative and qualitative results in order to draw conclusions and make policy recommendations. The quantitative chapter demonstrates the significance of particular variables - including state and society variables - in particular independence and power distance. Coupled with the in-depth qualitative analysis of three pairs of cases, this research has made significant inroads to move beyond traditional explanations of dyadic conflict. This theory explains cases that aren't accounted for in the traditional international 
relations literature. In doing so, it provides a unique framework for analysis that offers fertile ground for the addition of cases and expanding the dataset. 


\section{Chapter 2: Literature Review}

This dissertation is rooted in the dyadic conflictual ${ }^{1}$ dynamics scholarship, in particular between states with fundamental normative differences. This approach moves beyond material forces in the explanation of conflict, instead focused on norms, ideas and perceptions. While this research offers a unique contribution to the field, a drawback of this approach is that there are limited established resources available that utilize the same assumptions. In order to construct a thorough literature review, I rely on an interdisciplinary approach, utilizing a variety of international relations and political theory literatures. The literature review will feature the inclusion of a variety of explanations for conflict, while the political theory literature will be discussed in the theory and methods chapter. The literature review will examine three of the predominant literatures that examine dyadic conflict. The literature is organized in three sections, with the first discussing the relationship between dyads of varying regime types (democratic, autocratic, etc.), the second discussing the relationship between dyads of varying ideational factors of leadership and society and the third discussing the role of perceptions. The purpose of this literature review is to provide a survey of the literature surrounding this topic, as well as identify shortcomings of the established scholarship. Once the pertinent literature has been surveyed, my theoretical contribution will be discussed.

\section{Regime Type}

The first set of literature examines the relationship between regimes of the same/different types. The focus of this analysis is on the role of regime type (and the associated norms and institutions) that reduce the likelihood of conflict between like-dyads. The most prominent and

\footnotetext{
${ }^{1}$ I use the definition provided by Brecher and Wilkenfield (1997), which includes a verbal act, political act, economic act, external change, other non-violent act, internal verbal or physical challenge, non-violent military act, indirect violent act and violent act.
} 
developed literature is the democratic peace literature, which posits that structural and normative constraints reduce the likelihood of conflict between democratic dyads. While the causal logic is different, the outcome is the same: democracies tend to go to war with each other at a much lower rate than other types of regimes. ${ }^{2}$ The question is answered by each approach through an examination of the dyadic relationship between regime types. This level of analysis is on the regime type (whether democratic or autocratic) and the associated norms and institutions of having said type of regime. In addition to the shared norms and/or institutions of like-regimes, the perception of likeness is also an important point of discussion. It should be noted that this is not an exhaustive analysis of all regime-type literature, but rather limited to dyadic explanations of conflict. Furthermore, the emphasis of this dissertation is on normative explanations of conflict, so this broad literature will be truncated.

The structural and institutional approaches only apply to democratic dyads, not to monadic behavior or mixed dyads. ${ }^{3}$ Mixed-dyads produce much different results, as these dyads do not share the same norms or institutions. Non-democracies rely on violence and expect their opponents to use violence in order to resolve political conflicts. This creates a sense of mistrust and fear between democratic and non-democratic states. ${ }^{4}$ As a result, democratic states tend to perceive nondemocratic states as a greater threat. In some cases, this can result in democratic states adopting nondemocratic norms of conflict resolution, including preemptive violence. ${ }^{5}$

\footnotetext{
${ }^{2} 98 \%$ of conflicts since WWII have consisted of mixed (autocratic and democratic) dyads (Mark Peceny, Caroline C. Beer, and Shannon Sanchez-Terry, "Dictatorial peace?," American Political Science Review 96, no. 1 (2002): 1526.). See also Bueno de Mesquita and Lalman 1992; Doyle 1986; Maoz and Russett 1993; Owen 1994; Small and Singer 1976.

${ }^{3}$ Harald Müller and Jonas Wolff, "Dyadic democratic peace strikes back," In 5th Pan-European International Relations Conference, The Hague, 2004.

${ }^{4}$ Bruce Russett, Grasping the democratic peace: Principles for a post-Cold War world (Princeton university press, 1994).

${ }^{5}$ Ibid.
} 


\section{Structural Explanations}

The structural approach is couched in Kant's Perpetual Peace, which posits that peaceful relations between states can only be achieved through the worldwide adoption of constitutional republics. ${ }^{6}$ The behavior of democratic states can be differentiated from other regime types insofar as they are held accountable by citizens. Citizens are less inclined to go to war than elites, because they bear the costs of warfare (whether it be their lives or money). ${ }^{7}$ Citizens in democracies also have the ability to manipulate decision-making through elections and other democratic institutions, exerting their preferences to resolve crises without the use of belligerence.

In addition to constituent aversion to war, other institutional constraints made it difficult for leaders to mobilize without a large coalition. Democratic leaders only have a limited amount of resources to allocate to different policy goals, which means they must choose how to maximize the desires of constituents. ${ }^{8}$ There are two implications to this scenario: first, democratic leaders must attempt to increase the size of the coalition and democratic leaders are more selective in their wars. In order to provide the largest benefit to most citizens, democratic leaders must increase the size of their coalition. Unlike autocratic leaders, who only have a small coalition of needs to satisfy, democratic leaders need to meet multiple competing demands of a majority. Coupled with the size of the coalition, winning is also paramount. The audience costs of going to war are much higher than autocracies if unsuccessful, which means that democratic leaders only choose to fight winnable wars. ${ }^{9}$ Since all democracies are aware of these institutional constraints, it acts as a

\footnotetext{
${ }^{6}$ A constitutional republic, defined by Kant, consists of three parts (1) establishment by free men, (2) a common legislation and (3) law of equality.

${ }^{7}$ Russett, Grasping the democratic peace, 30.

${ }^{8}$ Bruce Bueno De Mesquita, James D. Morrow, Randolph M. Siverson, and Alastair Smith, “An institutional explanation of the democratic peace," American Political Science Review 93, no. 4 (1999): 793.

${ }^{9}$ Michael W. Doyle, “Liberalism and world politics," American Political Science Review 80.4 (1986): 1151-1169; James D. Fearon, "Domestic Political Audiences and the Escalation of International Disputes," American Political Science Review. 88(3) (1994): 577-92.
} 
signal to other democratic regimes. ${ }^{10}$ For democratic dyads, leaders are aware of their constraints and the domestic constraints of their adversaries, allowing for more time to explore non-violent resolutions of conflict. ${ }^{11}$ The ability to navigate crises through shared and understood institutional constraints can also be applied to non-democratic dyads. The same logic has been applied to dictatorial dyads, with scholarship finding that military juntas and personalist dictatorship dyads also have much lower rates of conflict than mixed-dyads. ${ }^{12}$

\section{Normative Explanations}

The alternative logic for democratic peace is rooted in dyadic shared democratic norms, rather than domestic institutional constraints. Democratic states have a different set of norms regarding domestic political conflict resolution than nondemocratic states. Political conflicts that occur within domestic politics are settled through compromise rather than conflict. ${ }^{13}$ One of the tenets of democratic rule is a peaceful transition of power after an election. Winning candidates do not eliminate their competition, and losing candidates are able to run again. ${ }^{14}$ These "norms of peaceful conflict resolution" are unique to democratic regimes. ${ }^{15}$ Alternatively, political competition in nondemocratic regimes is characterized as being zero-sum. Winners of political

\footnotetext{
${ }^{10}$ Bruce Bueno De Mesquita et al 1999, "An institutional explanation of the democratic peace," 794; Bruce Bueno De Mesquita, and Randolph M. Siverson, "War and the survival of political leaders: A comparative study of regime types and political accountability," American Political Science Review 89, no. 4 (1995): 841-855; Dan Reiter and Allan C. Stam, "Democracy, war initiation, and victory," American Political Science Review 92, no. 2 (1998): $377-$ 389.

${ }^{11}$ Michael W. Doyle, "Liberalism and world politics," American Political Science Review 80.4 (1986): 1151-1169; James D. Fearon, "Domestic Political Audiences and the Escalation of International Disputes," American Political Science Review. 88(3) (1994): 577-92.

${ }^{12}$ Mark Peceny, Caroline C. Beer, and Shannon Sanchez-Terry, "Dictatorial peace?," American Political Science Review 96, no. 1 (2002): 16-18.

${ }^{13}$ Russett, Grasping the democratic peace, 59-62; Spencer R. Weart, Never at war: Why democracies will not fight one another (Yale University Press, 1998).

${ }^{14}$ Zeev Maoz and Bruce Russett, "Normative and structural causes of democratic peace, 1946-1986," American Political Science Review 87, no. 3 (1993): 624-626.

${ }^{15}$ Bruce Russett, "The Fact of Democratic Peace," In Debating the democratic peace (1996): 97.
} 
competition are able to eliminate their competition, because they view them as a future threat to their rule.

The norm of peaceful conflict resolution also guides the foreign policy behavior of democratic leaders. Since democratic leaders are acclimated to resolving political conflicts through nonviolent means in the domestic political arena, they rely on these strategies when engaging in international disputes. ${ }^{16}$ Put another way, states "externalize the norms of behavior that are developed within and characterize their domestic political processes and institutions". ${ }^{17}$ This does not imply that democratic dyads do not have conflicts, rather that conflicts between democratic dyads will be resolved through non-violent means. When conflicts between liberal democracies dyads do occur, both sets of leaders will follow these norms of conflict resolution with the expectation that the other party will do the same. This mutual understanding of their opponent, coupled with the extension of peaceful norms of conflict resolution, will result in less frequent and less militarized conflicts between democratic states.

An alternative to democratic norms as a causal mechanism for peaceful relations between like-dyads is economic norms. The relationship between democratic regimes and economic liberalism is strongly correlated. As a result, peaceful relations between democratic states may be the result of norms of economic liberalism as opposed to shared democratic norms. Shared economic liberalism establishes similar interests between states that reduces the desire for conflict. ${ }^{18}$ However, the existence of shared economic ties between states is not enough to avoid conflict. $^{19}$

\footnotetext{
${ }^{16}$ William J. Dixon, "Democracy and the management of international conflict," Journal of Conflict Resolution 37, no. 1 (1993): 42-68.

${ }^{17}$ Zeev Maoz and Bruce Russett, "Normative and structural causes of democratic peace, 1946-1986," American Political Science Review 87, no. 3 (1993): 625.

${ }^{18}$ Erik Gartzke, “The capitalist peace," American journal of political science 51, no. 1 (2007): 166-191.

${ }^{19}$ Paul A. Papayoanou, "Interdependence, institutions, and the balance of power: Britain, Germany, and World War I," International Security 20, no. 4 (1996): 42-76.
} 


\section{Ideational Factors}

The second set of this literature review examines the relationship between dyads of the same/different ideologies, which includes both regime ideology and culture. Ideological approaches within international relations are considered to be more constructivist in nature. Constructivism augments the analyses of neorealism and neoliberalism by including ideational factors to security and threat perception. ${ }^{20}$ This stems from the importance of identity as the "property of intentional actors that generates motivational and behavioral dispositions". ${ }^{21}$ This perspective challenges the realist and liberal explanation of state behavior as the result of material interests, while accepting its assumptions about the international system.

In a perfect system, actors would be clear regarding their preferences and interests. However, there is a lack of incentive for actors to be honest with their intentions. In addition, actors tend to assume that the actions of others are more coordinated and logical than they actually are. As a result, actors rely on their beliefs regarding other actors in an attempt to determine intentionality. In this way, actors navigate the logic of two-level games as well as deconstruct the logic of action or inaction. Because actors are operating with less than perfect knowledge, they tend "to notice certain things and to neglect others, to immediately and often unconsciously draw certain inferences from what is noticed, and to find it difficult to consider alternatives. New information will be perceived through a "prism" formed from assumptions about other actors and about cause and effect in the international environment". ${ }^{22}$ There are two broad literatures that have explained the dyadic behavior of states as responding to ideational phenomena. These

\footnotetext{
${ }^{20}$ Ronald L. Jepperson, Alexander Wendt, and Peter J. Katzenstein, "Norms, identity, and culture in national security," in Culture and National Security, ed. Peter J. Katzenstein (New York: Columbia University Press, 1996), 33-75.

${ }^{21}$ Alexander Wendt, Social theory of international politics (New York: Cambridge University Press, 1999), 224.

${ }^{22}$ Robert Jervis, Perception and Misperception in International Politics (Princeton: Princeton University Press, 1976), 145.
} 
literatures are focused on ideological distances between leaders and cultural differences between states.

\section{Leadership Ideology}

The ideology of leaders can be characterized as "particular principles upon which a particular leadership group attempts to legitimate its claim to rule and the primary institutional economic, and social goals to which it swears allegiance." ${ }^{23}$ At its core, ideologies refer to the beliefs or ideals of individuals or groups. Leadership ideology is an extremely volatile concept, one that can rapidly change through a regime change. Unlike regime types (which are relatively stable), the changing of political elites can rapidly alter the ideology of a regime. The monadic decision-making of a different regime can change depending on the ideology of leaders (hardliners, moderates, etc.). For the purpose of this research, the focus is on the relationship between dyads rather than independent behavior. The examination of leadership ideology becomes more interesting when taking into consideration the ideological distance between leaders of different states.

Through three different mechanisms, the demonstration-effects, communications and conflict-probability, the perception of threat is increased in the case of increased ideological distance between dyads. The "demonstration-effects" mechanism, which is predicated on the notion that domestic ideological threats will be bolstered by other states that share in the ideology. Because of the fear of the gains that rival domestic groups will achieve, leaders experience greater fear towards states that exhibit those ideologies. ${ }^{24}$ Additionally, internal threats of rival ideologies can be quenched by attacking it abroad. ${ }^{25}$ The "communications" mechanism, which attributes

\footnotetext{
${ }^{23}$ Mark L. Haas, The ideological origins of great power politics, 1789-1989 (Cornell University Press, 2005), 5.

${ }^{24}$ Ibid., 6.

${ }^{25}$ John M. Owen, The Clash of Ideas in World Politics: Transnational Networks, States, and Regime Change, 15102010: Transnational Networks, States, and Regime Change, 1510-2010 (Princeton University Press, 2010), 4.
} 
misperception due to the fact that leaders attribute different meanings to the same symbols and events. ${ }^{26}$ Misperception of threat is due to an obfuscation caused by having a different worldview. Even when costly signaling is used, ideology can act as an impediment to effective communication. Lastly, the "conflict-probability" mechanism asserts that ideological distance contributes to the mistrust between leaders. The perception of decision-makers contrives conflicts of interest, even when they do not exist.

This causal logic asserts that political ideological differences (which are real and measurable concepts) are the root of misperception and fear that result in conflicts. While the case studies chosen by Haas (2005) demonstrate the effect that ideological distance has on threat perception, it appears to be an intervening variable rather than an independent variable. At its core, ideologies refer to the beliefs or ideals of individuals or groups. However, ideologies are not ex nihilo phenomena, and are malleable given a particular set of circumstances. Ideologies of individuals can change, based on personal experience, political climates or pressure from above. For instance, the ideology of decision makers may change because of a transition of power (through election or other means) as well as over time as attitudes change. While ideology of leaders can shift vehemently after an election (or other means of power transition), it does not always necessitate belligerence. The ideological distance between states is an important way of conceptualizing the state behavior towards leaders of varying ideologies, but does not appear to be the sole cause of conflict.

\section{Cultural Differences}

Scholarship has identified cultural differences between states as a catalyst for conflict. The most notable example of this literature is Clash of Civilizations, which posited that the post-Cold

\footnotetext{
${ }^{26}$ Haas, The ideological origins of great power politics, 15.
} 
War world would be characterized by conflict along cultural fault lines. Civilizations were defined as the "highest cultural grouping of people and the broadest level of cultural identity...which distinguishes humans."27 Huntington identified nine different major civilizations, based on differences in "language, history, religion, customs, institutions and subjective self-identification of people." 28 He contended that these fundamental differences are entrenched within society and unmalleable. These fundamental differences between states, coupled with increased interactions, will result in conflicts out of cultural preservation.

Other scholars have attempted to dissect the cultural differences between peoples in different parts of the world. By examining specific issue attitudes, scholars have found some issue cleavages on issues such as gender rights, abortion, gay rights and other progressive ideals. ${ }^{29}$ Generally, Clash of Civilizations was not well-received by the academic community, as it was criticized for making broad generalizations without empirical evidence to support his claims. ${ }^{30}$ Scholars who performed empirical testing on these hypotheses found little correlation between civilization differences and increased conflict. ${ }^{31}$

In addition to defined cultural differences between states, perceptual cultural differences are a factor in threat perception. The perception of another states' actions is interpreted through the image of the other. ${ }^{32}$ This image is constituted through "the total cognitive, affective, and

\footnotetext{
${ }^{27}$ Samuel P. Huntington, “The clash of civilizations?,” Foreign affairs (1993): 24.

${ }^{28}$ Ibid.

${ }^{29}$ Ronald Inglehart and Pippa Norris, “The true clash of civilizations," Foreign policy (2003): 63-70.

${ }^{30}$ John Ikenberry, "The West: Precious, not Unique: Civilizations Make for a Poor Paradign Just like the Rest," Foreign Affairs 76 (March-April 1997): 162-3; Donald J. Puchala, "International Encounters of Another Kind," Global Society 11 (January 1997): 5-29; Stephen M. Walt, "Building Up New Bogeymen," Foreign Policy 106 (Spring 1997):176-89.

${ }^{31}$ Inglehart and Norris, "The true clash of civilizations," 63-70; Jonathan Fox, "Ethnic minorities and the clash of civilizations: A quantitative analysis of Huntington's thesis," British journal of political science 32, no. 3 (2002): 415-434. Bruce M. Russett, John R. Oneal, and Michaelene Cox, "Clash of civilizations, or realism and liberalism déjà vu? Some evidence," Journal of Peace Research 37, no. 5 (2000): 583-608.

32 Kenneth Ewart Boulding, The image: Knowledge in life and society (University of Michigan Press, 1956).
} 
evaluative structure of the behavior unit, or its internal view of itself and its universe". ${ }^{33}$ The way in which states respond to other states in the internal system is dependent on the type of image, based on both material and ideological factors. States may react to the same action of two different states differently if the content of those images is also different. States that are perceived to be culturally inferior or superior alter the perception of threat. ${ }^{34}$

Another subset of literature that emphasizes the role of culture is the national strategic culture scholarship. Strategic culture describes a fundamental belief structure within a state, characterized as the "sum total of ideas, conditioned emotional responses, and patterns of habitual behavior." 35 Other scholars have described strategic culture as the "nation's traditions, values, attitudes, patterns of behavior, habits, symbols, achievements and particular ways of adapting to the environment and solving problems." ${ }^{36}$ Both of these descriptions cast strategic culture in a similar light to a states' civil religion. However, there are several notable differences between these concepts. First, the concept of strategic culture is inextricably linked to national security. ${ }^{37}$ These dogmas and beliefs offer a context for foreign policy decision-making which encourages or restrains elite behavior. The concept of civil religion is independent of physical security, instead providing domestic legitimization of the regime and norms and good citizenship. Differences in civil religion play a role in ontological threat perception, in particular whether or not a belief structure threatens your identity and reality. Secondly, the strategic culture literature fails to take

\footnotetext{
${ }^{33}$ Ibid, 121-122.

${ }^{34}$ R. K. Herrmann, J. F. Voss, T. Y. E. Schooler, and J. Ciarrochi, "Images in international relations: An experimental test of cognitive schemata," International Studies Quarterly, 41(1997), 407-409.

35 Jack Snyder, The Soviet Strategic Culture: Implications for Limited Nuclear Operations (Santa Monica: Rand, 1977), .8.

${ }^{36}$ Ken Booth, "The concept of strategic culture affirmed," in Strategic Power: USA/USSR, ed. Carl Jacobsen (London: Palgrave Macmillan, 1990), 121.

${ }^{37}$ Charles A. Kupchan, The Vulnerability of Empire (Ithaca: Cornell University Press, 1994), 22.
} 
into account the beliefs of other states in the international system. This dissertation aims to develop a theory of dyadic relations, whereas the strategic culture literature is monadic in nature.

Previous scholarship that has given serious consideration to cultural explanations of conflict has been influential in this research. However, the contributions of Huntington and strategic culture are not without their shortcomings for the research questions posed herein. The focus of this dissertation is to explain the variation in state behavior towards different opponents that hold distinct beliefs as opposed to a single state. The strategic culture literature is useful in identifying key variables and casual mechanisms of interest, but does not offer a satisfying answer to the research question herein. While the implications of Huntington's thesis were criticized by many, there are some redeemable assumptions that can be utilized in future research. Cultural differences between peoples living in different states do vary from country to country. ${ }^{38}$ However, rather than conceptualizing these differences in terms of unique mutually-exclusive cultures (as Huntington did), each state should be treated on a sliding scale of a multitude of values. The values of people are linked to the cultural identities, language and histories, which are unique to a particular geographic area. ${ }^{39}$ Dyadic cultural differences may not be the causal mechanism for conflictual relations, but it should be treated as a distinct variable in a larger equation.

\section{Perceptual Factors}

Modern scholarship has moved beyond the archaic formula of international relations as the result of merely material forces and capabilities. Instead, these scholars have developed a more sophisticated and nuanced approach to understanding state behavior, based on perceptions, images

\footnotetext{
${ }^{38}$ Shalom H. Schwartz, "Universals in the content and structure of values: Theoretical advances and empirical tests in 20 countries," Advances in experimental social psychology 25 (1992): 1-65; Shalom H. Schwartz, "Are there universal aspects in the structure and contents of human values?," Journal of social issues 50, no. 4 (1994): 19-45; Geert Hofstede, "Culture and organizations," International Studies of Management \& Organization 10, no. 4 (1980): $15-41$.

${ }^{39}$ Harry Triandis, Individualism \& collectivism. New directions in social psychology (Boulder, CO: Westview Press, 1995).
} 
and belief structures. These two broad perceptions literatures - liberal and threat perception, which offer different explanations for dyadic conflict. The liberal perception literature is built on the aforementioned democratic peace literature with one notable exception: rather than examining the distance between regime types, it focuses on the perception of regime type. The second body of literature, threat perception, is paramount in understanding how states understand and interpret the actions of other states.

\section{Liberal Perception}

The relationship between dyads with similar regime types is complicated, since there is certainly a strong correlation but no clear consensus regarding the causal mechanism for increased peaceful relations. The literature is divided over the underlying source of these relations, whether it is domestic institutions, shared norms or something else altogether. Furthermore, there are a handful of cases in which two democratic states have gone to war. ${ }^{40}$ For each of these conflicts, both states are classified as being democratic, based on commonly used indicators such as universal suffrage, constraints on the executive and competitive elections. However, in each of these examples it is questionable whether the states perceived each other as democratic.

One of the important caveats to the argument that shared norms reduce conflict is that democratic norms are subjective. Democratic peace scholarship is largely contingent on measuring level of democracy using the Polity dataset, which scores a country based on dimensions of democracy (10) or autocracy $(-10) .{ }^{41}$ These measurements are based on several factors, which operationalize the concept of 'democratic', taking into account the electoral

\footnotetext{
${ }^{40}$ Examples include the following cases: War of 1812, Papal States vs. France (1949), American Civil War (1861), Ecuador-Colombia War (1863), Franco-Prussian War (1870), Boer War (1899), Spanish-American War (1898), Second Philippine War (1899), World War I, World War II, Lebanon vs. Israel (1948 and 1967) (Russett, Grasping the democratic peace, 17.)

${ }^{41}$ Bruce Russett and John Oneal, Triangulating peace: Democracy, Interdependence, and International Organizations (New York 2001).
} 
competition and constraints on executive power. ${ }^{42}$ In some of the alleged wars between democracies, it was due to a lack of recognition of those norms by peer democracies. States which are not perceived to be democratic are treated with more hostility, relative to states perceived to be democratic. ${ }^{43}$ Liberal states, which are less likely to engage in military conflict with other liberal states, do tend to engage autocratic states at a much higher rate.

The perception of another state being liberal is based on (1) having an enlightened citizenry and (2) people live under enlightened political institutions. ${ }^{44}$ The problem with both of these criteria is that they are highly subjective, since "enlightened" is in the eye of the beholder. Democratically elected monarchies, for instance, may or may not be considered enlightened, depending on the policies and preferences of the state. This was the case in France after World War I, which failed to recognize Germany as a liberal state, even though it was governed by the Weimar constitution. The French, who had a longstanding historical rivalry with Germany, ignored the domestic political process, instead focusing on the recent war and subsequent reneging of reparations. ${ }^{45}$ This is exacerbated through the construction of friends and enemies, which is predicated on domestic norms and institutions of other states. ${ }^{46}$ The creation of an 'us versus them' dynamic increases tension and the potential for conflict between states.

\footnotetext{
${ }^{42}$ Based on the American form of democracy and developed by American political scientists (Ido Oren, Our enemies and US: America's rivalries and the making of political science (Cornell University Press, 2003), 268). ${ }^{43}$ John M. Owen, "How liberalism produces democratic peace," International security 19, no. 2 (1994): 125; Ido Oren, "The subjectivity of the "democratic" peace: changing US perceptions of imperial Germany," International Security 20, no. 2 (1995): 147-184.

${ }^{44}$ Owen, "How liberalism produces democratic peace,", 123.

${ }^{45}$ Christopher Layne, "Kant or cant: The myth of the democratic peace," International security 19, no. 2 (1994): 549.

${ }^{46}$ Thomas Risse-Kappen, "Democratic peace—warlike democracies? A social constructivist interpretation of the liberal argument," European Journal of International Relations 1, no. 4 (1995): 491-517.
} 


\title{
Threat Perception
}

Threat perception is a very broad literature within international relations, which has been conceptualized by a variety of scholars in different ways. There are a variety of schools of thought within international relations, ranging from neo-liberal to neo-realist, that postulate the relevance of perceptions on dyadic conflict. This literature stems from the dissatisfaction with theories that only focus on material forces to explain conflict and compromise. ${ }^{47}$ Rather than relying on rational actor theories, these scholars were interested in state behavior as a result of their respective construction of reality. Some scholars have posited that alliance formation is based on the perception of threat from others states. States which are perceived to be threats are based on four criteria: strength, geography, offensive capability and intentions. Rather than balancing against hard power, states tend to balance against the perceived intent of other states. ${ }^{48}$

Image theory is another perceptual theory, which identifies images as the source of state decision-making towards different opponents. The way in which these stereotypes, images and perceptions are generated is described as follows:

\begin{abstract}
People were cognitive misers often overwhelmed by too much information and anxious to manage it in useful and convenient ways directed attention to the shortcuts they used to do this. One of the most common shortcuts is to operate with categories that countries can be placed in and then use the category's general attributes to describe the country rather than concentrate on its idiosyncratic detail. $^{49}$
\end{abstract}

Images and perceptions of an opponent are fairly rigid constructs, and once established, they are used to explain the behavior of another state. This was the case during the Cold War in the United States, in which John Foster Dulles had developed an "inherent bad faith image" of the

\footnotetext{
${ }^{47}$ Kenneth Waltz, Theory of International Politics (Reading, MA: Addison-Wesley, 1979); Robert Gilpin, War and change in world politics (Cambridge University Press, 1983); John Mearsheimer, The Tragedy of Great Power Politics (New York: Norton Publishers, 2001).

${ }^{48}$ Stephen Walt "Alliance Formation and the Balance of World Power," International Security, vol 9, no 4 (Spring 1984), 8-9.

${ }^{49}$ R.K. Herrmann, "Perceptions and image theory in international relations," in Handbook of Political Psychology 334-363, eds D. Sears, L. Huddy and J. Levy (New York: Oxford University Press, 2013), 345.
} 
Soviet Union. ${ }^{50}$ Through this constructed image, aggressive Soviet behavior was interpreted as a threat whereas complacent Soviet behavior was interpreted as weakness. The implications of images allow a state to more easily understand the behavior of other states, but it can also create a self-fulfilling prophecy. The use of an image can also be used as a way of demonizing an enemy, reducing inhibitions towards conflict. By perceiving the enemy to be culturally inferior, it fundamentally changes the rules of war. ${ }^{51}$

\section{Unique Contribution}

Previous literature has demonstrated the importance of norms, institutions, ideological difference and perceptions in conflict resolution and escalation. This literature is invaluable in understanding the relationship between a multitude of factors and dyadic conflict. Unlike the regime-type and leadership ideology literature, my focus is on more fundamental differences between peoples living in different states. There is a void in the literature with respect to the interplay between value differences and threat perceptions. My theory attempts to bridge the gap between actual value differences and perceived cultural value differences. In doing so, this theory will remedy many of the puzzles that exist within the current body of literature.

In particular, there are several intriguing puzzles that exist within the current body of literature. First, the literature has difficulty in explaining the variation in state behavior towards different opponents that share the same ideological tendencies and regime-type. There have been numerous examples of the same regime demonstrating restraint in one crises and belligerence in another. When examining these crises through a traditional neo-realist perspective, it is difficult to understand why a regime would practice restraint in a more winnable conflict while aggressively

\footnotetext{
${ }^{50}$ Ole R. Holsti, “Cognitive dynamics and images of the enemy,” Journal of International Affairs 21, no. 1 (1967): 16-39.

${ }^{51}$ Herrmann, "Perceptions and image theory in international relations," 342.
} 
belligerent in a more evenly-matched (or outmatched) conflict. Secondly, the literature on cultural differences and perceptions lacks generalizable empirical evidence to support their claims. The notion that imbedded cultural differences of a dyad may result in increased hostilities is theoretically sound, but lacks empirical testing to support these claims. Through the use of both qualitative and quantitative strategies, this research will attempt to develop a generalizable test and specific instances of cultural friction on a case-by-case basis.

My theoretical contribution to the literature is to develop causal mechanisms that explain conflict based on fundamental moral differences between states, based on their respective civil religion. By moving beyond more malleable variables, such as leadership ideology and regime type, this research will attempt to identify the basal source of hostility between states. This approach is novel, in that moral belief structures and cultural dynamics between states is underdeveloped within international relations. 


\section{Chapter 3: Theory and Methods}

This chapter will explain the theory of this dissertation and the methods that will be used to test the aforementioned theory. The first section is dedicated to developing the theoretical expectations of this research project. This will be done by outlining the important concepts of the theory, which include civil religion, political change and ontological threat. These three causal mechanisms are instrumental in understanding dyadic state behavior through the lens of differences in civil religion. The second section is devoted to the research design of this project. The quantitative design will describe each of the dependent, independent and control variables included in the models. The qualitative design will outline the process tracing method that will be used to develop three pairs of case studies. Case selection will also be discussed in this section.

\section{Theoretical foundations}

The forthcoming sections will be dedicated to explaining the causal mechanisms of my theory. This theory posits that all states have an underlying civil religion, which has been forged through shared historical experience, culture and language, which has formed the identity of the state. In addition to an identity, the civil religion serves as the moral foundation from which societal norms and legal institutions are based upon. The regime within the state has its own ideology, which can be characterized as dealing with practical political and economic matters. When there is a regime change that results in an ideological shift, these changes are recognized by other states. When the stable routinized relationship between states is broken, it creates an ontological crisis for the dyad. States experiencing this crisis of identity will revert to their values enshrined in their civil religion. Dyads that share similar moral systems are more likely to resolve the crisis peacefully as opposed to dyads with competing value structures. 
Figure 3-1: Casual Mechanisms and Interaction

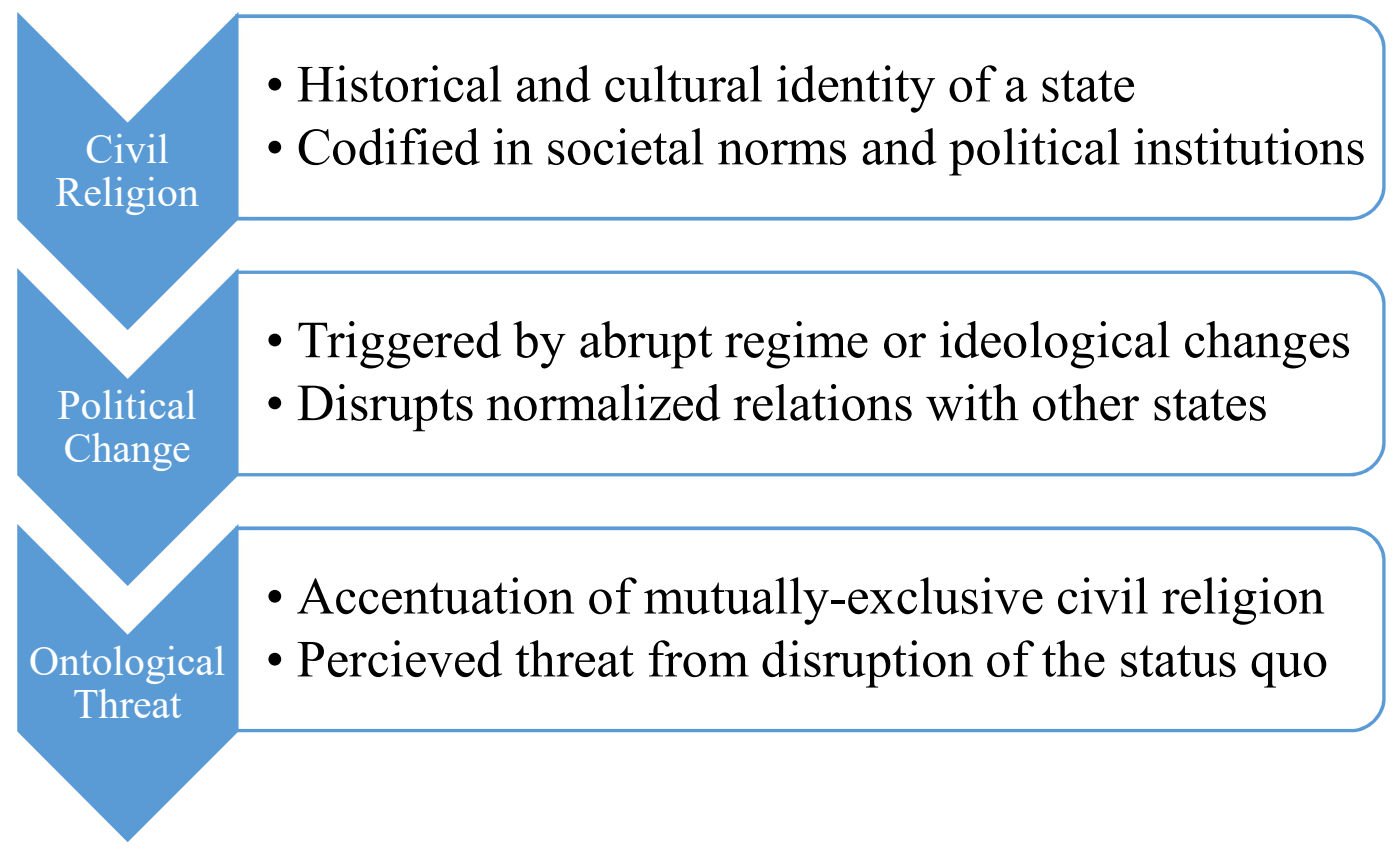

\section{Civil Religion}

The term civil religion ${ }^{1}$ was coined by Jean-Jacques Rousseau in The Social Contract, which refers to the set of national beliefs, dogmas and rituals which resemble a religion, but rooted in the secular. Rousseau was writing during a time of decaying religious importance, and noted how states maintained moral continuity without the use of religion. He describes the differences between civil religion and theological religion:

Religion, considered in relation to society, which is either general or particular, may also be divided into two kinds: the religion of man, and that of the citizen. The first, which has neither temples, nor altars, nor rites, and is confined to the purely internal cult of the supreme God and the eternal obligations of morality, is the religion of the Gospel pure and simple, the true theism, what may be called natural divine right or law. The other, which is codified in a single country, gives it its gods, its own tutelary patrons; it has its dogmas, its rites, and its external cult prescribed by law; outside the single nation that follows it, all the world is in its sight infidel, foreign and barbarous; the duties and rights of man extend for it only

\footnotetext{
${ }^{1}$ Civil religion has been used by Bellah (1967) and others almost exclusively describing the American experience. While the American founding, and subsequent establishment of a constitutional republic that explicitly separates church and state was unique at that time, many nations since then have followed suit and organized secular "religions".
} 
as far as its own altars. Of this kind were all the religions of early peoples, which we may define as civil or positive divine right or law. ${ }^{2}$

Civil religion can be differentiated from theological religion with respect to the treatment of divinity. Theological religions rely on the belief in transcendental and/or supernatural sources. Through these beliefs, individual members practice rituals and rites in service of the transcendental/supernatural. This can be distinguished from civil religion, which serves as "the empowerment of religion, not for the sake of religion, but for the sake of enhanced citizenship."3 The features of traditional religions, including the belief structures, and practice of rituals and rites are preserved in secular forms. By doing this, the norms of the 'good citizen' can be given a "transcendent or sacred quality to the basic values of the social construct that emerges." 4

The source of a states' civil religion is rooted in their national historical experience, which includes cultural norms and values. Similar to the development of religious doctrine, civil religion is developed organically from the collective consciousness of society. ${ }^{5}$ Individuals participate through a variety of nationalistic rituals ${ }^{6}$ and 'worship' political martyrs. ${ }^{7}$ While the origins are organically established on the societal level, states also institutionalize these values in order to maintain societal control. Others would argue that the content of civil religion is largely contingent on theological religions for content - acting as a middleman between traditional religious beliefs and the state. ${ }^{8}$ They would contend that civil religion is not a religion, per se, but the representation

\footnotetext{
${ }^{2}$ Jean-Jacques Rousseau, The social contract, or, Principles of political right, No. 83 (George Allen \& Unwin, 1895), 223.

${ }^{3}$ Ronald Beiner. Civil Religion: A Dialogue in the History of Political Philosophy (Cambridge University Press, 2010), 2.

${ }^{4}$ Elizabeth McKeown, "Civil Religion: Prophetic Freedom or Cultural Captivity," Proceedings of the Catholic Theological Society of America 31 (2012): 195.

5, Anthony Giddens, Modernity and self-identity: Self and society in the late modern age (Stanford University Press, 1991), 28.

${ }^{6}$ Such as standing for national anthems, celebrating national holidays and flag worship.

${ }^{7}$ For Americans this would include George Washington, Abraham Lincoln and John F. Kennedy.

${ }^{8}$ Richard John Neuhaus, Time Toward Home: The American Experience as Revelation (New York: Seabury, 1975), 188.
} 
of religious values. These perspectives are not mutually exclusive, whether organically developed or inspired by religious beliefs, the end result is a civil religion of the state that reflects its moral identity, which is encapsulated through positive laws and societal norms.

The development of civil religion within a given state can differ on a case-by-case basis. Some scholars, such as Bellah, posit that civil religion is a unique American invention, which was forged from Christian values and secular laws. In an effort to separate church and state, the American Founders codified their theist sentiments in a secular way in the Constitution and Declaration of Independence, which both distinctly mention God. The founders institutionalized these religious beliefs and values in a secular religion, which was not a replacement for Christianity, but rather a complement. While the process that forged the civil religion in America may have resulted from unique circumstances, it is not the only way of achieving those ends. Bellah describes this in further detail:

The American civil religion was never anticlerical or militantly secular. On the contrary, it borrowed selectively from the religious tradition in such a way that the average American saw no conflict between the two. In this way, the civil religion was able to build up without any bitter struggle with the church powerful symbols of national solidarity and to mobilize deep levels of personal motivation for the attainment of national goals.

Such an achievement is by no means to be taken for granted. It would seem that the problem of a civil religion is quite general in modern societies and that the way it is solved or not solved will have repercussions in many spheres. One need only to think of France to see how differently things can go. The French Revolution was anticlerical to the core and attempted to set up an anti-Christian civil religion. Throughout modern French history, the chasm between traditional Catholic symbols and the symbolism of 1789 has been immense. ${ }^{9}$

There are a variety of different manifestations of civil religion that would fall outside of the parameters set forth by Bellah, who describes it as a uniquely American invention. Other scholars have referred to these other manifestations as "alternative civil religions". ${ }^{10}$ These

\footnotetext{
${ }^{9}$ Ibid., 11.

${ }^{10}$ John Coleman, “Civil Religion,” Sociological Analysis 30 (1969):72
} 
alternative civil religions replace traditional religious values with nationalistic ideologies. This would include the previous example of France after the French Revolution. Fueled by rampant anti-Christian values, Christian institutions were supplanted by a worship of the French state and Reason. Even after the revolutionary regime was overthrown, these changes made a lasting impact on the national identity of France. ${ }^{11}$ While not recognized within the literature as being the same typology, some scholars have recognized that the cultural aspect is the same, "the world of representations," symbols, and images that emerges from society - that is society's self-conception of its ethos"12 In this regard, my treatment of civil religion follows this logic: regardless of the circumstances surrounding its conception, many states utilize a civil religion which is rooted in their historical experience and cultural values.

The use of civil religion by states is important for two reasons. First, it promotes social solidarity amongst citizens and legitimizes the regime. Civil religion represents the conduit between citizen and state, by offering domestic "rules of the game" that governs interactions within society. The establishment of a common morality is important for states because it promotes their version of the "Good". ${ }^{13}$ Second, it provides an overarching goal for the political process. It serves as a legitimizing function that provides the "ultimate system of meaning". ${ }^{14}$ The use of civil religion as a means of civic solidarity provides order and stability to a state.

\footnotetext{
${ }^{11}$ Marcela Cristi, From civil to political religion: The intersection of culture, religion and politics (Wilfrid Laurier Univ. Press, 2006), 144.

12 Ibid.,151.

${ }^{13}$ Steven M. Delue, Political Thinking, Political Theory and Civil Society (Boston: Allyn and Bacon, 1997), 157.

${ }^{14}$ Ibid., 32.
} 
Rousseau describes the function of civil religion in the following way:

It unites the divine cult with love of the laws, and, making country the object of the citizens' adoration, teaches them that service done to the State is service done to its tutelary god. It is a form of theocracy, in which there can be no pontiff save the prince, and no priests save the magistrates. To die for one's country then becomes martyrdom; violation of its laws, impiety; and to subject one who is guilty to public execration is to condemn him to the anger of the gods: Sacer estod..$^{15}$

The functionality of civil religion extends beyond the symbolic or moral attitudes of a state. Civil religion also "provides a grounding for the rights of man that makes any form of political absolutism illegitimate, it also provides a transcendent goal for the political process". ${ }^{16}$ This highlights the most important facet of civil religion, it provides a foundation and a goal for future generations of regimes. In other words, regardless of individual leaders' political and economic ideology, leaders are constrained through these legal and moral imperatives engrained within the civil religion. Civil religion is a latent bedrock for identity in all states, drawing from the values of the collective consciousness of society. Civil religion does not offer any apparent ipso facto threat to other states, but specific regimes may be more or less aligned to the latent values of the state.

For the purposes of this dissertation, I will utilize a broad definition of civil religion. The choice of using a broad definition is that scholarship is in disagreement over the definitions and examples of religion underpinning the state. I will accept/reject the following assumptions from the literature. First, the religious aspect of civil religion can be derived from a variety of sources - whether cultural, historical or theological - which serves as a moral foundation. Moving beyond the strict definition of Rousseau and Bellah, the concept of civil religion can be applied to states with different religious backgrounds, or no religious background. The source of the morals that

\footnotetext{
${ }^{15}$ Rousseau, The social contract, or, Principles of political right, 224.

${ }^{16}$ Robert N. Bellah, "Civil religion in America," Daedalus (1967): 2.
} 
underpin a states' laws and norms is less important than the existence of said laws and norms. The religious aspect of civil religion can refer to secular worship of the state itself, which is agreed upon in the literature.

Secondly, all established states have an inherent civil religion, which has enshrined their cultural and moral values in societal norms organically over time. The state uses this foundation as a justification for their rule and promotion of the 'good citizen'. Even Rousseau, who first postulated the concept, argued that politics must have a civil religion, such that a "state has never been founded without religion serving as its base"17 But when analyzed to determine what he means by religion, he goes on to reject Christianity, monotheism and theocratic rule. He fails to endorse any viable option for the religious foundation of civil religion. There are some states that do not fit this qualification, because they are unstable or failed states.

\section{Political Change}

While the civil religion of the state represents the link between state and society, domestic political changes also play an important role in ontological threat perception. There are two different considerations of domestic political change: (1) revolutionary change and (2) evolutionary change. Both of these changes can have an impact on the treatment of civil religion and threat perception. The first type, revolutionary change, is the result of rapid transformation of domestic politics from one regime type to another. Revolutionary regime change, which can include higher levels of internal violence and major shifts in ideological orientation, significantly alters the foreign policy of the state as well as the foreign policy towards the state. As a result, these states are more likely to experience a conflict in the aftermath of drastic domestic changes. ${ }^{18}$

\footnotetext{
${ }^{17}$ Rousseau, The social contract, or, Principles of political right, 127.

${ }^{18}$ Zeev Maoz, Domestic sources of global change (University of Michigan Press, 1996), 92-93.
} 
Dyads that include a state which recently experienced revolutionary changes are the most susceptible to conflict.

While domestic regime change is a significant factor in explaining the onset of a conflict, it does not differentiate how foreign policy behavior can differ between different dyads. For instance, Iran after the 1980 revolution would be classified as a revolutionary state. Based on the International Consequences of Political Change (ICPC) theory, Iran was more likely to experience a conflict due to the drastic shift in regime type and ideology. However, it is less clear from this theory which dyad(s) would be most likely to experience a crisis with Iran. This is the benefit of looking at the differences in the historical and cultural context of their respective states' civil religion. Even revolutionary regimes have a limited ability to drastically change the cultural values of society in a short period. In the case of Iran, the values of the revolution were already latent and persistent within society, not the other way around. When examining dramatic regime change, the actions of leadership should be viewed through the lens of cultural and historical traditions.

The second type of domestic political change, evolutionary changes, include a transfer of power or change in leadership. There are a countless number of economic, political, and social ideologies that can shift within a state. I concur with the definition posited by Haas, ideologies are the "principles upon which a particular leadership group attempts to legitimate its claim to rule and the primary institutional, economic, and social goals to which it swears allegiance". ${ }^{19}$ These changes should not dramatically change the foreign policy behavior of the state or behavior towards the state. These ideological differences do not prohibit states from cooperating, as we see through trade partnerships and global initiatives. Dyads of greater ideological difference is not a necessary and sufficient condition for conflict, albeit are at higher risks than ideologically similar

\footnotetext{
${ }^{19}$ Mark L. Haas, The ideological origins of great power politics, 1789-1989 (Cornell University Press, 2005), 5.
} 
states. $^{20}$ However, individual leadership preferences can result in aggressive foreign policy towards certain dyads.

Within evolutionary changes, individual leadership preferences become increasingly important for understanding foreign policy behavior. There are several important factors that shape the behavior of individual actors. First, this behavior is rooted in the domestic political environment, which ranges from accommodationist to radical hardliner leaders. ${ }^{21}$ Accommodationist states, also known as status quo states, attempt to maintain the current structure of the international system. This can be contrasted with revisionist powers, who strive to alter the international system for their benefit. ${ }^{22}$ In addition, the individual leaders' preferences and interests can influence the outcome of decision-making. It is impossible to ignore the individual leader(s) who are ultimately making decisions on behalf of a state. However, I contend that individual decision-making is constrained by the underlying civil religion of the state. In some cases, new leaders can accentuate the underlying civil religion and generate tensions with differing belief structures. In other cases, new leaders demonstrate more restrained behavior towards states with different belief structures. Even in the face of crisis and regardless of individual leadership preferences, leaders are unlikely to go to war against a state with a similar civil religion. This is illustrated in both the Argentina and Iraq case studies. Even when faced with a crisis from a similar state, Argentine and Iraqi leadership maintained their resolve to negotiate a settlement prior to conflict. After experiencing evolutionary leadership change, individual preferences were aligned with an ingrained historical narrative that defined the contentious relationship between Iran-Iraq and Argentina-Great Britain. The individual preferences towards each opponent only accentuated

\footnotetext{
${ }^{20}$ Haas, The ideological origins of great power politics, 16-20.

${ }^{21}$ John A. Vasquez, The war puzzle revisited (Cambridge University Press, 2009), 227.

${ }^{22}$ Randall Schweller, “Neorealism's Status Quo Bias: What Security Dilemma?” Security Studies 5, no. 3 (Spring 1996) 90-121.
} 
the underlying differences in their civil religions. That is not to say that individual preferences do not matter, but that they are not ex nihilo phenomena, and in some cases are derived from the underlying historical narrative surrounding states' civil religion. In other words, individual leaders can derive their preferences through an internalization of the narrative. A deeper understanding of this narrative can serve to better understand the relationship between civil religion and individual preferences.

\section{Ontological Threat}

Domestic regime changes, whether peaceful or violent, can disrupt normalized relations (even with ideologically different) states. Routinization, even with an ideologically distanced state, fosters the sense of ontological security. ${ }^{23}$ While not all regime changes are perceived to be a threat by other states, when rapid change occurs, the new regime may be perceived as an ontological threat or perceive other regimes as such. ${ }^{24}$ 'Ontological security' was coined by psychiatrist R.D. Laing as "a centrally firm sense of own and other people's reality and identity"25 While this theory was developed on the individual level, scholars have applied it to states as well. ${ }^{26}$ In addition to physical security, states also strive to maintain their ontological security. Ontological security refers to "security-as-being", as opposed to physical security, which refers to survival. ${ }^{27}$ Put another way, ontological security is achieved through stable and ordered relations with other states. Through these ordered experiences, states gain a sense of self-identity and meaning in the world. Through the use of routinized relations with other actors, states derive their own self-identity. The routinization of relations between states provides a security blanket for

\footnotetext{
${ }^{23}$ Anthony Giddens, Modernity and self-identity: Self and society in the late modern age (Stanford university press, 1991), 36.

${ }^{24}$ Haas, The ideological origins of great power politics, 16-17.

${ }^{25}$ R.D. Laing, The Divided Self: An Existential Study in Sanity and Madness (Harmondsworth: Penguin, 1960), 39.

${ }^{26}$ See Mitzen (2006), Zarakol (2017), and Steele (2005).

${ }^{27}$ Bill McSweeney, Security, identity and interests: a sociology of international relations (Cambridge University Press, 1999), 157.
} 
states that remove ontological fears. ${ }^{28}$ When a stable dyadic relationship is disrupted by domestic political changes, it calls into question the security of the self. In this trauma, states rely upon the "social order...which reproduces a general ontological security until she can pick herself up again". ${ }^{29}$ In this case, the social order is represented by the civil religion, which provides this ontological security in troubling times. The way in which other states respond to these domestic political changes is largely dependent on the content of their respective civil religions.

Contrary to Haas, I would argue that it is not merely the ideological distance between states, but the dyadic compatibility of their civil religion. What is meant by compatibility? Whether the underlying values of a particular state are inclusive or exclusive of another states' values. All states espouse a particular vision of the 'Good', which serves as a metaphysical mission statement to provide structure and legitimacy to their regime. This can be peripherally seen in their policies, rhetoric and ideals. A result of promoting this view of the 'Good' is that it implies competing concepts of 'Good' are heretical. The mutually exclusive nature of the components of civil religion can represent irreconcilable differences between states. In other words, states with complementary values are drawing from the same well of morality. Alternatively, states with differences in civil religion rely upon different normative foundations in which they view the world. When disputes occur between these dyads, they are exacerbated by these normative differences.

In addition to actual ontological differences between states, perception of differences also plays an important role in state behavior. States that perceive another state to be ontologically different are more likely to dehumanize their enemies. In other words, if a state believes that an enemy is inferior, regardless if they actually are, it is more likely to act aggressively. When a

\footnotetext{
${ }^{28}$ Jennifer Mitzen, "Ontological security in world politics: State identity and the security dilemma," European Journal of international relations 12, no. 3 (2006): 348.

${ }^{29}$ Ibid.
} 
leader believes that their civil religion is the correct version of the 'Good', they use it as justification for conflict. The alternatives to their own civil religion are perceived to be inferior and weak. The soldier and statesman "believes in what he is doing, believes that his own nation is superior and right, and believes that the enemy is inferior, evil and in the wrong". ${ }^{30}$

\section{Theory and Hypotheses}

The concepts of civil religion, political change and ontological threat are interconnected and serve as the casual mechanisms for this theory. At the core, fundamental values and moral belief structures are individualistic, passed generationally to children in their youth. While individual values may differ, they aggregate on the societal level to form collective societal values. These values are instrumental in developing the social contract between individuals and government, who enshrines these aggregate values in positive laws and norms. The identity of the state is derived from these values, which are codified in a states' civil religion - or national dogmas, rites and rituals. Civil religion acts as a proxy for understanding their perceived identity and worldview of other competing value structures. As an image, these value structures filter information according to that which is familiar. In the event of a rapid regime or political change, normalized relations between states is supplanted by fear and mistrust. In this period of uncertainty, states rely on known quantities, which include the differences in moral belief structures. If the content of these belief structures is vastly different between dyads in crisis, it can pose an ontological threat, or threats directed towards another's identity. When in crisis, the variation in state behavior (restraint/belligerence and/or limited/total war) is based on the similarities and differences in civil religion.

In order to test this theory, the following hypotheses are posited:

\footnotetext{
${ }^{30}$ Ken Booth, Strategy and Ethnocentrism (New York: Holmes \& Meier, 1979), 95.
} 
H1: Dyads with greater differences in civil religion are more likely to experience hostility than dyads with similar civil religions.

Inherent tensions exist between states that have fundamentally different perspectives on the 'correct' social and political order. These dyads are volatile because each state operates within a different moral framework. This theory posits that conflict escalation is the result of fundamental differences between states. However, that is not to say that conflict escalation can be the result of other external sources, but rather that moral and cultural differences are one of the primary driving forces behind it. In other words, dyads with similar belief structures are more likely to resolve a conflict than dyads with greater differences. Negotiation and compromise is less likely between groups that are perceived to be fundamentally different. When conflict does erupt between dyads with greater differences in belief structures, states are more likely to 'double down', rather than a negotiated settlement.

H2: Dyads with greater differences in civil religion that are experiencing a crisis are more likely to escalate the crisis rather than negotiate.

The outcome of a crisis varies dramatically, with some resolved prior to war and others escalating to belligerence. A crisis has been characterized as "a situation in which three conditions, deriving from a change in a state's external or internal environment, are perceived by the highestlevel decision-makers of the state: (a) a threat to basic values, (b) an awareness of finite time for response to the external threat to basic values, and (c) a high probability of involvement in military hostilities." 31 The behavior of decision-makers is contingent on a variety of factors, including public opinion, perceived advantages and expected outcome. Dyads of states with greater similarities in civil religion are more likely to resolve a crisis prior to escalation. This is the result

\footnotetext{
${ }^{31}$ Michael Brecher and Jonathan Wilkenfeld. "International Crisis Behavior Project, 1918-2001.” (2004).
} 
of having shared normative belief structures which facilitate peaceful resolution through effective communication and signaling.

H3: Dyads with greater differences in civil religion are more likely to experience greater brutality during conflict.

The mutually exclusive nature of civil religion represents irreconcilable differences between states. In other words, states with the same civil religion are drawing from the same well of morality. Alternatively, states with differences in civil religion rely upon different normative foundations in which they view the world. When disputes occur between dyads, they are exacerbated by these normative differences. This is rooted in moral superiority, or the logic that one's beliefs are of greater virtue than their opponents' beliefs. When a leader believes that their civil religion is the correct version of the 'Good', they use it as justification for brutal behavior during conflict. Since their opponents are perceived to be inferior and different, strategy towards non-combatants, the environment and culture becomes aggressive.

H4: Dyads of similar civil religions are less likely to perceive ideological or regime change as an ontological threat.

When routinized relations between dyads are broken, states will perceive greater threat from states that operate from different value structures. Dyads that have compatible ideologies are more likely to resolve their conflicts peacefully (or the use of limited warfare). These dyadic states still can have a crisis with ideologically similar states, but are more likely to resolve these conflicts peacefully, because they do not perceive the state as a threat to their identity.

\section{Methodology}

In order to test the aforementioned hypotheses, a mixed-methods approach will be used. Quantitative analysis will be conducted on Hypotheses I and II, which are concerned with testing 
the relationship between civil religion and escalation of conflict and crisis. Conflict escalation will be measured using the Militarized Interstate Dispute (MID) dataset and crisis variables are from the International Crisis Behavior (ICB) dataset. Since civil religion is such an abstract concept, it will be measured using the six dimensions of culture from the Values Survey Module 2013 (VSM 2013). Qualitative analysis will be conducted on Hypotheses III and IV, which are concerned with testing the perceived threat and the manifestation of differences in civil religion through conflict behavior. These hypotheses will be tested using historical narratives of three pairs of dyads. In each of these cases, the same state was involved in two different crises with two ideologically different states. The resulting crises were resolved through peaceful settlement or military intervention. Those that resulted in military intervention displayed the brutality of moral superiority towards inferior beliefs. These case studies will provide a better understanding for state behavior in crises with similar and different opponents.

\section{Quantitative}

Qualitative hypotheses testing will be conducted using two different dependent variables (derived from hostility level) and a common set of independent and control variables. The first hypothesis will be tested using a binary dependent variable representing conflict. The second hypothesis will be tested using the five-point hostility level scale. The dataset used has been created using variables from several sources, including Militarized Interstate Dispute (MID), International Crisis Behavior (ICB) and Value Survey Module 2013 (VSM 2013). The dataset has been arranged in non-directed dyad-year format, ranging from 1816 to 2008. This data was exported through EUGene, where it was subsequently merged with the six dimensions of culture data. ${ }^{32}$ Due to the nature of autocorrelation in the time-series data, each dyad was treated as a

\footnotetext{
${ }^{32}$ The six dimensions of culture for each country were available Hofstede Insights. Additional details of certain countries were only available through the country comparison tool on Hofstede Insights. Several individual
} 
panel throughout the regressions. The first model, which will test the first hypothesis, uses a binary hostility level $(0=$ no action; $1=$ threat, display, use of force and war $)$ as the dependent variable. Each of the six dimensions of culture (power distance, individualism, masculinity, uncertainty avoidance, long term orientation and indulgence) are included as independent variables, along with several control variables (major power dummy, capability ratio ${ }^{33}$, mixed regime and contiguity $\left.{ }^{34}\right) .{ }^{35}$ The second model, which will test the second hypothesis, will use a five-point hostility level scale. The only other notable addition to the second model is the inclusion of a limiting the scope to crisis cases. Rather than testing the model across all cases, the second model is limited to dyads in a crisis. ${ }^{36}$ The specific variables used in these models will be introduced in this section, along with a discussion of the methods.

Dependent variable: hostility level

The first two hypotheses will be tested using hostility level as the dependent variable. However, the treatment of this variable will differ for each model. The first model will utilize a collapsed dependent variable based on the cwhostd variable from the MID dataset. This variable exhibits no militarized action coded as 0 and all other actions - up to and including war-coded as 1. This variable indicates a disruption in peaceful relations between a dyad. By collapsing this variable, the first model is testing the relationship between dyadic hostility and the six dimensions of culture.

\footnotetext{
countries were not specifically identified in the data, including "Africa West", "Africa East", and "Arab Countries". Upon further investigation, the "Africa West" dimensions were coded for the following countries: Benin, Ivory Coast, Gambia, Guinea-Bassau, Liberia, Mauritania, Niger and Togo. "Africa East" coding was used for the following countries: Sudan, South Sudan, Madagascar, Mauritius, Comoros, Seychelles and Burundi. The "Arab Countries" coding was used for the following countries: Bahrain, Oman, Qatar, Somalia, Tunisia and Yemen.

${ }^{33}$ From the COW Composite Indicator of National Capabilities (CINC).

${ }^{34}$ Levels range from 1-6. 1) land contiguity; 2) contiguous for up to 12 miles of water; 3) contiguous for 13-24 miles of water; 4) contiguous for 25-150 miles of water; 5) contiguous for 151-400 miles of water. Level 6 indicates that the states are not contiguous (or are contiguous over more than 400 miles of water).

${ }^{35} \mathrm{~N}=248650$

${ }^{36} \mathrm{~N}=64438$
} 
In accordance with the second hypothesis, the dependent variable will be the five-point scale of hostility level. This measurement is operationalized using the cwhostd variable from the MID dataset. The decision to not use the same collapsed variable in the second model was due to the correlation between the values of crisis and increased hostility. The purpose of the second model is to test the relationship between hostility escalation during crisis and the six dimensions of culture. Therefore, a variable limiting the scope of the analysis will be added to the model. These variables, crisis and icbongo are included from the ICB dataset. This variable is coded 0 (no crisis) and 1 (crisis or ongoing crisis). The logic behind this model is that the onset or ongoing nature of a crisis is the result of differences in civil religion. This variable is coded between 1 and 5 , representing the hostility levels between the dyad in the particular year:

\section{Hostility level of dispute (H2)}

$\begin{array}{ll}1 & \text { No militarized action } \\ 2 & \text { Threat to use force } \\ 3 & \text { Display of force } \\ 4 & \text { Use of force } \\ 5 & \text { War }\end{array}$

The threat to use force is defined as "verbal indications of hostile intent". ${ }^{37}$ Hostile intent is ascertained through ultimatums which clearly outline a punitive action if the state does (or does not) act in a particular fashion. A display of force is a non-violent military act demonstrated towards a particular target. This can include military mobilization, public demonstrations, and border violations. The use of force occurs when a state engages in military operations against another state. This includes all aggressive military actions, including blockades, occupation of territory, clashes and declarations of war. War is achieved when combat operations escalate to a minimum of 1000 total battle deaths. ${ }^{38}$

\footnotetext{
${ }^{37}$ Daniel M. Jones, Stuart A. Bremer, and J. David Singer, "Militarized interstate disputes, 1816-1992: Rationale, coding rules, and empirical patterns," Conflict Management and Peace Science 15, no. 2 (1996): 170.

${ }^{38}$ Ibid., 170-173.
} 
Independent variables: six dimensions of culture

The independent variables will include the six dimensions of culture, as classified by Hofstede, Hofstede and Minkov and derived from the results of the Values Survey Module 2013 (VSM 2013). ${ }^{39}$ The VSM 2013 is a 30-item questionnaire, composed of 24 content and 6 demographic questions that has been administered in 120 different states. The 24 questions are organized on the basis of the 6 dimensions of culture, with 4 questions dedicated to each cultural dimension. The respondent is asked the question, and has the option to answer each question using a 5-point scale. ${ }^{40}$ Each of these 6 dimensions are aggregated on the state-level, with the mean of respondents used. The six cultural dimensions are (1) power distance, (2) individualism, (3) masculinity, (4) uncertainty avoidance, (5) long-term orientation and (6) indulgence.

Along with GLOBE and the World Values Survey (WVS), the VSM is one of the top-3 most utilized datasets for quantifying cultural values. The VSM has been found to be a more accurate indicator of cultural values than the GLOBE, which merely elicited preferences of respondents. ${ }^{41}$ Both the VSM and WVS suffer from similar problems of preference bias, however, researchers have found the VSM to be a superior measurement of actual values (albeit not perfect). ${ }^{42}$ It is for this reason that the VSM has been utilized within the fields of business management and organization sciences ${ }^{43}$, psychology ${ }^{44}$ and sociology ${ }^{45}$.

\footnotetext{
${ }^{39}$ Geert Hofstede, Gert Jan Hofstede, and Michael Minkov. Cultures and organizations: Software of the mind, Vol. 2, (London: McGraw-Hill, 2010).

${ }^{40}$ See Appendix 2 for full questionnaire.

${ }^{41}$ Robbert Maseland and André Van Hoorn, "Explaining the negative correlation between values and practices: A note on the Hofstede-GLOBE debate," Journal of International Business Studies 40, no. 3 (2009): 527-532.

${ }^{42}$ See House et al (2004), 140; Javidan et al (2006); Maseland and van Hoorn (2016).

${ }^{43}$ See Anjum, Muhammad and Raza (2014), Randall (1993), Soeters and Schreuder (1988), Sondergaard (1994), and Bradley, Lowe and Gibson (2006).

${ }^{44}$ See Spector, Cooper and Sparks (2001) Taras, Kirkman and Steel (2010) and Spector, Allen and Poelmans (2007).

${ }^{45}$ See Wilhelm and Gunawong (2016).
} 
One of the assumptions made by this research is that the Hofstede Dimensions of Culture accurately represent the civil religion of the state. In the beginning of the theoretical section, civil religion was described in terms of foundational belief structures within a given state. While the practices, rituals and symbols of a culture can change from generation to generation, the values are much less malleable. This is in part because values are learned at a young age (the first 10 to 12 years) from parents that were also taught similar values at a young, impressionable age. In other words, cultural values are generationally passed from parents who tend to "reproduce the education they received, whether they want to or not". ${ }^{46}$ It is for this reason that one value has been assigned to each state as opposed to time series data. The following sections will introduce the meaning and process by which these cultural dimensions have been collected.

\section{Power Distance}

The first cultural dimension of interest is power distance. All societies have some degree of power inequality between members and/or groups within society. Power distance is the measurement of acceptable inequality within a given society. This is a normative measure of whether or not people believe that power should be distributed equally. The implications of this measure is strongly related to the dependence between authority and subordinates. In states with small power distance, there is limited dependence on authority figures and a preference for consultation. ${ }^{47}$ Examples of small power distance states include Austria, Germany, Israel, Nordic states, Baltic states, the United States and Great Britain. ${ }^{48}$ Alternatively, states with large power distance exhibit large dependence of subordinates on authority, as a result of preference or

\footnotetext{
${ }^{46}$ Hofstede, Hofstede, and Minkov. Cultures and organizations, 13.

${ }^{47}$ Ibid., 61 .

${ }^{48}$ Ibid., 60.
} 
counterdependence. $^{49}$ Examples of large power distance states include Malaysia, Philippines, Slovakia, Russia, Panama and Mexico. ${ }^{50}$

In order to compute the value of power index per state, the following formula is used:

$$
\text { PDI }=-35 m(03)+35 m(06)+25 m(14)--20 m(17)-20
$$

The values of $\mathrm{m} 03, \mathrm{~m} 06, \mathrm{~m} 14$ and $\mathrm{m} 17$ are the mean scores for that particular question from all individuals within a given state. The value can range from 0 (small power index) to 100 (large power index).

$\underline{\text { Individualism }}$

Individualism captures the societal connections between people; whether respondents identified as being autonomous or identified in strong cohesive groups. The researchers describe their measurement in the following way: "Individualism pertains to societies in which the ties between individuals are loose: everyone is expected to look after him- or herself and his or her immediate family. Collectivism as its opposite pertains to societies in which people from birth onward are integrated into strong, cohesive in-groups, which throughout people's lifetime continue to protect them in exchange for unquestioning loyalty". ${ }^{1}$ Put another way, this variable can be described as independence vs. interdependence among actors within society. Individualism places emphasis on the independent self-actualization of the individual person. Individuals are responsible for the betterment of their lives and are rational and calculating in their decisions. In particular, North Americans and Western Europeans tend to espouse the view of the individual as

\footnotetext{
49 Ibid., 61.

50 Ibid., 60.

${ }^{51}$ Ibid., 92.
} 
an autonomous, unique and rational actor. ${ }^{52}$ That being said, there is much variation on this scale within regions and regime types.

In order to compute the value of individualism per state, the following formula is used:

$$
\text { IDV }=35(\mathrm{m04}-\mathrm{m01})+35(\mathrm{m09}-\mathrm{m06})
$$

The values of m04, m01, m09 and m06 are the mean scores for that particular question from all individuals within a given state. The value can range from 0 (collectivist) to 100 (individualist).

$\underline{\text { Masculinity }}$

The third dimension of masculinity refers to the accepted gender roles within society. This is a question of the appropriate gender roles (masculine and feminine). Gender roles can vary from state to state, with different societal norms and conventions assigned to each sex. Traditional masculine roles are associated with assertiveness and toughness whereas feminine roles are associated with tenderness and understanding. ${ }^{53}$ The masculinity variable measures the rigidness of traditional gender roles within a given state. This is a normative measurement, whether or not people believe that gender roles should be defined or fluid. States with high measures of defined gender roles include Great Britain, the United States, Ireland, Australia, Japan, China, Venezuela, Mexico and Colombia. Alternatively, states with lower measures of defined gender roles include Norway, Latvia, the Netherlands, Denmark and Finland.

In order to compute the value of power index per state, the following formula is used:

$$
\text { MAS }=+60 \mathrm{~m}(05)-20 \mathrm{~m}(07)+20 \mathrm{~m}(15)-70 \mathrm{~m}(20)+100
$$

\footnotetext{
52 Hazel R. Markus and Shinobu Kitayama. "Culture and the self: Implications for cognition, emotion, and motivation." Psychological review 98.2 (1991): 224.

${ }^{53}$ Hofstede, Hofstede, and Minkov. Cultures and organizations, 140.
} 
The values of $\mathrm{m} 05, \mathrm{~m} 07, \mathrm{~m} 15$ and $\mathrm{m} 20$ are the mean scores for that particular question from all individuals within a given state. The value can range from 0 (fluid gender roles) to 100 (traditional gender roles).

Uncertainty Avoidance Index

The fourth cultural dimension is uncertainty avoidance. This has been defined as "the extent to which the members of a culture feel threatened by ambiguous or unknown situations" In other words, the amount of tolerance of ambiguity within a given society. The fear of the unknown, as a subjective phenomenon, can provoke a much different reaction in some people than other. The ways of dealing with anxiety are learned behaviors, reinforced by societal norms and institutions. ${ }^{55}$ States with high uncertainty avoidance index scores indicate a societal reluctance towards uncertainty. Examples of these states include Greece, Portugal, Guatemala, Russia, El Salvador, Poland and Japan. On the other hand, states with low uncertainty avoidance index scores indicate less societal reluctance towards uncertainty. Examples of these states include Singapore, Jamaica, Denmark, Sweden, Vietnam, China, Ireland and Great Britain.

In order to compute the value of uncertainty index per state, the following formula is used:

$$
\mathrm{UAI}=+25 \mathrm{~m}(13)+20 \mathrm{~m}(16)-50 \mathrm{~m}(18)-15 \mathrm{~m}(19)+120
$$

The values of $\mathrm{m} 13, \mathrm{~m} 16, \mathrm{~m} 18$ and $\mathrm{m} 19$ are the mean scores for that particular question from all individuals within a given state. The value can range from 0 (low uncertainty avoidance) to 100 (high uncertainty avoidance).

\section{$\underline{\text { Long-Term Orientation }}$}

The fifth cultural dimension is long-term orientation. This has been defined as "the fostering of virtues oriented towards future rewards", which is opposed to "the fostering of virtues

${ }^{54}$ Ibid., 191. 
related to the past and present". ${ }^{56}$ This can also be conceptualized as being forward thinking as opposed to living in the moment. States that can be characterized as long-term oriented include China, Hong Kong, Taiwan, Japan, Germany, Brazil and India. Alternatively, states with shortterm orientation include the United States, Mexico, Argentina, Venezuela, Iran, Colombia and Egypt.

In order to compute the value of long-term orientation index per state, the following formula is used:

\section{LTO $=-20 m(10)+20 m(12)+40$}

The values of $\mathrm{m} 10$ and $\mathrm{m} 12$ are the mean scores for that particular question from all individuals within a given state. The value can range from 0 (long-term orientation) to 100 (short-term orientation).

$\underline{\text { Freedom/restraint }}$

The sixth cultural dimension is the appropriate amount of freedom one should have. If one accepts the premise that human nature is inherently good, it would necessitate believing in more freedom. Alternatively, if human nature is inherently evil and needs to be restrained, less freedom should be imposed. With respect to governing, the amount of individual freedom is strongly correlated with the rights afforded to citizens.

This is conceptualized by the VSM 2013 as indulgence vs. restraint. The researchers discuss this dichotomy in the following way: "indulgence stands for a tendency to allow relatively free gratification of basic and natural human desires related to enjoying life and having fun. Its opposite pole, restraint, reflects a conviction that such gratification needs to be curbed and regulated by strict social norms". ${ }^{57}$ The value is a good proxy measurement of how important

${ }^{56}$ Ibid., 239.

${ }^{57}$ Ibid., 281 
freedom of self-actualization is to citizens of a state. In a similar fashion to the first dimension, the following formula is used:

\section{IVR $=35(\mathrm{~m} 12-\mathrm{m} 11)+40(\mathrm{~m} 17-\mathrm{m} 16)$}

The values of $\mathrm{m} 12, \mathrm{~m} 11, \mathrm{~m} 17$ and $\mathrm{m} 16$ are the mean scores for that particular question from individuals within a given state. The value can range from 0 (extreme restraint) to 100 (extreme indulgence).

\section{Qualitative}

Hypotheses III and IV will be tested using historical narratives and process tracing to explain specifically how these differences alter threat perception and subsequent conflict behavior. The use of process tracing as a methodology within international relations has yielded fruitful results. ${ }^{58}$ In order to confirm hypotheses, process tracing "focuses on the unfolding of events or situations over time...characterize[ing] key steps in the process. ${ }^{59}$ Process tracing relies on a variety of qualitative data sources in order to gain a deeper understanding of the causal mechanisms. Specifically, theory-testing process-tracing will be the method utilized. This type of process tracing is based on "translating theoretical expectations into case-specific predictions of what observable manifestations each of the parts of the mechanism should have if the mechanism is present in the case". ${ }^{60}$ These historical narratives will follow the same structure as the theory, from the foundations of civil religion of each respective state, the changes in domestic politics, the ontological threat perception of other states and the states' response to the threat.

\footnotetext{
58 See Tannenwald (1999), Bennett (2010) and Schultz (2001).

59 David Collier, "Understanding process tracing," PS Political science and politics 44.4 (2011): 823.

${ }^{60}$ D. Beach and R.B. Pedersen, Process-tracing methods: Foundations and guidelines (Ann Arbor: University of Michigan Press, 2013), 14.
} 


\section{Figure 3-2: Ontological Threats and Outcomes}

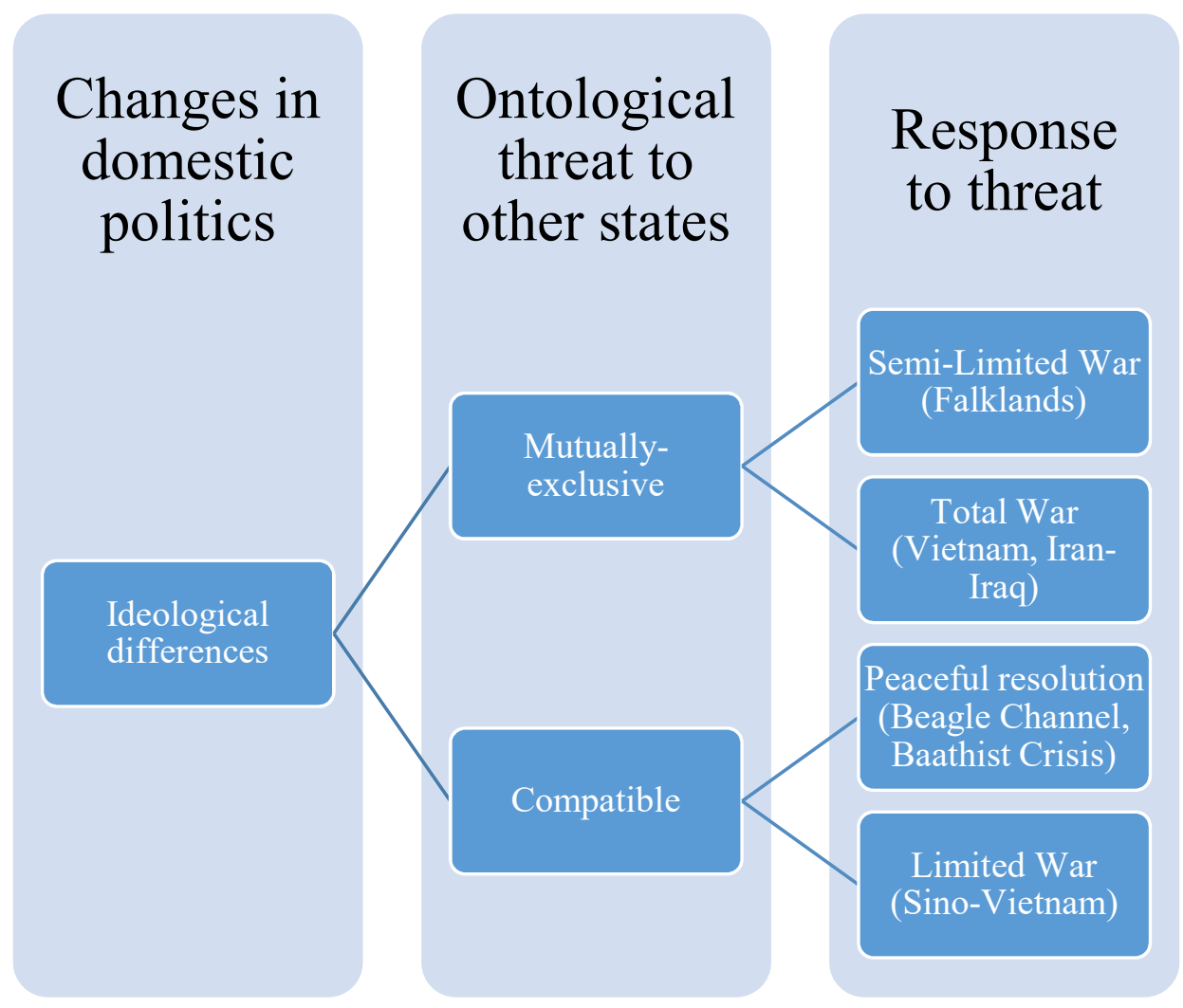

Each case study will begin with an overview table describing the important variables of each state involved in the dyadic conflicts. These variables include the predominant religious values of the state, the virtues of their respective civil religion and institutional arrangements at the time of the conflict(s). These variables serve as both the background for understanding dyadic relations and the underlying catalyst behind the escalation or resolution of crisis. For each focal country, they resolved a crisis with a state that shared similarities in moral beliefs and civil religion. On the other hand, a crisis was escalated with a state with differing belief structures. These variables will be discussed in further depth throughout the respective case studies, with special attention on the similarities and differences in belief structures and civil religions of each dyad. 


\section{Case Selection}

The way in which cases have been selected is a most similar systems (MSS) design. The three case studies have been divided into two dyadic crises. Each case study involves one pivot state $(\mathrm{A})$ and two variable states $(\mathrm{B}, \mathrm{C})$, represented by two dyads (A-B, A-C). The regime type of the one (A) state remains constant over the duration of both crises, allowing for thorough investigation of the regime decision-making and outcomes. The three primary states of interest are Argentina, Vietnam and Iraq. The choice of these three actors as pivot states was for a variety of reasons. First, each of these states represents a completely different geography, regional actors and historical experience. By choosing states from South America, Asia and the Middle East, it is an attempt to generalize this theory in a variety of different geo-political contexts. At the same time, all the dyads faced crisis during the Cold War period, which holds constant the larger bipolar international order. Second, each of these pivot states were faced with crises in a short period of time under the same regime. When faced with challenges from different actors, these states responded in much different ways. While there were many other crises during the same time period involving many other states, rarely did these events naturally occur in short succession as with these six dyads.

\section{Argentina}

Domestically, Argentina was politically fragmented after the death of Peron in 1974. His successor, Isabel Martinez de Peron, was overthrown in a military coup by Jorge Rafael Videla. Life under the military junta was harsh, intellectuals and activists disappeared, were tortured and/or deported. The behavior of Argentinian leaders indicated that the seizing of these territories was done because they felt a right to self-determination. ${ }^{61}$ Argentina was involved in two crises during

\footnotetext{
${ }^{61}$ Arie Marcelo Kacowicz, Peaceful territorial change (University of South Carolina Press, 1994).
} 
the period of the military junta (1976-1983), with Chile over the Beagle Channel (1979) and Great Britain over the Falkland/Malvinas Islands (1982).

The Beagle Channel crisis involved three islands, Lennox, Nueva and Picton, located at the entrance to the Beagle Channel. The dispute over ownership of the islands was adjudicated by the International Court of Justice (ICJ), which awarded them to Chile in May 1977. In December 1977, Argentina delivered a note to the government of Chile protesting the terms of the ICJ ruling. In conjunction, reservists in the Mendoza region were called upon. In response, Pinochet deployed armor and infantry between Puero Natales and Punta Arenas along with warships patrolling the Magellan Straits. Throughout the month of January 1978, Argentina and Chile continued preparations for military engagement. However, on February 20, the Pinochet and Videla signed the "Act of Puerto Montt", which postponed military action for 180 days. Nearly two months after the 180-day window closed, no meaningful progress was made on the negotiation of the territory. On October 16, Argentina began mobilizing reservists along the Chilean border. In response, Chile also mobilized forces along the border. Minor clashes between the two forces continued into the winter months. On December 16, Chile began taking up a defensive position along the border, to which Argentina responded by submitting a formal complaint to the UN Security Council. With the help of Pope John Paul II, acting as a mediator, the crisis was averted through the Declaration of Montevideo, signed on January 8, 1979.

The Falkland Islands is a low population $(2,000)$ archipelago located south of Argentina. Since their discovery in 1592, the Falklands have been under control of the British, French and Spanish. Once gaining independence in 1816, Argentina asserted sovereignty over the islands, but was usurped by the British in 1833. Argentina had made several complaints to the United Nations, which challenged the U.K. sovereignty over the islands, to no avail. Argentina sent military 
personnel to occupy the island on April 2, 1982. The United Kingdom dispatched a large naval force on April 5. On May 21, 5,000 British troops landed on the East Falkland Island. After several weeks of fighting, Argentina surrendered on June 14.

These cases are especially intriguing because Argentina had a greater likelihood of success against Chile, yet resorted to Papal mediation. Alternatively, Argentina was militarily outmatched by the British, yet invaded the Falkland/Malvinas Islands, triggering a military conflict. Through process-tracing, these case studies will examine the historical conditions, leadership decisionmaking and perceptions of ontological threat that resulted in vastly different outcomes.

In order to complete the first case study involving Argentina (Falkland Islands), I am going to rely on primary and secondary historical sources that focus on the decision-making of leaders within Argentina and Great Britain. Secondary sources include historical analysis of the conflict, including the historical tension between Argentina and Great Britain and the issue of territorial sovereignty. ${ }^{62}$ In addition to these historical sources, there are also declassified documents from the conflict, which includes military history and strategy. ${ }^{63}$ Primary sources, which includes declassified documents from the Argentinean and British governments, were made available under the 30 -year rule.

In a similar fashion to the first case study, the Beagle Channel case study will be developed using both primary and secondary sources. The purpose is to rely on historical sources that demonstrate the decision-making of Argentina and Chile before and during this crisis. This includes secondary sources that describe the historical and legal challenges over sovereignty of the

\footnotetext{
${ }^{62}$ See Goebel (1927); Gough (1992); Hastings and Jenkins (1986); Fisher et al (1997); Dolzer (1992); Keesing's World News Archives.

${ }^{63}$ See Braswell (1983); Sanders and Korkin (1985); Otero (1983).
} 
Beagle Channel. ${ }^{64}$ In addition to the historical sources, there are primary sources, including but not limited to agreements of negotiation, which are available on Facts on File.

Iraq

In 1968, Ahmed Hassan al-Bakr and Saddam Hussein staged a bloodless coup against Abdul Rahman Arif, establishing a new Baathist regime in Baghdad. The next decade could be characterized as contentious with other factions within the state, including the Iraqi Communist Party (ICP) and Shi'ites. The transition from al-Bakr to Saddam was even more tumultuous, because other Baathists were not confident in his rule, even while he was the de facto ruler in 1977. During the first twelve years of Baathist rule, Iraq was involved in two major crises, which included the dyads of Syria (1976) and Iran (1980).

After the 1967 defeat at the hands of Israel, Syrians were divided between moderates under Hafez al-Assad and radicals of the Baath party. In 1970, al-Assad seized control of the state, along with separating himself from the Saddam regime. The new Baathist regime in Syria under Hafez al-Assad (1971) immediately clashed with the Iraqi Baathists. With both sides ascribing to the same ideology while striving for their own Baathist legitimacy, tensions mounted over the next decade. Several incidents involving Syria, including the Agreement on Disengagement, Euphrates water rights and the Lebanese Civil War, pushed tensions between Iraq and Syria to the brink. Throughout 1976, Iraq had mobilized troops, cut oil pipeline shipments and performed reconnaissance missions along the border. By June 1976, it appeared that Iraq was planning a preemptive strike against Syria in order to occupy the Karatshuk oilfields and expand their territory along the Euphrates. However, the dispute did not escalate beyond troop mobilization. By the

\footnotetext{
${ }^{64}$ See Buzan (1983); Calvert (1983); Fisher (1970); Keesing's World News Archives.
} 
end of the year, both sides had demobilized along the border, shifting their resources to internal propaganda and terrorist activities.

The Iraq-Iran conflict occurred from September 1980 until August 1988 and was fought between the Islamic Republic of Iran and the Republic of Iraq. The conflict was the longest duration of war during the twentieth century, with military casualties exceeding 300,000 and civilian casualties exceeding 100,000. Civilian targeting was a common facet, through the use of indiscriminate ballistic-missile attacks against metropolitan areas and chemical weapons. While the Geneva protocol enshrined the norm against using these forms of weapons in combat, they failed the established guidelines regarding the production, storage or enforcement of these norms. ${ }^{65}$

By 1984, Iraqis began extensively using chemical weapons against dug in Iranian targets. The first use of a nerve agent in conflict, tabun was deployed against Iranian forces during the Khaybar I campaign near Basra. The tactical advantage of using chemical weapons allowed for supply lines to be cut, which provided an opportunity to fight against less supplied and lower morale troops. This practice continued until early 1988, when chemical weapons targets were expanded to include offensive strikes, as opposed to those relegated to recapturing lost territory. This was even more pronounced during the period known as the "war of the cities" from February to March 1988, in which both Iran and Iraq began to deliberately target civilian populations with ballistic missile attacks. It was during this period that Iraq used chemical weapons against Kurdish forces, in particular the attack on Halabjah, in which civilians and military personal were indiscriminately targeted.

These case studies will examine the historical conditions that underlie the crises between Iraq-Syria and Iraq-Iran during the Baathist regime. The purpose of these cases is to better

\footnotetext{
${ }^{65}$ Javed Ali, “Chemical Weapons and the Iran-Iraq War: A Case Study in Noncompliance," The Nonproliferation Review 8, no. 1 (2001): 44.
} 
understand the Iraqi decision-making during these crises, with particular emphasis on the perceived ontological threat. Whereas Iraq and Syria were disputing over territorial and political alignment in the region, both Iraq and Syria had a similar value structure and were more receptive to détente. Alternatively, the Iranian revolution was a turning point for relations between IraqIran, which was perceived by Iraq as a threat to their way of life. By casting this conflict in a historical Persian-Arab context, it justifies the use of chemical weapons and indiscriminate missile attacks against civilians.

In order to complete the first case study involving Iraq, I am going to rely on primary and secondary historical sources that focus on the decision-making of leaders within Iraq and Iran. Secondary sources include historical analysis of the conflict, including the historical tension between Iraq and Iran $^{66}$ and the question of territorial sovereignty. ${ }^{67}$ Primary sources, which includes declassified and translated documents of Iraqi and Iranian decision makers, are available from the Wilson Center Digital Archive.

In a similar fashion to the Iran-Iraq War case study, the Baathist crisis with Syria will be performing using primary and secondary historical source material. Baathist documents from the founders and similar value structures of Iran and Syria will be expounded upon. ${ }^{68}$ Secondary sources include a historical analysis of the development of Baathism in Syria and Iraq. ${ }^{69}$

\section{Vietnam}

The Vietnam case can be differentiated from the previous cases because Vietnam is not the aggressor state. Vietnam experienced drastic regime change after gaining independence from France through the First Indochina War (1954). Transitioning from decades as a colonial state to

\footnotetext{
${ }^{66}$ See Balfour-Paul (1984); Khadduri (1988); Pipes (1994); Schofield (1986); Keesing's World News Archives.

${ }^{67}$ See Hunseler (1984); Kaikobad (1988).

${ }^{68}$ See Devlin (1976); al-Bath (1963); Binder (1959); Alfaq (1958).

${ }^{69}$ See Khadduri (1978); Hinnebusch (1989); Sassoon (2011); Jansen (1986).
} 
a perceived communist state under Ho Chi Minh disrupted normalized relations. Vietnam was involved in two crises in the coming decades: The Vietnam War(1964-1973) and Sino-Vietnamese War (1979).

The Vietnam War escalated following the Gulf of Tonkin Incident, which a Destroyer, the USS Maddox, was allegedly attacked by three North Vietnamese torpedo boats. As a result of this attack, the Gulf of Tonkin Resolution was passed by congress, which authorized President Johnson to assist "any member of the protocol state of the Southeast Asia Collective Defense Treaty". On March 8, 1965, combat troops were deployed to Vietnam, ballooning to over 200,000 by years' end. While the official explanation for involvement in Vietnam was the containment of communism, the strategy of the United States was extremely aggressive toward non-military targets. Domino theory fails to explain the level of indiscriminate warfare conducted in Vietnam, which included body count quotas, failed pacification efforts and defoliation of civilian food supply. To put it in perspective, between 1965 and 1973, over 8 million tons of ordinance and 20 million gallons of herbicides were deployed in Vietnam.

China and Vietnam have an asymmetrical historical relationship, dating back to the Han empire (111 B.C.). For the next century, Vietnam unsuccessfully rebelled against Chinese occupying forces. In 938 A.D., Vietnamese forces under Ngo Quyen successfully gained independence from China. Aside from a brief period under the Ming Dynasty (1407-1428), Vietnam was an independent state until being colonized by the French in the mid-19 $9^{\text {th }}$ century. After the defeat of French and American forces, Vietnam had finally returned to normalized relations with China. The rivalry between Vietnam and China was rekindled after several incidents including the invasion of Cambodia, territorial disputes and the treatment of Hoa. This culminated with punitive action against Vietnam when in 1979, when China launched a limited war against 
Vietnam with over 450,000 infantry. The goals of the conflict were inherently limited, capture the northern capitals as punishment for their behavior in the region. Chinese soldiers were educated in Vietnamese culture, and were given specific instructions to assist civilian populations through the principles of political work. The shared cultural values between these combatants resulted in a limited war which was specifically targeted towards enemy combatants.

These case studies will develop the historical and cultural linkages between China-Vietnam and United States-Vietnam, with particular emphasis on the ontological threat posed by Vietnam in both cases. The United States strategy in Vietnam reflected this ontological threat, whereas the cultural similarities between China and Vietnam resulted in a much different type of conflict. The purpose of these case studies are to flush out the cultural differences and similarities that led to these very different manifestations of conflict.

In order to perform the first cast study of the Vietnam War, I am going to rely on primary and secondary sources that provides historical analysis and an understanding of behavior of the United States and North Vietnam. The areas of interest are the ways in which the United States perceived the Vietnamese people; likewise, how the Vietnamese people perceived the presence of United States forces. In addition to perceptions, there is a vast literature regarding the war crimes perpetrated by both sides during the conflict. ${ }^{70}$

In order to complete the second case study, the Sino-Vietnamese War, it is pivotal to explore the relationship between China and Vietnam. This will be accomplished through primary and secondary sources that examine the reasons for going to war, and more importantly, the perceptions of one another. There is an immense body of literature that examines the relationship between Vietnam and China. ${ }^{71}$ Primary source materials will include speeches, international

\footnotetext{
70 See Herman (1970); Dellums (1972); Knoll and McFadden (1970); Melman (1972)

${ }^{71}$ See Amer (1994); Burton (1979); Chen (1983); Chen (1992); Hood (1992); Vogel (2011); Zhang (2005)
} 
memos and notes of high ranking officials within Vietnam and China, housed by the Wilson Center Digital Archive. 


\section{Chapter 4: Quantitative Analysis}

This chapter is dedicated to providing statistical evidence to support the theoretical claims herein. Whereas the case studies will uncover specific mechanisms through process tracing, quantitative analysis will test the generalizable relationships between civil religion and dyadic hostility. In order to accomplish this goal, this chapter will be organized in the following manner: first, an overview will restate the hypotheses and deconstruct the concept of civil religion into three generalizable categories. Secondly, results from the hypothesis testing will be presented. Lastly, an analysis and discussion of results will address the theoretical strengths and shortcomings of the model(s).

\section{Overview}

This quantitative analysis will empirically test the first two hypotheses, with the purpose of generalizability. This will be accomplished through an empirical test using a random-effects logit model and a GLS random-effects model. The use of large-N datasets, including MID, ICB and VSM 2013, is to generalize this theory across a variety of dyads since 1816. As previously introduced in the methodology section, The VSM, ICB and MID variables have been merged and formatted in non-directed dyad year format. ${ }^{1}$ The first analysis will test the first hypothesis with hostility (from MID IV) as the dependent variable. The second analysis will test the second hypothesis with hostility level (from MID IV) as the dependent variable. The independent variables for both models will include the six cultural dimensions, as coded by the VSM 2013. Based on the theoretical expectations, greater differences in moral and belief structures are a causal mechanism for dyadic hostility and crisis escalation.

\footnotetext{
${ }^{1}$ The total number of cases enumerates 861,598
} 
This is based on the logic that every state operates from their own moral and belief structures. When facing an ontological threat from an opposing set of beliefs, the compatibility of the dyads' belief structures will be a key factor in dyadic hostility and the escalation of conflict. This is for a myriad of reasons: first, dyads of states with greater differences have a reduced bargaining range and a more difficult time compromising and communicating on issues. Secondly, dyads of states with greater differences feel threatened by the existence of a competing belief structure. As a result, this can lead to increased likelihood of hostilities (H1) and crisis escalation (H2). In order to test these hypotheses, a rigorous quantitative analysis will be conducted.

This chapter will test the following hypotheses:

H1: Dyads with greater differences in civil religion are more likely to experience hostility than dyads with similar civil religions.

H2: Dyads with greater differences in civil religion that are experiencing a crisis are more likely to escalate the crisis rather than negotiate.

In order to test these hypotheses, two different statistical analyses will be conducted. The first model has been constructed to measure the effect of civil religion on dyadic hostility. The theoretical expectation is that differences in civil religion (operationalized through the six cultural differences) facilitates latent tensions between dyads. Therefore, hostilities resulting in militarized action are more likely among dyads with greater differences than dyads that are similar. The second model has been constructed to measure the effect of civil religion on crisis escalation. The purpose of isolating dyads exhibiting crisis is to determine the effect of civil religion (operationalized through the six cultural differences) on dyads already experiencing a crisis. The theoretical expectations are dyads with greater differences in civil religion are at increased risk of 
crisis escalation. This is the result of a limited bargaining range, miscommunication and misperception, which creates a morally mutually exclusive environment. The concept of civil religion will be disaggregated and tested using the VSM 2013 dataset. This includes the following six cultural dimensions: power distance, individualism, masculinity, uncertainty avoidance, longterm orientation and indulgence-restraint. These variables can be conceptualized in a variety of ways, however it would seem that they are thematic. The following sections will group these cultural dimensions into three broad categories, which will help to identify trends in the results.

\section{State and Society}

The first category, which includes power distance, individualism and indulgence-restraint represents the normative correct ordering between the individual and the state. These three cultural dimensions are all related to the preferred ordering of people within society. In other words, these cultural dimensions provide insight into the normative thinking of a people with respect to equality, identity and freedom. Since different peoples living in different states conceptualize these foundational beliefs differently, they are integral to the study of civil religion.

Power distance (PDO) is focused on the desired equality of decision-making within a state. States with lower PDO scores (shaded in red) value consultative decision-making, in which people want to be equally included in the governing process. This can be contrasted with states with higher PDO scores (shaded in blue), which place emphasis on strong top-down leadership. The PDO scores of each state (included in the survey) are depicted in the following map and histogram: 
Figure 4-1: Power Distance Index
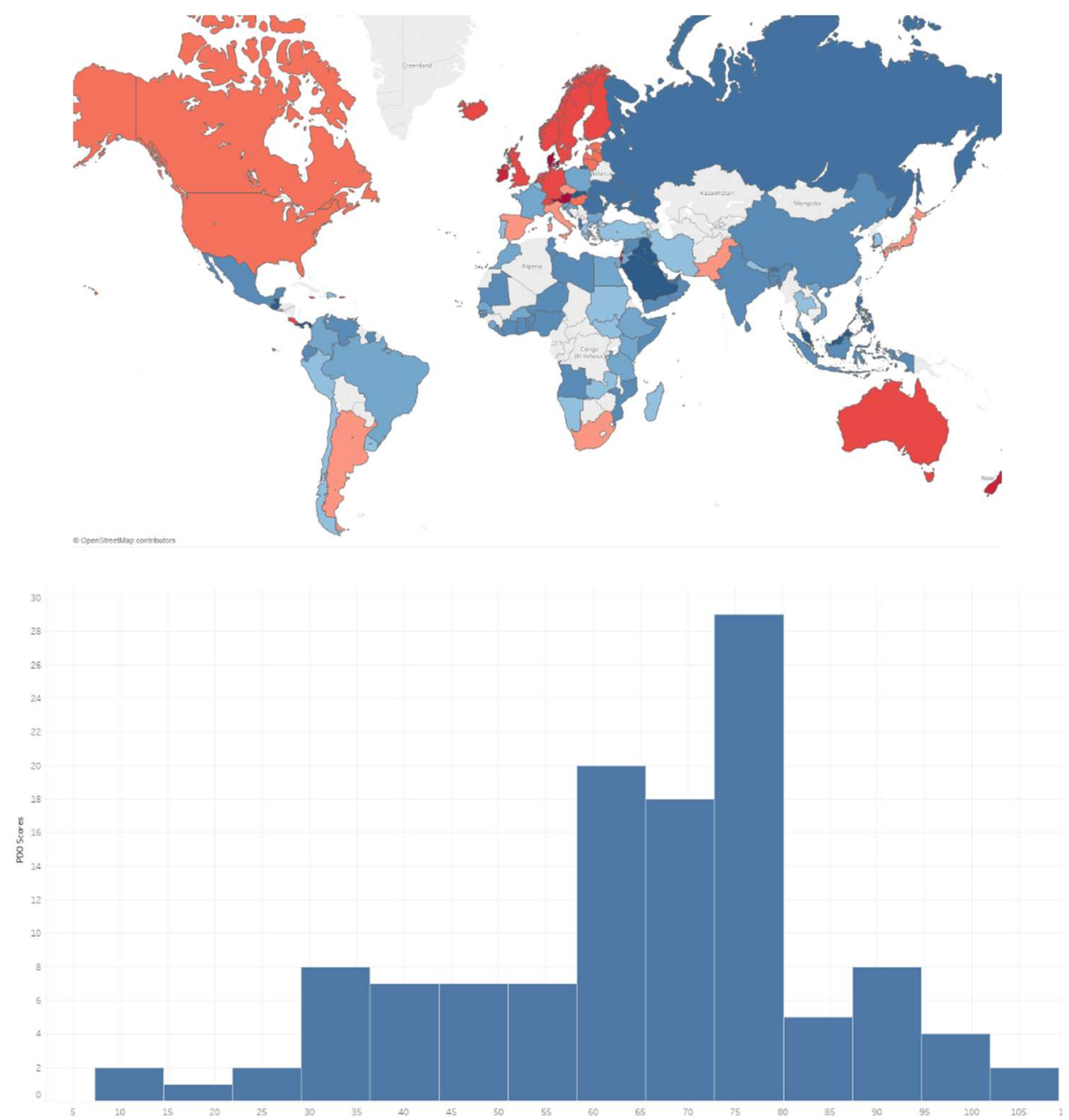

Individualism (IDV) is focused on the relationship between individuals and groups within a state. States with lower values of IDV (shaded in red) exhibit a group identity, in which individuals identify with a larger population. On the other hand, states with higher values of IDV (shaded in blue) are more individualistic, with people identifying as distinct members. The values of each state (included in the data) are illustrated in the following map and histogram: 
Figure 4-2: Individualism Index
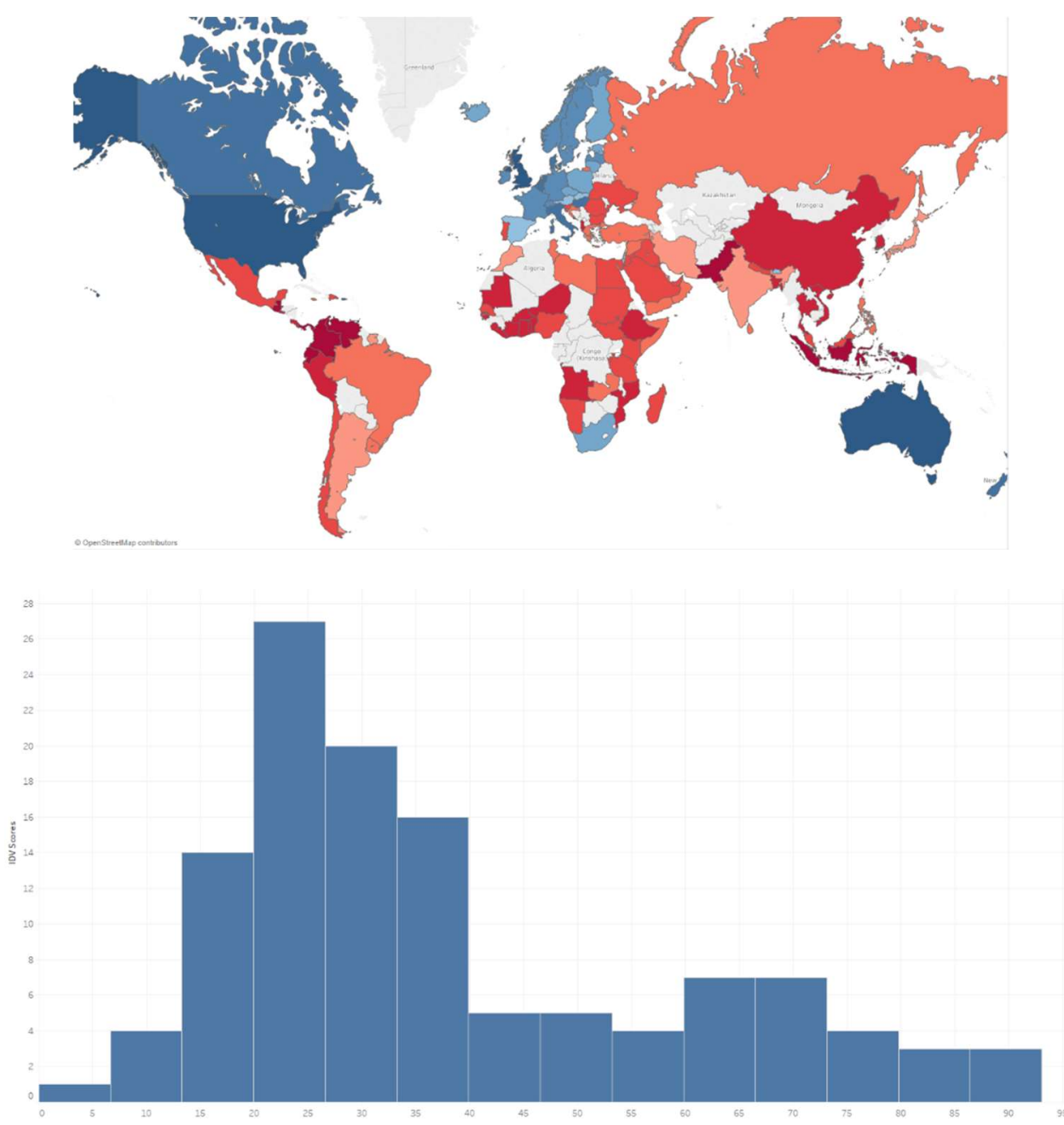

Indulgence-restraint (IVR) examines the personal freedom of individuals within a state. States with lower values of IVR (shaded in red) exhibit values of strong societal norms that govern individual behavior. On the other hand, states with higher values of IVR (shaded in blue) exhibit the values of individual choice and responsibility. The values of each state are illustrated in the following map and histogram: 
Figure 4-3: Indulgence-Restraint Index
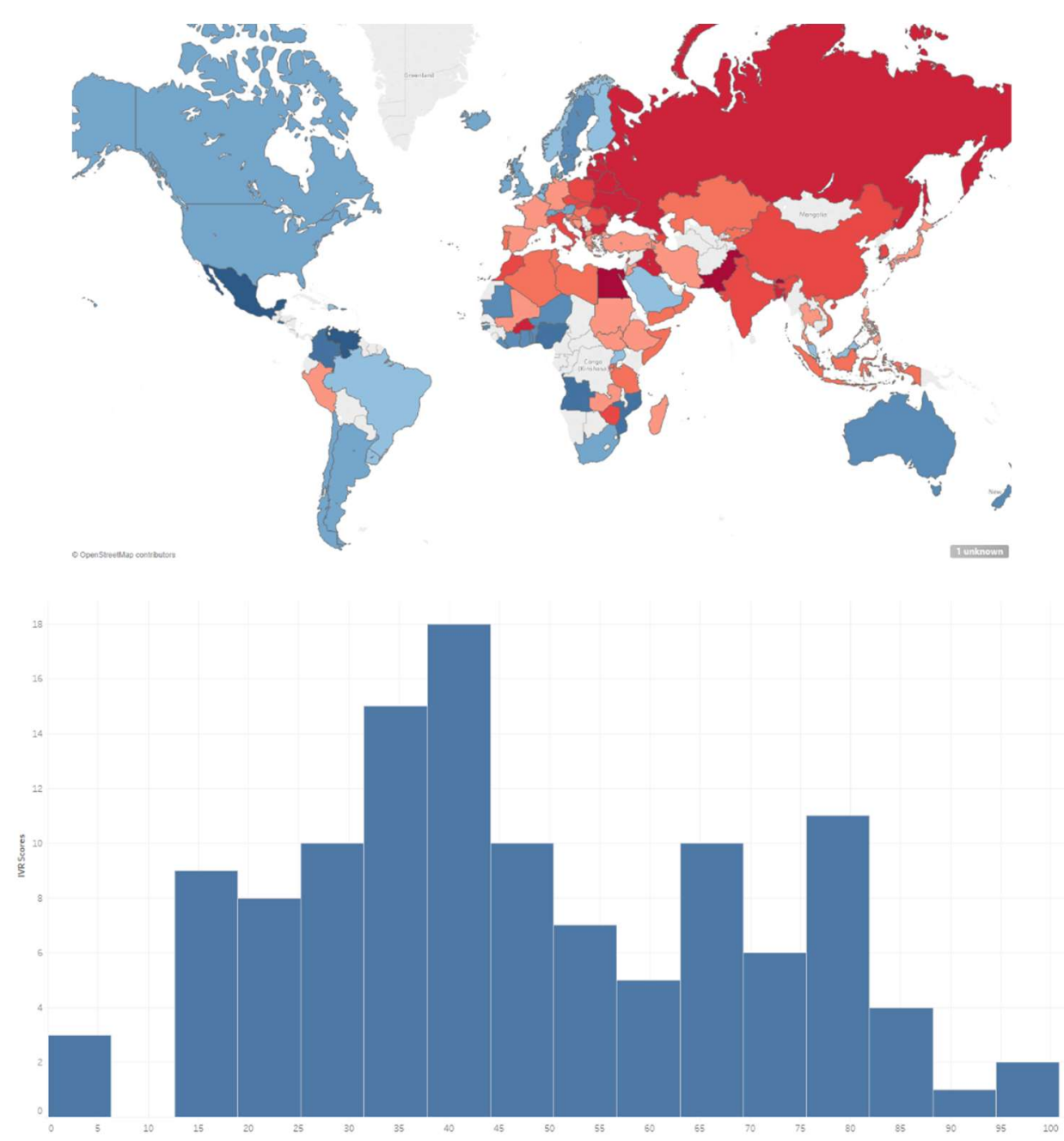

The values of power distance, individualism and indulgence-restraint provide the researcher with a holistic approach to better understanding the relationship between society and individuals. As normative measures, these variables demonstrate the proper ordering with respect to equal governing, individual identity and personal freedom.

\section{Uncertainty and the future}

The next category, which includes uncertainty avoidance and long-term orientation, emphasize the relationship between society and external sources of stress, including uncertainty and the future. These two particular dimensions are less foundational than the first three, as they attempt to isolate feelings of uncertainty and the future. These variables capture a much different 
phenomenon than the first category by examining sources of stress within society. As such, they are worthy of future consideration and study, albeit independently less useful to understanding the relationship between civil religion and culture.

Uncertainty avoidance (UAI) measures the amount of societal anxiety towards the unknown. States with lower values (shaded in red) are more amenable to unknown situations and ambiguity. On the other hand, states with higher values (shaded in blue) are much more sensitive to unknown and ambiguous situations, perceiving these situations as stressful. The values for each state are displayed in the following map and histogram:

\section{Figure 4-4: Uncertainty Avoidance Index}
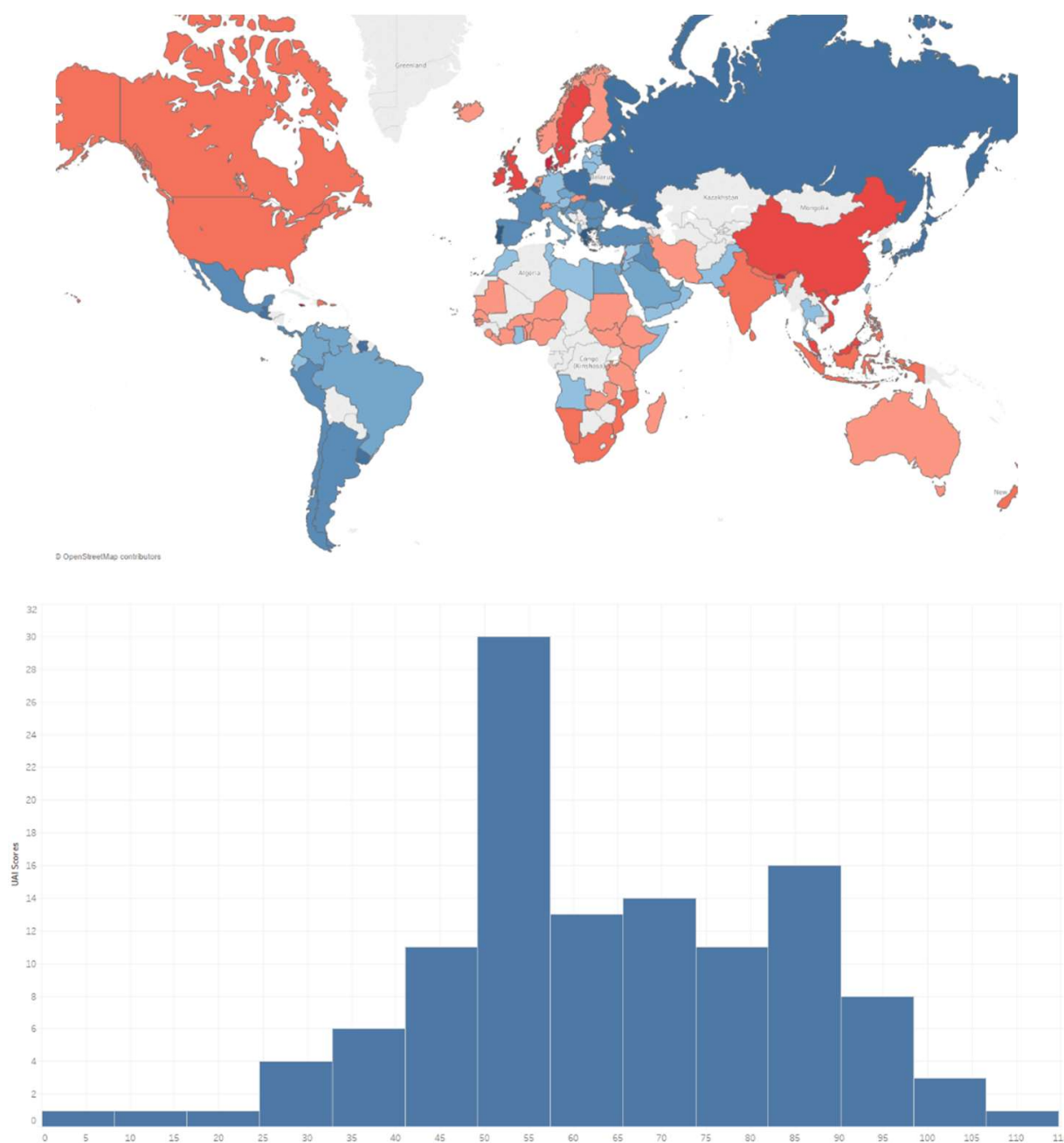
Long-term orientation (LTO) examines the relationship between society and the future. States with low values (shaded in red) accentuate the importance of historical virtues on the current way of life. On the other hand, states with high values (shaded in blue) are concerned with fostering virtues for future rewards. The following map and histogram illustrates the long-term orientation of states:

Figure 4-5: Long-Term Orientation Index
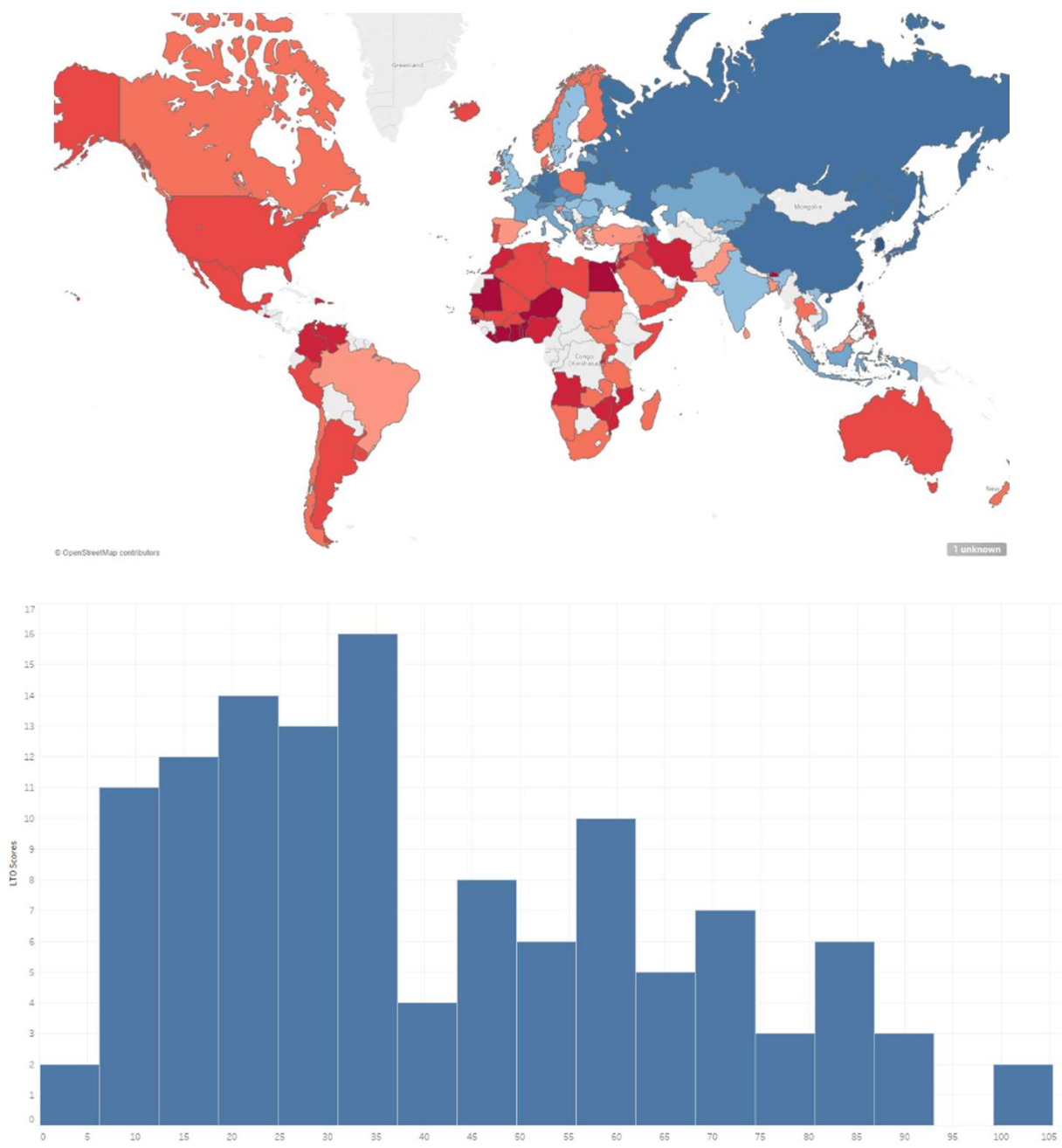

\section{Masculinity}

The final category includes one cultural variable: masculinity. This variable is a unique measurement of acceptable gender roles within a given state. Gender studies within international relations has been gaining traction in recent decades, including the effect of development and 
globalization on gender roles. This variable attempts to capture the traditional gendered roles within states. States with lower values (shaded in red) are those that exhibit more fluidity in gender roles - or those that do not assign particular roles to a particular gender. States with higher values (shaded in blue) believe that gender roles should be determined by sex, with each gender assigned a particular masculine or feminine role. The following map and histogram illustrates the attitudes towards gender roles:

Figure 4-6: Masculinity Index
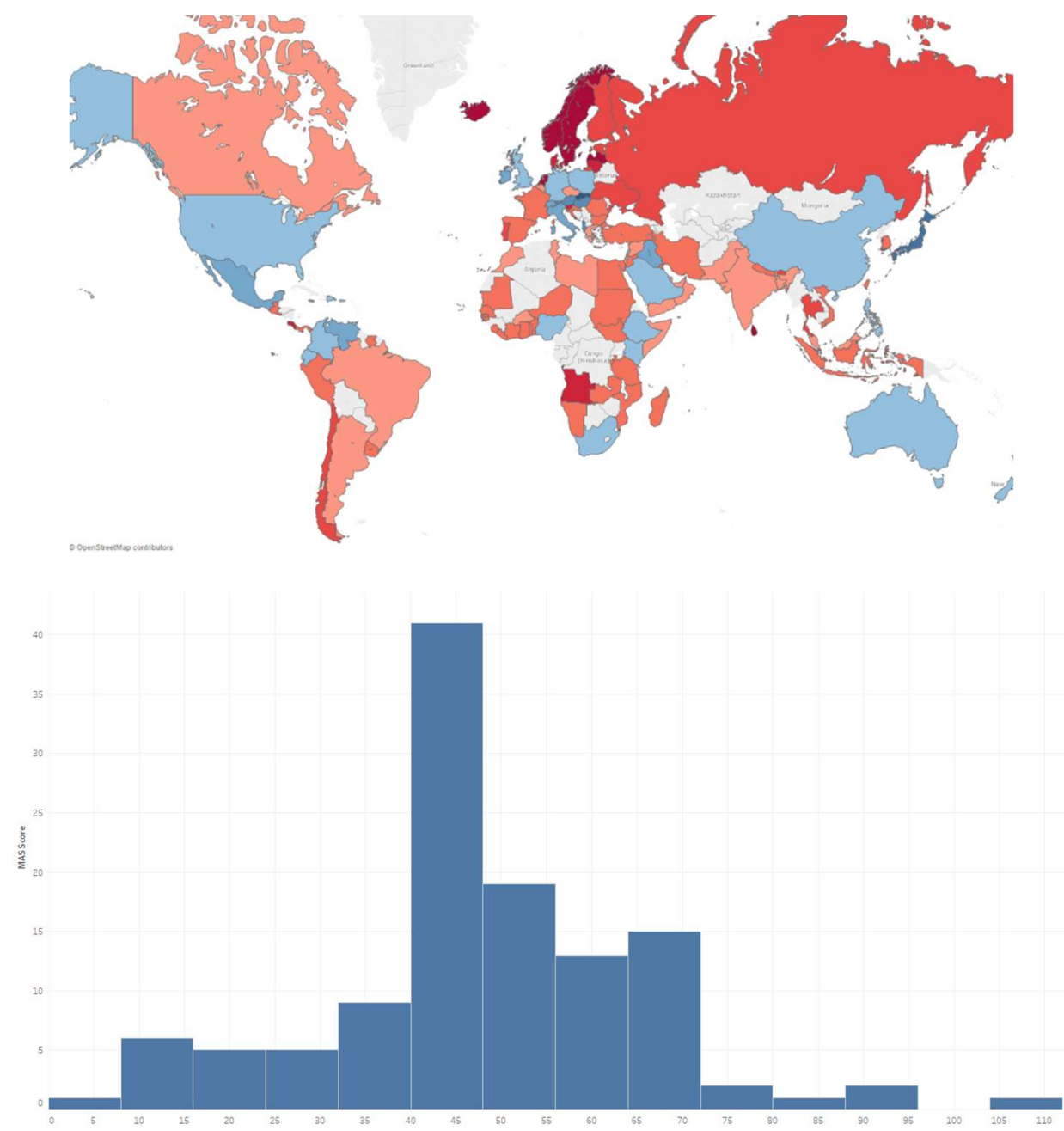

The categorization of the six cultural dimensions to three broad categories will allow the researcher to speak to the effectiveness of each category during the analysis. The expectation is that the state and society variables should outperform the other categories, since it is more in-line 
with the theoretical expectations surrounding foundational belief structures. The subsequent sections will empirically test these hypotheses.

\section{Statistical Analysis}

The aforementioned hypotheses will be tested in this section. The first hypothesis will be tested using a random-effects logit model, with the dependent variable - hostility - coded as 0 (no militarized action) and 1 (militarized action). The second hypothesis will be tested using a GLS random-effects model, with the dependent variable - hostility level - ranging from 1 (no militarized action) to 5 (war). Both models contain the same independent variables - the six dimensions of culture - and control variables. The results of the analysis are contained in Table 4-1:

\section{Table 4-1: Statistical Analysis \\ Hypothesis 1: Hostility (random-effects logit)}

Power Distance Difference

Individualism Difference

Masculinity Difference

Uncertainty Avoidance Difference

Long-Term Orientation Difference

Indulgence Difference

Major Power Dummy
$-.0028453$

$(-0.70)$

$.010598^{* * * *}$

(3.15)

.003854

.0021034

$(0.61)$

$-.0020012$

$(-0.67)$

$-.0087857^{* * *}$

$(-2.58)$

(17.95)
(1.03)

$1.742568^{* * *}$
Hypothesis 2: Hostility level during crisis (GLS randomeffects) 


\section{Table 4-1: Statistical Analysis (cont.)}

\begin{tabular}{|c|c|c|}
\hline Capability Ratio & $\begin{array}{c}.1399092 \\
(1.09)\end{array}$ & $\begin{array}{c}.0431988^{* * *} \\
(3.57)\end{array}$ \\
\hline Mixed Regime Dummy & $\begin{array}{c}.421266^{* * *} \\
(8.55)\end{array}$ & $\begin{array}{c}.0669048^{* * *} \\
(10.80)\end{array}$ \\
\hline Contiguity & $\begin{array}{c}-.5522605^{* * *} \\
(-16.08)\end{array}$ & $\begin{array}{c}-.0883358^{* * *} \\
(-25.01)\end{array}$ \\
\hline$N$ & 248650 & 64897 \\
\hline
\end{tabular}

Results

Hypothesis testing has yielded fruitful results, finding mixed-support for the theory. The results of the first hypothesis, evaluating the effect of cultural difference on dyadic hostility, has found limited support with this model. Of the six dimensions of culture, only individualism $(t=3.15)$ was significant. This would indicate that of all dyadic cultural differences, group or autonomous identification of actors within society captured the fundamental source of contention. The other dimensions of culture were a mixed-bag of significance, with indulgence, long-term orientation and power distance producing results in the opposite direction. In addition to the independent variables, several control variables - major power status, mixed regime type and contiguity were significant.

The results of the second hypothesis, evaluating the effect of cultural differences on crisis escalation, has also found limited support with this model. Of the six dimensions of culture, only individualism $(\mathrm{t}=1.82)$ and power distance $(\mathrm{t}=1.72)$ were significant. This would indicate that of all dyadic cultural differences, group/autonomous identification and acceptable power distance within society captured the fundamental source of crisis escalation. Masculinity and long-term orientation were both significant, but in the opposite direction of the theoretical expectations. 
Uncertainty avoidance and indulgence produced results in the expected direction, albeit not significant. In addition to the independent variables, all control variables - major power status, capability ratio, mixed regime type and contiguity were significant.

Analysis

The results of hypothesis testing can be used to construct a narrative that emphasizes the importance of certain variables (or categories of variables). Of the three categories of civil religion - state and society, uncertainty and the future and masculinity - the variables in the state and society category were more powerful indicators of state behavior. In particular, individualism and power distance were the only statistically significant variables from either model. While these results provide mixed results for the theoretical expectations, the significant results are fruitful for the construction of a narrative.

The results of the first hypothesis demonstrate limited support for the theory, with individualism serving as the only significant variable. The variable of individualism represents the way in which individuals identify as autonomous actors or with a broader group. Individualism is one of the most essential components of the ontological worldview of a society. The variable of individualism captures the societal connections between people. The researchers describe their measurement in the following way: "Individualism pertains to societies in which the ties between individuals are loose: everyone is expected to look after him- or herself and his or her immediate family. Collectivism as its opposite pertains to societies in which people from birth onward are integrated into strong, cohesive in-groups, which throughout people's lifetime continue to protect them in exchange for unquestioning loyalty".2

\footnotetext{
${ }^{2}$ Hofstede, Hofstede, and Minkov. Cultures and organizations, 92.
} 
The significance of individualism in the first model illustrates the cleavages that exist between individualistic and collective societies. Based on the theoretical expectations, these cleavages may act may augment other dyadic differences, such as regime type or leadership ideology. It is also possible that these cleavages operate in a manner similar to the other dyadic differences, facilitating mistrust and ineffective communication between dyads. As a result, these foundational belief differences increase the likelihood of hostility and military action.

The results of the second hypothesis demonstrate limited support for the theory, with individualism and power distance serving as the only significant variables. This is a more refined analysis of hypothesis testing, as it is focused on the escalation of a crisis. This can be differentiated from the previous analysis, which looked at all dyads over time. By isolating only crisis dyads (coded by ICB), this analysis serves the purpose of understanding crisis escalation vis a vis cultural differences. The importance of individualism was previously discussed with respect to the first hypothesis. Power distance is another essential component of the relationship between state and society. All societies have some degree of power inequality between members and/or groups within society. Power distance is the measurement of acceptable inequality within a given society. This is a normative measure of whether or not people believe that power should be distributed equally.

The implications of this measure is strongly related to the dependence between authority and subordinates. In states with small power distance, there is limited dependence on authority figures and a preference for consultation. ${ }^{3}$ This variable is a key indicator of normative equality in the deliberative process within a state. In other words, should citizens have equal access in the decision-making process or should it be left up to political elites. The significance of power

\footnotetext{
${ }^{3}$ Ibid., 61.
} 
distance in the second model indicates that cleavages exist between states with high and low power inequality. With respect to conflict escalation, power distance and individualism are indispensable for understanding legitimacy in domestic politics and foreign policy. These two normative measurements assert the level of autonomy/collectivism and acceptable inequality within society. In short, dyads that are currently experiencing a crisis are more likely to escalate hostilities based on these fundamental differences. Likewise, similarities between states facilitates an environment to resolve crises without the use of increased hostilities.

A potential concern of the significance of the results (individualism and power distance) is correlation with Polity values. It is logical to assume that some cultural characteristics of states, especially power distance and individualism, may be related to the regime type. States with lower individualism scores (exhibiting a collective spirit), tend to be less democratic states. On the other hand, states with higher individualism scores (identifying as autonomous individuals) are more democratic in nature. The same can be said about power distance, states with lower power distance (consultative) being more democratic and states with higher power distance (subjective) being more autocratic. In order to discover the possibility of correlation between these variables, correlation tests have been performed on individualism and power distance scores for each state to their Polity IV scores. ${ }^{4}$ Figure 4-7 illustrates the scatterplots of the two variables in question with Polity scores. The results of the scatterplot and the correlation tests are promising for the significance of individualism and power distance. The results indicate that significant correlation does not exist, which means that the cultural variables of note are distinct from other alternative approaches.

\footnotetext{
${ }^{4}$ Correlation between individualism and polity score $=0.46$ and 0.49 ; Correlation between power distance and polity score $=-0.59$ and -0.50 .
} 


\section{Figure 4-7: Scatterplots of Variable Correlation to Polity Scores}
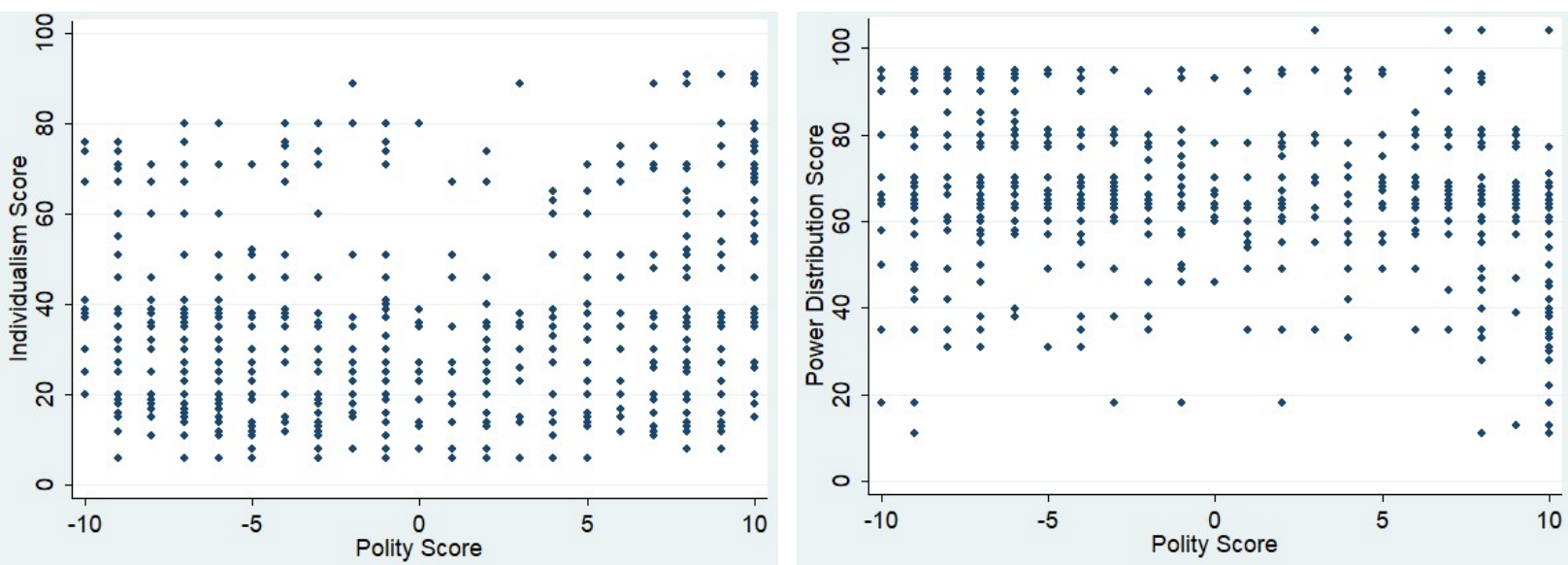

\section{Conclusion}

The quantitative analysis provided mixed support for the hypotheses. For both hypotheses, individualism is statistically significant and power distance is significant only for the second hypothesis. Given the theoretical importance of the cultural dimensions, it is disappointing that more independent variables did not demonstrate significance. However, individualism and power distance are two of the most essential belief structures for understanding cultural differences between states. Individualism and power distance are a proxy measurement for the importance of certain fundamental beliefs of governance. The importance of the individual is a cultural construct that can differ from society to society. In cases that emphasize the former, individuals are valued as ends in themselves. This can be contrasted to a utilitarian approach, which treats individuals as a means to an end. This includes the maximization of utility ${ }^{5}$ for the entire group, as opposed to any individual. The implication for individualistic and collectivist societies are reflected in the variety of norms and laws that distinguish each state. This can be manifest in a variety of state issues, including but not limited to: private property, tax policy, social mobility, economic

\footnotetext{
${ }^{5}$ This has been conceptualized in many different ways by scholars of utilitarianism. Most commonly used is the definitions of Bentham or Mill.
} 
freedom, environmental protection and personal freedom. The spectrum of power distance can vary from state to state. On the one hand, people in some states believe that decisions should be made through a consultative process. On the other hand, peoples in some states believe that decisions should be made by governing elites. The implication for high and low power distance are reflected in the variety of norms and laws that distinguish each state. This can manifest in a variety of ways within a state, including but not limited to: electoral fairness, economic and political equality and the rule of law.

The theoretical expectation was that states with common foundational beliefs are able to communicate more effectively, mediate disputes through bi-lateral negotiation and arbitration and in certain cases of escalation - limit their scope and goals of the conflict. While not all cultural dimensions seem to matter equally, this analysis has identified two that provide explanatory power to this theory. This analysis provides another layer of analysis in which dyadic hostility and crisis management is explained through the beliefs of individualism and power distance. This approach unlocks domestic norms and traditions as a possible explanation for the outbreak of hostility and escalation of crisis. Individualism and power distance represent fundamental beliefs that transcend regime type and leadership ideology. This analysis illustrates the importance of ontological differences between states in hostility and crisis escalation. The subsequent three chapters will evaluate the remaining hypotheses through a series of case studies on crisis management. 


\section{Chapter 5: Argentine Crisis Management (1978-1982)}

Argentina was governed from 1976 to 1983 under the military dictatorship known as the National Reorganization Process (Proceso de Reorganizacion Nacional), which was often referred to as "the Process". The military seized power during the 1976 coup, in the wake of the void left by the death of President Juan Domingo Peron. During this time, four different sets of leaders occupied the highest positions of the junta. One of the points of emphasis of all junta leaders was reclaiming rightful entitlements of Argentina, which included the Beagle Channel and Falkland/Malvinas Islands. ${ }^{1}$ The implications of regaining these territories was symbolic (legitimization of the regime) as well as material (natural resource extraction). The primary difference between these territorial disputes was the decision-making of the junta and subsequent outcome.

The intriguing puzzle of these crises was the decision-making of the junta to resolve the Beagle Channel crisis via Papal mediation and the Falklands/Malvinas crisis through military force. The decision-making of the junta is counterintuitive to realist logic, which favored Argentina in a military conflict over the Beagle Channel. Argentina had superior military capabilities and regional alliances that favored them in a conflict against Chile. Successful action reclaiming the Beagle channel under Videla would have provided much needed economic and prestige benefits. Surprisingly, the Videla junta (1976-1981) actively pursued neutral mediation, which not only had unpredictable results but would not provide immediate remedy for the domestic problems the junta was facing. When facing a similar situation over the Falkland/Malvinas Islands, the junta was desperate for immediate results and opted for military intervention. The

\footnotetext{
${ }^{1}$ Joseph S. Tulchin, "Authoritarian Regimes and Foreign Policy: The Case of Argentina," in Latin American Nations in World Politics, ed. Heraldo Muñoz and Joseph S. Tulchin (Boulder: Westview Press, 1984 ), 182.
} 
Argentine economy continued to crumble during the Galtieri junta (1981-1982), and the regime was hemorrhaging global and regional legitimacy. When it was clear that the international community would not intervene on behalf of Argentina, and bi-lateral negotiations failed to achieve positive results, they resorted to military action. This decision was made even after it was clear that they were at a military disadvantage. Despite the warning signs of a British response and resolve to support the islanders, Argentina leadership only pursued military resolution of the conflict.

The main purpose of these case studies is to understand the behavior of the Argentina junta in these two crises. Given the similar nature of the crises, including reclaiming lost territory, mineral rights and legitimacy of the regime, it begs the question why Argentina would choose to fight a war with lower probability of success. I contend that while successful action was important to the regime, the ontological threat of Great Britain was the catalyst for military action. On the other hand, the multiple cultural and historical linkages between Argentina and Chile was behind the decision to seek mediation.

Table 5-1 provides an overview of the important variables related to these cases. It includes three sets of variables, the predominant religious values of the state, the virtues of civil religion and institutions at the time of crises. The culture and language of Argentina and Chile has been described as a unique blend of European and Amerindian - or indigenous people of the Americas. ${ }^{2}$ Even centuries after the resulting Spanish conquests of South America, both Chile and Argentina remained heavily influenced by European sources. The language and culture of both states would forever alter to reflect Spanish occupation. This can be compared to Great Britain, who is a staunch

\footnotetext{
${ }^{2}$ Gabriela Nouzeilles and Graciela Montaldo, eds, The Argentina reader: History, culture, politics (Duke University Press, 2002); Elizabeth Quay Hutchison, Thomas Miller Klubock, Nara B. Milanich, and Peter Winn, "The Chile Reader: History, Culture." Politics (2014).
} 
source of Western culture and the English language. There are other specific differences between the cultures of Argentina/Chile and Great Britain.

The Catholic Church was established as an organizing principle during Spanish occupation of Chile and Argentina. ${ }^{3}$ Even after gaining independence and the subsequent introduction of separations of church and state in the early twentieth century, the vast majority of the population were devout Catholics. ${ }^{4}$ The Catholic belief structure was rigidly hierarchical, with the Pope as the undisputed leader. The Church hierarchy also has a monopoly on the orthodox interpretation of the Bible, with the Pope as the infallible representative of God. ${ }^{5}$ The belief structures of Roman Catholicism are strongly correlated to the development of their respective states' civil religion. Argentina and Chile share a historical legacy of statist corporatism, in which elites have served as populist autocrats. For much of their history since independence, Argentine and Chilean leaders have used their position to nationalize the economy while suppressing opposition parties. ${ }^{6}$ The Chilean military junta under Pinochet (1973-1990) and the Argentine National Reorganization Process (1976-1983) were the most extreme manifestations of these structured hierarchical beliefs. ${ }^{7}$ During these juntas, opposition parties were eliminated through a variety of methods, including the Dirty War and Operation Condor.

The Church of England also served as an organizing principle within Great Britain, which separated from the Roman Catholic Church in 1534. The Church of England still remains the official state religion of England, serving as a symbolic and pragmatic source of morality. ${ }^{8}$ The

\footnotetext{
${ }^{3}$ Simon Collier and William F. Sater. A History of Chile, 1808-1994 (Cambridge University Press, 1996), 22-25.

${ }^{4}$ Collier and Sater. A History of Chile, 1808-1994, 305-306; Austen Ivereigh, Catholicism and politics in Argentina, 1810-1960 (Springer, 2016), 4-7.

${ }^{5}$ Matthew 16:18; Luke 22:31-32; John 21:15-17.

${ }^{6}$ Malamud-Goti, Jaime E, Game without end: State terror and the politics of justice (University of Oklahoma Press, 1996), 183.

${ }^{7}$ Susan Tiano, "Authoritarianism and Political Culture in Argentina and Chile in the Mid-1960's." Latin American Research Review 21, no. 1 (1986): 73-98.

${ }^{8}$ Moorman, John. History of the Church in England. Church Publishing, Inc., 1980.
} 
structure of Anglicanism can be contrasted with the Roman Catholic hierarchy, as it has no central authority. ${ }^{9}$ The Archbishop of Canterbury serves as spiritual leader, but interpretation of the Bible is left to individual members. These beliefs are represented in the British civil religion, which has been identified as British traditionalism. This reflects the beliefs of individual autonomy within society, with a largely symbolic figurehead operating at the top of a defined structure. ${ }^{10}$ From the onset, the British Monarch was granted leadership powers as the Supreme Governor of the Church of England. These powers became largely ceremonial after the adoption of the Thirty-Nine Articles in 1562. However, the Church of England remained a powerful interest group in British politics, with 26 bishops guaranteed seats in the House of Lords.

\section{Table 5-1: Overview of Variables}

\section{Great Britain}

Culture

Language

\section{Religious Values Protestant Christianity}

No central religious hierarchy, which gives wide latitude for each church to decide policy. The Archbishop of Canterbury is a spiritual leader, but has no legal authority over individual parishes.

Protestants believe that each individual member of the church has the ability to interpret the Bible.

The sacrament of Eucharist is believed to be a symbolic act.

Women and married persons are able to become ordained priests and bishops.
Argentina Chile

Euro-Amerindian Spanish

\section{Roman Catholic \\ Established traditional hierarchy, which includes priests, bishops, cardinals and the Pope. The Pope is not only the undisputed leader of the church, but also the Vicar of Christ and infallible on matters of doctrine. \\ The Roman Catholic Church alone has the authority to interpret the Bible. \\ Belief in transubstantiation, which the bread and wine of the sacrament of Eucharist is transformed into the actual body and blood of Jesus Christ.}

The priesthood is reserved for unmarried men.

\footnotetext{
${ }^{9}$ Susan Doran and Christopher Durston, Princes, Pastors and People: The Church and Religion in England, 15001689 (Routledge, 2002), 62-68.

${ }^{10}$ Krishan Kumar, The making of English national identity (Cambridge University Press, 2003), 18-25.
} 


\section{Table 5-1: Overview of Variables (cont.)}

Civil Religion

Institutions

\section{British Traditionalism}

Independent autonomous citizenry that operate within a defined class structure.

Strict adherence to traditional norms, including respect for the influence of the head of state, even if he/she is merely a figurehead.

Gradual development of political systems over hundreds of years, in contrast to revolution or other rapid change.

\section{Constitutional Monarch \\ Weak sovereign with power limited by constitutional constraints. Mix of democratically elected and appointed legislature that has governing authority. \\ Integrated Church and State, with the monarch serving as the Supreme Governor of the Church of England and 26 bishops guaranteed seats in the House of Lords.}

\author{
Statist Corporatism \\ Individualism is superseded by an allegiance to \\ elites, who are granted authority beyond the rule \\ of law. \\ Colonial legacy of exploitation by the ruling \\ class creates distrust for the state while also \\ creating dependency on its institutions. \\ Rapid succession of differing political systems \\ since achieving independence.

\section{Dictatorship} \\ Strong leadership under military government, \\ consisting of generals representing the Army, \\ Navy and Air Force (and Police in Chile). \\ A history of opposition repression since gaining \\ independence, through paramilitary \\ organizations and secret police. This most \\ recently evident through the Dirty War and \\ Operation Condor.
}

The case studies will be organized following the causal logic of the theory. First, the moral foundation of civil religion will be discussed, including the historical and normative context of the crisis. Since these conflicts are couched in a historical dimension of previous foreign relations, it is important to provide background of contention over the Beagle Channel and Falkland Islands. Secondly, the tipping point of relations occurred in the wake of the Argentine junta assuming power in 1976. In modern times, the historical tensions flared up between Argentina and Chile/Great Britain because of domestic and international policy. The third section is dedicated to the perception of the domestic changes, namely the ontological threat other states posed this new regime. Both of these crises will be arranged in the same manner, followed by a summary of the findings. 


\section{The Beagle Channel Crisis (1978)}

The Beagle Channel Crisis was a territorial and regional hegemony dispute that occurred between Chile and Argentina in 1978. Both sides mobilized and prepared for war, but a peaceful settlement was reached through Papal mediation. While tensions between these states have persisted for several decades, they have never escalated to military conflict. The purpose of this case study is to analyze the Beagle Channel Crisis, which was the most escalated conflict between Argentina and Chile. I contend that the reason for restraint during this crisis was the result of shared cultural and historical beliefs which facilitated Papal mediation.

Chile and Argentina have common geographic, historical and cultural aspects, which underscored their previous relations. Since gaining their respective independence from Spain in the early 1800 s, a rivalry has developed between these states for regional hegemony in South America. Chile and Argentina are contiguous states with the third-longest international border, over 3,300 miles long. Several incidents have occurred regarding territorial rights, which include the Snipe Incident (1958), Laguna del Desierto Incident (1965) and the Beagle Channel Crisis (1978). ${ }^{11}$ Previous incidents were de-escalated quickly and without the use of mediation, the Beagle Channel Crisis was the notable exception.

The Beagle Channel Crisis was a border dispute between Argentina and Chile, which included the possession of Picton, Lennox and Nueva Islands (which will be referred to as PLN henceforth). This border demarcation was challenged by both states for nearly a hundred years, culminating in international arbitration in 1971. In the aftermath of this arbitration decision in 1977, Argentina was dissatisfied with the outcome and continued to press for bilateral negotiations. Unlike the previous territorial disputes, the ascension of the military junta altered the decision-

\footnotetext{
${ }^{11}$ Jacob Bercovitch and Judith Fretter, Regional guide to international conflict and management from 1945 to 2003 (CQ Press, 2004), 126-127.
} 
making calculus of Argentine leadership. The hardline approach of President Videla on recapturing rightful Argentine possessions, coupled with domestic instability and a regional quest legitimacy, further escalated the Beagle Channel Crisis. Chile, who was awarded a favorable decision through arbitration, had no intention of renegotiation. This nearly resulted in a war between these states in 1978, only to be thwarted by the efforts of the Holy See in December 1978. Given the circumstances, it appeared highly unlikely that these territorial issues could be peacefully resolved.

When this crisis is examined through the lens of realism, Argentina's behavior cannot be explained. With military superiority and alliances secured with Peru, along with the belligerent disposition of the junta, their behavior is puzzling. I contend that the only reason Argentina sought mediation was because they did not perceive Chile as an ontological threat. Even while flexing their military muscle, Argentina continued to try to negotiate both bi-laterally and through an international mediator. The Papacy was the only mediator that was held in high esteem by both parties, because of their similar cultural and historical beliefs. This case study will answer this question, through the guise of shared beliefs and ontological threat. I will demonstrate that war did not occur, even though all of the ingredients were present, because of the shared linkage of Catholicism.

\section{Civil Religion}

The civil religion, or the secular national beliefs, dogmas and rituals, of Argentina and Chile are strikingly similar. The historical experience of both states was rooted in Spanish colonialism, which imported Roman Catholic beliefs. This religious doctrine has permeated political and social life in Argentina and Chile. When relations between these states soured over

the Beagle Channel, both states were steadfast in their resolve against a compromise. Because of 
their mutual affinity towards Roman Catholicism, the only mediator that was mutually-respected by both states was the papacy. These shared beliefs were the only successful catalyst for negotiation during the Beagle Channel dispute. The following section will discuss in further detail the historical nature of the conflict and normative similarities, which were decisive in resolving the dispute prior to escalation.

\section{Historical Context}

The Beagle Channel is located at the extreme southern tip of South America, south of the Tierra del Fuego. This area is relatively isolated and underdeveloped region, with a subpolar oceanic climate, with average temperatures below 50 degrees year-round and snowfall is not uncommon in summer. Due to the relative geographic isolation of the Channel, it was not of much importance to either Chile or Argentina, yet served as a boundary between the states, as illustrated by the map below:

Figure 5-1: Boundary between Argentina and Chile ${ }^{12}$

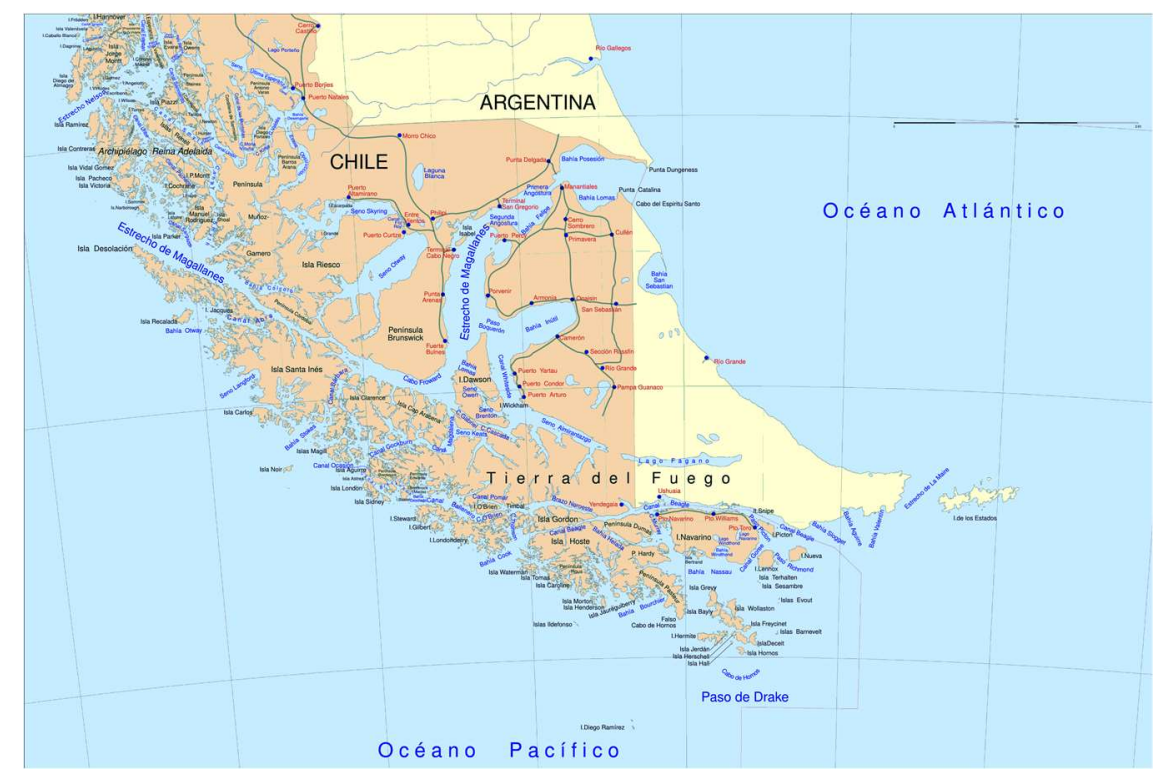

\footnotetext{
${ }^{12}$ Distributed under a CC BY-SA 3.0 Unported License.
} 
The Channel was first discovered in 1826, during an expedition of the HMS Adventure and HMS Beagle, tasked with surveying the Patagonia region. While venturing around Cape Horn along the western coast of South America, inclement weather forced Lt. Robert Fitzroy to change course. A longboat was dispatched by M. Murray with a small crew to navigate the waters of a previously unexplored two-mile long channel. This channel was further investigated during the 1833 expedition of the HMS Beagle, which included Darwin. It was during this expedition that the Channel was named after the ship, henceforth it was known as the Beagle Channel. ${ }^{13}$ The Beagle Channel became the center of controversy between Argentina and Chile when determining the southern borders of these states. Both states made territorial claims on the Channel, culminating in the Boundary Treaty of 1881.

The Boundary Treaty of 1881 was signed on July 23, 1881 by Bernardo de Iringoyen (Argentina) and Francisco de Borja (Chile). The purpose of this treaty was to clearly define all borders between Argentina and Chile. ${ }^{14}$ The agreement had partitioned Patagonia and the island of Tierra del Fuego. The purpose was to provide equal access to the Atlantic and Pacific for each state. ${ }^{15}$ With respect to the Beagle Channel, Article III is of important note because all future proceedings rely upon this Article as the legal basis of sovereignty, as noted below:

In Tierra del Fuego a line shall be drawn, which starting from the point called Cape Espíritu Santo, in parallel $52^{\circ} 40^{\prime}$, shall be prolonged to the south along the meridian $68^{\circ} 34^{\prime}$ 'west of Greenwich until it touches Beagle Channel. Tierra del Fuego, divided in this manner, shall be Chilean on the western side and Argentine on the eastern. As for the islands, to the Argentine Republic shall belong Staten Island, the small islands next to it, and the other islands there may be on the Atlantic to the east of Tierra del Fuego and of the eastern coast of Patagonia; and

\footnotetext{
${ }^{13}$ Philip Parker King, Narrative of the Surveying Voyages of His Majesty's Ships Adventure and Beagle (London: Colburn, 1839), 1:480.

${ }^{14}$ James L. Garrett, "The Beagle Channel Dispute: Confrontation and Negotiation in the Southern Cone," Journal of Interamerican Studies and World Affairs 27, no. 3 (1985): 82.

${ }^{15}$ George E. Fisher, "The Beagle Channel: Chile and Argentina's Gulf of Agaba” (PhD Diss, U.S. Naval War College, 1970), 5.
} 
to Chile shall belong all the islands to the south of Beagle Channel up to Cape Horn, and those there may be to the west of Tierra del Fuego ${ }^{16}$

Several other Treaties were necessary to further clarify the boundaries between these states, due to the vague language of the Treaty of 1881. This included the Treaty of 1893, which introduced the Bi-Oceanic Principle, which stated that "the sovereignty of each State over the respective littoral is absolute so that Chile cannot claim any point towards the Atlantic nor can the Argentine Republic claim any point towards the Pacific." 17 This Bi-Oceanic Principle is of special importance, because it is the cornerstone of Argentinian territorial claims on the Beagle Channel. ${ }^{18}$

In order to prevent deadlock that may arise from any future bilateral negotiations, the Treaty of 1902 established a framework for resolving boundary disputes using a neutral arbiter, the United Kingdom. In this particular case, King Edward VIII served as arbiter. The results were published on January 17, 1903 and is still used to this day as the framework for this process. This treaty set the precedent that a foreign nation could intervene as arbiter in any dispute over territory between Argentina and Chile. While nearly all questions of territory were solved through this treaty, King Edward VIII did not render a decision on the Rio Palena and the Beagle Channel. For the next 50 years, there were some minor complaints from one party or the other, but the complaints were never escalated to an arbiter.

The previous treaties served as the legal precedent for sovereignty and were largely respected by both states. By the 1950s, the Beagle Channel became of interest to both states, but for Argentina in particular, because of increased commercial and passenger ship travel through the Beagle Channel, development in Antarctica and Ushala and the discovery of manganese and oil deposits. ${ }^{19}$ Argentina had hoped that if they were spotted a favorable boundary in the Beagle

\footnotetext{
16 “Boundary Treaty of 1881," July 23, 1881.

17 "Protocol limits between Chile and Argentina 1893," May 1, 1893.

18 "The Myth of the Bi-Oceanic Principle," El-Mercurio, as translanted by Chilean Embassy, Washington, D.C., 2.

${ }^{19}$ Fisher, "The Beagle Channel: Child and Argentina's Gulf of Agaba," 25.
} 
Channel, it would also translate to additional maritime territory and Antarctic claims. Due to the geographic vagueness of the boundary line in the Treaty of 1881, Argentina protested the nautical boundaries, which consisted of 30,000 square miles south of Cape Horn. This culminated with an attempt to finally resolve the Beagle Channel boundary.

In order to finally resolve this dispute, Argentina and Chile offered different venues of mediating this boundary line. At first, both states submitted a joint declaration to the International Court of Justice (ICJ), for the purposes of adjudication. Chile reneged on this declaration, instead invoking the Protocol of 1902, which would defer arbitration to Great Britain. On December 11, 1967 the Chilean Ambassador in London, Don Victor Santa Cruz, delivered a note to the British Government concerning the issue of sovereignty between Argentina and Chile. This note included the following passage:

As it is imperative to find an early solution to this dispute, and having regard to the above-mentioned default of agreement, the Government of Chile has decided to have recourse to Her Majesty's Government as permanent arbitrator under the 1902 General Treaty of Arbitration [sc. between Chile and Argentina], and in this connection to invite them to intervene as Arbiter in the manner provided for in Article 5 of that Treaty. ${ }^{20}$

Argentina preferred to directly negotiate a settlement of the islands, which Chile refused. In order to compromise, a neutral arbiter court was agreed upon on July 22, 1971. The five-person neutral Arbitral Court, was composed of five ICJ Justices: Hardy C. Dillard (United States), Gerald Fitzmaurice (United Kingdom), Andre Gros (France), Charles Onyeama (Nigeria), and Sture Petren (Switzerland). ${ }^{21}$ The scope of this arbitration was limited to the region surrounding the Beagle Channel, limited to the following area:

\footnotetext{
${ }^{20}$ United Nations Reports of International Arbitral Awards, Boundary dispute between Argentina and Chile concerning the frontier line between boundary post 62 and Mount Fitzroy (1994), XXII:63.

${ }^{21}$ Lisa Lindsley, "The Beagle Channel settlement: Vatican mediation resolves a century-old dispute." Journal of Church and State 29, no. 3 (1987): 437-8.
} 
Figure 5-2: Contested Area of Interest for ICJ Arbitral Court ${ }^{22}$

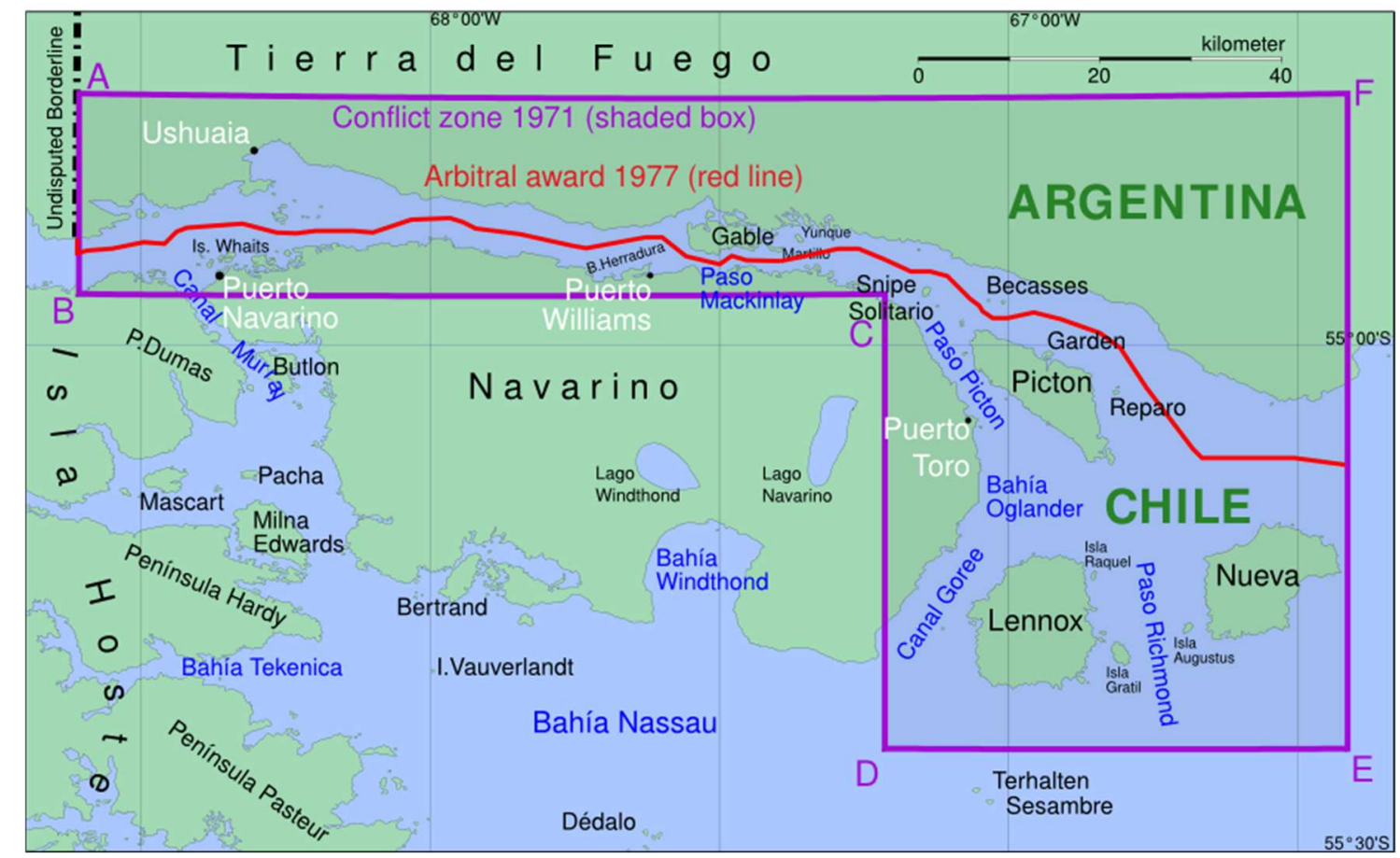

The only issue of concern for the court was the disputed territory east of the boundary line at co-ordinates $54^{\circ} 45^{\prime} 68^{\circ} 36^{\prime} 38.5^{\prime \prime}$ and $54^{\circ} 57^{\prime} 68^{\circ} 36^{\prime} 38.5^{\prime \prime}$. The court explicitly limited the scope of the arbitration to this area, because it was the only unresolved boundary between these states. The focus of this court was on the boundary line flowing east from the Beagle Channel, with particular interest to the PNL islands. ${ }^{23}$ The implication of this decision extended beyond the sovereignty of the islands, but more importantly the mineral rights in the Atlantic Ocean, south of Cape Horn. The amount of nautical territory that would change hands between the Chilean and Argentinean borderline was staggering. Given the recent discoveries in oil and mineral resources in the pacific, the decision of the court was pivotal for economic development of these states.

The variation in border lines proposed by both states is illustrated below:

\footnotetext{
${ }^{22}$ Distributed under a CC BY-SA 3.0 Unported License.

${ }^{23}$ United Nations Reports of International Arbitral Awards, Boundary dispute between Argentina and Chile concerning the frontier line between boundary post 62 and Mount Fitzroy (1994), XXII:118-9
} 


\section{Figure 5-3: Alternative Beagle Channel Boundaries ${ }^{24}$}

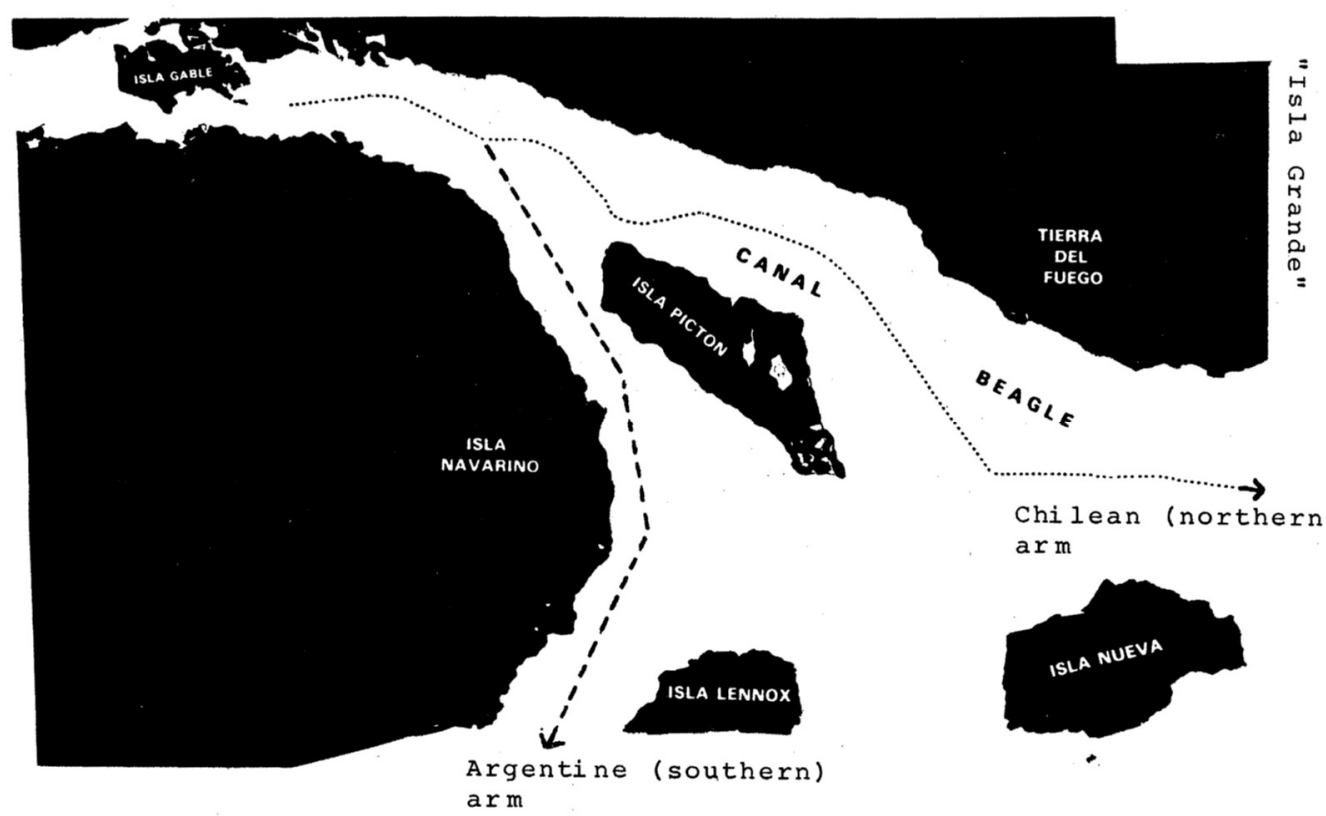

For the next five years, the arbitral court served as the venue for Chile and Argentina to state their respective positions. Argentina contended that the boundary should turn south from the end of the Beagle Channel, granting them jurisdiction over the islands. The Argentine argument was couched in the 1881 Treaty, who invoked the sentence "to the Argentine Republic shall belong Staten Island, the small islands next to it, and the other islands there may be on the Atlantic." 25 The Argentine position was that the PNL islands referenced are the 'other islands'. The other precedent was rooted in the Uti Possidetis Juris of 1810, which granted jurisdiction to all islands on the Atlantic to Argentina. ${ }^{26}$ Furthermore, they invoked the Bi-Oceanic Principle, which granted Argentina all territory on the Pacific. Based on these three arguments, they contended that the islands would be part of this arrangement, therefore making the border flow south around Nararino, rather than East (North of the Islands). The Chilean rebuttal was also based on Article III of the

\footnotetext{
${ }^{24}$ Garrett, "The Beagle Channel Dispute: Confrontation and Negotiation in the Southern Cone," 83.

25 "Boundary Treaty of 1881," July 23, 1881.

${ }^{26}$ United Nations Reports of International Arbitral Awards, Boundary dispute between Argentina and Chile concerning the frontier line between boundary post 62 and Mount Fitzroy (1994), XXII:81.
} 
1881 Treaty, which granted Chile "all of the islands to the south of the Beagle Channel". ${ }^{27}$ This treaty allocated all territory south of the Beagle Channel to Chile. Chile framed the dispute over what was considered to be south of the channel. Legal precedent and cartography was in Chile's favor, which demarcated the Channel flowing north of the islands. ${ }^{28}$

\section{Normative Similarities}

Historically, the Catholic Church has been an important facet of Latin American society. In Argentina, Article 2 of the 1853 Constitution specifically states that "the federal government supports the Roman Catholic apostolic creed."29 Under Juan Carlos Ongania, the civil code was modified to protect the Church as a 'legal entity of a public nature', which extended certain benefits to the Church. ${ }^{30}$ Even under the military dictatorships, the public display of religious symbols, such as the crucifix and statues of Virgin Mary are constitutionally protected. This included government buildings, public schools, roads and parks. Prior to the reforms of Carlos Menem in 1994, it was a requirement for the President of Argentina to be Catholic. ${ }^{31}$

During the Spanish colonial period in Chile, the church and state were inseparable. The Spanish monarch had the right of patronato, which granted them control over the bishops and publications within Chile. Furthermore, the "union of throne and alter" treated clergy as civil servants, as well as the Church playing a role in public affairs. ${ }^{32}$ Once gaining independence from Spain, a coalition was formed between the Conservative Party and the Catholic Church, which

\footnotetext{
27 “'Boundary Treaty of 1881," July 23, 1881.

${ }^{28}$ United Nations Reports of International Arbitral Awards, Boundary dispute between Argentina and Chile concerning the frontier line between boundary post 62 and Mount Fitzroy (1994), XXII: 183-5.

${ }^{29}$ Argentina Constitution (1994), chapter 1, section 2.

${ }^{30}$ H.R. Bermudez, La libertad religiosa en la Constitucion Nacional, in R. Bosca and J.G. Navarro Floria (eds.), La libertad religiosa en el Derencho argentine (Buenos Aires: Konrad Adenuer Stiftung, 2007), 94-98.

${ }^{31}$ Argentina Constitution (1957), Section 93.

${ }^{32}$ Paul E. Sigmund, "Revolution, counterrevolution, and the catholic church in Chile," The ANNALS of the American Academy of Political and Social Science (1986): 26.
} 
resulted in some compromises. ${ }^{33}$ Measures were taken in the 1925 constitution that separated the church and state, however the Conservative Party and Falange National Party (later known as the Christian Democratic Party) actualized the values of the church into policy. The Christian Democratic Party (PDC) was closely associated with Roman Catholic values, which was perceived as one of the "few crosscutting and unifying forces" in Chile. ${ }^{34}$

In addition to Catholic norms, a unique variant of Catholicism was developed in Latin America, known as liberation theology. Liberation theology was heavily influenced by the social teaching of the Church under Leo XIII, including the Rerum Novarum, which established the first political and social doctrine. ${ }^{35}$ This encyclical examined the inequality between working class and wealthy segments of society, challenging the Catholic community to more equitably distribute resources. This was expounded upon by Pius XI in the Quadragesimo Anno, published on the fortieth anniversary of Rerum Novarum in 1931. Pius condemned the excesses of capitalism, advocating for additional workers' rights, including fair wages and more humane conditions.

The pivotal moment was the Second Vatican Council (Vatican II) in 1959, which established the framework for the development of liberation theology in Latin America. This was the twenty-first ecumenical council, which were used to establish the vision and doctrine of the Church. One of the four documents resulting from Vatican II was Gaudium et spes, which clearly defined the Church's position on economics and social justice. The opening line of this document recognized that "The joys and the hopes, the griefs and the anxieties of the men of this age,

\footnotetext{
${ }^{33}$ This included a monopoly on cemeteries and marriages.

${ }^{34}$ G.W., Grayson, "Chile's Christian Democratic Party: Power, Factions, and Ideology," The Review of Politics, 31(02): 147.

${ }^{35}$ Anne Fremantle, The Social Teaching of the Church (New York: Mentor-Omega, 1963), 20-56.
} 
especially those who are poor or in any way afflicted, these are the joys and hopes, the griefs and anxieties of the followers of Christ." 36

In the wake of Church reforms, Latin American theologians ${ }^{37}$ relied upon scripture for answers to social justice questions. One of the major contributions of $A$ Theology of Liberation was the preferential option for the poor, the idea that God is on the side of the poor. ${ }^{38}$ When taken in the context of the Latin American experience of colonialization and dependency, liberation theology offered an empowering and uplifting message. In addition to a positive message, liberation theology advocated for freedom as a biblical promise. Just as Moses led the Israelites out of Egyptian oppression, social justice was achieved when the poor and enslaved are liberated from their oppressors. ${ }^{39}$ In Latin America, this was directed towards the economic and politically repressive regimes, such as the military juntas in Argentina and Chile. Liberation theology was used as the ideological basis for Marxist movements in these states, much to the chagrin of the Vatican.

This posed to be a problem for the military dictatorships of Latin American states, including Argentina and Chile, which were predicated on eliminating the Communist threat. After assuming power in May 1973, Pincohet welcomed the support of the Chilean Christian Democratic Party, who hailed him as an anti-Communist force. While Pinochet's regime was involved in questionable tactics towards opposition parties, the Vatican overlooked these transgressions,

\footnotetext{
${ }^{36}$ Pope Paul VI. Gaudium et Spes. December 7, 1965. Papal Archive. The Holy See.

$<$ http://www.vatican.va/archive/hist_councils/ii_vatican_council/documents/vat-ii_cons_19651207_gaudium-etspes_en.html>.

${ }^{37}$ Including Paulo Freire, Gustavo Gutierrez, Leonardo Boff, Hugo Assmann and Juan Luis Seguando.

${ }^{38}$ Exodus 1:8-14; 3:7-10; Luke 4:16-30

${ }^{39}$ Gustavo Gutierrez and Caridad Inda. A theology of liberation: History, politics, and salvation. Edited by Caridad Inda and John Eagleson (New York: Orbis Books, 1988), 346
} 
because he was an agent for good. Pope John Paul II even made an appeal to the British government for his release during his extradition for crimes against humanity. ${ }^{40}$

In the wake of Peron's death, factionalism took Argentina by storm, culminating in the seizure of power by the military and General Jorge Videla. During the 'dirty war' campaign against leftist opposition groups, the Church remained neutral to the atrocities committed. In fact, soldiers even reported that priests routinely performed confession for those directly involved in the killings and offered suggestions of more humane ways of killing. ${ }^{41}$ In both Argentina and Chile, liberation theology was a threat to the very existence of the regimes. With the support of the Vatican, Videla and Pinochet portrayed their actions against leftists as a defense against the anti-Christian forces of Communism. Waging a war against a regime with similar domestic problems would only de-legitimize their existence, while empowering domestic social movements.

\section{Domestic Political Change}

Domestic political change is one of the major catalysts for instability between states. Rapid regime change can alter the status quo peaceful relations between states. This was the case in Argentina, where the military coup signaled an end to Peronist leadership. In the wake of this domestic upheaval, the relations between Chile and Argentina became more belligerent than during previous administrations. This led to a crisis over the Beagle Channel from 1977 to 1979, with both states mobilizing for war.

During the five-year deliberation of the arbitral court, there was a significant political development in Argentina. Juan Peron, who was serving his third non-consecutive term (1946$1955 ; 1973-1974)$ had died in office on July 1, 1974. Peron was a populist strongman, whose

\footnotetext{
${ }^{40}$ James G. Cussen, “'Tordesillas' - or how soft power works sometimes” (Paper presented at the International Symposium on Cultural Diplomacy, Berlin, 2011), xi.

${ }^{41}$ Ibid., Xiii.
} 
political and economic ideology transcended the dominant ideologies of capitalism and communism. While his critics viewed him as a dictator who used the military to suppress dissention, he also was praised for enacting progressive legislation that supported the working class. $^{42}$ In the wake of Juan Peron's death, Isabel Martinez de Peron ascended to the presidency. While the tried to continue the rule of her husband, she was ousted by military dictatorship on March 24, 1976.

The military coup established the first of several military juntas (1976-1983), known as the Process for National Reorganization. The junta was ideologically characterized as "a combination of economic liberalism and repression" 43 The junta was extremely repressive towards political opponents, launching the Dirty War, which targeted left-wing dissidents. Detention camps were established throughout the country which were used to detain and torture political opponents. During this period, between 10,000 and 30,000 suspected dissidents were killed by security services. ${ }^{44}$ Under Videla, economic emphasis was placed on creating an export-based economy and stimulating foreign investment into the economy. ${ }^{45}$ These economic and political changes did not have the anticipated effects on creating stability. The late 1970 s had created much domestic unrest, in part because of the failed economic policies and the Dirty War against political opponents.

In light of these domestic political changes, an arbitral decision on the Beagle Channel was reached on February 1977. Chile was awarded sovereignty over the three islands and divided the channel to allow navigable waters for both states. The court relied heavily on the logic of the 1881 treaty, which specifically referenced islands "south of" the channel. The court interpreted these

\footnotetext{
42 This included universal social security and health care, paid maternity leave and free education.

${ }^{43}$ Oakes, Diversionary war: Domestic unrest and international conflict, 75.

44

${ }^{45}$ Martin Honeywell and Jenny Pearce, Falklands/Malvinas; whose crisis? (Latin American Bureau, 1982 ), 69.
} 
islands referenced to be Picton, Nueva and Lennox. If the Argentine argument was valid, and the channel turned southward along the coast of Navarino, the reference to the islands "south of" the channel would be invalid. In accordance with this treaty, it was determined the Beagle Channel must flow in an east-west direction between Tierra del Fuego and the group of islands. As such, it was determined that the islands in question would belong to Chile. ${ }^{46}$

The territorial implications of the 1977 arbitral ruling over the Beagle Channel resulted in Argentina losing maritime sovereignty in the Antarctic region. Even in the aftermath of the ruling, Argentina was more concerned with the loss of Antarctic territory than the islands themselves. Following this ruling, bi-lateral negotiations with Chile was to regain territory south of Cape Horn. ${ }^{47}$ The map below illustrates the boundary line as determined by the 1977 Arbitration and the proposed adjustments by Argentina.

\section{Figure 5-4: Difference between 1977 Arbitration and Proposed Borders}

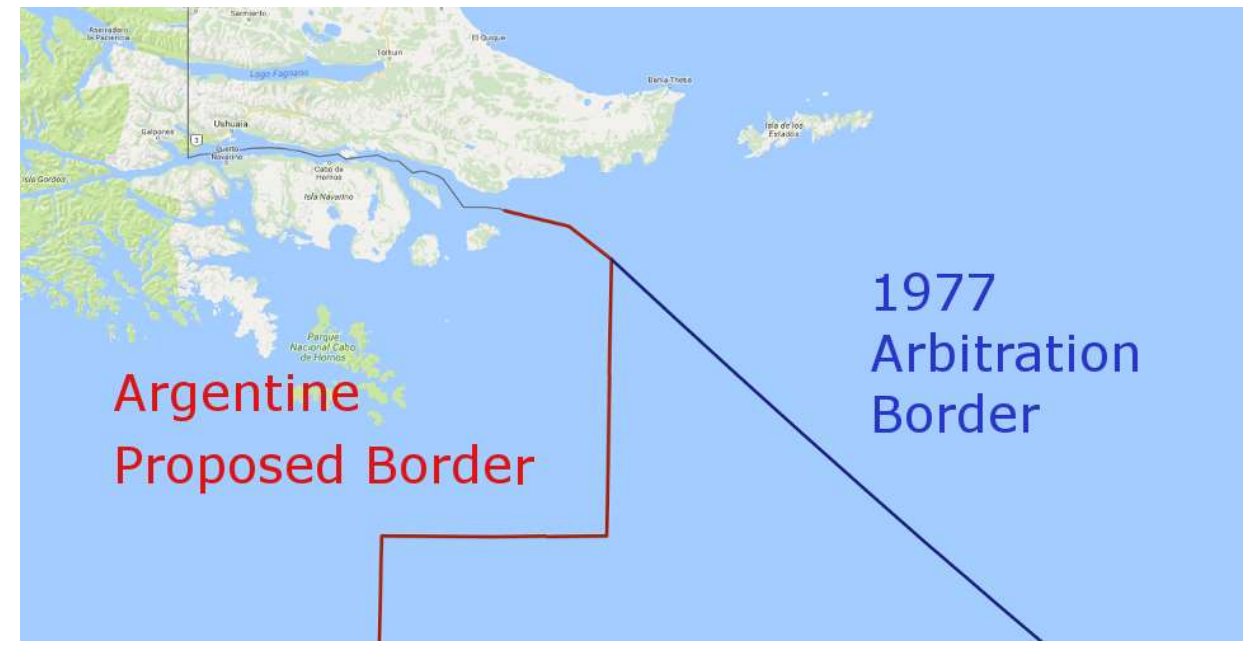

This was a disastrous result for Argentina, who not only failed to secure the sovereignty of the islands, but actually lost nautical territory in the Atlantic. Argentina believed that the court had errored, because the Oceanic Principle was granted Patagonia in exchange for Chilean

\footnotetext{
46 "Boundary Treaty of 1881," July 23, 1881.

${ }^{47}$ Lindsley, "The Beagle Channel settlement: Vatican mediation resolves a century-old dispute," 438.
} 
sovereignty over the Magellan Straits. ${ }^{48}$ Immediately following the decision, Argentina entered bilateral negotiations with Chile which respected the sovereignty of the Islands, shifting focus of the discussion to maritime sovereignty south of Cape Horn. Argentina had offered to respect the decision of the court in exchange for a reduction of maritime sovereignty from 200-miles to three miles (based on the Treaty Limits of 1881) ${ }^{49}$ The perceived loss of territorial, and associated mineral rights, would set the stage for a crisis between Chile and Argentina.

\section{Ontological Threat}

The Beagle Channel Crisis unofficially began in the wake of the 1977 arbitral ruling, when it became clear that the international community would not assist Argentina in their rightful claims over the islands. It was after this ruling that Argentina and Chile both began military mobilization, while simultaneously engaging in bi-lateral negotiations. The wild-card of the dispute was the desire of Argentina to invite a third-party mediator to rule on the dispute. Argentina perceived the ruling of arbitral court to be too legalistic and biased towards Chile. After aborting the planned invasion of the Islands (Operation Soberania), the Papacy fully committed to resolving the dispute peacefully. This section will examine the multi-faced behavior of the Videla regime, which included aggressive posturing towards Chile, while maintaining bi-lateral negotiations and attempting to secure third-party mediation.

Following the arbitration, tensions between Argentina and Chile escalated rapidly. Argentina felt betrayed by the decision of the arbitral court. Domestically, Argentina used this decision to unify under the guise of "national security", resource exploration and movement. ${ }^{50}$ In response, Argentina focused on military buildup, pressing Chile for concessions. This resulted in

\footnotetext{
${ }^{48}$ U.S. Department of State, ARGENTINE LEGAL ARGUMENTS IN BEAGLE DISPUTE. September 11, 1978.

${ }^{49}$ Lindsley, "The Beagle Channel settlement: Vatican mediation resolves a century-old dispute," 438.

${ }^{50}$ Garrett, "The Beagle Channel Dispute: Confrontation and Negotiation in the Southern Cone," 93.
} 
a mini arms race between Chile and Argentina from 1977 to 1979. The military expenditures of both Argentina and Chile increased dramatically. Throughout this entire mini arms race, Argentine expenditures were nearly double that of Chilean expenditures. The Argentine military budget increased from $\$ 800$ million in 1977 to 3.3 billion in $1980 .{ }^{51}$ During the same period, the Chilean military budget increased from $\$ 400$ million to just over $\$ 1$ billion. ${ }^{52}$ As a result of increased resources, the Argentine armed forces were both qualitatively and quantitatively superior to that of Chile. $^{53}$

There were no illusions regarding the military response from Chile over the Beagle Channel. In addition to their own armament, Argentina had also constructed regional alliances with Peru and Bolivia, who wanted to reclaim Chilean territory lost in the 1879 War of the Pacific. ${ }^{54}$ Peru is of special importance, because it shared a northern border with Chile along the Atacama Desert. A war against Argentina and Peru would occur on two-fronts, on the extreme north and south of Chile. Since both Argentina and Peru had territorial claims against Chile, it would have increased the likelihood of success for both parties if they attacked simultaneously, forcing Chile to defend completely different areas of the country. In addition, Peru was militarizing at a rapid rate, receiving a majority of arms from the Soviet Union after $1973 .{ }^{55}$ It would be difficult for Chile to compete militarily with either Argentina or Peru in 1980, let alone both simultaneously.

\footnotetext{
${ }^{51}$ Richard F. Nyrop, Brazil: A Country Study (Washington, D.C., 1982), 278.

52 William Perry, Contemporary Brazilian Foreign Policy: The International Strategy of an Emerging Power (Philadelphia, PA: Sage Publications, 1976), 22.

${ }^{53}$ Stockholm International Peace Research Institute (SIPRI), World Armaments and Disarmament (Cambridge, MA: Oelgeschlager, Gunn and Hain, Inc., 1982), 154.

54 Thomas Princen, Intermediaries in international conflict (Princeton University Press, 2014), 142-3.

55 Stephen Gorman, "Peruvian Foreign Policy Since 1975: External Political and Economic Initiatives," InterAmerican Economic Affairs 33 (1978): 124.
} 
The internal dynamics within Argentina did not favor a peaceful outcome, with the junta placing great pressure on Videla to achieve a positive outcome. Videla felt internal pressure from the other members of the junta to receive a favorable outcome, either by force or mediation, or risk replacement as leader of Argentina. ${ }^{56}$ The military junta in Argentina during the Crisis consisted of General Roberto Viola (Army), Admiral Armando Lambruschini (Navy) and General Omar Graffigna (Air Force). General Videla was the President, whose role was separate from the junta, but was still held accountable and could be removed at any time by a unanimous decision. ${ }^{57}$ Videla felt immense pressure to not back down with Chile over the islands, because he feared that it would result in his removal and a loss of prestige for the regime. ${ }^{58}$ As a result, the Argentine regime maintained an aggressive posture towards Chile, which included military mobilization along the border and denouncing the 1977 award. At the same time, Videla was privately searching for a peaceful resolution of the dispute. Throughout the entire dispute, Argentina maintained a position of bi-lateral negotiations with Chile.

\section{Bilateral negotiations}

For the next year, a series of bi-lateral negotiations were undertaken, while Argentina began military mobilization along the border. While negotiating with Chile, Argentina also publicly denounced the verdict of the Court, declaring that the Beagle Channel Award was "null and void" based on historical and geographical errors made by the arbiter. ${ }^{59}$ Simultaneously, Argentina began navy maneuvers when Admiral Massera boarded the Aircraft Carier 25 de

\footnotetext{
${ }^{56}$ Thomas Princen, Intermediaries in international conflict (Princeton University Press, 2014), 143.

${ }^{57}$ Craig L. Arceneaux, Bounded Missions: Military Regimes and Democratization in the Southern Cone and Brazil (Penn State Press, 2001), 112.

${ }^{58}$ David R. Mares, Violent Peace: militarized interstate bargaining in Latin America (Columbia University Press, 2001), 146.

${ }^{59}$ U.S. Department of State, ARGENTINA REJECTS BEAGLE AWARD. January 25, 1978.
} 
Mayo. ${ }^{60}$ Argentina refused to participate in any negotiations involving an international arbiter, pressuring Chile for bi-lateral negotiations. Argentina refused an offer made by Chile to appear before The Hague, insisting on bi-lateral negotiations. In these bi-lateral negotiations, Videla proposed an adjustment of the border line east of Isla Nueva through Isla Evout and bisecting Isla Hornos. Chile counter-offered an adjustment south of Cape Horn. ${ }^{61}$

Bilateral negotiations were agreed upon by both Argentina and Chile in February 1978, the Act of Puerto Montt, with the timeline of three distinct periods. The first period of 45 days was allocated to "create the conditions of harmony that will facilitate later more specific work". ${ }^{62}$ This would be followed by a second period of 6 months, which would be dedicated to defining boundaries. The final period was intended to prepare international agreements based on these discussions. ${ }^{63}$ Upon completion of the first phase, many issues were deliberated, including navigation, rescue operations, vehicular traffic, mineral exploration and trade. ${ }^{64}$ However, the issue of the Beagle Channel and nautical sovereignty were difficult to address. At that point in the negotiation, Argentina has become distracted by the World Cup, and abruptly ended negotiations on August 16, 1978. ${ }^{65}$ Talks would resume on September 13 with the explicit purpose of negotiating maritime boundaries, Antarctic interests, the Magellan Strait, Straight base lines and economic development. ${ }^{66}$

\footnotetext{
${ }^{60}$ U.S. Department of State, ARGENTINA TO REJECT BEAGLE CHANNEL RULING; NAVY BEGINS MANEUVERS. January 10, 1978.

${ }^{61}$ U.S. Department of State, CHILEANS REQUEST USG GOOD OFFICES ON BEAGLE DISPUTE January 7, 1978

${ }^{62}$ U.S. Department of State. BEAGLE CHANNEL; PRESIDENTS TO SIGN AGREEMENT FEBRUARY 20. February 17, 1978.

${ }^{63}$ U.S. Department of State. BEAGLE CHANNEL; PRESIDENTS TO SIGN AGREEMENT FEBRUARY 20. February 17, 1978.

${ }^{64}$ U.S. Department of State. ARGENTINE-CHILEAN COMMISSION ISSUES REPORT ON BEAGLE CHANNEL DISCUSSIONS. April 7, 1978.

${ }^{65}$ U.S. Department of State. BEAGLE CHANNEL TALKS. June 1, 1978.

${ }^{66}$ U.S. Department of State. BEAGLE CHANNEL TALKS: PHASE TWO RESTARTED. September 15, 1978.
} 
While Chile remained optimistic regarding negotiations, they also recognized the Argentinian military mobilization along the border. ${ }^{67}$ The Chilean hope was that either a settlement or a 10-year moratorium on the issue of territorial rights could be reached before military intervention. ${ }^{68}$ Argentina was also concerned with the progress of negotiations, as they feared Chile was biding their time in order to prepare for war. Argentinian negotiator General Etcheverry Boneo expressed these concerns to Videla on October $30,1978 .{ }^{69}$ By the first of November, both governments accused one another of military mobilization and aggressive action on the border. ${ }^{70}$ Argentina alleged that Chile violated Argentine air space and territorial waters on several occasions. Argentina also accused Chile of mobilizing air forces and armored units in the south. ${ }^{71}$ The government of Chile issued a rebuttal, which outlined that the air space and nautical territory were actually Chilean and demonstrated several examples of Argentinian aggression. ${ }^{72}$ This included 36 threatening statements (which were published in full), in addition to a variety of leaked documents $^{73}$, administrative restrictions, and refusals of assistance.

Chile issued an ultimatum, giving Argentina three weeks to accept third party mediation or they would file a complaint with the International Court of Justice (ICJ). ${ }^{74}$ Argentina agreed to said mediation. ${ }^{75}$ According to Chilean sources, there were never any expectations to solve the

\footnotetext{
${ }^{67}$ U.S. Secretary of State. REPORT OF ARGENTIEN TROOP MOVEMENTS ON CHILEAN BORDER. September 12, 1978.

${ }^{68}$ U.S. Secretary of State. BEAGLE CHANNEL TENSIONS SUBSIDE; SOLUTION AT HAND?. September 20, 1978.

${ }^{69}$ U.S. Secretary of State. ARGENTINE MOVES IN BEAGLE CHANNEL DISPUTE. October 26, 1978.

${ }^{70}$ U.S. Secretary of State. BEAGLE CHANNEL UPDATE. November 1, 1978; U.S. Secretary of State. ARGENTINA GLOOMY ON BEAGLE SOLUTION PROSPECTS. October 31, 1978.

${ }^{71}$ U.S. Secretary of State. ARGENTINA GLOOMY ON BEAGLE SOLUTION PROSPECTS. October 31, 1978.

${ }^{72}$ U.S. Secretary of State. BEAGLE CHANNEL UPDATE. November 1, 1978.

${ }^{73}$ Which included a high school questionnaire which gauged the opinion of war with Chile. In addition, leaked memos from the Argentina Interior Minister which discussed operations to mobilize public support for war.

${ }^{74}$ U.S. Secretary of State. BEAGLE CHANNEL: PRESS COMMENTS AND TALK WITH AMBASSADOR BARROS. November 8, 1978.

${ }^{75}$ U.S. Secretary of State. ARGENTINA AMENABLE TO MEDIATION IN BEAGLE DISPUTE. November 9, 1978.
} 
dispute through meditation, but rather use it to de-escalate tensions. ${ }^{76}$ While this may bade time for Chile, there were concerns that military action would be inevitable if Argentina did not receive a favorable outcome. ${ }^{77}$

A report was intercepted from Argentine Army HQ that alerted field units of an upcoming operation that would include military occupation of all the Chilean islands east of Cape Horn, including Cape Horn and PLN islands. ${ }^{78}$ By December 16, the US Embassy regarded conflict as "imminent". 79 Argentina planned on launching Operation Soberania on December 22, 1978, which was a military operation to occupy the Islands. However, the operation was aborted before any of the forces arrived at the destination. ${ }^{80}$ The Argentine intention of taking matters into their own hands and occupying the islands by force was a viable option. However, the intervention of the Papacy as a mediator was a more desirable option for the Videla regime.

\section{Papal Mediation}

During a dinner on October 26 between Videla and several Cardinals, it was suggested by Cardinal Aramburu to ask Pope John Paul II for assistance. ${ }^{81}$ Argentina would not respect a decision from an international body, such as the ICJ. Chile attempted to invite Argentina to resolve the dispute before the ICJ in the past. ${ }^{82}$ Chile preferred such mediators because they derive their judgement based on legal precedent, which favored Chile. ${ }^{83}$

\footnotetext{
${ }^{76}$ U.S. Secretary of State. CHILEAN EMBASSY VIEWS ON BEAGLE DISPUTE. November 15, 1978.

${ }^{77}$ U.S. Secretary of State. BEAGLE CHANNEL DISPUTE. December 5, 1978.

${ }^{78}$ U.S. Secretary of State. ALLEGED ALERT ORDER REGARDING INITIATION OF MILITARY OPERATIONS. December 14, 1978.

${ }^{79}$ U.S. Secretary of State. BEAGLE CHANNEL DISPUTE. December 16, 1978.

${ }^{80}$ Garrett, "The Beagle Channel Dispute: Confrontation and Negotiation in the Southern Cone," 97.

${ }^{81}$ U.S. Secretary of State. BEAGLE CHANNEL AFFAIR AND POSSIBLE POPE'S PARTICIPATION. October 27, 1978.

${ }^{82}$ U.S. Secretary of State. BEAGLE CHANNEL SIDPUTE: CHILE CONSIDERS REPEATING ICJ INVITATION. December 19, 1978.

${ }^{83}$ U.S. Secretary of State. BEAGLE CHANNEL DISPUTE. December 9, 1978.
} 
While they did not immediately agree to Papal mediation, there were many discussions within the regime as who could best mediate the conflict. By December 12, less than two weeks prior to the planned invasion of the PNL islands, the Argentine ambassador to the United States noted the potential mediators being discussed. This list included the King of Spain, the United Nations, the Queen of England, Henry Kissinger and the Pope. ${ }^{84}$ Argentina was obviously concerned with the fairness of the outcome, so they preferred a neutral 'friendly' mediator. On December 12, Hernan Cubillos and General Carlos Pastor, respective foreign ministers of Chile and Argentina, met and agreed to Papal mediation. ${ }^{85}$ On December 14, this sentiment was echoed by Papal Nuncio Pio Laghi, who encouraged Videla to seek Papal mediation in order to prevent conflict. $^{86}$ After a mediator was unable to be agreed upon, efforts were directed toward Papal mediation. The Vatican was more than amenable to "do all it can" to diffuse tensions between Argentina and Chile. ${ }^{87}$

The Holy See contacted both governments in order to express "my Disposition -- also my desire -- to send to the two capitals my special representative, in order to obtain more direct and concrete information regarding the respective positions and to examine and search together the possibility for an honorable and peaceful solution to the dispute." ${ }^{\prime 8}$ This offer was accepted by both parties on the same day. For Chile, it urged that the emissary arrive before Christmas, because of growing concern that Videla and the junta would succumb to pressure from hardline generals. ${ }^{89}$

\footnotetext{
${ }^{84}$ Princen, Intermediaries in international conflict, 139.

${ }^{85}$ Princen, Intermediaries in international conflict, 116.

${ }^{86}$ Princen, Intermediaries in international conflict, 143.

${ }^{87}$ U.S. Secretary of State. BEAGLE CHANNEL: VATICAN VIEWS. December 16, 1978.

${ }^{88}$ U.S. Secretary of State. BEAGLE CHANNEL: POPE'S REMARKS ON SPECIAL ENVOY. December 22, 1978.

${ }^{89}$ U.S. Secretary of State. BEAGLE CHANNEL: CHILE ACCEPTS EMISSARY BUT PLANS TO INVOKE RIO TREATY TONIGHT OR TOMORROW. December 22, 1978.
} 
Upon arrival in Buenos Aries on December 26, Cardinal Samore immediately began crisis management, meeting with both sides in order to gain a deeper understanding of the tension. Argentina originally persisted that any negotiated settlement through Papal mediation must overturn the previous arbitral award and rely upon the Bi-Oceanic Principle, which was largely ignored by the previous international arbitration..$^{90}$ Chile refused to accept these conditions, but Samore was able to persuade the Argentines to abandon these demands and eventually accepted mediation on January 5, 1979. This culminated in the signing of The Act of Montevideo on January 8, 1979 which both parties agreed "that they will raise no objection to the expression by the Holy See, during these proceedings, of such ideas as its thorough studies on a disputed aspects of the problem of the southern zone may suggest to it, with a view to contributing to a peaceful settlement acceptable to both Parties." ${ }^{91}$

During Papal mediation, this maritime sovereignty became apparent to Cardinal Samore and Monsignor Faustino Sainz Munoz, who spent the first several months gaining a better understanding of both positions. ${ }^{92}$ Each side met with the mediators separately, but were provided strict guidelines for the negotiations, including a limited scope, which would not include sovereignty of the islands. By removing the sovereignty of the islands and the Beagle Channel boundary, the mediators were able to focus their attention on the boundary in the Atlantic, which was the real concern of the Argentines.

After months of information gathering, the first document proposed was the Sea of Peace Proposal, which compromised on the disputed borders by creating a Zone of Common and

\footnotetext{
${ }^{90}$ Laudy, Mark. "The Vatican Mediation of the Beagle Channel Dispute: Crisis Intervention and Forum Building." Words Over War: Mediation and Arbitration to Prevent Deadly Conflict, edited by Melanie C. Greenberg, John H. Barton, and Margaret E. McGuinnes (2000): 308

${ }^{91}$ U.N. Treaty Series, Act of Montevideo (Montevideo 1979), MLXXXVIII: 135.

${ }^{92}$ Laudy, "The Vatican Mediation of the Beagle Channel Dispute," 310-312.
} 
Concerted Activities (ZACC) area in between the 1977 Arbitration and Argentine Proposed borders. Within this jurisdiction, a Zone of Common and Concerted Activities (ZACC) would allow equal access for resource extraction. ${ }^{93}$ This was a sticking point for the Argentine delegation, who foresaw difficulties with this shared territory arrangement.

By 1982, neither party was any closer to signing a binding document, with Chile threatened to take the case to the ICJ ${ }^{94}$ As a result, the Accord of Vatican City was signed, which provided the Vatican with ultimate decision-making over the case, even if it was relegated to the ICJ. During this time, negotiations had stalled because of the Argentinian invasion of the Falkland/Malvinas Islands. It was only after the election of Raul Alfonsin to the Presidency of Argentina in 1983, that an important point of emphasis was placed on the resolution of the Beagle Crisis. A full accord was reached on October 4, 1984, which recognized Chilean sovereignty over the Islands, granted expanded maritime sovereignty to Argentina and eliminated the ZACC. The final result was the establishment of borders in accordance with the Argentine borders, which extended southward around Cape Horn.

\section{Summary}

For nearly fifty years, tensions between Argentina and Chile surrounded the Beagle Channel. While Argentina utilized limited military engagements (including the Snipe Incident, Laguna del Desierto incident, and Operation Soberania), it is intriguing that the crisis over the Beagle Channel never escalated to war. When examining this conflict through a realist framework, it is puzzling as to why Argentina practiced restraint in this case for several reasons: First, Argentina was militarily superior to that of Chile. Secondly, an escalation of the conflict to include regional allies would favor Argentina, because they had agreements with Peru and Bolivia. Lastly,

\footnotetext{
${ }^{93}$ Lindsley, "The Beagle Channel settlement," 446.

${ }^{94}$ Ibid.
} 
while publicly posturing towards war, the Videla administration went to great lengths to secure papal mediation. It would appear that Videla was merely "using military force as a bargaining tactic rather than a decision to settle an interstate dispute through war." 95 The restraint of the military junta, and Videla in particular, seemed to be contrary to traditional logics of power politics.

I posit that the reason for restraint practiced against Chile was rooted in moral compatibility between dyads. Both Chile and Argentina had strong ties to the Roman Catholic Church, which created a shared ontological worldview. This reduced the likelihood of conflict between these dyads. Previous scholarship has identified the significance of linkage of Catholicism played in Papal mediation. The cultural and ontological importance of Catholicism in Argentina and Chile was a commonality, which can provide an environment that facilitated mediation. ${ }^{96}$ The shared value structure between Chile and Argentina is rooted in Roman Catholicism, which is why the Papal mediation was so effective at de-escalating the crisis. Even under the dictatorships of Pinochet and Videla, the Church "authoritatively judge[d] what is Good or Evil, and what actions or omissions may lead to eternal damnation." 97 These shared moral tenets were deeply engrained in the societies of both Argentina and Chile. ${ }^{98}$ One such tenet was peaceful resolution of conflict. For the church, "peace is one of the greatest human values and its pursuit and realization a desire, nay more, a mandate of the Son of God made Man, the Prince of Peace, whose vicar Providence has made me among men." 99 The queen of peace, the Virgin Mary, holds special importance in

\footnotetext{
95 Mares, Violent Peace, 7.

${ }^{96}$ Peter J., Carnevale and Dong-Won Choi, "Culture in the mediation of international disputes," International Journal of Psychology 35, no. 2 (2000): 108.

${ }^{97}$ Matthew C. Mirow, "International Law and Religion in Latin America: The Beagle Channel Dispute," Suffolk Transnat'l L. Rev. 29 (2004): 16.

${ }^{98}$ Luis Alfonso Tapia, Esta Noche: La Guerra (1997), 110-112.

99 Thomas Princen, "International Mediation_-The View from the Vatican," Negotiation Journal 3, no. 4 (1987): 349.
} 
Latin America. The Virgin of Guadalupe is an important image for Catholics in Latin America. ${ }^{100}$ The papacy recognized this connection, which lead to Pius X naming her the Patroness of Latin America. ${ }^{101}$ In other words, it was a moral imperative to resolve the conflict peacefully, one which could not be ignored by either military dictatorship. In addition to the mediation, common linkages in religion stalled Argentine aggressiveness. The historical importance of the Catholic Church in Argentina and Chile were strikingly similar. In more recent years, the spread of liberation theology among Latin America created a common domestic enemy for Videla and Pinochet. These shared experiences acted as a deterrent during the Beagle Channel conflict.

\section{Falkland/Malvinas War (1982)}

The Falkland/Malvinas War was a war between Argentina and Great Britain over the territory of the Falkland/Malvinas Islands, a 4,700 square-mile archipelago located 300 miles east of Patagonia. Given the circumstances surrounding the sovereignty of the islands, the rash decision-making of the Argentine regime was uncharacteristic of the military junta. I contend that the reason for Argentine belligerence was the result of differences with Great Britain with respect to cultural and historical beliefs. These differences contributed to the Argentine perception of a British ontological threat, which explains their erratic and irrational decision to invade and occupy the islands.

The Falkland/Malvinas Islands had been a point of contention for the past several centuries, changing hands between several states. The British seized an opportunity to occupy and settle the islands in 1833. For the next 149 years, Argentina resented the British for these actions, claiming that the territory rightfully belonged to Argentina. Argentina pursued bi-lateral negotiation and

\footnotetext{
100 Bruno Passarelli, El Delirio Armado: Argentina-Chile, La Guerra que Evito el Papa (Editorial Sudamericana 1998), 136-7.

101 “Our Lady of Guadalupe,” New Catholic Encyclopedia (New York: McGraw Hill, 1967), VI:822.
} 
U.N. intervention under the Peron and Videla regimes, which appeared to be making great strides in facilitating a resolution. The centuries-old rivalry between Great Britain and Argentina over the sovereignty of the islands was reignited under the military junta. This culminated in the bold decision of President Galtieri to invade and occupy the Islands in 1982. In response, the British launched a counter-attack that led to a ten-week long conflict, resulting in Argentine defeat.

When this crisis is examined through the lens of realism, Argentina's behavior is puzzling. The British military was experienced, quantifiably larger, and quantitatively more sophisticated than the Argentine military. While the junta was exposed to imperfect information, they were aware of a British response both prior to invasion and after invading the islands. Argentina did not pursue any form of multi-lateral negotiations or arbitration, opting for a strictly military solution. Even in the face of several favorable U.N. resolutions, which acknowledged Argentine sovereignty over the Falklands/Malvinas Islands, they did not use any of the political capital for peaceful resolution of the dispute. In order to develop a better understanding of Argentine decision-making, the historical conditions and cultural differences between Great Britain and Argentina will be relied upon. The framework and proposed theory shall offer an alternative explanation for Argentine behavior during this conflict. One of the underlying mechanisms in the dyadic relationship between Argentina and Great Britain was ontological dissimilarity, which is manifested in different cultural norms, language, and expectations. At the very least, these differences contributed to the misperceptions, and possibly even the reason why Argentina decided to invade, knowing that the odds of success were low.

\section{Civil Religion}

The civil religion, or the secular national beliefs, dogmas and rituals, of Argentina and Great Britain are greatly different. The cultural norms, language, and religious significance vary 
greatly between these states. These differences provoked Argentine leadership to operate from a position of moral superiority towards the British, whose culture was perceived to be decedent and soft. The historical contestation over the Falkland/Malvinas Islands only steeled the resolve of the islanders and Argentine leadership, coupled with fundamentally different worldviews, led to a conflict. The following section will flush out the causal mechanisms that contributed to differences in civil religion, including the historical conditions and normative differences between Argentina and Great Britain.

\section{Historical Context}

The Falkland/Malvinas Islands are located approximately 250 miles off the eastern coast of Argentina. The Island chain is composed of several hundred smaller islands, but two primary islands - referred to as East and West. In total square miles, East and West Falkland/Malvinas are nearly 5,000 square miles of territory. ${ }^{102}$ In 1982 , approximately 1,800 people inhabited the islands, with a majority being native British citizens. ${ }^{103}$ Due to the proximity to the arctic circle and inclement weather, these islands only became desirable in recent centuries after being discovered.

\footnotetext{
${ }^{102}$ Lawrence Freedman, The official history of the Falklands: The Origins of the Falklands conflict (London: Routledge, 2005), 1.

${ }^{103}$ Max Hastings and Simon Jenkins, The Battle for the Falklands (New York: Norton, 1983), 1.
} 
Figure 5-5: Geography of the Falkland/Malvinas Islands ${ }^{104}$

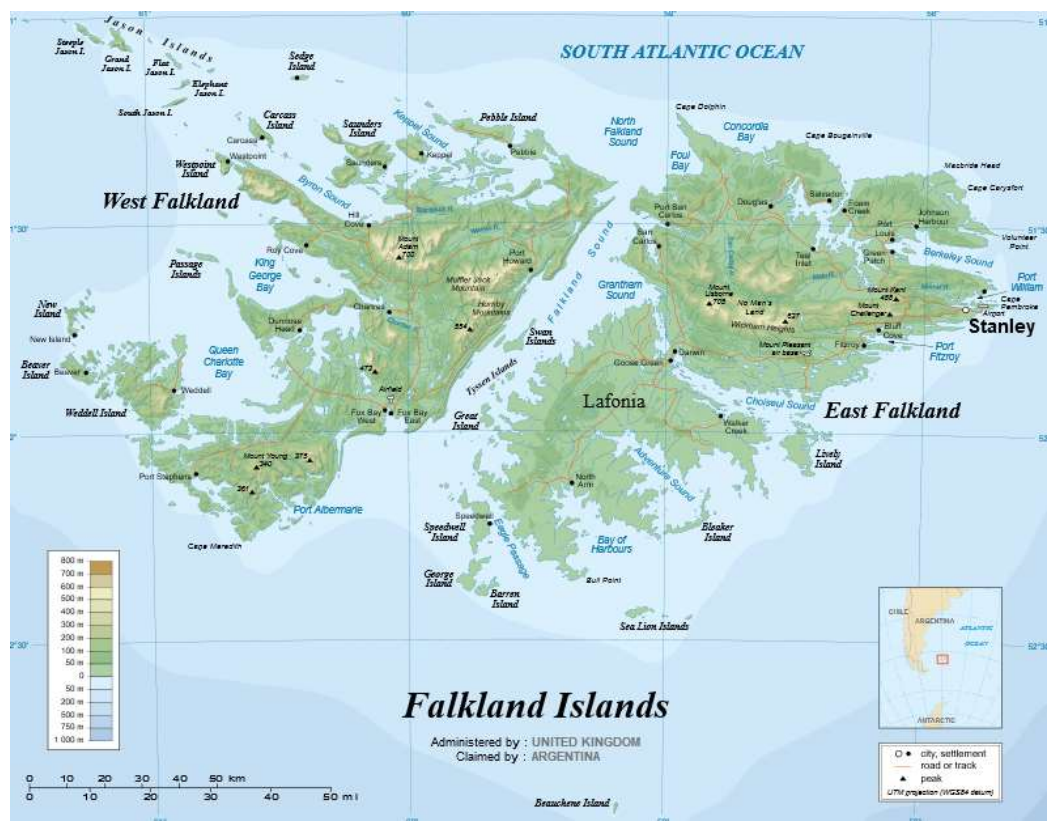

The Falkland/Malvinas Islands were originally discovered by Americo Vespucio of Portugal in 1502 and later Hernando de Magallanes of Spain in 1520. Because of their remoteness and lack of natural resources, they remained unclaimed by either state. However, once discovered by British Captain John Strong in 1690, they became a point of contention among colonial powers. It was the British that bestowed the name 'Falkland' upon the islands, named after the First Lord of the Admiralty Lord Falkland. ${ }^{105}$ Even the nomenclature used to refer to the islands differs between Argentina and Great Britain. ${ }^{106}$

Both the French and British independently established settlements on the main Islands in the 1760s. As the result of a negotiation between France and Spain, the sovereignty of the islands was transferred to Spain in 1766. This resulted in a dispute between Spain and Britain, who refused

\footnotetext{
${ }^{104}$ Map by Eric Gaba, distributed under a CC BY-SA 3.0 Unported License.

105 Ibid., 2.

${ }^{106}$ The British refer to the islands as "Falklands", whereas the Argentines refer to them as the "Malvinas". The use of different discourse towards the same islands is a fundamental way of differentiating claims on the islands (C. Acosta-Alzuru and E. Roushanzamir, "A war by any other name: A textual analysis of Falklands/Malvinas War," in The global dynamics of news: studies in international news coverage and news agendas, ed. Malek A., and Kavoori, P. A. (Ablex: Connecticut, 2000), 112.
} 
to acknowledge this agreement. After Spain began mobilizing for war with Britain, they opted to voluntarily abandon the island in $1774 .{ }^{107}$ The issue of sovereignty became an issue again in 1816 , when Argentina declared their independence from Spain and claimed all territory in the Atlantic, which included the Falkland/Malvinas Islands. In 1829, Argentina had appointed a governor of the island, Louis Vernet. Under his rule, a skirmish between American forces and Argentine forces ensued, resulting in the USS Lexington occupying and liberating the islands from Argentine rule. The British took the opportunity to reassert their claim on the islands, with Captain Onslow of the HMS Clio occupying the territory and raising the British flag on January $3,1833 .{ }^{108}$ From this point onward, the stage was set for confrontation between Argentina and Britain over the sovereignty of the islands.

For nearly 150 years, the issue of sovereignty over the Falkland/Malvinas Islands was moot, but became exacerbated by claims of natural resources in the surrounding waters. The dispute over sovereignty was escalated to the U.N. Committee on Decolonization which codified the United Nations General Assembly Resolution 2065 on December 16, 1965. The resolution acknowledged the dispute and "invites the Governments of Argentina and the United Kingdom of Great Britain and Northern Ireland to proceed without delay with the negotiations recommended by the special committee on the situation with regard to the Implementation of the Declaration of Independence to Colonial Countries and Peoples. ${ }^{109}$

This resolution recognized the dispute, but rather than issue a judgement, it invited the parties to come to a peaceful bi-lateral resolution. This resolution was unanimously voted for, with 94 votes for and 14 abstentions. In addition, when negotiating the future of the islands, the

\footnotetext{
${ }^{107}$ Freedman, The official history of the Falklands, 5.

${ }^{108}$ Lawrence Freedman, and Virginia Gamba-Stonehouse, Signals of war: the Falklands conflict of 1982, (Princeton University Press, 2014), xxxii.

${ }^{109}$ General Assembly Resolution 2065, Question of the Falkland Islands (Malvinas). (16 December 1965).
} 
resolution urged that the United Nations General Assembly Resolution 1514 be taken into consideration. This Resolution, passed on December 14, 1960, affirmed the right to selfdetermination for those living in colonial states. ${ }^{110}$

U.N. General Resolution 3160 was passed on December 14, 1973, which reaffirmed the commitment of peaceful resolution expressed in Resolution 2065: "gravely concerned at the fact that eight years have elapsed since the adoption of resolution 2065 without any substantial progress."111 Interestingly, this resolution also acknowledged the positive attempts that Argentina has made to resolve this dispute, including a preamble that is "a clear and explicit endorsement of Argentina's rights and an urge to Britain to restore the islands to Argentine sovereignty". ${ }^{112}$ Even with this endorsement, the U.N. had no intention of directly intervening in the dispute.

Natural resources in the waters surrounding the Falklands/Malvinas were a cause for concern for British officials. British officials were concerned that the discovery of oil in the waters surrounding the Falkland/Malvinas Islands would escalate the dispute with Argentina. This concern was first raised during a British cabinet meeting on October 24, 1969. It was suggested during this meeting by the foreign office that the presence of oil should be concealed by the government. ${ }^{113}$ Even though several British, American and Canadian oil exploration companies had applied for licenses, the British stalled until a political solution could be reached. ${ }^{114}$

Meanwhile, Argentina had granted licenses to Shell Capsa for exploration in the waters between the mainland and Falkland/Malvinas Islands. During 1969-1970, at the cost of over a million dollars, Shell Capsa had successfully performed exploration in the areas surrounding the

\footnotetext{
${ }^{110}$ General Assembly Resolution 1514, Declaration on the Granting of Independence to Colonial Countries and Peoples. (14 December 1960).

111 General Assembly Resolution 3160, Question of the Falkland Islands (Malvinas). (14 December 1973).

112 Roberto C. Laver. The Falklands/Malvinas Case: Breaking the Deadlock in the Anglo-Argentine Sovereignty Dispute (Martinus Nijhoff: The Hague, 2001), 101.

113 Gustafson, The Sovereignty Dispute over the Falkland (Malvinas) Islands, 83.

114 Ibid.
} 
Falklands/Malvinas. The results were published by Geocom, Inc., which strongly suggested that significant reserves were present in the Malvinas basin. ${ }^{115}$ Several years later, U.S. researchers concluded that reserves more plentiful than the middle east, upwards of 200 billion barrels of oil. ${ }^{116}$

British officials also issued permits for exploration in the waters surrounding the Falklands/Malvinas, albeit with the utmost discretion so as to not incense Argentina. The report from this exploration was published in 1971, which was promising enough to warrant future exploration. This was conducted by the HMS Endurance (1972) and HMS Shackleton (1971, 1973). By 1975, the British were overwhelmed by license requests from several oil companies who wanted to develop these resources. The Islanders were also excited by the prospects of the economic benefits associated by resource extraction. At the same time, Argentina's representative to the U.N. contended that it was outside the authority of the British to allow oil exploration in the South Atlantic, since it was not rightfully their territory. ${ }^{117}$ The foreign office was in a difficult position, wedged between the domestic interest of increasing resource development and the international pressure from Argentina.

Until this point, the British authorities had practiced as much discretion as possible, but it was clear that it was not a sustainable long-term solution. They tasked Lord Shackleton to conduct a diplomatic mission in Argentina, which was met with much Argentine resistance. A wide range of responses, up to and including invading the islands, dominated the national dialogue. ${ }^{118}$ In the mist of paranoia by Great Britain, several incidents had occurred which signaled the displeasure of resource development around the Falklands/Malvinas. On January 16, 1976, when equipment

\footnotetext{
115 Ibid.

${ }^{116}$ Bernardo Grossling, Petroleum Prospects in the Energy Crisis, Geological Survey Bulletin 1411.

${ }_{117}$ Patrick Hamilton Armstrong and Vivian Forbes, The Falkland Islands and their Adjacent Maritime Area (1999), 11.

${ }^{118}$ Gustafson, The Sovereignty Dispute over the Falkland (Malvinas) Islands, 90.
} 
and engineers were deployed at Port Stanley. Their stated purpose was to upgrade the runways to passenger and commercial air traffic. On January 15, 1976, a bomb was detonated at the British Cultural Institute at Cordoba. Finally, a standoff between the HMS Shackleton and Almirante Storni, in which the Argentine warship fired warning shots before boarding the HMS Shackleton. The intended target was the HMS Endurance, but it was mistaken for the incorrect ship. The purpose is unclear, but the presumption is the Argentines wanted to detain Lord Shackleton's crew. ${ }^{119}$ Either way, the message that the Argentines were trying to send was being heard by the international community.

In order to resolve the dispute over the development of natural resources in the area, British officials proposed several forms of bi-nationality for the Falklands/Malvinas, with the expectation that it would reduce tensions between the states. In December 1978, negotiations in Geneva were fruitful, with both states agreeing to scientific cooperation (including oil exploration) in the region. ${ }^{120}$ That being said, the Islanders and the Falkland lobby applied great pressure against this course of action, coupled with Argentine overtures towards full sovereignty, resulting in a stalemate.

\section{Normative Differences}

The relationship between Great Britain and Argentina had been historically contentious over the issue of Falkland/Malvinas sovereignty. I contend that while material and symbolic benefits were the primary goals behind Argentine aggression, the underlying motivation for undertaking such a risky operation lied in the normative differences between Great Britain and Argentina. The Argentine identity towards Great Britain was forged from a combination of

\footnotetext{
119 Ibid., 94.

${ }^{120}$ Ibid., 106.
} 
narratives. This included a belief structure that Argentina was destined to be greater than the traditional European powers.

Throughout the historical development of Argentinean culture, much emphasis has been placed on competing with 'European' and Western states. ${ }^{121}$ To that end, they developed close relationships with European states, pursued policies that encouraged immigration from Europe and foreign investment. ${ }^{122}$ Argentineans developed a unique brand of culture forged from Native American, African, Spanish and European identities. In the wake of successful development, the Argentine economy expand rapidly, along with per capita income that ranked in the global top10. ${ }^{123}$ By the end of World War II (and in particular under Peron), Argentina had become more nationalistic and protectionist, but the culture was still rooted in Argentine exceptionalism.

Argentine superiority complex, or Argentina Potencia was based on the idea that Argentina is destined to become a regional hegemon and global power. ${ }^{124}$ The narrative that a former colony could compete in the global arena with the former colonizer was a powerful motivator. However, this narrative was maintained even after the loss of prestige and power under Peron. This was because it also removed the accountability of actors, assuming that problems of the country would be solved automatically (i.e. by God). ${ }^{125}$ When economic and political conditions worsened under the junta, superiority became coupled with resentment towards Western ideas. The combination of superiority and resentment fueled the sentiment that "life owes them something", while also depreciating Western values. ${ }^{126}$

\footnotetext{
${ }^{121}$ Nora Femenia, National identity in times of crises: The scripts of the Falklands-Malvinas War (Nova Publishers, 1996), 58.

${ }^{122}$ David Rock, Argentina, 1516-1982: from Spanish colonization to the Falklands War (Berkeley: University of California Press, 1985), 146.

${ }^{123}$ Ibid., 172.

124 "Great power at the level of the most advanced countries" (Femenia, National identity in times of crises, 66.)

${ }^{125}$ Femenia, National identity in times of crises, 64.

${ }^{126}$ Mempo Giardinelli, El país de las maravillas: los argentinos en el fin del milenio (Buenos Aires: Planeta, 1998), 262.
} 
The conflict over the Falklands embodied a larger moral struggle against Western Idealism. Argentines perceived Western states, including Great Britain as being morally bankrupt and weak. ${ }^{127}$ The conflict was framed as a "Holy War", in which the Argentine military were soldiers acting on behalf of God. ${ }^{128}$ With the U.N. on their side, yet unwilling to interject into the dispute over sovereignty, Argentine leaders felt that the entire international system (of Western Liberal states) was against them. This resulted in Argentine "exceptionalism", the perception that your state is objectively better than others. ${ }^{129}$ This perception of self-inflated greatness over the rest of the world was at direct odds with Western liberalism. This was exacerbated through the moratorium placed on the Falkland/Malvinas Islands by the Islanders' themselves. This pitted self-determination against historical claims, which Argentina fought to secure. The milestone of 150 years was much more important to the Argentines than the British. ${ }^{130}$

\section{Domestic Political Change}

Domestic political change is one of the catalysts for escalating crisis between dyads. The shift from Peronism to military junta was a shock to the status quo relations between Argentina and Great Britain. While a series of junta leaders had proclaimed Falkland/Malvinas sovereignty as an issue, but it wasn't until the Galtieri junta that demonstrable action was taken. Since neither side was interested in a compromise over the Islands, Argentina took drastic action in response to this ontological threat. This section is dedicated to explaining the events that led to the crisis, as well as the motivating factors behind Argentine military action.

\footnotetext{
${ }^{127}$ Frank Graziano, Divine Violence: Spectacle, Psychosexuality, and Radical Christianity in the Argentine "Dirty War," (Boulder, CO: Westview: 1992), 122.

${ }^{128}$ Femenia, National identity in times of crises, 99.

${ }^{129}$ Joseph S. Tulchin, "Continuity and Change in Argentine Foreign Policy", in Latin American Nations in World Politics, 2nd ed., eds. Heraldo Muñoz and Joseph S. Tulchin (Boulder: Westview Press, 1996).

${ }^{130}$ Alexander Haig, Caveat: Realism, Reagan, and foreign policy (MacMillan Publishing Company, 1984), 262.
} 
This issue was benign until the military junta overthrew the Peron regime in 1976, establishing Lieutenant General Jorge Rafael Videla as the first of three presidents under the junta. The commander of the navy, Admiral Emilio Massera, originally posited the idea of reclaiming the Falkland/Malvinas Islands. ${ }^{131}$ This was couched in the strategic benefits it would provide, including control over the shipping routes around Cape Horn. One of the subordinates under Massera, Jorge Anaya, was obsessed over the recapture of the islands. ${ }^{132}$ In his view, the recapture of the Falklands/Malvinas was essential for the economic and political future of Argentina. ${ }^{133}$ It is no surprise that Anaya found an ally in Galtieri, who had his own political ambitions to become president. The plan came to fruition on December 22, 1981, when the Admiral Jorge Anaya and Brigadier General Lami Dozo forced the resignation of President Roberto Viola.

While the Argentine junta was using the Islands as a means of achieving their own goals, the British claim was based on self-determination of the Islanders. British officials were not inherently against transferring sovereignty to Argentina, but faced great pressure from Falklands/Malvinas lobbying groups. ${ }^{134}$ The root of the problem in this case was selfdetermination of the inhabitants of the island. Britain had maintained that they were protecting the interests of citizens, who through self-determination, wanted to remain with Britain. ${ }^{135}$ Even though the original inhabitants on the island were British immigrants, after 130 years of British rule, the modern inhabitants wanted to continue to remain British. They were afforded British citizenship, and identified more closely with British culture than Argentine. ${ }^{136}$ Those born on the

\footnotetext{
${ }_{131}$ Oscar Raúl Cardoso et al., Falklands: The Secret Plot, trans. Bernard Ethell (Preston Editions, 1987), 4.

${ }^{132}$ Steven G. Stransky, "Re-examining the Falkland Islands War: The Necessity for Multi-Level Deterrence in Preventing Wars of Aggression," Georgia Journal of International \& Comparative Law 473, (2011-2012): 484-5.

${ }^{133}$ Paul Eddy et al., War In The Falklands: The Full Story (Time Warner Paperbacks, 1982), 28.

${ }^{134}$ Jorge O. Laucirica, "Lessons from Failure: The Falklands/Malvinas Conflict," Seton Hall J. Dipl. \& Int'l Rel. 1 (2000): 82

${ }^{135}$ Freedman, The official history of the Falklands, 21.

${ }^{136}$ Ibid.
} 
islands were extended the opportunity of self-determination, which complicated matters for the U.N. If the islanders had felt oppressed by the British, it would have been easier to intervene in the conflict. As a result, the U.N. made overtures towards a transfer of sovereignty with Great Britain spearheading the change, but refused to directly intervene. ${ }^{137}$

Bi-lateral negotiations between Argentina and Great Britain were largely ineffective. Beginning in 1971, the governments publicly committed to reaching an amicable settlement over the Islands. ${ }^{138}$ For the next 8 years, no substantial progress was made on the issue of Falkland/Malvinas sovereignty. In 1980, efforts were made by Great Britain to resolve the issue by giving the Islanders' Legislative Council several options for proceeding with Argentina. These options included the a 25-year moratorium on the dispute, a lease-back arrangement in which Argentina would be sovereign owners and lease the islands to Britain and a joint administration of the islands by both Argentina and Great Britain. ${ }^{139}$ The Falklands Legislative Council opted for the moratorium on the dispute, which was presented to the Argentines. This was unacceptable to Argentina, who only became more hardline in further negotiations, demanding full Argentine sovereignty over the islands. When they failed to achieve a favorable outcome, it became apparent that they would resort to other means of achieving their goals.

\section{Ontological Threat}

The Galtieri junta had no intention of backing down over the issue of Falkland/Malvinas sovereignty. In addition to making territorial gains, the military junta operated from the perspective of a British ontological threat. This attitude towards Great Britain and the West was exhibited in negotiations over the Islands, in which the bargaining range was extremely limited

\footnotetext{
${ }^{137}$ Lowell S. Gustafson, The Sovereignty Dispute over the Falkland (Malvinas) Islands (US: Oxford University Press, 1988), 81-2.

${ }^{138}$ Keesing's Contemporary Archives 24, 968 (Dec. 4-11, 1971).

${ }^{139}$ W. Michael Reisman, “The struggle for the Falklands," The Yale Law Journal 93, no. 2 (1983): 310.
} 
because neither party wanted to make concessions on the issue of sovereignty. While bi-lateral negotiations persisted for over a decade, few compromises were actually agreed upon. The British held the leverage in negotiations, as there was no legal challenge to their Falklands sovereignty. Year after year of negotiations were perceived by the British as biding their time, as they had no intention of actually resolving any issues surrounding sovereignty. ${ }^{140}$ This position of non-action was reaffirmed when they allowed the Islanders to vote on the future of their sovereignty.

On the other side, the Argentine belief was that the Islands were rightful territories, and emboldened by the U.N. Resolutions, expected Britain to accommodate this request. Argentina had established a hardline position over the islands, in which they would accept no less than full sovereignty. By March 2, 1981, they withdrew from bi-lateral negotiations because it became clear that this would not be achieved, opting for other means. ${ }^{141}$ Prior to the invasion of the Falkland/Malvinas Islands, the Argentines conducted maneuvers at South Georgia Island, which served as a test of British response. It should have been readily apparent from the concerns regarding British reinforcements that a response to invasion was inevitable, yet they ignored these signals and proceeded with the Falkland/Malvinas invasion a week later.

After nearly 150 years of contestation over the Falkland/Malvinas Islands, the die was cast on March 19, 1982. Argentine had transported at least 50 Argentina Marines, who posed as civilian scrap metal salvagers, aboard the Bahia Buen Suceso to South Georgia Island, which was located nearly 1,000 miles to the east of the Falkland Islands. ${ }^{142}$ They occupied an abandoned outpost at Leith Harbor and raised the Argentina flag. ${ }^{143}$ The following day, when this action was

\footnotetext{
${ }^{140}$ Richard Ned Lebow, "Miscalculation in the South Atlantic: The Origins of the Falklands War," in Psychology and Deterrence, ed. Robert Jervis (Johns Hopkins University Press, 1985), 106.

${ }^{141}$ Ibid., 108.

142 Nick van der Bijl, Nine Battles to Stanley (London: Leo Cooper, 1999), 8.

${ }^{143}$ Franks Report Para 169.
} 
communicated to Sir Rex Masterman Hunt, the Governor of the Falkland/Malvinas Islands, he communicated with Captain Briatore of the Bahia Buen Suceso, demanding that forces be withdrawn from the island. ${ }^{144}$ While the ship departed with some men on the evening of March 22, a garrison was left behind. ${ }^{145}$ The following morning, March 23, British officials concluded that the Argentine government was behind the actions at South Georgia, and posited that the Falklands/Malvinas Islands might be their next target. ${ }^{146}$

Upon hearing of these maneuvers, British forces numbering 22 Royal Marines were immediately dispatched aboard the HMS Endurance from the Falklands/Malvinas. ${ }^{147}$ They were positioned off the coast awaiting a diplomatic response prior to engaging. In order to attempt a diplomatic resolution, Lord Carrington sent an ultimatum to Costa Mendez, the Foreign Minister of Argentina, which demanded that Argentine personnel be removed from South Georgia or else the HMS Endurance would be dispatched. ${ }^{148}$ The junta had becoming entrenched in their position, which was exacerbated by the British ultimatum to retreat. This was communicated to British officials, who signaled that they would take action to forcibly remove the Argentine forces from South Georgia.

On March 23, a meeting was held with members of the Argentine junta. The junta agreed that additional forces should be deployed on the Bahia Paraiso in order to reinforce the garrison at Leith. ${ }^{149}$ On March 24, the ARA Bahia Paraiso arrived with additional reinforcements along with Lieutenant Alfredo Astiz. The HMS Endurance maintained a distant profile, in order to avoid capture, but on March 27 a scouting team was sent to investigate the Argentine activity. The $H M S$

\footnotetext{
${ }^{144}$ Lawrence Freedman and Virginia Gamba-Stonehouse, Signals of War: The Falklands Conflict of 1982 (Princeton University Press, 1991), 56.

${ }^{145}$ Her Majesty's Stationary Office, Falkland Islands Review (1983), para. 170.

${ }^{146}$ Freedman and Virginia Gamba-Stonehouse, Signals of War, 58-59.

${ }^{147}$ Her Majesty's Stationary Office, Falkland Islands Review (1983), para. 176.

${ }^{148}$ Her Majesty's Stationary Office, Falkland Islands Review (1983), para. 184.

${ }^{149}$ Freedman and Gamba-Stonehouse, Signals of War, 64.
} 
Endurance opted to maintain distance and bide their time, in order to avoid a direct confrontation with Argentine Marines. ${ }^{150}$ Argentine officials interpreted the lack of response from the British as a signal that they were awaiting reinforcements.

It was at this point that Argentine officials realized that the British government would respond to the military action. They had gathered intelligence that indicated several additional ships would be dispatched to reclaim the South Georgia Island. This included two supply ships, the RRS John Biscoe and RRS Bransfield, that were active in the Antarctic region. ${ }^{151}$ In addition, reinforcements from other areas, including the HMS Exeter from Belize, along with the Royal Navy destroyers and HMS Spartan from Gibraltar, Fort Austin and nuclear submarines and HMS Splendid were dispatched. ${ }^{152}$ This was noted by CIA cables, which declared that "the Argentine military almost certainly anticipates a British military response to the invasion and probably will soon begin re-provisioning and reinforcing their forces on the islands before any British warships arrive." 153 If their fears were confirmed, the British reinforcements would be formidable enough to thwart their plans.

In terms of available forces for operations, Argentina was at great disadvantage in the quality of all forces, with the exception of aircraft. Argentina had access to more fixed wing aircraft, totaling 216 compared to the British total of 55. ${ }^{154}$ While Argentina had strength in numbers, the British Harriers had a technological advantage being equipped with advanced Sidewinder missiles. This helped to offset facing greater numbers with superior air-to-air capability. In terms of Naval capability, British forces were more numerical and more

\footnotetext{
${ }^{150}$ Her Majesty's Stationary Office, Falkland Islands Review (1983), para. 201. 203, 210.

${ }^{151}$ Roger Perkins, Operation Paraquat: The Battle for South Georgia (Chippenham: Picton Publishing, 1986), 52.

${ }^{152}$ Freedman and Gamba-Stonehouse, Signals of War, 75-77.

${ }^{153}$ US Central Intelligence Agency, Falkland Islands Situation Report \#1., 4.

${ }^{154}$ John Arquilla and Maria Moyano Rasmussen, "The Origins of the South Atlantic War," Journal of Latin American Studies 33 (2001), 755.
} 
technologically superior to their Argentine counterparts. The Argentine navy was composed of a variety of pre-WWII (General Belgrano and Veinticinco de Mayo) and modern ships (i.e. Destroyers Santisima Trinidad and Hercules). ${ }^{155}$ The British Royal Navy forces that were committed to the Falklands operations were formidable. They deployed nearly 90 total vessels, 60 of which were support vessels. Of the remaining 30, it included two aircraft carriers (HMS Hermes and HMS Invincible), eleven frigates, five nuclear-powered submarines, and eight amphibious landing craft.

There was also great disparity in the experience of the ground forces. While Argentina had the advantage of being dug-in and defending a fixed position, British forces were expertly trained and equipped for the operation. The British warfare tradition gave them a distinct advantage over their enemies, which was no secret to Argentine commanders. Researchers have noted that "with few exceptions, the Argentine Army did not train its men or prepare them for the battle ahead."156

The international community, including the United States, began to take note of the situation brewing in the South Atlantic. CIA intelligence of the impending Falkland/Malvinas invasion prompted President Reagan to personally contact President Galtieri on April 1, warning him of a guaranteed British military response to invasion. ${ }^{157}$ The warning signs were present, with the British and United States signaling to the regime that there would be a military response to invasion. Even with this information prior to invading the Falkland/Malvinas, the junta opted to press forward with their plans.

\footnotetext{
${ }^{155}$ Sandy Woodward and Patrick Robinson, One hundred days: the memoirs of the Falklands Battle Group Commander (Naval Institute Press, 1997), 74.

${ }^{156}$ Nora K. Stewart, Mates and Muchachos: Unit Cohesion in the Falklands-Malvinas War, (Potomac Books Incorporated, 1991), 60.

157 "If the only option is a military invasion, I assure you, Mr. President, that the British will respond militarily...Ms. Thatcher is a decisive woman and she will have no choice but to fight back." (Gary W. Wynia Argentina: Illusions and Realities (New York: Holmes \& Meier, 1986), 15.
} 
The first amphibious forces were landed by the ARA Santisima Trinidad south of Stanley in conjunction with additional forces landed by the ARA Cabo San Antonio near the Stanley airport. On the morning of April 2, 1982, Argentine special forces attacked the Moody Brook barracks and Yorke Bay, followed by a final engagement at Government House. Argentine forces quickly overwhelmed the meager garrison and forced Governor Hunt to surrender the islands. As the Argentines had anticipated, British reinforcements had already been dispatched prior to the invasion, including the nuclear submarines HMS Spartan, HMS Splendid, HMS Superb and Royal Fleet Auxiliary Fort Austin. ${ }^{158}$ On April 5, the British government committed to a coordinated liberation of the Islands, directing forced towards Ascension Island, which was an RAF base located off the coast of Brazil. Within 74 days, Argentine forces were bested by the well-trained, technologically superior forces of the Crown. On June 14, 1982, they surrendered the Islands back to Great Britain.

\section{Summary}

Unlike the appeal for mediation over the Beagle Channel, the Galtieri junta had no intentions of mediation or arbitration, which is surprising given their support from the U.N. The reason mediation was not an option was because no neutral third-party was interested in mediating the dispute. In previous cases, Great Britain was utilized by Argentina as a neutral arbiter, which was notable in several boundary disputes with Chile (codified in the Treaty of 1902). Given their stake in the settlement, Great Britain could not serve in this capacity over the Falkland/Malvinas Islands. For Argentina, the British had greater influence over western NATO states, which would lead to biased arbitration. This included the United States, who intervened after the Falklands invasion, prior to the British response.

\footnotetext{
${ }^{158}$ On March 29, Prime Minister Thatcher and Lord Carrington decided to dispatch additional reinforcements to the region (Her Majesty's Stationary Office, Falkland Islands Review (1983), para. 213.)
} 
The United States had a vested interest in de-escalating the conflict, as an NATO ally to Great Britain and partner with Argentina against Nicaragua. The chief mediator, U.S. Secretary of State Alexander Haig, was not respected or trusted by Argentine or British officials. ${ }^{159}$ The Argentines had feared that Haig was not a truly neutral arbiter, which was confirmed by several incidents that portrayed him on the side of the British. ${ }^{160}$ In the event that mediation was facilitated by another third party without vested interests in the result, it is doubtful whether the outcome would have been viewed as legitimate by both parties. Papal mediation was successful in deescalating conflicts between Chile and Argentina because of the multiple ontological linkages, which included cultural and religious linkages which were not shared with Great Britain, in particular because they were not Catholic. ${ }^{161}$

Realists would note that Argentina must have believed they would be successful in their mission in order to undertake it, because of the potential negative domestic and international consequences. That was not the case within Argentina, as several divisions existed between the Navy and Air Force/Army. The choice to invade the Falklands appears to be less motivated by the likelihood of success and more by the projection of power against Western Liberalism. Argentine leaders perceived western democracy to be too decadent and weak; the invasion of the Falklands was to demonstrate the superior rule of the junta. ${ }^{162}$ The outcome of the conflict seemed less important to Argentine leadership than sending a message to the West. It is no surprise that Western states in the EEC and NATO (despite their own self-interest), supported Great Britain in their military response.

\footnotetext{
159 D. George Boyce, The Falklands War (Palgrave Macmilan, 2005), 81.

160 This included a Nightline story as well as Haig himself revealing British plans to the Argentines (Haig, Caveat: Realism, Reagan, and Foreign Policy, 266, 270.

${ }^{161}$ Cussen, "'Tordesillas' - or how soft power works sometimes," xxx.

${ }^{162}$ Haig, Caveat: Realism, Reagan, and Foreign Policy, 266-7
} 
The 140 years of British occupation of the Falkland/Malvinas Islands strained the relationship between themselves and Argentina. Argentine officials protested to the U.N., which passed several unanimous resolutions which affirmed Argentine historical sovereignty over the Islands. The difficulty for Argentina was actualizing these claims, because the U.N. did not want to directly intervene. Taking matters into their own hands, the junta had directly negotiated with Great Britain, with the expectation of securing their intended goals. Once putting the matter to a vote, which placed a moratorium on the issue of sovereignty, it became clear that Argentina would be forced to achieve their goals in a different way. If there were any doubts that Britain would muster these available forces for a counterattack on the Falkland/Malvinas Islands, it should have been dispelled after the events at South Georgia. The swift response of the Crown should have indicated the commitment of Britain to these islands. ${ }^{163}$ Furthermore, the capture of their only warship and garrison in the region during operations at South Georgia necessitated additional reinforcements be sent from home.

\section{Conclusion}

The Argentine junta exhibited much different behavior towards Chile and Great Britain during their respective crises. The Argentine crises with Great Britain and Chile were extremely similar in their characteristics, insofar as they surrounded historical territorial rights. The previous historical narratives describe the events that led to the vastly different outcomes in papal mediation and military intervention. This analysis section is dedicated to challenging the conventional logic that equivocated Argentine belligerence with diversionary theory. Through the application of my theory to these cases, ideological differences and similarities of the dyads better explains the junta's behavior.

\footnotetext{
${ }^{163}$ Bruce W. Watson and Peter M. Dunn, Military Lessons of the Falkland Islands War (Boulder: Westview Press, 1984), 135-139.
} 
Domestically, the Argentine junta strived for regional hegemony and international legitimacy during both the Videla and Galtieri regimes. The common explanation for the regimes' aggressive behavior is diversionary theory. ${ }^{164}$ The Falkland/Malvinas War has been interpreted as diversionary, for the purpose of increasing domestic support for the regime. ${ }^{165}$ This scholarship contends that President Galtieri inherited a collapsing economy and domestic unrest. ${ }^{166}$ After incurring a no-decision over the Beagle Channel, the Galtieri junta yearned for a symbolic win that would legitimize their regime. Nearly a week after new junta was established, plans were being laid to retake the islands between Galtieri, Anaya and Dozo. ${ }^{167}$ Each member of the junta had their own personal rationale for undertaking this mission, "President Galtieri believed that a successful invasion of the Falklands would help solidify his control of the government and the country; Admiral Anaya thought a military victory in the Falklands would be a sort of vindication for the years he spent planning for the war; and Brigadier General Lami Dozo viewed the war as a prerequisite for the maintenance of the Junta's power structure." ${ }^{168}$ Of the three members of the junta, Lami Dozo was the most reluctant to the mission, but agreed because he felt that it could salvage the legitimacy and reputation of the regime. Upon invading the Falklands, Argentinians poured into the streets, expressing their support for the regime. This post hoc support for the regime after challenging Great Britain over the Falkland/Malvinas Islands has been used as evidence as their actions being diversionary. However, this logic of explaining Argentine action through divisionary theory suffers from two problems. First, none of the Argentine juntas were

\footnotetext{
${ }^{164}$ See Wright (1965), Haas and Whiting (1956) and Mayer (1967).

165 Jack Levy and Lily I. Vakili, "Diversionary Action by Authoritarian Regimes: Argentina in the

Falklands/Malvinas Case," in The Internationalization of Communal Strife, ed. Manus I. Midlarsky (New York:

Routledge, 1992), 134-5.

${ }^{166}$ Amy Oakes, Diversionary war: Domestic unrest and international conflict, (Stanford University Press, 2012), 78-9.

${ }^{167}$ Cardoso et al., Falklands: The Secret Plot, 26.

${ }^{168}$ Stransky, "Re-examining the Falkland Islands War: The Necessity for Multi-Level Deterrence in Preventing Wars of Aggression," 487.
} 
concerned with or affected by popular support. Secondly, the domestic problems facing the Galtieri junta were the same problems facing the Videla junta, yet the Videla regime actively sought mediation.

The Argentine junta never relied upon public support for their rule; The Dirty War against political opponents created a system of self-repression. The junta used fear and repression in order to carry out their policies, rather than relying on key stakeholders within civil society. As John Arquilla and María Rasmussen argue, "after 1976, military juntas could afford to govern without being liked."169 This led to, "no formal political opposition to the regime, and there were no organized groups that systematically subjected the actions of the government to public discussion and whose criticism represented a factor that the government had to take into account."170 While it should be noted that popular support favored the action in the Falklands, there is no evidence that the purpose of the invasion was to act as a diversion for domestic policy failure.

Another misnomer of interpreting the junta's actions as diversionary is that many of the domestic problems that existed during the Galtieri regime were also problems facing the Videla regime. While diversionary theory provides a justification for the use of force in the Falklands, it does not explain the lack of military action over the Beagle Channel. The military take-over in 1976 coincided with failed austerity measures that crippled the Argentine economy. As a result, the junta managed to secure the support of both wealthy elites and middle classes, who perceived the junta as a means of restoring prosperity to Argentina. ${ }^{171}$ "The Process", Process for National Reorganization, "became known as a combination of economic liberalism and repression"172

\footnotetext{
169 John Arquilla and Maria Moyano Rasmussen, “The Origins of the South Atlantic War," Journal of Latin American Studies, no. 4 (November 2001): 747.

170 Tulchin, "Authoritarian Regimes and Foreign Policy: The Case of Argentina," 189.

${ }^{171}$ Daniel K. Gibran, The Falklands War: Britain Versus the Past in the South Atlantic (McFarland, 1998), 59-60.

172 Oakes, Diversionary war: Domestic unrest and international conflict, 75.
} 
Under Videla, economic emphasis was placed on creating an export-based economy and stimulating foreign investment into the economy. ${ }^{173}$ These economic and political changes did not have the anticipated effects on creating stability. The late 1970 s had created much domestic unrest, in part because of the failed economic policies and the Dirty War against political opponents. From 1977 to 1979 , organized labor had become more emboldened, resulting in a strike of nearly $30 \%$ of all Argentine workers. ${ }^{174}$ Under diversionary theory, Videla should have been motivated to invade the Beagle Islands in order to consolidate support for the regime and distract from internal economic woes.

The boundary disputes involving the Argentine junta over the Falkland/Malvinas Islands and Beagle Channel share many common themes. In both cases, Argentine leadership was motivated to reclaim territory that was unjustly occupied by another state. The junta, who had visions of exerting military dominance in the region, seized on these historical claims in order to justify military action. The primary difference between these cases was the other state involved, Chile and Great Britain. Argentina would have benefitted from going to war with either of these states, but opted to actively seek mediation with Chile. Even with an alliance with Peru and military superiority, the Videla junta sought a peaceful resolution of the conflict, even with the outcome of mediation in doubt. On the other hand, the Galtieri junta did not pursue any forms of mediation, and even after U.S. intervention, had no intention of backing down against a superior opponent. This seemed to be motivated by fervent nationalism, a feeling of moral superiority towards western idealism and resentment towards western powers. The shared identity with Chile was a deterrent from going to war, the lack of these linkages solidified the decision to engage Great Britain.

\footnotetext{
${ }^{173}$ Martin Honeywell and Jenny Pearce, Falklands/Malvinas; whose crisis? (Latin American Bureau, 1982 ), 69.

${ }^{174}$ Gibran, The Falklands War: Britain Versus the Past in the South Atlantic, 62.
} 


\section{Chapter 6: Iraqi Crisis Management (1975-1988)}

Iraq was governed from 1968 to 2003 under the Baathist regime of Hassan al-Bakr and Saddam Hussein. Iraq faced two major crises during their first decade in power, against Syria and Iran. These crises shared many characteristics, including being centered on territorial rights and ideological legitimacy. While these conflicts had much in common, the decision-making of the Baathist regime could not have been more different. During the crisis of Baathist legitimacy against Syria, Iraqi forces were mobilized along the border with no further provocation. On the other hand, during the Iran-Iraq War, tactics of total warfare were practiced - including civilian targeting and the use of chemical weapons. The intriguing puzzle of these conflicts is understanding the restrained behavior towards Syria, even after they threatened their Baathist legitimacy and Euphrates water rights. Alternatively, why was Iraq so threatened by Iran that they were willing to use chemical weapons and targets civilians (in violation of international protocols) in order to exert dominance?

Upon the dissolution of the Ottoman Empire, many of the newly created states were left with a leadership void, resulting in decades of political upheaval. Political factions rushed to fill the void, only to be replaced by other factions through peaceful (and bloody) transfers of power. Since becoming completely independent in 1946 and 1958, Syria and Iraq experienced multiple regime changes. The Baathist ideology was one such faction that made inroads throughout the newly created Ottoman states, in particular Iraq and Syria. By the early 1970s, stability was achieved in both states under Baathist leadership. While one might have expected these likeminded regimes to cooperate, even achieving the Baathist principal of Arab unity (such as the UAR), the opposite actually occurred. Iraq and Syria embarked on a decades-long rivalry for Baathist legitimacy, which nearly led to war in 1976. However, it was only through these shared 
ideological linkages that Iraq showed restraint, and subsequent mediation to de-escalate by mutually-respected Egypt.

During the same period of Baathist rule in Iraq, a dangerous situation was also brewing with Iran over the Shatt al-Arab waterway and Kurdish separatism. The Iranian revolution and subsequent propaganda campaign against Iraq was the catalyst for military action. Under the guise of Arab liberation and water rights, Iraq invaded Iran on September 22, 1980. The Iraq-Iran War was the longest conflict of the twentieth century, spanning nearly eight years. The total number of military and civilian deaths enumerated to over one million, with tens of millions of dollars in damage to infrastructure. Furthermore, this conflict featured two unique tactics not unleashed since World War I: the use of chemical weapons and the intentional targeting of civilians. Iraqi decision-making to use chemical weapons and targeting civilian populations was the result of historical Arab-Persian tensions. When the conflict is examined through the guise of these ontological differences, it provides a deeper understanding on the decision to go to war and tactics deployed.

The main purpose of these case studies is twofold: First, to develop a framework for interpreting the Iraqi decision to go to war with an ontologically different opponent (Iran) and only threaten force against an ontologically-similar Baathist regime (Syria). The situation between Iraq-Iran and Iraq-Syria were extremely similar; Both cases featured decades of hostility over territorial rights and the struggle for regional hegemony, but differed vastly in their outcomes. In the end, Iraq was able to communicate effectively with Syria, because of shared Baathist ideology, in order to resolve their differences. Alternatively, Iraq acted belligerently towards an Iranian ontological threat of Islamic Fundamentalism that directly challenged the legitimacy and existence of the Baathist ideology. The second goal of this case study is to better understand Iraqi decision- 
making during the conflict with Iran. Even prior to the stalemate between states in 1984, Iraq had committed to the development and deployment of chemical weapons. The war of the cities was also a calculated action by the Iraqi regime to target 'Persian' civilian areas during the third phase of the conflict, which only reinforced the historical and ideological differences. The decisionmaking of the Iraqi regime leading up to and during the conflict with Iran elucidates the ArabPersian dichotomy that fueled the ontological threat.

Table 6-1 provides an overview of the important variables related to these cases. It includes three sets of variables, the predominant religious values of the state, the virtues of civil religion and institutions at the time of crises. The culture of Iraq and Syria has been self-described as Arab, which is a squishy, loosely defined ethnic identification. The Arab identity is tied to shared linguistic and historical experience. This can be compared to Iran, who identifies as Persian and Islamic in culture, with a completely different set of underlying beliefs. ${ }^{1}$

While Iran (Sunni), Iraq (mixed) and Syria (Shia) are all predominately Islamic states, the beliefs and implications of their respective beliefs vary dramatically. ${ }^{2}$ The differences between Shia and Sunni denominations of Islam stem from the disagreement over the line of succession after the Prophet Muhammad. Sunnis believe that Abu Makr - the father of Muhammad's wife was the rightful heir based on the Quran which dictates that leaders are elected by the Muslim community. Alternatively, Shias believe that Muhammad appointed a successor prior to his death, his cousin Ali Ibn Abi Talib, which would make the caliph a generational birthright. The divide over the line of succession was only one difference between Sunnis and Shias. Sunni Islam is more textual, with clerics deferring to a textual interpretation of the Quran. Alternatively, Shia

\footnotetext{
${ }^{1}$ Sandra Mackey, The Iranians: Persia, Islam, and the soul of a nation (Plume, 1998), 13-39.

${ }^{2}$ Iran is over $90 \%$ Shia; Iraq is $50 \%$ Shia and Syria is $>20 \%$ Shia.
} 
Islam is more decentralized, with individual Imams wielding the power to interpret the Quran as they see fit.

The way in which each state has actualized their religious doctrine in their respective civil religion varies on a case-by-case basis. The leadership of newly-independent Syria and Iraq were dominated by Sunni-majority factions until recently. However, Islam was never a governing principle for any of the Iraqi or Syrian regimes which were secular in nature. These regimes were organized around the civil religion of Arab nationalism, forging an identity from ethnic similarities rather than religious identity. ${ }^{3}$ Once overthrowing the British-supported Hashemite monarch, Arab nationalists took the form of Abd al-Karim Qasim (1958-1963), Abdul Salam Arif (1963-1968) Ahmed Hassan al-Bakr (1968-1979) and Saddam Hussein (1979-2003). Arab nationalism was also a persistent theme within Syria since achieving independence from the French Mandate. The mantra of Arab unity was introduced through the rise of the Baath Party in Iraq (1968-2003) and Syria (1963-present). ${ }^{4}$ The government that prescribed these beliefs took the form of a dictatorship. Through the use of emergency powers and manipulating vote counts, the Baathist regimes in Syria and Iraq operated outside of any codified rule of law. ${ }^{5}$

Iran has been organized around the principles of Shia Islam since the conversion under Ismail I. Beginning in 1600, Iran was transformed from a minority Shia state to the modern-day bastion of Shia Islam. ${ }^{6}$ Over the two-hundred-year process, Sunni (among other denominational) clerics were exiled or killed in order to establish a homogenous Shia state. This began a process by which Islamic fundamentalism was established as the civil religion in Iran. The most recent

\footnotetext{
${ }^{3}$ Bassam Tibi, Arab Nationalism, 3rd ed. (New York: St. Martin's Press, 1997), 150-155

${ }^{4}$ John F. Devlin, The Ba'th party: a history from the origins to 1966 (Hoover Institution Press, 1976), 1-4

${ }^{5}$ Raymond A. Hinnebusch, "State and civil society in Syria," Middle East Journal 47, no. 2 (1993): 243-257.

${ }^{6}$ Mehran Kamrava, The modern Middle East: a political history since the First World War (Berkeley: University of California Press, 2005), 28-32.
} 
transformation took place in the aftermath of the Iranian Revolution, which inaugurated the modern-day Islamic republic through popular referendum. This cemented the importance of Shia Islam on the Iranian identity. The official religion of Iran is expressed in the 1982 constitution as the Twelver Ja'fari school (Shia Islam). The regime can be characterized as a theocracy, with an unelected Supreme Leader and Guardian Council, who wield considerable political power. The democratic institutions, such as the President, Assembly of Experts, and Parliament require the approval or vetting of the Supreme Leader and/or Guardian Council.

Table 6-1: Overview of Variables

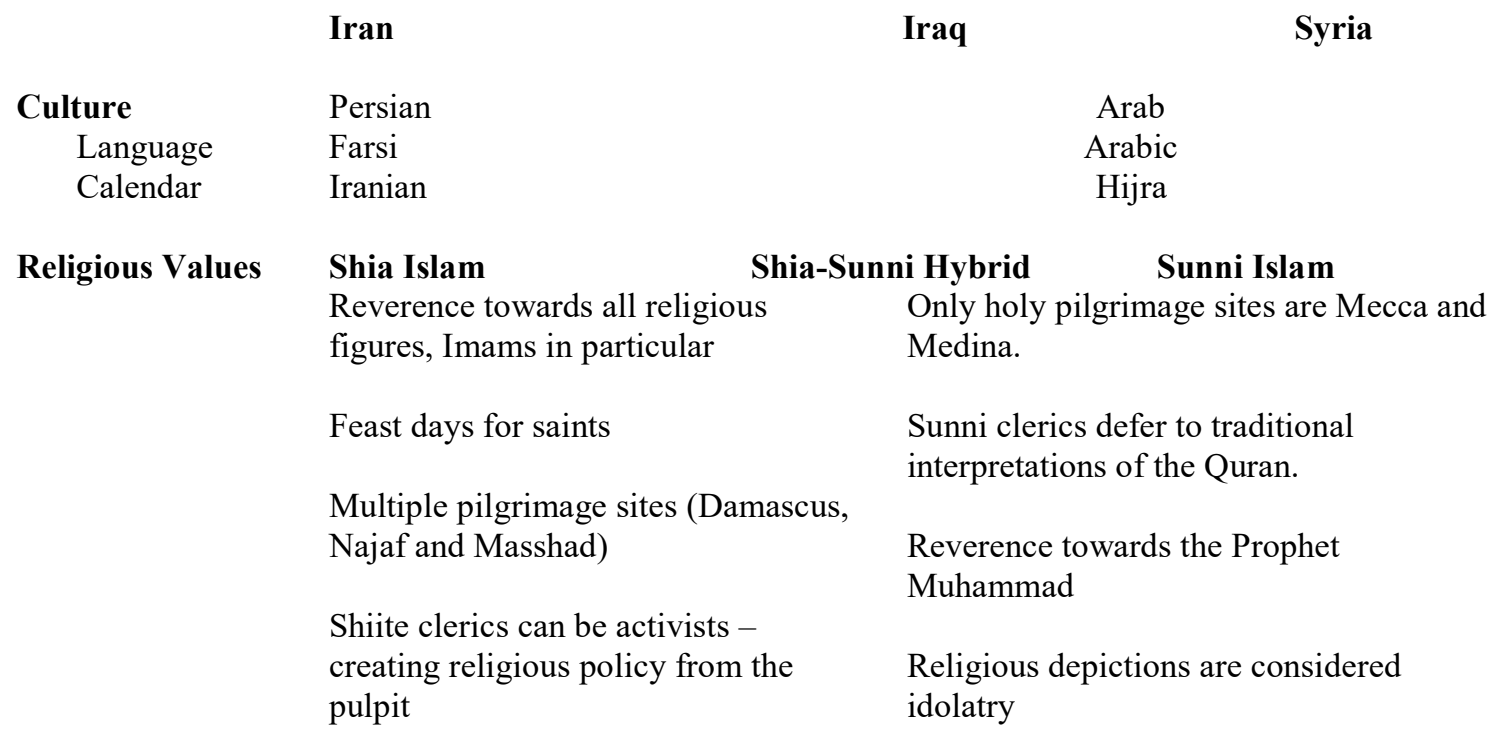

\section{Civil Religion}

Islamic Fundamentalism Group identity is defined by Islamic beliefs.

Theocratic rule - Islam as the primary ordering principle within society

Anti-western and anti-secular values which call for Jihad.

\author{
Arab Nationalism \\ Group identity is defined by having Arab \\ ethnicity \\ Unification of the Arab world, which was divided \\ by Western powers after WWI. \\ Self-determination and freedom from foreign \\ domination - regardless of orientation and source.
}




\section{Table 6-1: Overview of Variables (cont.)}

\section{Institutions}

\author{
Democratic Theocracy \\ Strong theocratic leadership in \\ the form of the Supreme \\ Leader, who is influential in \\ shaping policy. \\ Democratically elected \\ legislature (Islamic \\ Consultative Assembly) and \\ President.
}

\author{
Dictatorship \\ Strong secular leadership under military \\ dictatorship. \\ Elected legislature which served as a figurehead \\ under the dictator.
}

The case studies will be organized in the following fashion: First, the moral foundation of the civil religions will be discussed, including the historical and normative context of the dyads. The shared history of Iraq and Syria and historical division of Iraq and Iran played a large role in constituting their identities. Secondly, the tipping point of Iraqi relations soured shortly after regime changes in Iran and Syria. Relations between Syria and Iraq were tense after the disputes surrounding Euphrates water rights, the Agreement of Disengagement and the Lebanese Civil War. Relations between Iran and Iraq were pseudo-stable after the Algiers Agreement, but the Iranian revolution was the tinderbox that undermined all progress made. The third section is dedicated to the perception of these domestic changes, namely the ontological threat these changes posed to Iraq.

\section{Syrian-Iraq Crisis (1975-1976)}

The Syrian-Iraq Crisis was a dispute over territory and Baathist legitimacy between Syria and Iraq in 1975 and 1976. At the height of tensions in the summer of 1976, both sides mobilized and prepared for war, but the conflict de-escalated when Syrian President Hafez al-Assad signaled peaceful intentions. The crisis was officially resolved in the fall of 1976 with Egyptian mediation. The purpose of this case study is to analyze the Syrian-Iraq Crisis, which was the most escalated 
conflict between Syria and Iraq. I contend that the reason for restraint during this crisis was the result of shared cultural and historical beliefs, which facilitated de-escalation.

Syria and Iraq have many cultural and linguistic similarities, stemming from their shared historical experience under the Ottoman Empire. Once gaining independent statehood, both regimes struggled for Baathist supremacy in the region. The stable Baathist leadership of Iraq under Ahmed Hassan al-Bakr (1968-1979) and Syria under Hafez al-Assad (1971-2000) should have been the catalyst for Arab unification, but only resulted in soured relations. The rival Baathist regimes experienced a series of disputes over the Yom Kippur War, Euphrates water rights and the intervention in the Lebanese Civil War.

On multiple occasions during these events, Iraq and Syria mobilized troops along the border and engaged in border skirmishes. However, it was not until June 8, 1976 that Iraq appeared poised to invade a vulnerable Syria when they mobilized along the Syrian border. Unlike previous mobilization and skirmishes, Syrian officials were legitimately concerned about an Iraqi invasion of the Karatshuk oilfields. Syrian officials were so troubled with the Iraqi threat that they reallocated troops stationed in the Golan Heights to reinforce their eastern front with Iraq. In order to signal peaceful relations, Syrian President Assad went on a European vacation, which quelled tensions temporarily. It was not until the Egyptian-brokered mediation in the fall 1976 that troops were fully demobilized along the border. Even though relations between Iraq and Syria were tense, the situation was defused prior to escalating to war.

When this crisis is examined through the lens of realism, Iraq's decision to practice restraint is difficult to understand. Iraq had a golden opportunity to establish their ideological supremacy over Syria, who was weakened from the Yom Kippur War with Israel and was currently engaged militarily in the Lebanese Civil War. I contend that the reason for restrained behavior was because 
Iraq did not perceive Syria as an ontological threat. This crisis is imbedded in a larger geopolitical context in the middle east, which was experiencing a crisis of identity among independent states that were previously part of the Ottoman Empire. Syria and Iraq had a similar historical experience under the Ottoman rule as well as shared cultural norms. This facilitated communication between these states, which included signaling of a peaceful resolution that was understood by Iraqi officials.

\section{Civil Religion}

The civil religion, or the secular national beliefs, dogmas and rituals, of Syria and Iraq have been influenced by their shared historical experience under the Ottoman Empire. The resulting cultural and historical beliefs favored secular leadership, nationalism and Arab unity. These beliefs were actualized in the regimes that followed independence, whether socialist, military or Baathist in nature. A common theme among these regimes was self-determination of the Arab people, striving for a re-creation of the greatness under the Ottoman Empire. This section will develop these concepts further, explaining how historical conditions shaped shared cultural norms in Iraq and Syria.

\section{Historical Context}

The modern-day territory of Iraq and Syria were part of a variety of empires throughout history. Most recently, Syrian territory (previously under the control of the Mamluk Empire) was conquered by the Ottoman Empire under Sultan Selim I in 1516. Iraq was ruled by the Persian Safavid Dynasty $(1508-1533 ; 1622-1638)$ until being incorporated into the Ottoman Empire as well. The modern day states of Iraq and Syria were both incorporated into the Ottoman Empire through the Treaty of Zuhab, signed on May 17, 1639. Iraq and Syria would remain part of the Ottoman Empire until the dissolution of the Empire following World War I. The Sykes-Picot 
Agreement, signed between France and Great Britain in May 1916, described the plan for re-allocating eastern Ottoman territory.

Figure 6-1: Sykes-Picot Map (1916) ${ }^{7}$

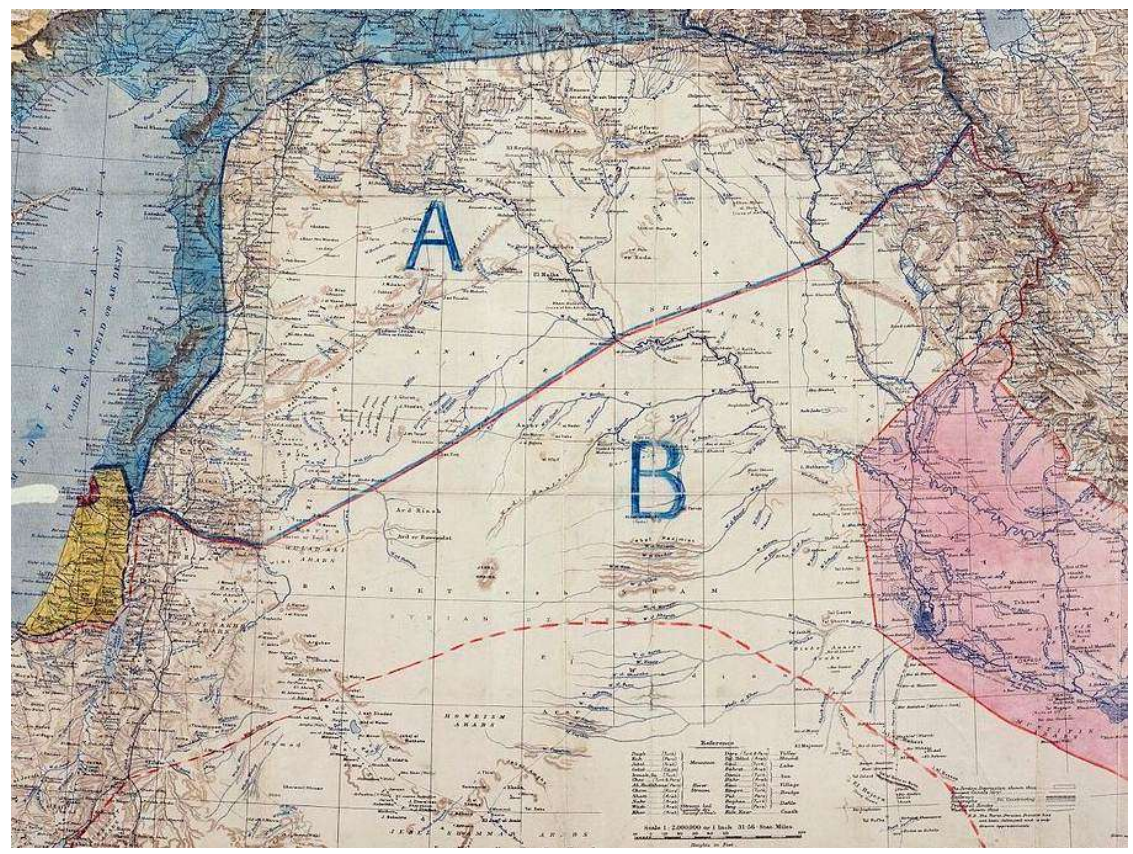

The Sykes-Picot Agreement granted France all blue territory denoted by the letter A and Great Britain was allocated all territory in red denoted by the letter B. The blue and red areas, respectively, "shall be allowed to establish such direct or indirect administration or control as they desire and as they may think fit to arrange with the Arab State or Confederation of Arab States." 8 The areas in brown were determined to be subjected to international administration. While this secret agreement between France and Great Britain was not legally binding, it provided the framework for the conference of San Remo (1920), which partitioned the territories of Syria and Mesopotamia (Iraq).

\footnotetext{
${ }^{7}$ Map of Eastern Turkey in Asia, Syria and Western Persia. The National Archives (United Kingdom), MPK1/426. 8 “Sykes-Picot Agreement," https://wwi.lib.byu.edu/index.php/Sykes-Picot_Agreement (accessed February 15, 2017)
} 
Syria and France began negotiations for an independent Syrian state in 1934. France outlined a 25-year plan for gradual independence, which would grant statehood to Syria while maintaining French interests in Syria. ${ }^{9}$ While this proposal was accepted by both parties, it failed to be ratified in French parliament prior to the outbreak of World War II. ${ }^{10}$ On September 27, 1941, General Catroux declared that Syria was granted full independence. This decision was solidified by the United Nations on October 24, 1945 when they officially recognized Syria as a founding member state. ${ }^{11}$ Iraq was officially granted independence as a result of the Treaty of Lausanne in 1923, but remained an extension of Great Britain until the Anglo-Iraq Treaty of 1930. ${ }^{12}$ While the British relinquished direct control over the area, they still maintained military forces until 1954. While there were early attempts made by King Faisal I of Iraq to reunify Syria and Iraq, which were created arbitrarily by World War I allied powers, the major powers fought to maintain the status quo. ${ }^{13}$ The divisions between Syria and Iraq only intensified over time, with three major events that negatively affected their foreign relations: The Agreement on Disengagement, Euphrates Water rights and The Lebanese Civil War.

\section{Normative Similarities}

The single most important linkage between Syria and Iraq is the normative approach of Arab nationalism. The concept of Arab nationalism was developed by Sati' al-Husri, who postulated that nationalism was not a voluntary association, but rather "a living organism which has developed organically through common language and history" ${ }^{14}$ This core assumption was appropriated by the respective leaders of Syria and Iraq and further developed by Baathism. The

\footnotetext{
${ }^{9}$ Philip Shukry Khoury, Syria and the French Mandate: The Politics of Arab Nationalism, 1930-1945 (Princeton University Press, 2014), 383-385.

${ }^{10}$ Ibid., 394.

${ }^{11}$ Kais Firro, Inventing Lebanon: Nationalism and the State under the Mandate (London: IB Tauris, 2002$), 187$.

12 “Anglo-Iraq Treaty of 1930," June 30, 1930, 132 LNTS 363.

${ }^{13}$ Nur Masalha, “Faisal's Pan-Arabism, 1921-33," Middle Eastern Studies 27, no. 4 (October 1991): 689-690.

${ }^{14}$ Bassam Tibi, Arab Nationalism, 3rd ed. (New York: St. Martin's Press, 1997), 152.
} 
founders of Baathism were Michel Aflaq, a Greek Orthodox Christian, Salah al-Din Bitar, a Sunni Muslim and Zaki Arsuzi, an Alawi Muslim. While each man had a unique background and experience, they were involved in a working group striving towards the development of a united Arab political organization. ${ }^{15}$ While this particular endeavor only lasted one meeting, they were in agreement on the issue of Arab Nationalism. More particularly, re-inventing Arabism without foreign influences that dominated the Middle East prior to World War I (Ottomans) and afterwards (Europeans). The Baath movement was officially founded in $1940 .{ }^{16}$ The name Baath (Resurrection) was first used in 1943 in a statement by Aflaq and Bitar. ${ }^{17}$ They filed official paperwork on July 10, 1945 to establish themselves as a political party. The first Party Congress was held on April 4, 1947 at the Luna Park Coffee House in Damascus. ${ }^{18}$ During this Congress, a Baath Party constitution was established which described the goals of the movement as "Arab unity, liberty and socialism." 19

Arab unity is the key tenet of Baathism, accentuated in the first article of the Baath Party Constitution: "The Arabs are a single nation, having a natural right to exist within a single state and to be free to realize all its potentialities." ${ }^{20}$ The ultimate goal of Aflaq was to unite Arab states that shared in Arab values. For Aflaq, being 'Arab' meant speaking Arabic, sharing a connection with the Arab people and living in Arab lands. ${ }^{21}$ During the nineteenth century, cultural Arabism was developed out of historical experience, European values and Ottoman reformism. For

\footnotetext{
${ }^{15}$ Devlin, The Ba'th party, 8.

${ }^{16}$ Michel Alfaq, "Thawriyat al-Wihdah al-Arabiyah," in Ma'rakat al-Masir al-Wahid (Beirut: Dar al-IIm li alMalayin, 1958), 18.

${ }^{17}$ Nidal al-Bath, Beirut (Beirut: Dar al-Taliah, 1963), vol 1, 28.

18 Devlin, The Ba'th party, 14.

${ }^{19}$ Leonard Binder, trans., "The Constitution of the Arab Resurrection Socialist Party," Middle East Journal 13 (Spring 1959): 196.

${ }^{20}$ Ibid.

${ }^{21}$ The region including the "Taurus mountains, the Zagros mountains, the Persian Gulf, the Arabian Sea, the mountains of Ethiopia, the Sahara desert, the Atlas range and the Mediterranean Sea." (Leonard Binder, trans., "The Constitution of the Arab Resurrection Socialist Party," Middle East Journal 13 (Spring 1959): 196-7.)
} 
Baathists, "The Arab nation is a cultural unit. All of the differences among its members are artificial accidents" 22 While acknowledging the historical greatness of Arab civilization, Arab scholars wanted to demonstrate the cultural compatibility with modern institutions. ${ }^{23}$ This resulted in a renaissance of the Arab language, which replaced the ornate structure practiced in Ottoman correspondence. ${ }^{24}$ The Arab state would be rooted in the unique historical experience that many middle eastern states shared. While this included an appeal to return to the traditional virtues of Islam, "Nationalism would take the place of Islam as the focus of belief for the Arabs." 25

Both Syria and Iraq enshrined these beliefs in the civic religion of their respective states, unifying under nationalist rather than religious tenets. Nationalist forces would come to power in the 1958 coup of the Hashemite Monarchy, with the pledge of Arab unity and secular rule. The 1958 Interim Constitution reflects these ideals, including an emphasis on rule of law ${ }^{26}$ and freedom of religion. ${ }^{27}$ It also explicitly regards the kingdom of Iraq as a partnership between Kurds and Arabs. On July 16, 1970, one year after Bakr assumed the Presidency, an amended constitution was drafted. In this particular iteration, government remained secular ${ }^{28}$ (albeit the powers of the executive branch were expanded) and Arabism was of a defining characteristic. ${ }^{29}$ In Syria, Assad also ushered a new era of secular rule in Syria, distancing himself from Islam. This included the 1973 constitution, which failed to include Islam as the official religion of the state. ${ }^{30}$

\footnotetext{
${ }^{22}$ Leonard Binder, trans., "The Constitution of the Arab Resurrection Socialist Party," Middle East Journal 13 (Spring 1959): 196.

${ }^{23}$ Youssef M. Choueiri, Arab Nationalism: A History (Oxford: Blackwell, 2016), 68.

${ }^{24}$ Ibid., 69.

${ }^{25}$ Devlin, The Ba'th party, 25.

26 "1958 Interim Constitution," Article 8; Article 9

(http://confinder.richmond.edu/admin/docs/1958_Interim_Constitution_English_.PDF)

27 "1958 Interim Constitution," Article 12

(http://confinder.richmond.edu/admin/docs/1958_Interim_Constitution_English_PDF)

28 "1958 Interim Constitution," Article 3; Article 5

29 "The New Interim Constitution," Article 5(b) (http://www.hrcr.org/hottopics/statute/scans/iraq1.pdf)

${ }^{30}$ Raymond Hinnebusch, Syria: Revolution from above (Routledge, 2004), 62.
} 
The second major theme of Baathist literature is liberation from foreign domination. In the wake of World War I, European powers had redrawn the borders of the Ottoman empire. By the end of World War II, European powers had occupied many of the Arab states. Baathists believed in returning the Arab homeland to the Arabs as, "they alone have the right to utilize its resources and its wealth, and to control its potentialities." 31 The third major theme of Baathist thought is socialism, which is defined as "limited to economic organization that aims to reconsider the distribution of wealth in the Arab fatherland and to lay out economic bases which would guarantee equality." ${ }^{\prime 2}$ This can be differentiated from communism, insofar as it over-exaggerates the importance of material forces and ignores the historical development of nationalism. ${ }^{33}$

A commonality of these regimes were the principles of secular leadership and Arabism. Beginning on July 14, 1958, Nationalist forces under Abd al-Karim Qasim had overthrown the Hashemite Monarchy, which was established under the British Mandate in 1921. While Qasim, the new Prime Minister of Iraq, did not espouse Baathist ideology, self-actualization was welcomed by the Baathists. ${ }^{34}$ This relationship of convenience was short-lived for several reasons, chief among them was his changed stance on Pan-Arabism and communist sympathy. ${ }^{35}$ Fragmentation between different elements within government, including Arif and Baathist forces, led to his overthrow in February 1963.

The Baathist regime first gained power in February 1963, with support from the middle and upper classes of society. ${ }^{36}$ In-fighting and political repression, especially towards communist sympathizers, led to the demise of the regime after nine months. After a brief stint in jail, Ahmed

\footnotetext{
${ }^{31}$ Leonard Binder, trans., "The Constitution of the Arab Resurrection Socialist Party," Middle East Journal 13 (Spring 1959): 196.

${ }^{32}$ Michel Aflaq, Fi Sabil al-Ba 'ath, ed., Sa'dun Hamadi (Beirut: Dar al-Taliy'a, 1959), 210.

${ }^{33}$ Ibid., 222.

${ }^{34}$ Devlin, The Ba'th party, 120.

${ }^{35}$ Ibid., 122-3.

${ }^{36}$ Ibid., 256.
} 
Hassan al-Bakr was elected as the Secretary General of the Regional Command. When the military government in Syria, under Hafiz al-Assad, purged Michel Aflaq (one of the prominent founders of Baathism) from government, al-Bakr reinstated him as party leader in Iraq. ${ }^{37}$ Ahmed Hassan Al-Bakr, who was elected as the Secretary General of the Regional Command, reunited the party and launched a bloodless coup on July 17, 1968. Saddam Hussein, who also participated in the coup, was named president on July 16, 1979.

\section{Domestic Political Change}

The Baath Party had made substantial gains in both Iraq and Syria, establishing Regional Branches in both Syria and Iraq. However, during the tenure of Michel Aflaq as Secretary General, the Baath Party was ousted from Syria in 1958. Younger leadership began to emerge within Syria and Iraq that guided the Baath party in a new direction. In the wake of the collapse of the United Arab Republic (between Syria and Egypt), regionalism became a point of emphasis by new Baathist leadership. ${ }^{38}$ This change was reflected in the Sixth National Congress, which prioritized the establishment of Baathist principles in Iraq and Syria with respect to their individual circumstances over the unity of Arab lands. ${ }^{39}$

The National Command of the Baath Party was severely undermined by the reestablishment of the Syrian Regional Branch in 1962. Notable leaders of the Syrian Regional Branch, including Yasin al-Hafiz and Jamal al-Atasi, radicalized the party towards the "Arab road to socialism'. The main point of contention was the traditional Baathist views towards private ownership of property. Syrian Baathists believed that socialism would be the best mechanism for serving the interests of the common people. ${ }^{40}$

\footnotetext{
${ }^{37}$ Sandra Mackey, The reckoning: Iraq and the legacy of Saddam Hussein (WW Norton \& Company, 2003), 211.

${ }^{38}$ Devlin, The Ba'th party, 220.

${ }^{39}$ Nidal al-Bath, Beirut (Beirut: Dar al-Taliah, 1963), vol. 4, 227.

${ }^{40}$ Devlin, The Ba'th party, 216.
} 
The ideological schism between regionalization/unity and socialist/capitalist factions within the Baath Party ultimately led to the split between Iraqi and Syrian Regional Branches. This was most evident in the 1966 Syrian coup detat, in which the government was purged of National Command elements and replaced by the Regional Command, led by Salah Jadid. This was followed by the "corrective movement" in 1970, launched by a military-dominated faction of Baathists, led by Hafez al-Assad. The purpose of this movement was "the advancement of which all resources and manpower [would be] mobilized [was to be] the liberation of the occupied territories". ${ }^{41}$ Assad reneged on the hardline socialist ideology of former leader Salah Jadid and opted to privatize the economy in order to generate economic growth within Syria. ${ }^{42}$

The 1968 Iraqi coup that re-established Baathist rule under al-Bakr and Hussein only intensified regionalism efforts by both parties. When the Assad government in Syria purged Michel Aflaq (one of the prominent founders of Baathism) from government, al-Bakr reinstated him as party leader in Iraq. ${ }^{43}$ Tensions were exacerbated along religious fault lines, with Alawi's finding an ally in Assad and Sunni's with al-Bitar and Hussein. ${ }^{44}$ During the first decade of relations between Baathist Syria and Iraq, several events transpired that strained relations between these states. These include the Agreement on Disengagement, Euphrates water rights and the Lebanese civil war. The following sections will discuss each of these cleavages in greater detail.

\section{The Agreement on Disengagement}

The Yom Kippur War was fought between Israel and a coalition of Arab states, led by Syria and Egypt, from October 6 to 25, 1973. Egyptian operations were focused in the Sinai,

\footnotetext{
${ }^{41}$ Hinnebusch, Syria, 61.

${ }^{42}$ Ibid., 62.

${ }^{43}$ Mackey, The reckoning, 211.

${ }^{44}$ Raymond Hinnebusch, "Syria-Iraq Relations: State Construction and Deconstruction and the Mena States System,” LSE Middle East Centre Paper Series, 4 (October 2014), 9-11.
} 
whereas Syrian operations were focused in the Golan Heights, which were both repelled by Israeli Defense Forces (IDF). In fact, Israel made territorial gains in both the Golan Heights and the Sinai Peninsula during the conflict. By the conclusion of the conflict on October 25, 1973, Israel had control over the entire Golan Heights. Even after the ceasefire, tensions remained high between Syria and Israel, resulting in thousands of skirmishes between Syrian militias and IDF. In lieu of these continued hostilities, the United States facilitated The Agreement on Disengagement between Syria and Israel, signed on May 31, 1974.

Figure 6-2: The Israeli-Syrian Disengagement Agreement ${ }^{45}$

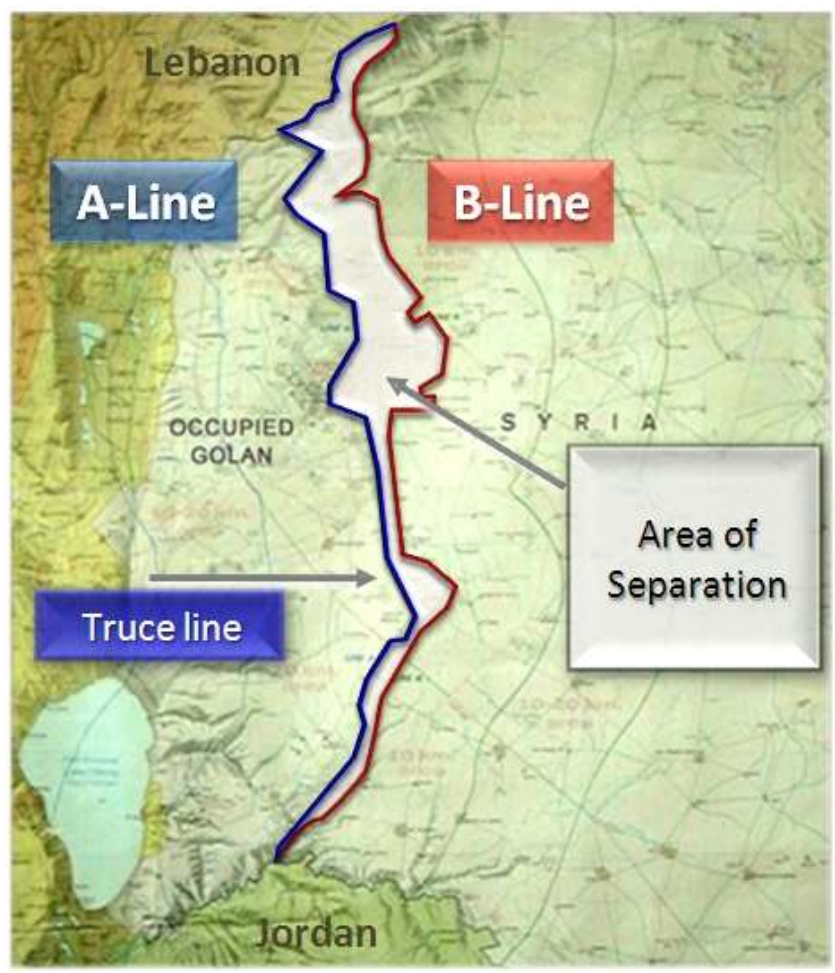

The purpose of the Agreement of Disengagement was to separate Israeli and Syrian forces from one another, creating a buffer zone between Syria and Israel. This area would be administered under a United Nations Disengagement Observer Force (UNDOF), which was

\footnotetext{
${ }^{45}$ United Nations Disengagement Observer Force (1974) "Map of the Area of Separation (AOS)." UNDOF, http://www.undof.unmissions.org/Default.aspx?tabid=9229\&language=en-US, retrieved on 04/05/2013. abbr.: United Nations 1974.
} 
established through UN Resolution $350 .{ }^{46}$ Iraqi President Bakr was extremely critical of the Syrian regime for accepting the UNDOF buffer zone in addition to UN Resolution 242 (ending the six-day war) and UN Resolution 338 (ending the Yom Kippur War). ${ }^{47}$ Iraqi officials called for a "unified fighting front" against Israel and the liberation of all usurped Arab territories. ${ }^{48}$ These Iraqi gestures were largely ignored by Syria, who called for the renewal of the UNDOF in late 1975.

\section{Euphrates Water Rights}

The Euphrates River extends from Turkey to Iraq, with a majority of the river in Iraqi territory. The Euphrates River has special importance for Iraq, as it is a major source of water for the barren regions. ${ }^{49}$ During the late 1960s and early 1970s, Turkey and Syria began to construct dams for hydroelectric power generation and water diversion for irrigation. ${ }^{50}$ This substantially affected Iraqi irrigation efforts, especially during dry seasons in 1974 and 1975. Iraq and Syria had disputes over the amount of water that should be allocated to each state. The Syrian position was that Iraq had other sources of water, including the Tigris. Syria, on the other hand, relied on the Euphrates for over $80 \%$ of its irrigation needs. ${ }^{51}$ After the 1974 drought, Syria agreed to release some water stored in Asad Lake, but refused after the 1975 drought. $^{52}$ In April 1975, Iraq had requested mediation through an emergency meeting of the Arab League foreign ministers. This provoked Syria to close embassies in Iraq and threatened to bomb the Tabqa dam. ${ }^{53}$

\footnotetext{
46 “Agreement on Disengagement," Geneva, June 5, 1974. UN Document S/11302/Add. 1-3.

${ }^{47}$ Eberhard Kienle, Ba'th v. Ba'th: The conflict between Syria and Iraq, 1968-1989 (London: IB Tauris, 1990), 104.

${ }^{48}$ Ibid., 104, 106.

${ }^{49}$ Majid Khadduri, Socialist Iraq: A study in Iraqi politics since 1968 (Middle East Institute, 1978), 161.

${ }^{50}$ Ibid., 161-2.

${ }^{51}$ Ibid., 163.

${ }^{52}$ Ibid., 164.

53 Jacob Berocovitch and Judith Fretter, Regional Guide to International Conflict and Management from 1945 to 2003 (CQ Press, 2004), 284-285.
} 


\section{Figure 6-3: Euphrates River and Iraq}

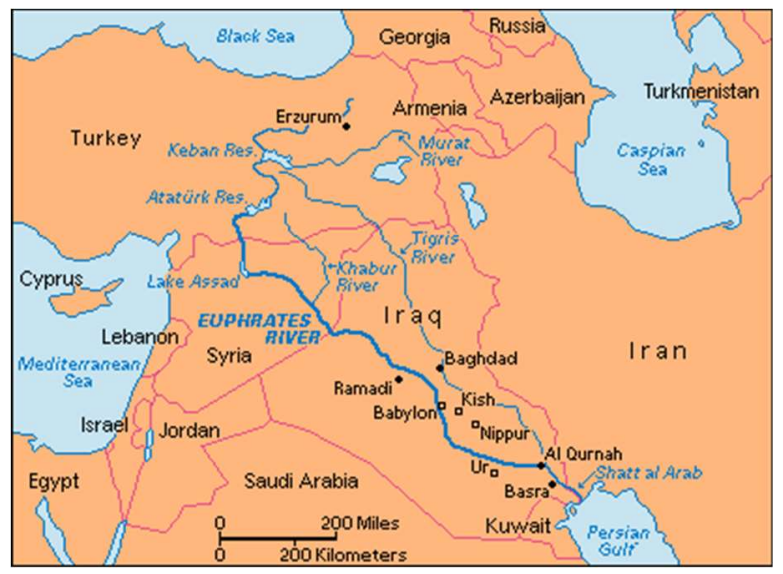

The Arab League meeting was held on April 22, 1975, which appointed a technical team of seven experts to examine the claims asserted by both parties. ${ }^{54}$ The recommendation of the committee was to divert additional water resources to Iraq in the short-term, which Syria rejected on the grounds of a "prior appropriation" clause for the long-term. ${ }^{55}$ Saudi Arabia had also attempted to broker mediation on May 3, based on a $60-40$ split of water resources $(60 \%$ in favor of Iraq), which was also inconclusive. ${ }^{56}$ The issue of Euphrates water allocation remained a point of contention between Syria and Iraq, resulting in several border skirmishes over the next several months.

\section{Lebanese Civil War}

Since the creation of independent states from the Ottoman Empire, Syria had always taken a special interest in Lebanon, which was perceived to be arbitrarily split from Syria. Even prior to the civil war in Lebanon, Syria had aspirations of uniting Lebanon and Syria once again, Assad made several remarks in the early 1970 s that "Syria and Lebanon are a single country...one nation with two governments." ${ }^{57}$ The interest in Lebanon only intensified after the eruption of a civil

\footnotetext{
${ }^{54}$ Ibid., 284-285.

${ }^{55}$ Khadduri, Socialist Iraq, 164.

56 Ibid.

${ }^{57}$ Daniel Pipes, Greater Syria: The History of an Ambition (Oxford University Press, 1992), 119.
} 
war. The Lebanese Civil War (1975-1990) was the result of a multitude of social, political and religious cleavages within Lebanon. Sectarian violence between the National Movement coalition and Maronite Christians boiled over in the spring of 1975, which resulted in a series of murders, including the Karantina and Damour massacres.

The decision for direct military intervention by Syria was twofold: (1) control over the PLO and (2) preventing a partitioned state. The increased involvement of other groups in the civil war, including the Palestine Liberation Organization (PLO), was concerning to Syrian legitimacy. The involvement of the PLO challenged the Syrian position as the defender of Arab interests against western forces. In an attempt to throttle the PLO, Syria had attempted to form a United Political Command with them in early in March 1975, which never came to fruition. ${ }^{58}$ Rogue actors, such as the PLO, concerned Syrian officials who feared that the civil war might evolve into an armed confrontation with Israel. ${ }^{59}$ In order to ensure that this proxy war did not evolve into an actual war between Israel and Syria, Kissinger brokered a "Red Line Agreement" that demarcated an acceptable area for Syrian troop deployments.

The second goal of intervention was to prevent a partition of Lebanon. The defeat of Christian militias would ultimately result in a two-state solution: A National Movement-PLO and pro-Israeli Christian state. Syria would be excluded from influence over either state, with Iraq and Libya exerting control over the National Movement-PLO state and a Christian state allied with the West. $^{60}$ Direct military intervention was the only option to preserve Syrian interests within Lebanon.

\footnotetext{
${ }^{58}$ Kienle, Ba'th v. Ba'th, 89.

${ }^{59}$ Kienle, Ba'th v. Ba'th, 91.

${ }^{60}$ Itamar Rabinovich, The War for Lebanon: 1970-1985 (Ithaca, NY: Cornell University Press, 1985), 201-236.
} 
After the Lebanese Presidential election of Elias Sarkis and subsequent refusal of former President Suleiman Frangieh to abdicate power, Syria intervened militarily. On June 1, 1976, Syria invaded Lebanon with 12,000 troops, reinforced by another 13,000 by September, with the total number eclipsing 30,000 by the end of 1977. ${ }^{61}$ All Arab league states endorsed the Syrian intervention with the exception of Iraq, who was threatened by the influence of Syria in Lebanon. Iraq accused Syria of cooperating with western powers, but in reality they were concerned over the relative gains of legitimacy the Syrian regime had made in recent years.

\section{Ontological Threat}

Iraq became increasingly displeased with the Syrian Disengagement Agreement with Israel (1974), Euphrates Water Rights (1975) and the active participation in the Lebanon Civil War (1975-1976). During the confrontation over Euphrates Water Rights, both Syria and Iraq mobilized troops along their borders. Iraqi mobilization was met with Syrian countermeasures, including mobilizing troops at the Euphrates High Dam at Tabqa and to Karajuk to protect the oilfields in the north. ${ }^{62}$ Troops remained stationed in these positions until November 1975 , when relations between the two began to thaw. Iraq opted to constrain Syrian behavior through economic incentives, which included the decision in April 1976 to stop transporting oil through Syrian pipelines. This decision had an economic impact on Syria of 500 million dollars. ${ }^{63}$ The Iraqi strategy changed in June 1976 after the Syrian troop deployments to Lebanon on June 1. At the time, the remainder of Syria's military was dedicated to reinforcing the Golan Heights, making

\footnotetext{
${ }^{61}$ Mordechai Nisan, "The Syrian Occupation of Lebanon,” in Peace with Syria: No Margin for Error (ACPR, 2000), 53-54.

${ }^{62}$ Kienle, Ba'th v. Ba'th, 107.

${ }^{63}$ Daniel Dishon and Varda Ben-Zvi, "Inter-Arab Relations," in Middle East Contemporary Survey, ed. Colin Legum (New York: Holmes \& Meier Publishers, 1978), 1:161.
} 
them particularly vulnerable to attack. Iraqi attempted to capitalize on the overextended Syrian military deployments in the Golan Heights and Lebanon.

In surprising fashion, Iraq mobilized over 30,000 troops on June 8, 1976 along the Syrian border, with additional reinforcements deployed on June 17. This included at least two armored divisions as well as five infantry divisions. ${ }^{64}$ An additional armored division along with an air defense brigade was stationed along the Euphrates River. Aircraft had been spotted performing reconnaissance missions along the Syrian border. Publicly, Iraq claimed that the troop mobilization was for a peacekeeping mission in the Golan and Palestine. ${ }^{65}$ Sources within the Syrian government contested this assertion, because they did not give consent for Iraqi troops to pass through their territory. In addition, the location of mobilized Iraqi troops centered in the Uwaynat province, which exacerbated the perceived Iraqi intent of capturing the Karatshuk oilfields. ${ }^{66}$ The Syrian response included mobilizing two divisions along with an SA-6 surfaceto-air missile brigade with air support and reconnaissance aircraft. ${ }^{67}$ A majority of these troops deployed were previously stationed in the Golan Heights. ${ }^{68}$ Just as the crisis had begun, Syrian President Assad went on a diplomatic trip to France.

Arriving on June 17, 1976 Assad went to France with the purpose of meeting with French President Valery Giscard d'Estaing about the situation in Lebanon. Over the course of the three-day meeting, private talks were scheduled. ${ }^{69}$ The Iraqi ambassador to France, who was

\footnotetext{
${ }^{64}$ U.S. Central Intelligence Agency, The President's Daily Brief, CIA-RDP79T00936A013400010029-7, June 15, 1976.

${ }^{65}$ Kienle, $B a^{\prime}$ th v. Ba'th, 115.

${ }^{66}$ Ibid.

${ }^{67}$ U.S. Central Intelligence Agency, The President's Daily Brief, CIA-RDP79T00936A013400010029-7, June 15, 1976.

${ }^{68}$ U.S. Central Intelligence Agency, The President's Daily Brief, CIA-RDP79T00936A013400010027-9, June 12, 1976.

${ }^{69}$ Edwin Eytan, “Syria will Continue Intervention in Lebanon, Assad says,” Jewish Telegraphic Agency, June 18, 1976.
} 
invited to the reception dinner, declined because he was not "prepared to shake a blood-stained hand that is carrying out the plans of international Zionism to liquidate the revolution and the Arab liberation movement." ${ }^{70}$ With no record of diplomatic correspondence between Syria and Iraq during this period, it is unclear what specifically de-escalated the crisis on June 17. According to one source, the visit to France "signaled the decline of threat perception" to Iraq. ${ }^{71}$

Both sides had altered their foreign policy strategies, dedicating resources to opposition groups and launching widespread propaganda campaigns against one another. The two sides opted to engage in a subversive campaign against one another without the use of military forces. This included a propaganda campaign against one another, along with the support of internal opposition forces. Iraq had accused Syria of capitulation with the West (and Israel) in accepting the Golan Heights disengagement agreement (May 1974) and political contact with the United States. ${ }^{72}$ Syria accused Iraq of supporting the Black June Organization, who perpetrated attacks against the Semiramis Hotel in Damascus (September 26, 1976) and Syrian Embassies in Rome and Istanbul (October 26, 1976). ${ }^{73}$ Iraq accused Syria for support of the Patriotic Union of Kurdistan (PUK), which was founded on June 1, 1975. ${ }^{74}$ Iraq also blamed Syria for multiple assassination attempts on Baathist officials, including Ahmad al-Azzawi, who was killed on a second attempt on July 10, $1976 .{ }^{75}$

While the military conflict was temporarily defused in June, it was not until late November that troops were demobilized troops along the border. The Arab League summit on October 16, 1976 in Riyadh was attended by Saudi Arabia, Egypt, Syria, Kuwait, Lebanon and the PLO. The

\footnotetext{
${ }^{70}$ Ibid.

${ }^{71}$ Michael Brecher and Jonathan Wilkenfeld, A Study of Crisis (University of Michigan, 1997), 648.

${ }^{72}$ Daniel Dishon and Varda Ben-Zvi, "Inter-Arab Relations," in Middle East Contemporary Survey, ed. Colin Legum (New York: Holmes \& Meier Publishers, 1978), 1:160.

${ }^{73}$ Ibid., 161.

${ }^{74}$ Ibid.

${ }^{75}$ Ibid., 114.
} 
focus was on ending the Civil War in Lebanon. This was immediately followed by another Arab League Summit in Cairo on October 25, 1976. The Arab heads of state approved a peace plan and cease-fire in Lebanon, which was only rejected by Iraq ${ }^{76}$ With a peace plan in effect, there was no strategic benefit for Iraq to maintain forces along the border. ${ }^{77}$ By the end of November, intelligence sources had confirmed that Iraq had been withdrawing troops and Syria returned troops to bases in southern Syria. ${ }^{78}$

While the Baathist leadership of Iraq and Syria had their differences, they were united by their Arab values. Both Syria and Iraq ascribed to the beliefs of Arab Nationalism, even prior to the coups of Baathists Bakr and Assad. Nationalist forces had liberated Iraq from foreign domination and ruled from 1958 to 2003 . These forces were not unified under a common ideology, which resulted in multiple regimes during this time period. With a majority of the Syrian military dedicated to Golan Heights and the Lebanese Civil War, Iraq had an opportunity to seize valuable oil territory and embarrass the regime. Syria was in a vulnerable position after losing the Yom Kippur War. While they mobilized troops as a threat to action in Lebanon, Iraq did not take advantage of the situation.

\section{Summary}

Syria and Iraq have a shared historical, cultural, linguistic and religious linkages under the Ottoman Empire (1639-1919). Independent statehood for Syria and Iraq invited Baathist ideology, which was predicated on Arab Nationalism. Ironically, relations between Syria and Iraq became increasingly tense under the Baathist regimes of Ahmed Hassan al-Bakr and Hafez al-Assad. The

\footnotetext{
${ }^{76}$ UPI, "Sadat tells Israel: Forget Lebanon," The Chicago Tribune. October 26, 1976.

${ }^{77}$ Henry Tanner. "Syria and Iraq Reach an Accord to Pull Back Troops on Border," The New York Times. November 27, 1976.

${ }^{78}$ U.S. Central Intelligence Agency, The President's Daily Brief, CIA-RDP79T00024A000300060005-1, November 27,1976
} 
struggle for Baathist legitimacy and territorial rights resulted in a massive campaign of subversion and propaganda for decades. This resulted in troop mobilizations, border skirmishes and threats of invasion by Iraq. Syrian involvement in the Lebanese Civil War was the final straw for Iraq, who mobilized with the intent of taking advantage of a vulnerable Syria, preoccupied in Lebanon and Golan Heights. Even in this tense environment, Assad leaving the country on June 17, 1976 signaled to the Iraqi regime that they were willing to negotiate. While a more permanent peaceful solution was not agreed upon until November 1976, tensions never escalated to armed conflict because of their ability to relate vis-à-vis Baathist ideological similarities.

\section{Iran-Iraq War (1980-1988)}

The Iran-Iraq War was the longest conflict of the $20^{\text {th }}$ century, spanning nearly eight years, costing over three-hundred thousand lives and millions of dollars of damage. Tensions between Iran and Iraq have existed for decades after Iraqi independence, but it wasn't until the Iranian revolution (1979) that military action was taken. Unlike other middle east conflicts at that time, the Iran-Iraq war featured same of the most brutal tactics, which included the intentional targeting of civilian populations and the use of chemical weapons by Iraq. I content that the Iraqi decision to unleash total war against Iran was due to historical and cultural differences, which posed an ontological threat to Iraq.

Iran and Iraq had a similar historical experience as part of Persian Empires until 1639, when the modern borders of Iran-Iraq were drawn. From this point forward, the cultural and historical identity of Iraq and Iran were tied to this demarcation. Since the Hashemite monarch was overthrown (1958), Iraq has emphasized a secular Arab identity that has been used to create solidarity with Egypt and Syria and opposed Israel and Iran. Alternatively, Iran has forged a unique Persian identity, largely based on historical and religious (Islamic) tenets. The collision 
course of these identities was manifest in territorial issues between the states, most notably the question of sovereignty over the Shatt al-Arab waterway. While this was resolved through the Algiers Agreement in 1975, a larger threat was looming - the Iranian revolution. Unlike the conflicts over territory, the ideology of Khomeini was a direct ontological threat to the Iraqi Baathist regime.

The resulting conflict, the Iran-Iraq War, can be differentiated in length from other middle eastern conflicts (such as India-Pakistan or Arab-Israeli) as well as unconventional tactics used. The Iran-Iraq War lasted eight years in total, devastating entire cities, such as Khorramshahr, Basra and Abadan. Estimates of the number of casualties of war range between several hundred thousand ${ }^{79}$ and a million. ${ }^{80}$ In addition to the scope of the conflict, the use of chemical weapons by Iraq and the targeting of civilian areas was unprecedented for the time.

When this crisis is examined through the lens of realism, Iraq's decision-making is questionable. Iran was a vulnerable target because of the domestic upheaval associated with the Iranian revolution. The decision to launch a surprise attack on Iraq at this pivotal time only steeled their resolve and anti-secular bias against Hussein and Bakr. Furthermore, the use of chemical weapons and civilian targeting by Iraq was a risky gamble because of their violations of international law. It seemed that this response was motivated by more than territorial expansion over the Shatt al-Arab, but rather fundamental hatred towards a Persian ontological threat. This case study will answer this question, through the guise of different beliefs and ontological threat. The decision to go to war (and tactics chosen) were the result of these differences.

\footnotetext{
${ }^{79}$ Dilip Hiro, The Longest War: The Iran-Iraq military Conflict (Psychology Press,1991), 250; Lawrence Potter and Gary Sick, eds., Iran, Iraq and the Legacies of War (Springer, 2006), 8; John Bulloch and Harvey Morris, The Gulf War: its origins (London: Methuen, 1989).

${ }^{80}$ Jacob Bercovitch and Richard Jackson, International Conflict: A Chronological Encyclopedia of Conflicts and Their Management 1945-1995 (CQ Press, 1997); Clodfelter, Michael, Warfare and Armed Conflict: A Statistical Reference to Casualty and Other Figures, 1618-1991 (McFarland \& Company:1992).
} 


\section{Civil Religion}

The civil religion, or the secular national beliefs, dogmas and rituals, between Iraq and Iran are derived from a much different historical experience under the Ottoman and Persian Empires. These historic rivals contested over the territory of modern day Iraq for hundreds of years before ultimately establishing the modern boundary through the Treaty of Zuhab in 1639. From that point onward, the respective territories developed unique Arab and Persian identities. Once Iraq achieved independent statehood, these historical identities guided the policy choices of al-Bakr and Hussein in their quest for Arab superiority over Persia. This section will outline the historical conditions that created such a powder keg, as well as the cultural perceptions that led to war.

\section{Historical Context}

The shared histories of Iran and Iraq are intertwined through the empires that ruled over both modern-day states. The ethos of these empires were distinctly Persian, which included the Archaemenid Empire (550-330 BC), Parthian Empire (247-224 AD) and Sasanian Empire (224651 AD). Within the Empires, a variety of cultures and ethnicities thrived, including Soghdians, Hephtalites, Kurds and Persians. ${ }^{81}$ A turning point occurred in 633, when Arab Muslims established the Umayyad dynasty (661-750), which spanned from Syria to Central Asia. While the Persians were able to maintain a strong national identity, the Zoroastrian religion was supplanted by Islam. Even in accepting Islam by the sixteenth century, Persians opted for the more heterodox division of Shiite. ${ }^{82}$ After the Mongol conquests of the Middle East and Asia, territory between Iraq and Iran was demarcated in the region between the Ottoman Empire (1299-1922)

\footnotetext{
${ }^{81}$ M.G. Morony, "Conquers and Conquered: Iran," in Studies on the First Century of Islamic Society, edited by G.H.A. Juynboll (Cardale: Southern Illinois University Press, 1982), 73.

${ }^{82}$ Khadduri, Socialist Iraq, 6-11.
} 
and various dynasties of the Persian empire, which included Safavid (1501-1736), Afsharid (17361796), Zand (1750-1794), Qajar (1785-1925) and Pahlavi Dynasties (1925-1979).

After years of conflict between the Empires, the Treaty of Zuhab, signed on May 17, 1639 provided the original establishment of modern-day boundaries between Iraq and Iran. This agreement transferred sovereignty of western Georgia and Armenia to the Ottoman Empire. This extended the boundary of the Ottoman Empire to include all of ancient Mesopotamia, which included modern-day Kuwait and Iraq. This demarcation between Iran and Iraq is integral to the development of their respective culture, language and ontology.

\section{Figure 6-4: Ottoman Territory before and after the Treaty of Zuhab}

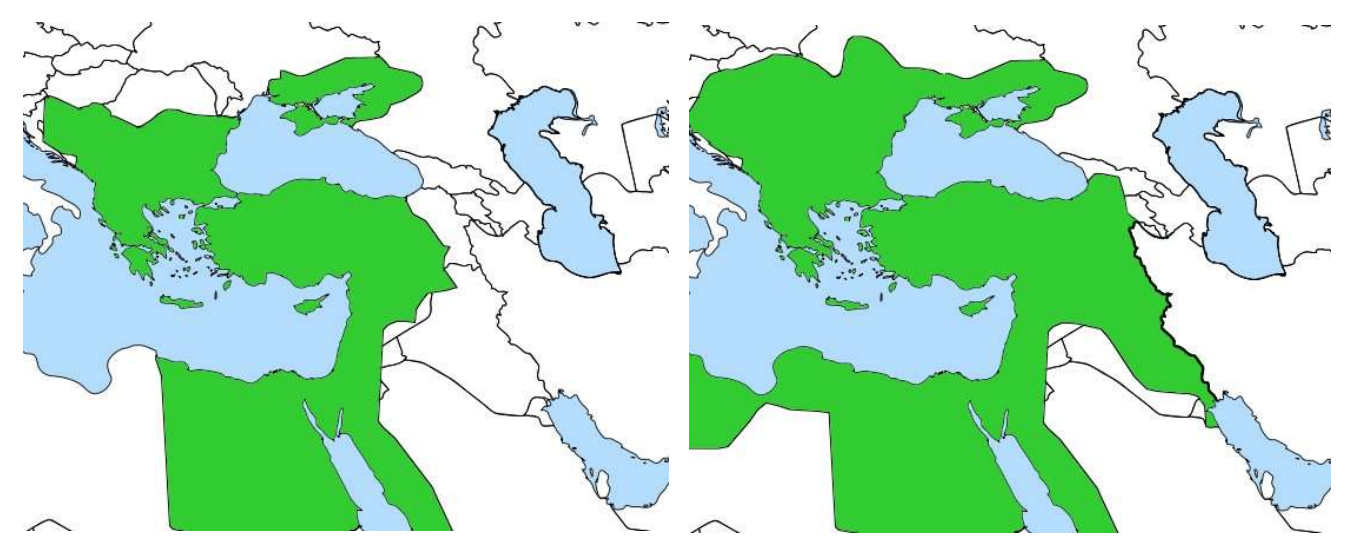

The boundary was a point of contestation in a series of future conflicts between these empires, including an invasion of Persia by the Ottomans in 1724. The Treaty of Kurdan (1746) and the Treaty of Erzurum (1823) reaffirmed this historical boundary. ${ }^{83}$ Iraq was officially granted independence as a result of the Treaty of Lausanne in 1923, but remained an extension of Great Britain until the Anglo-Iraq Treaty of $1930{ }^{84}$ While the British relinquished direct control over the area, they still maintained military and administrative power until 1954.

\footnotetext{
${ }^{83}$ Bruce Masters, "The Treaties of Erzurum (1823 and 1848) and the Changing Status of Iranians in the Ottoman Empire," Iranian Studies 24:1 (1991): 10.

84 “Anglo-Iraq Treaty of 1930," June 30, 1930, 132 LNTS 363.
} 
Immediately following the Iranian recognition of Iraq as an independent state, tensions over the border ensued. Iraq submitted a formal complaint in November 1934 to the League of Nations alleging that Iran did not honor the historical border. Some examples of Iranian transgressions included the construction of security outposts on Iraqi territory, the construction of dams on the Gunjan Cham (which affected Iraqi water supply) and interference in the Shatt-al$\operatorname{Arab}^{85}$

$\underline{\text { Shatt al-Arab }}$

One of the longstanding grievances between Iraq and Iran was the sovereignty over the Shatt al-Arab waterway. The Shatt al-Arab is an important strategic and economic waterway for Iraq, because it is the only access to the Persian Gulf. A boundary treaty was agreed upon by the Kingdom of Iraq and Empire of Iran concerning the border in 1937, with special attention to the Shatt al-Arab waterway. ${ }^{86}$ The 1937 Treaty reaffirmed the borders from the Turco-Persian Delimitation Protocol (1913), along the low-water mark on the eastern side of the river, which granted Iraq a considerable amount of contested territory. ${ }^{87}$ The only exception was around key Iranian port cities, which were demarcated using the thalweg principle. ${ }^{88}$ The use of the waterway was also negotiated in Article 4 of the treaty, which stipulated that "The Shatt-al-Arab shall remain open on equal terms to the trading vessels of all countries...The Shatt-al-Arab shall remain open for the passage of vessels of war and other vessels of the two High Contracting Parties not engaged in trade". 89 Both sides were discontent with this arrangement, as both wanted additional

\footnotetext{
${ }^{85}$ Joseph J. Cusimano, “An Analysis of Iran-Iraq Bilateral Border Treaties,” Case Western Reserve Journal of International Law (1992), 97.

86 "Boundary Treaty and Protocol Concerning the Shatt-al-Arab Waterway,". July 3, 1937, International Legal Materials 8, no. 3 (May 1969).

${ }^{87}$ Efraim Karsh, The Iran-Iraq War 1980-1988 (London: Osprey, 2002), 8.

88 "Boundary Treaty and Protocol Concerning the Shatt-al-Arab Waterway,". July 3, 1937, International Legal Materials 8, no. 3 (May 1969).

${ }^{89}$ The Thalweg Doctrine defines the boundaries between states as the point of greatest depth within the waterway.
} 
concessions. The Iranians wanted the entire waterway to be demarcated by the thalwg principle; Iraq wanted total sovereignty over the Shatt al-Arab.

Figure 6-5: The Shatt al-Arab Waterway ${ }^{90}$

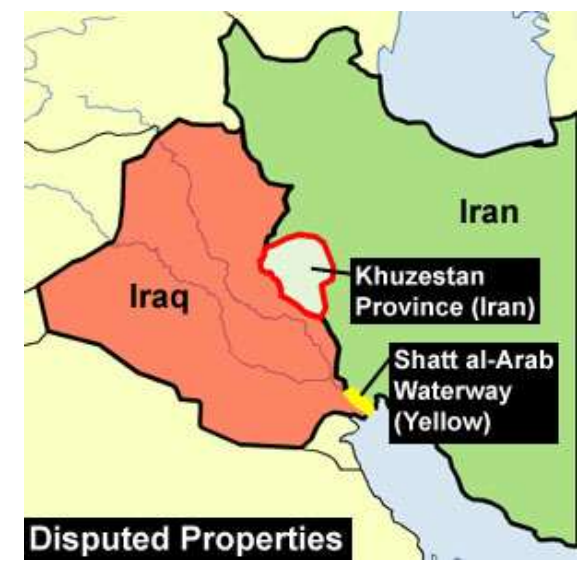

The governments of Iran and Iraq were agitated with the interpretation of the 1937 Treaty, culminating in the first major incident on November 28, 1959. On November 28, Mohammad Reza Pahlavi, the Shah of Iran, declared in a News Conference that the status quo arrangement over the waterway was "intolerable". ${ }^{91}$ He blamed the new Iraqi Qasim regime for not being as friendly as the previous regime. In particular, Iran felt that Iraq was overcharging for maintenance costs of the river. In response, President Qasim aired his own grievances surrounding the 1937 agreement. This included a three mile stretch of land near Abadan where the border is mid-river, as opposed to the thalweg line. ${ }^{92}$ He declared on December 2 that the Shatt al-Arab was a "grant not an acquired right" of Iran and "If the boundary problems are not resolved in the future we shall not be bound... and will restore them to our motherland." 93 Qasim asserted that the 1937 agreement was signed under Iranian coercion, including leverage over the oil companies. ${ }^{94}$ The escalated

\footnotetext{
${ }^{90}$ Worldology, LLC, “Iran-Iraq War (1980-1988)," http://www.worldology.com/Iraq/iran_iraq_war.htm (accessed August 8, 2017).

${ }^{91}$ Talat Parveen. Iran's Policy Towards the Gulf (Concept Publishing Company, 2006), 18.

${ }^{92}$ Uriel Dann, Iraq under Qassem: a political history, 1958-1963 (New York: Praeger, 1969), 264.

${ }^{93}$ Parveen. Iran's Policy Towards the Gulf, 18.

${ }^{94}$ Dann, Iraq under Qassem, 264.
} 
tensions between the states resulted in militarization and several minor border clashes on December 23. ${ }^{95}$ The conflict was resolved through a bi-lateral agreement, which stipulated a joint administration of the Shatt-al-Arab as well as third-party arbitration to conclude the border disputes. ${ }^{96}$ For the remainder of Qasim's regime, little progress was made to remedy these territorial issues.

The issue of sovereignty over the Shatt-al-Arab led to numerous border clashes in April 1969. On April 15, 1969, Iraq demanded that all Iranian ships must lower the Iranian flag when passing through the waterway and all Iranian nations should disembark from Iraqi ships. Iran took a hardline stance, abrogated the 1937 Treaty, declaring that they would "no longer admit anything but an equal distribution of the whole Shatt-al-Arab."97 On April 20, Iran and Iraq mobilized troops along the border areas of Khorramshahr and Abadan. On April 22, Iran deployed military escorts for civilian shipping vessels, who refused to lower their colors. ${ }^{98}$ Iraq submitted a complaint to the United Nations on April 28, Iran responded to on May 5. No action was taken by the United Nations, even though a coalition of Iranian, Pakistani, Turkish, United Kingdom and United States pursued negotiations. ${ }^{99}$ Ultimately, no resolution over the waterway was concluded until the 1975 Algiers Agreement, which was directly influenced by the Kurdish uprisings in northern Iraq.

\section{$\underline{\text { Kurdish Rebellion }}$}

Several other developments in the region only exacerbated tensions between Iran and Iraq. Kurdish separatists began their struggle for independence in 1961, and were supported by the

\footnotetext{
${ }^{95}$ Mahboob Alam, Iraqi foreign policy since revolution (Mittal Publications, 1995), 68

${ }^{96}$ Parveen. Iran's Policy Towards the Gulf, 18.

${ }^{97}$ P. Martin, "Iran Forces on Full Alert in Dispute with Iraq," The Times, April 21, 1969.

${ }^{98}$ Karsh, The Iran-Iraq War 1980-1988, 8

${ }^{99}$ Shahram Chubin and Sepehr Zabih, The Foreign Relations of Iran: A Developing State in a Zone of Great-Power (University of California Press, 1974), 185
} 
Iranian government. Additionally, Kuwaiti independence in June 1961 was welcomed by Iranian leaders. ${ }^{100}$ As the Baathists were struggling for power within Iraq, the Kurds took advantage of the domestic disarray. The Kurdistan Democratic Party, led by Mullah Mustada Barzani, began their campaign for independence, which resulted in a two-year civil war. ${ }^{101}$ After a temporary cease-fire, fighting resumed on a much larger scale in 1974. The Iranians, among other major international players, supported the Kurdish rebellion because of the weakening effect it would have on the new regime. ${ }^{102}$ One of the major points of contestation in the civil war was control of the oil resources in the Kirkuk region. The Iraqi regime had no choice but to make concessions over Shatt-al-Arab sovereignty in order to reduce Iranian support for the Kurds.

The 1975 Algiers Agreement between Iran and Iraq established a new boundary in accordance with the Constantinople Protocol of 1913, which demarcated the entire Shatt-al-Arab along the thalweg line. In exchange, Iran would "restore security and mutual confidence along their joint borders", which was a subtle way of signaling that Iranian would no longer support the Kurds. ${ }^{103}$ Iran had successfully used the Kurdish rebellion as leverage for regaining additional sovereignty over the Shatt-al-Arab. Iran took full advantage of the geopolitical situation within Iraq, forcing Iraqi leaders to accept a loss of regional prestige by conceding territory along the Shatt-al-Arab in exchange for the security of northern Iraq. The actions of Iran throughout these crises sowed seeds of mistrust and discontent and would be remembered by Iraqi leadership, especially Saddam Hussein.

\footnotetext{
${ }^{100}$ Alam, Iraqi Foreign Policy Since Revolution, 68.

${ }^{101}$ David McDowall, A Modern History of the Kurds (London: IB Tauris, 2003), 302-42.

102 Nader Entessar, "The Kurds in post-revolutionary Iran and Iraq," Third World Quarterly 6, no. 4 (1984): 920.

103 "Treaty Concerning the State Frontier and Neighbourly Relations between Iran and Iraq," June 13, 1975, UNTS 136.
} 


\section{Normative Differences}

Theoretically, Baathist and Islamic ideologies derive their identities from different sources. The primary focus of Baathist thought is on the preservation of Arabism, defined as the shared cultural, historical and linguistic traditions that define Arab peoples. While different regional groups had different political aspirations, their commitment to the Arab identity remained solidly unchanged. This view of the self was challenged by Iranian Islamic Fundamentalists, who derived their identity from Persian and Islamic sources. For Persians, "[even] individuals with less religious backgrounds, Islam became a particularly prominent source of identity and selfesteem"104 Furthermore, the key tenet of Arab nationalism was challenged by Islamic scholars.

There were several cleavages between Baathist and Islamic Fundamentalist thought, which included the key tenet of Arab nationalism. Whereas Arab nationalists despised foreign influence on Arab affairs (which included the Turkish influence over the Ottoman empire), Fundamentalists admired the role of the Ottoman Caliphate. Islamic scholars, such as Hasan al-Banna wanted to restore the primacy of Islam as an ordering principle within society. He blamed westernization for the moral collapse of Muslim states. ${ }^{105}$ This was expounded by Sayyid Qutb, a Sunni Activist, who established a more hardline approach, which included purging all un-Islamic elements from society. In his view, there should be no compromise with "barbaric" society, advocating for a complete return to Islam. ${ }^{106}$ Both Sunni and Shia Fundamentalists were calling for a return to traditional Islamic values. Hasan al-Banna did not perceive nationalism and religion to be mutually exclusive, however, peoples should be united by religion rather than ethnicity. ${ }^{107}$ Others,

\footnotetext{
104 Salem, Bitter legacy, 137.

105 Ibid., 118.

${ }^{106}$ Ibid., 130.

${ }^{107}$ Hasan al-Banna, Mudhakkirat al-da'wa wa I-da'iya (Cairo), 106-108.
} 
such as Sayyid Qutb, called on true Muslims to declare jihad on the community of Islam to restore its traditional values and institutions. ${ }^{108}$

Even decades prior to the Iran-Iraq War, Fundamentalist and Baathist factions framed their interests as contradictory. The Iraqi Dawa Party, founded in 1957 by Mohammad Baqir al-Sadr, was for "the achievement of the Persian aspirations in the east of the Arab homeland, [an outlet for the] hidden hatreds against the Arab Nation" 109 Baathism recognized the importance of Islam on the daily lives of Arabs, but advocated for secular leadership. Alternatively, Sadr posited that the state should be governed by a mujtahid or scholar-king, with guidance from an elected assembly. ${ }^{110}$ The Iranian revolution and subsequent creation of the Islamic Republic of Iran established a similar form of government, with the head of state (Supreme Leader) appointed by an Assembly of Experts.

\section{Domestic Political Change}

The domestic political changes within Iran in the wake of the Iranian revolution were a catalyst for Iraqi military action. The previous regime under Mohammad Reza Shah was not friendly towards Iraq, but also did not pose a threat to the Baathist regime. The Iranian revolution had altered the course between these states, as the Baathists were fearful of the changes occurring within Iran. The critical and outspoken Ruhollah Khomeini, who transformed Iran into an Islamic Republic through popular vote, was a direct threat to the existence of the Baathists in Iraq. As a result of this ontological threat, Iraqi leadership launched military operations with the intent of inflicting as much damage as possible. This included tactics of intentional targeting of Persian

\footnotetext{
${ }^{108}$ Sayyid Qutb, Ma'alim fi-l-Tariq (Cairo: Dar al-Shuruq, 1964), 6.

109 "General Military Intelligence Directorate (GMID) Studies on the Foundation of the Da'wah Party and the Supreme Council of the Islamic Revolution Party," March-December 1995. SH-GMID-D-000-622, cited in Murray and Woods, The Iran-Iraq War, 132.

${ }^{110}$ Salem, Bitter legacy, 132.
} 
civilians and the use of chemical weapons. The following section will outline the political developments prior to the conflict and the resulting war.

Internal demonstrations against the Shah began in October 1977, spawned from the death of Mostafa Khomeini, which was believed to be the result of a SAVAK (Sāzemān-e Ettelā'āt va Amniyat-e Keshvar, Organization of Intelligence and National Security) operation. This resulted in a series of protests throughout Iran. ${ }^{111}$ Several notable incidents had occurred over the next year, including on January 7, 1978 in the city of Qom. Police and seminary students clashed over an unfavorable article written about Khomeini. Other incidents included a nationwide movement against government and western institutions. ${ }^{12}$ Riots in major cities were common during the spring of 1978. By the fall, tensions between revolutionaries and the state would reach a breaking point.

The month of August served as a tipping point in the populist movement. On August 19, an intentional fire at Cinema Rex caused the deaths of 375 people. ${ }^{113}$ SAVAK was blamed for the attack by revolutionaries, escalating violence against the state and western institutions. At the celebration of Eid-e-Fitr on September 4, clerics instigated the massive crowds to march through Tehran and the establishment of an Islamic republic. ${ }^{114}$ Martial law was declared on September 8, culminating in multiple clashes between protestors and military officials, leaving $89 \mathrm{dead}$. A series of strikes, protests and clashes between protestors and military officials continued until December 1978. The Shah, who faced immense pressure to abdicate, transferred authority to Prime Minister Shapour Bakhtiar who subsequently transferred power to Ruhollah Khomeini.

\footnotetext{
${ }^{111}$ Daniel Brumberg, Reinventing Khomeini: the struggle for reform in Iran (Chicago: University of Chicago Press, 2001), 92 .

${ }^{112}$ Ervand Abrahamian, Iran between two revolutions (Princeton University Press, 1982), 162.

${ }^{113}$ Gholam-Reza Afkhami, The Life and Times of the Shah (University of California Press, 2009). 459.

${ }^{114}$ Michael Axworthy, Revolutionary Iran: A History of the Islamic Republic (Oxford University Press, 2013), $112-$ 113.
} 
Following the re-establishment of Khomeini as the Supreme Leader of Iran and the referendum on the establishment of the Islamic Republic on March 30, 1979, relations between Iran and Iraq soured. ${ }^{115}$ Iraqi officials, including Saddam Hussein had encouraged cooperation with the new government, stating in a cabinet meeting that:

Their stability and unity will be something positive for us if Iran is not hostile to the Arab nation. But if Iran as it has declared up until now is an ally to the Arab nation, this will be a big achievement and an important accomplishment. The Arabs generally should, whenever possible, implement policies that will make Iran sympathize with the Arab nation and not be against it. ${ }^{116}$

Beginning in June, 1979, Khomeini's called on Iraqi Muslims to overthrow the secular Baathist regime. ${ }^{117}$ This resulted in targeted attacks towards several key officials, including the Deputy Premier, Tariq Aziz and Minister of Information Latif Nusseif al-Jasim. While they escaped assassination attempts, 20 Iraqi officials were murdered by Islamic Fundamentalists. ${ }^{118}$ Newly minted President of Iraq Saddam Hussein attempted to take advantage of the weakened revolutionary regime and, as a last ditch "offer of friendship" in order to renegotiate the agreements between the states. This included a withdrawal from the Gulf Islands seized by the Shah, a renegotiation of the 1975 Algiers Agreement and autonomy granted to ethnic Arabs living in Iran. ${ }^{119}$ This offer was rebuked by Iranian officials, which only intensified their calls of action against the Baathist regime.

The Iranian call for revolution was perceived as a threat to national security by Iraqi officials, declaring that they have "shown animosity toward us since the beginning, as if the main aspect of change that took place in Iran was designed with the intentions to be against the interests

\footnotetext{
$11598 \%$ of eligible citizens voted for the establishment of the Islamic Republic. (Axworthy, Revolutionary Iran, 16.)

116 "Saddam and High-Ranking Officials Discussing Khomeini, the Ethiopian-Eritrean conflict, the Potential for Kurdish Unrest, and the Iranian Economy," February 20, 1979, History and Public Policy Program Digital Archive, Conflict Records Research Center, National Defense University, SH-SHTPA-000-851

${ }^{117}$ Karsh, The Iran-Iraq War 1980-1988, 1-8, 12-16, 19-82.

${ }^{118}$ Ibid., 11.

119 Williamson Murray and Kevin Woods, The Iran-Iraq War: A Military and Strategic History (Cambridge University Press, 2014), 87.
} 
of Iraq."120 Iraq responded to the Iranian threats by expelling thousands of Shia Muslim subversives, in addition to the assassination of the Dawa Party Leader. The overtures and actions by both Iran and Iraq demonstrated the incompatibility of the regime's ideals, leading to military mobilization and skirmishes along the border in the summer of 1980.

\section{Ontological Threat}

The Iran-Iraq War was the longest war of the twentieth century, lasting from 1980 to 1988. The total number of military killed in action has been speculated to be over 1 million and civilian deaths total over $200,000 .{ }^{121}$ The decision to go to war and utilize certain tactics, such as the deployment of chemical weapons and civilian targeted are underscored by historical Arab and Persian tension. For Baathist leaders in Iraq, the secular Arab identity was perceived to be a threat by the Iranian revolution, which espoused ideals of Islamic fundamentalism. While both Iranians and Iraqis were overwhelmingly Islamic countries, Islamic Fundamentalism placed the greatest emphasis on shared religious linkages as opposed to nationalist ties. These fundamental ideological differences were latent during the Shah's tenure in Iran. However, the Iranian revolution established a new Islamic civil religion that was an ontological threat with secular Baathist Arab nationalism. This is contrast with Iraq, which has been described as "a secular country, where a majority of citizens identify with their national identity rather than their ethnic or religious identity"122

\footnotetext{
120 "Saddam and His Inner Circle Discussing Relations with Various Arab States, Russia, China, and the United States," November, 1979, History and Public Policy Program Digital Archive, Conflict Records Research Center, National Defense University, SH-SHTP-D-000-559

${ }^{121}$ Dilip Hiro, The Longest War: The Iran-Iraq military Conflict (Psychology Press,1991), 250; Lawrence Potter and Gary Sick, eds., Iran, Iraq and the Legacies of War (Springer, 2006), 8; John Bulloch and Harvey Morris, The Gulf War: its origins (London: Methuen, 1989).

${ }^{122}$ See Marquardt, "Reshaping Iraq"; Marquardt, "Division of Iraq
} 
After the Algiers Accord (1975) and prior to the Iranian Revolution (1979), lukewarm relations between Shah Pahlavi and Bakr become the status quo. ${ }^{123}$ Until the Iranian Revolution, Iran and Iraq had their share of disagreements and tensions, but none of which were unsolvable through mediation or bilateral negotiations. After the revolution, the domestic changes within Iran did not go unnoticed by Iraq, who perceived the war as more than just reclaiming territory along the Shatt al-Arab. Izzat al-Duri, a close advisor to Saddam, framed the war as an opportunity to “elevate the Arab nation's psychological level and its spiritual level, and its military and technical level to an elite level."124 This also contributed to a major war goal, which was the annexation of Khuzestan (called Arabistan), which was an Iranian province composed of a majority of ethnic Arabs. ${ }^{125}$ The war itself was framed by Saddam as the "Qadisiyyat Saddam", which referred to the battle of Qadisiyyah in 636 A.D. between Arab Muslims and Persians. ${ }^{126}$

The framing of the conflict along Arab-Persian lines was not limited to Iraq. At the start of the conflict, Iran invoked the Muslim tenet of defensive Jihad, which implores all Muslims to defend the homeland against an enemy that has invaded Muslim territory. ${ }^{127}$ Once repelling Iraq across the border, Iranian leaders could no longer claim defensive Jihad. The offensive war was justified under the Karbala paradigm. ${ }^{128}$ The conflict against Saddam was described as haqq vs. batel (truth vs. falsehood), drawing from the historical analogy of the Battle of the Badr. ${ }^{129}$

\footnotetext{
${ }^{123}$ Stephen C. Pelletiere, "Iraq's Decision to Go to War," in The Iran-Iraq War: The Iran-Iraq Conflict (New York: Praeger Publishers, 1992), 45.

124 "Meeting between Saddam Hussein, the National Command, and the Revolutionary Command Council Discussing the Iran-Iraq War," September 16, 1980.

${ }^{125}$ Ibranhim Anvari Tehrani, "Iraqi Attitudes and Interpretation of the 1975 Agreement," in The Iran-Iraq War: The Politics of Aggression, Rajaee, Farhang, ed. (Gainesville: University Press of Florida Press, 1993), 21.

126 John Obert Voll. Islam: Continuity and Change in the Modern World (Syracuse University Press, 1994), 335.

${ }^{127}$ Ardalan Rezamand, "Use of Religious Doctrine and Symbolism in the Iran-Iraq War," Illumine: Journal of the Centre for Studies in Religion and Society Graduate Students Association 9, no. 1 (2011): 86.

128 The Karbala paradigm refers to the Battle of Karbala (A.D. 680) between Husayn ibn Ali and Yazid I. This battle is central to Shi'a Muslim belief, which cast the conflict as representing the battle between good and evil.

${ }^{129}$ Ardalan Rezamand, "Use of Religious Doctrine and Symbolism in the Iran-Iraq War,": 90.
} 
On September 22, 1980, Iraq launched military operations against Iran. They began their pre-emptive attack with air strikes on strategic targets, with the intention of crippling the Iranian air force. This was immediately followed by an uncoordinated ground assault along six fronts. The Iranians, who were surprised by the invasion, did not mount a serious ground resistance. ${ }^{130}$ However, Iranian planes responded in launching strikes on Iraqi strategic targets, which was more effective than the initial Iraqi air attacks. During the first year of the conflict, the initial push of the Iraqi army was successful in sieging Khorramshahr in October, but faced a stalemate at Dezful. The fighting at Khorramshahr was not limited to military targets, as seven days of artillery bombardment was directed towards civilian targets. ${ }^{131}$ After several unsuccessful sieges along the Persian Gulf, Iraqi troops were met with heavy resistance, leading to the adoption of defensive tactics. Once demonstrating that they were capable of defeating a technologically superior enemy, Iranian forces pushed Iraqi troops back across the border in July 1982.

Once Saddam realized the change in momentum favored Iran, on June 20, 1982, he proposed an immediate ceasefire and negotiated peace. ${ }^{132}$ This offer was immediately rejected by Khomeini, who would only accept peace if the Baath party abdicated and was replaced by the Islamic Supreme Council of Iraq (ISCI). Khomeini declared that they "pledged to fight until the government of heathens in Iraq topples." 133 Saddam refused to relinquish power, shifting the military strategy to a defense of the border. Iraqi troops, who were dug-in and well equipped, repelled all significant Iranian attacks. By 1984, when the war appeared to be turning into a stalemate, the tactics of the combatants changed once more.

\footnotetext{
${ }^{130}$ Murray and Woods, The Iran-Iraq War, 110.

131 Ibid., 121.

132 Associated Press, "Iraq Vows to Quit Iran, Fight Israel," The New York Times, June 10, 1982.

${ }^{133}$ Ami Ayalon, "The Iraqi-Iranian War," in Middle East Contemporary Survey, ed. Colin Legum (New York: Holmes \& Meier Publishers, 1981), IV:21.
} 
The final phase of the war reflected the change in attitudes towards attrition. Beginning in 1984 until 1987, the Iraqi and Iranian military intentionally targeted cities along the border with the intention of demoralization of the enemy. It is also notable that during this time chemical and biological weapons were used by Iraqi forces on Iranian cities. After years of attrition coupled with increasing civilian casualties, Khomeini accepted U.N. Resolution 598, resolving the conflict on July 20, 1988. Of all the actions undertaken during the war, the third phase - including civilian targeting and the use of chemical weapons - is intriguing for this case study.

\section{Use of Chemical Weapons}

One of the unique facets of the Iran-Iraq War was the use of chemical weapons, which had not been deployed as a weapon of warfare since World War I. As a result, concerted efforts were made by the international powers to forbid the use of chemical weapons in future conflicts. A limitation on the manufacture and importation of chemical weapons was applied to Germany in the Treaty of Versailles (1919). ${ }^{134}$ This limitation was extended to the broader international community through the Geneva Protocol (1925). The Geneva Protocol strictly condemned the "use in war of asphyxiating, poisonous or other gases, and of all analogous liquids, materials or devices"135 Both Iran and Iraq signed the Geneva Protocol in 1929 and 1931, respectively. Even though both of the parties were signatories to the Geneva Protocol, there was definitive proof of Iraqi use of chemical weapons during the war. ${ }^{136}$ The Iraqi usage of chemical weapons elucidated the lack of international enforcement of the Protocol. Iraqi officials continued to evolve the capability of these weapons, even expanding their arsenal to include nerve agents.

\footnotetext{
134 “Treaty of Versailles,” June 28, 1919. Article 171.

135 “Geneva Protocol," June 17, 1925.

136 The use of chemical weapons by Iran has been disputed and lacks documented and substantiated evidence.
} 
Early in the Iran-Iraq War (November 1980), the first allegations of Iraqi use of chemical weapons at Susangerd began to surface. ${ }^{137}$ This is consistent with intelligence documents that confirmed that Iraq had pursued an aggressive development of chemical weapons before 1981, with importation of key equipment from Western Europe and Egypt for the production of mustard and nerve gases. ${ }^{138}$ Early in the war, American intelligence had identified two facilities at Salman Pak and Samarra, which had been used to produce chemical weapons. ${ }^{139}$ By 1982, Iranian forces were extremely concerned with the threat of chemical weapon deployment, which included preparedness measures and equipping protective masks. ${ }^{140}$

In November 1983, American intelligence confirmed the use of lethal (Mustard agent) and non-lethal (tear gas) chemical weapons against Iranian troops. The anticipated response of Iran was to adjust defensive tactics, but not to deploy their own chemical weapons. ${ }^{141}$ They confirmed that mustard gas was deployed at Haj Umran after the base was captured by Iranian forces and during an Iranian advance near Panjwin in October. ${ }^{142}$ In February 1984, CIA officials anticipated that nerve agents would be available for massive deployment by the summer of $1984 .{ }^{143}$ By March 1984, documents noted that Iraq already began to deploy nerve agents on the Al Basrah front. Future production at Samarra would yield over 3,000 nerve agent bombs by December. ${ }^{144}$

The Iranian foreign minister reported to the Conference on Disarmament that 49 different chemical weapons attacks had occurred prior to $1984 .{ }^{145}$ While not all of these incidents have

\footnotetext{
137 "Chemical Warfare in the Iraq-Iran War," Fact Sheet, Stockholm International Peace Research Institute, 2.

${ }^{138}$ David B. Low, "Prospects for Use of Chemical Weapons by Iraq against Iran over the next six months," February 24, 1984.

${ }^{139}$ U.S. Central Intelligence Agency, "Iran-Iraq: Situation Report Number 27,” July 29, 1982.

${ }^{140}$ U.S. Central Intelligence Agency, "Iran-Iraq: Situation Report Number 27," July 29, 1982.

${ }^{141}$ U.S. Central Intelligence Agency, "Iran's likely reaction to the Iraqi use of Chemical Weapons," November 4, 1983.

${ }^{142}$ Ibid.

${ }^{143}$ David Y. McManis, "Monthly warning meetings for February 1984,". March 13, 1984.

${ }^{144}$ U.S. Central Intelligence Agency, "Iraq: Use of Nerve Agent," March 23, 1984.

145 "Chemical Warfare in the Iraq-Iran War," Fact Sheet, Stockholm International Peace Research Institute, 2.
} 
been verified by an impartial party, the United Nations did confirm the use of chemical weapons on seven occasions between February 26 and March 17, 1984. Of the samples collected, researchers determined that the gas deployed were Mustard and Tabun.

Mustard gas (2-choloroethyl) is a cytotoxic agent, which means that it destroyed any living cells upon contact. The short-term effects of exposure vary, depending on the areas exposed. The skin will be mildly irritated before evolving into yellow blisters. Eye exposure can result in irritation before pain and blindness. The breathing of mustard gas can result in sinus pain, shortness of breath and cough. Other immediate physical effects can include diarrhea, fever and vomiting. Mustard gas can result in immediate fatality, but this only occurs in a small minority of cases. ${ }^{146}$ The long-term effects of mustard gas exposure are more alarming, which can include chronic respiratory illnesses, permanent blindness, cancer and second/third degree burns on the skin. ${ }^{147}$ Once deployed, mustard gas can linger for several hours, with victims unaware of exposure until hours or days later. By mid-1984, Iraq had discovered a mustard variation known as "dusty mustard." This form of mustard agent is much more effective, damaging tissue within ten minutes, rather than traditional mustard gas which can take between four to six hours. ${ }^{148}$

Tabun gas (ethyl NN-dimethylphosphoramidocyandate), also known as GA, is a nerve agent that causes immediate effects on victims. These immediate effects can include blurred vision, diarrhea, vomiting, and respiratory problems. Exposure to larger doses can result in loss of consciousness, seizures, paralysis and respiratory failure. ${ }^{149}$ Exposure to large doses of Tabun is extremely fatal. Other independent researchers have confirmed Iraq also used Chlorine, nitrogen

\footnotetext{
${ }^{146}$ Only 5\% of World War I combat deaths were attributed to mustard gas.

147 The Centers for Disease Control and Prevention, "Facts about Sulfur Mustard," https://emergency.cdc.gov/agent/sulfurmustard/basics/facts.asp (accessed January 22, 2017).

148 Javed Ali, "Chemical Weapons and the Iran-Iraq War: A Case Study in Noncompliance," The Nonproliferation Review 8, no. 1 (Spring 2001): 50.

149 The Centers for Disease Control and Prevention, "Facts about Tabun," https://emergency.cdc.gov/agent/sulfurmustard/basics/facts.asp (accessed January 22, 2017).
} 
mustard, anthrax and mycotoxins (T2, HT2, nivalenol and verrucarol). ${ }^{150}$ The deployment of chemical weapons include CS agent (via RPG missiles, mortars and artillery shells), Phosgene agent (mortar rounds), Mustard agent $(81 \mathrm{~mm} / 130 \mathrm{~mm}$ artillery shells) and White Phosphorus agent (MR-43 aircraft missiles). ${ }^{151}$

The Iranian ambassador to the United Nations submitted a series of letters to the Secretary General of the United Nations. On March 13, 1985, two incidents on the Hawizah front, resulting in over 180 injuries. ${ }^{152}$ Another incident reported on March 16, 1985, at least six capsules were dropped via airplane near the Majnoon Island. ${ }^{153}$ On April 11, 1985, a detailed dossier of attacks was presented to the Secretary General, which included 77 bombs, 23 rockets and 639 shells of chemical weapons, resulting in 32 deaths and 2,231 injuries. ${ }^{154}$ Internal Iraqi memos confirmed at least fifteen different occasions in which the aforementioned chemical agents were deployed on Iranian troops. ${ }^{155}$

One of the changes in late 1986 was the use of chemical weapons as an offensive rather than defensive tool, originally used to disorient troops prior to ground attack. It was also during this time that sources allege that Iran began to deploy their own chemical weapons (whether developed indigenously or captured stockpiles). Iran vehemently denied these accusations, and

\footnotetext{
150 "Chemical Warfare in the Iraq-Iran War," Fact Sheet, Stockholm International Peace Research Institute, 7-8.

151 "General Military Intelligence Directorate Memos on Iran's Chemical Weapons Capability and Alleged Use," October, 1987, History and Public Policy Program Digital Archive, Conflict Records Research Center, National Defense University, SH-GMID-D-000-898.

152 "Letter Dated 14 March 1985 From The Permanent Representative of the Islamic Republic of Iran to The United Nations Addressed to The Secretary General," 14 March 1985. S/17031.

153 "Letter Dated 20 March 1985 From The Permanent Representative of the Islamic Republic of Iran to The United Nations Addressed to The Secretary General," 21 March 1985. S/17046.

154 "Letter Dated 11 April 1985 From The Permanent Representative of the Islamic Republic of Iran to The United Nations Addressed to The Secretary General," 21 March 1985. S/17096.

${ }^{155}$ These dates include 1983 (Zarbatiyah) April 20, 1986 (Shatt al-Arab), December 26-28, 1986 (Shatt al-Arab), April 12, 1987 and April 9, 1987 ( $3^{\text {rd }}$ Corps sector), April 13, 1987 (Ta'limi Bridge) June 29, 1987, November 13, 1987 and July 8, 1987 (Mawit), March 23-24, 1988, April 13, 1988 (981 $1^{\text {st }}$ Light Battery), April 21, 1988 (3 $3^{\text {rd }}$ Corps sector), and April 16, 1988 (Zakhu).
} 
Khomeini invoked the tenet of Islamic that prohibits warriors from contaminating the environment. $^{156}$

War of the Cities

The 'War of the Cities' refers to a series of strategic bombing, artillery shelling and missile attacks directed toward cities during the period of 1984-1988. Prior to 1984, Iraq had attacked cities for the purposes of destroying military and economic infrastructure. This changed in 1984, with the direct targeting of civilian population centers with intent to kill civilians. In early 1984, Iraqi military planners began recommending targets based on ethnic composition, specifically noting the percentage of Arab and Persian populations of cities targeted. ${ }^{157}$ The shift in focus from economic to economic and civilian targets was noted by Abdul-Ghani Abdul-Ghafur, who justified the targeting of civilian targets because "cities have residents and economic facilities. Striking cities has a psychological effect that frustrates the Persian enemy." "158 In early 1984, Iraq launched several Scud missiles launched at Dezful, which killed 36 and injured 140. ${ }^{159}$ The Iranians responded by launching artillery strikes at Basra and airstrikes at Baghdad. This back and forth interaction continued until June, when UN mediation temporarily stopped such attacks. ${ }^{160}$

The temporary truce was broken by Iraq, when on March 4, 1985 they launched several air strikes on civilian targets in highly populated areas, including Tehran, Tabriz, Shiraz and Isfahan. ${ }^{161}$ Iran was prepared for counter-attack, purchasing \$3 billion dollars' worth of surface-

\footnotetext{
${ }^{156}$ Hiro, The Longest War, 201.

157 "Various GMID Reports and Correspondence with the General Command of the Armed Forces and Air \& Air Defense Force Regarding Suitable Iranian Targets, Economic and Military," SH-GMID-D-001-366.

158 "Saddam and His Advisers Discussing the Importance of Morale, Mobilizing Popular Support, and Targeting Iranian Cities," March 01, 1987, History and Public Policy Program Digital Archive, Conflict Records Research Center, National Defense University, SH-SHTP-A-001-023.

${ }^{159}$ Murray and Woods, The Iran-Iraq War, 236.

${ }^{160}$ Ibid.

${ }^{161}$ Edgar O'Ballance, The Gulf War: Nineteen Eighty to Nineteen Eighty-Seven (London: Brassey's Defense Publishers, 1988), 169.
} 
to-surface missiles after the first attacks in $1984 .{ }^{162}$ They counterattacked with their newly acquired Scud missiles by launching several attacks on Kirkuk and Baghdad. ${ }^{163}$

In the fall of 1986, Iraq launched an all-out offensive on dozens of Iranian cities. Between January 9 and February 16, Iraq deployed over 860 ordinances on 50 different cities, which included Tehran, Shiraz, Tobriz, Isfashan and Qom. During this time, Iran responded by firing multiple Scud missiles at Baghdad. During this period, Iraqi leaders first discussed the use of chemical weapons on civilian populations. As part of this conversation between Iraqi leadership, they discussed the language of the Geneva Protocol, attempting to find a loophole that would justify using chemical weapons on civilians living near military targets. ${ }^{164}$

In February 1988, Iraq once again launched several attacks which was retaliated by Iran Scuds on Baghdad. Iraq responded by launching an aggressive barrage of missiles, including 140 modified al-Hussein Scud missiles that could reach Tehran and Qom and 40 additional Scuds at closer cities. ${ }^{165}$ The most notable attack was on Halabjah in March 1988, which was occupied by Iranian forces. Iraqi forces launched chemical weapons at the town for over three days, killing between 5,000 and 8,000 civilians. ${ }^{166}$ By mid-1988, Iran was concerned about the prospects of Iraqi chemical warfare on civilian centers. The use of chemical weapons against the Kurdish civilians at Zardan in July 1988 and the lack of international response was especially concerning for Iranian officials. ${ }^{167}$ The threat of the widespread use of chemical weapons against Iranian cities

\footnotetext{
162 Murray and Woods, The Iran-Iraq War, 258.

163 Ibid., 259.

164 "Transcripts of Iraqi Leadership Meetings Discussing Responses to Iranian Missile Strikes," 12-24 September 1986. SH-SHTP-D-000-411.

165 Murray and Woods, The Iran-Iraq War, 317.

166 Javed Ali, "Chemical Weapons and the Iran-Iraq War: A Case Study in Noncompliance," The Nonproliferation Review 8, no. 1 (Spring 2001): 52.

${ }^{167}$ Ahmed Hasim, "Iran's military Situation," in Iran's strategic intentions and capabilities, ed. Patrick Clawson (Washington D.C.: Institute for National Strategic Studies, 1994), 211.
} 
gave them no choice but to capitulate. On July 20, 1988, Iran and Iraq accepted UN Resolution 598, which accepted the ceasefire.

\section{Summary}

The contentious history between the modern territories of Iran and Iraq can be traced to the Ottoman-Persian dynamic. The modern Arab and Persian identities were forged through these interactions. Once gaining independence, Iraq and Iran seemed to be set on a collision course for conflict over the Shatt al-Arab and other territorial rights. While the Shah of Iran was in power, Iraq deferred to the United Nations and bilateral negotiation (Algiers Agreement) on the issue of territorial sovereignty. The posture of Iraq changed after the Iranian Revolution, which was a direct ontological threat to the Iraqi Baathist regime. The eight-year conflict featured the use of chemical weapons that were previously banned by the Geneva Convention, as well as the war of the cities. These tactics caused a staggering death toll and massive economic destruction for both Iraq and Iran.

One of the common misconceptions about the Iran-Iraq War is that it was the result of historical tensions between Shiite and Sunni factions of Islam. Many scholars cast this threat perception in terms of Sunni-Shia differences, as Iran is predominately Shiite and Iran is predominately Sunni. This analysis attempts to typecast the entire conflict as being motivated by religious sectarianism, which may have been a small part of the decision calculus, but not the primary motivation for Iraq. A more likely explanation is that the conflict was the result of deepseeded historical Arab-Persian hostilities. These ontological differences had been ingrained for generations, but were rekindled by the Islamic Fundamentalist ideology of Khomeini. These differences were the result of fundamentally different moral constructs that transcended divisions between Shia and Sunni beliefs. 
Iraqi officials did make several references to Arab or Persian in their official correspondence. Most notably during several meetings between Armed Forces and the Air defense force in early 1984, decisions regarding civilian targeting was discussed. Prior to this meeting, military operations were focused on gaining and protecting territory. Due to the stalemate in combat operations, officials turned to more vulnerable population centers. Suitable targets were chosen based on the ethnic composition of the city, detailing the percentages of Arab and Persian in each city. Arial bombing campaigns were directed towards areas with higher proportions of 'Persian' populations. ${ }^{168}$ This challenges the conventional narrative that chemical weapons were only used as a tactic of attrition after the war descended into a stalemate. The production and use of chemical weapons, coupled with the war of the cities, was strategically designed for the purpose of purging Persians.

These historical tensions extended beyond the strategic planners, permeating Iraqi society as a whole. A majority of Iraqi armed forces deployed in the Iran-Iraq War were Shiite Muslims, yet there are no reports of desertion or unwillingness to fight against fellow Shiites from Iran. ${ }^{169}$ Domestically, Iraq had experience dealing with Shia disturbances, with a number occurring in February 1977 in Najaf and Karbala. Surprisingly, the reaction of the Iraqi regime was restrained, with troops given orders to control the mobs, rather than attack the crowds. ${ }^{170}$ The ideological differences between Baathist and Islamic Fundamentalist philosophies, rooted in the historic ArabPersian rivalry, was the true motivating force that transcended religious identification.

\footnotetext{
168 "Various GMID Reports and Correspondence with the General Command of the Armed Forces and Air \& Air Defense Force Regarding Suitable Iranian Targets, Economic and Military". SH-GMID-D-001-366.

${ }^{169}$ Samir Khalil, Republic of Fear: The inside story of Saddam's Iraq (New York: Patheon, 1989), 270-276.

${ }^{170}$ Uriel Dann and Ofra Bengio, "Iraq," in Middle East Contemporary Survey, ed. Colin Legum (New York: Holmes \& Meier Publishers, 1978), 1:408.
} 


\section{Conclusion}

The Middle East had experienced vast political, cultural and social changes in the early twentieth century. These changes resulted in an ontological crisis for many individuals (and states alike). In particular, the competition of different moral systems (with the extremes being Marxism on the left and Puritanical Islam on the right) disrupted the moral harmony of states. ${ }^{171}$ Different ideologies rushed to fill this void, including Arab nationalism vis-a-vis Baathism and Islamic Fundamentalism.

The experience of Middle Eastern states during the twentieth century was extremely turbulent. Prior to World War I, Arab territories were administered under the Ottoman empire. Arab Nationalists resented the Turkish influence over Arab politics, perceiving them to be a foreign power. ${ }^{172}$ Once the Ottoman Empire was dissolved at the conclusion of the war, Arab states were then subjected to the European influence of English and French administration. The Sykes-Picot Agreement, codified in the Conference of San Remo (1920) at the conclusion of the war and mandated to France the northern half of Syria (Syria and Lebanon). Britain was mandated Mesopotamia (Iraq) and the southern half of Syria (Palestine). These states were determined to "be provisionally recognized as independent States, subject to the rendering of administrative advice and assistance by a mandatory until such time as they are able to stand alone."173 After centuries of Ottoman rule, followed by European domination, several reactionary movements strived to re-define the Arab identity in order to adapt to the changing socio-political environment.

The three most prominent ideologies to fill this void were Arab Nationalism, Islamic Fundamentalism and Marxism. Each of these ideologies draw on a unique philosophical tradition

\footnotetext{
${ }^{171}$ Paul Salem, Bitter legacy: ideology and politics in the Arab world (Syracuse University Press, 1994$), 19$.

172 John F. Devlin, The Ba'th party: a history from the origins to 1966 (Hoover Institution Press, 1976 ), 1.

173 “San Remo Resolution” April 25, 1920 (b)
} 
with different pragmatic applications. In the case of Iraq and Syria, the Arab Nationalist ideology (incorporated through the Baath party), provided a common framework for discourse during crises. The Syrian threat to Iraq was perceived in terms of regional hegemony and Baath legitimacy. This can be juxtaposed to the Iran and Iraq, which featured Islamic Fundamentalist and Arab Nationalist ideologies, respectively. Iraq perceived the Islamic Fundamentalist ideology as an ontological threat to Arab Nationalism, which rapidly escalated hostilities after the Islamic Revolution.

Iraqi decision-making during the Baathist regime (Bakr and Hussein) demonstrates the ways in which differences in fundamental belief structures can alter the behavior of states during crisis. Iraq had serious tensions over territorial rights, foreign policy and support of internal opposition with both Baathist Syria (under Assad) and Iran (under Shah). Both states were a threat to the legitimacy of the Iraqi Baath party, who was striving to become a regional hegemon to compete with Nasser in Egypt. Even when tensions between these states escalated, Iraq threatened to use force, but always resorted to mediation or bilateral negotiations. The situation changed after the Iranian Revolution, which re-established a dormant civil religion whose ideals were incompatible with Baathism. Iraqi Baathists, who had weathered Syrian and Iranian coup attempts in the past, perceived the Islamic regime in Iran to be the greatest ontological threat to their legitimacy.

The subsequent eight-year war progressively evolved into attrition, with both sides ceding no territory. This stalemate only raised the stakes for Iraq, who was willing to inflict the most punishment on Persia as they could muster. The lack of respect for the human rights of Persians or adherence to the Geneva Convention resulted in the deployment of chemical agents, such as mustard and tabun gas. The decision to specifically target civilian areas that were predominately Persian was rooted in a sense of Arab superiority. The entirety of Baathist foreign policy can be 
characterized as re-establishing a glorious Arab state, which was the catalyst and justification for this conflict. 


\section{Chapter 7: Vietnamese Crisis Management (1964-1979)}

Over the past century, Vietnam has experienced much foreign intervention from a variety of actors. Whether it was French and Japanese colonialism or American and Chinese military intervention, Vietnam has fiercely defended their national identity. After gaining independence from France in the First Indochina War, Vietnam was involved in two additional Indochina Wars. These case studies will focus on the Second (aka The Vietnam War) and Third Indochina Wars. In both cases, the United States and China intervened militarily for the purpose of "correcting" domestic policies to suit their needs. The United States, fearful of the spread of communism from China to Southeast Asia, intervened in the civil war to contain the ambitions of the communist North. Several years following the conclusion of the Second Indochina War, China invaded Vietnam to punish them for their behavior in Cambodia, the treatment of Hoa and other territorial disputes. The reasons for each aggressor to invade Vietnam was much different, which was reflected in the tactics used during combat operations.

The intriguing puzzle of these crises was the behavior of the United States and China during their respective wars against Vietnam. The United States' strategy in Vietnam seemed counterintuitive to the objectives of the military intervention. Support for the Viet Minh relied upon Southern civilian populations, which the United States alienated through pacification and defoliation. The attrition-based strategy blurred the lines between insurgent and innocent, resulting in inflated body counts and kill quotas. This can be contrasted with the Chinese strategy towards civilians during the Third Indochina War. China made concerted efforts through the political work system to educate soldiers on the Maoist principles of warfare. This included a section dedicated to the preservation of civilian property, which was actualized during the war. 
There are numerous examples of Chinese soldiers going above and beyond to insulate civilian populations, as well as offering incentives to provide intelligence against governmental forces.

The purpose of these case studies is to better understand the strategy and tactics used by the United States and Chinese during their respective campaigns in Vietnam. Aside from the goals of the campaigns, these case studies will illustrate how ideological differences and ontological threats may result in different manifestations of combat strategy. In the case of the Second Indochina War, ideological polarization and ontological exclusivity between the United States and North Vietnam resulted in dehumanizing tactics towards civilians and destruction of the environment. In contrast, the ideological and historical similarities between China and Vietnam in the Third Indochina War placed great emphasis on differentiation between soldier and civilian as well as preserving the Vietnamese culture and way of life. The purpose of these case studies is to examine the motivation and objectives of leadership in these conflicts in addition to the warfare tactics used to achieve these objectives.

Table 7-1 provides an overview of the important variables related to these cases. It includes three sets of variables, the predominant religious values of the state, the virtues of civil religion and institutions at the time of crises. While distinct in their own ways, the culture of Vietnam and China share many elements. Vietnamese culture and language was dramatically influenced through the Chinese conquests during the Han and Ming Dynasties. The cultural beliefs of China and Vietnam are heavily influenced by Confucian thought, which promotes the common good through ordered relations. ${ }^{1}$ The cultivation of virtue is achieved through the participation in clearly defined structured relationships. ${ }^{2}$ The civil religion of Vietnam and China reflect these Confucian virtues, insofar as including Confucian questions on civil servant examinations. The civil religions

\footnotetext{
${ }_{1}^{1}$ Analects 3.3.
}

${ }^{2}$ Analects 2.3. 
of these states, defined as ideological nationalism, are focused on their independence from foreign entanglements while guarding their Confucian ideology from outside forces. This also revolves around the idea that Asia is Sino-centric, with all other regional states of lesser importance. ${ }^{3}$ As such, the legacy of Maoism is a cornerstone of Vietnam and Chinese institutional structure. This includes governing through a single-party that is integrated into the military command.

The religious values of the United States are rooted in Christian beliefs. While this may not translate to individual religiosity, there exists a system of self-reinforcing laws, norms and rites that all Americans live in a society with Christian values. These values are underscored by the fundamental beliefs that all people are granted free will ${ }^{4}$ and are equal. ${ }^{5}$ Through these beliefs, the civil religion of American exceptionalism was borne. This is a unique blend of individualism, democracy, republicanism and capitalism that defined the American experience and differentiated it from other states. ${ }^{6}$ This sense of ideological superiority has been the cornerstone of American foreign policy since inception. Citizens are treated as free equals through elections and under the rule of law. Additionally, institutional constraints, independent judiciary and individual rights and responsibilities reflect these virtues.

\section{Table 7-1: Overview of Variables}

\begin{tabular}{|c|c|c|c|}
\hline & United States & Vietnam & China \\
\hline Culture & Western & \multicolumn{2}{|c|}{ Sinic } \\
\hline Language & English & Vietnamese & Mandarin \\
\hline Calendar & Gregorian & \multicolumn{2}{|c|}{ Based on 授時曆 (Thu thời) } \\
\hline
\end{tabular}

\footnotetext{
${ }^{3}$ Brantly Womack, China and Vietnam: The Politics of Asymmetry (New York: Cambridge University Press, 2006), 65.

${ }^{4}$ Romans 3:23; Galatians 6:7.

${ }^{5}$ Genesis 1:27.

${ }^{6}$ Seymour Martin Lipset, American exceptionalism: A double-edged sword (WW Norton \& Company, 1997), $31-34$.
} 


\section{Table 7-1: Overview of Variables (cont.)}

Religious Values

\section{Civil Religion}

\section{Institutions}

\section{Christian}

Salvation is ensured through the death and resurrection of Jesus Christ, but can only be granted through the free will to believe.

All humans are equal under Imago Dei (image of God), meaning that every individual has an equal opportunity for salvation.

\section{American Exceptionalism Belief that the American ideology (a combination of individualism, democracy, republicanism and capitalism) is unique from other belief structures. This provides moral superiority over alternative belief structures. \\ The most important societal aspects include individual freedom and responsibility.}

\section{Democratic Republic}

The Executive and Legislature are determined through popular elections with universal suffrage.

The rule of law supersedes power or position, meaning that all members of society, regardless of class or means are subjected to the same codified laws.

\section{Confucian}

Order is achieved through a structured society promotes the collective good through the delegation of duties and responsibilities to each member, based on position.

The cultivation of $l i$ (virtue, duty) through rites and rituals that reinforce unequal relationships within society. This includes four relationships: ruler to ruled, father to son, husband to wife and elder to younger.

\section{Ideological Nationalism}

Belief that China is the cultural center of Asia, with other states acting as vassals and tributaries. In Dynastic China, the Emperor was granted power through the Mandate of Heaven, subjugating other regional states and branding them culturally inferior.

The most important societal aspects include the cultivation of $l i$ (virtue, duty) and expression of ren (humaneness) with others in society.

\section{Dictatorship}

Single-party leadership which was organized by hierarchy, ranging from the Party Secretary General, Politburo, Central Committee and Congress. Decisions and appointments are made through internal collective leadership and inner-party democracy.

Political work system that integrated party leadership (central command) with military command. The military was infused with ideals rooted in Maoist doctrine, which included a litany of structured concepts, including "the three major tasks", "the three major principles of political work", "the three democracies" and the "three rules of discipline and the eight points of attention.

These case studies will be organized following the causal logic of the theory. First, the moral foundation of civil religion will be discussed, including the historical and normative context 
of the crisis. Since these conflicts are couched in a historical dimension of previous foreign relations, it is important to provide the background between each dyad state. Secondly, the tipping point of relations occurred in the wake of Ho Chi Minh assuming power in Vietnam, along with the reunification of North and South Vietnam. Domino theory was the primary catalyst of hostilities between the United States and Vietnam. The invasion of Cambodia, border disputes and the treatment of Hoa were the primary causes of the Third Indochina War. The third section is dedicated to perception of these domestic changes, namely the ontological threat perceived by the United States and China. Both of these crises will be arranged in the same manner, followed by a summary of the findings.

\section{The Vietnam War (1964-1973)}

The Vietnam War was a military conflict between the United States and Vietnam between 1964 and 1973. The purpose of this case study is to analyze the United States decision-making during the Vietnam War, which included the treatment of civilians and use of chemical weapons. My theory would posit that this decision-making was informed by cultural differences, which cast Vietnam as an ontological threat to the United States. This provided justification for the use of body counts, civilian collateral damage and chemical weapons.

The United States and Vietnam are culturally dissimilar in many ways, which exacerbated the negative perception of the Vietnamese as a people. The United States had always taken a strategic interest in Indochina, but the ascendency of Mao Zedong in China increased threat perception of Ho Chi Minh. Domino Theory provoked fears of communism spreading across southeast Asia. The resulting military operations in Vietnam were one of the longest military incursions of the twentieth century, spanning a total of nine years from the Gulf of Tonkin 
Resolution to the Paris Peace Accords. This conflict featured some of the most exploitative tactics against civilian populations and environmental derogation.

This case study will examine the evolution of the historical relationship between Vietnam and the United States. After the fall of the French occupying force at Dien Bien Phu, the South Vietnamese government was supported by United States financing and advisors. When it became apparent that ARVN troops (under the leadership of Diem) would be ineffective in defeating the Viet Minh, direct military involvement by the United States ushered in a variety of tactics that aimed to destroy the Vietnamese people. This case study will focus on three different military tactics: (1) Attrition and body count, (2) pacification and (3) defoliation.

\section{Civil Religion}

The historical experience and cultural identities of the United States and Vietnam are extremely dissimilar. The Anglo-Saxon Christian set of beliefs permeated in the United States civil religion can be contrasted with Confucian values. More than simply linguistic and moral differences, these cultural belief structures have certain assumptions about the world which are fundamentally different. The implication of these dyadic differences is that neither side truly understood the other. In the case of United States decision-makers, the Vietnam way of life was looked at with disdain, which greatly informed the war strategy. This section will go into greater depth about these concepts, including the historical ties and normative differences between the United States and Vietnam.

\section{Historical Context}

United States involvement in Vietnam began during the Second World War, prior to the attack on Pearl Harbor. Vietnam was a protectorate of France, who obtained control over Indochina following the Sino-French War (1884-1885). After France was occupied by Germany, 
the Vichy regime administered the territories of Indochina. While the Allied powers were disputing the course of action for territories after the war, the Japanese overthrew the Vichy regime in Vietnam on March 11, 1945 subsequently followed by Emperor of Annam ${ }^{7}$ Bao Dai declaring Vietnam an independent state. The position of the United States remained unchanged, President Roosevelt issued a statement on April 3, 1945 reaffirming that "the United States felt that the postwar trusteeship structure...should be designed to permit the placing under it of the territories mandated after the last war". 8 The United States invoked the Atlantic Charter of 1941, which granted the "respect the right of all peoples to choose the form of Government under which they will live; and they wish to see sovereign rights and self-government restored to those who have been forcibly deprived of them".

Internally, Vietnam was experiencing a transition of power from Bao Dai to Ho Chi Minh. The Viet Minh, who were formed in 1941 to resist Japanese and French occupation, had great support amongst the people of Vietnam. Advisors that were close to Bao Dai recognized the writing on the wall, suggesting that he abdicate his position before being dispatched like Tsar Nicholas II. ${ }^{9}$ Bao Dai, in an effort to avoid bloodshed, was willing to abdicate the throne in order to preserve the legitimacy of the government. The abdication was dated August 25, which was posted outside the palace and surrounding cities. The official ceremony took place on August 30, in which a golden seal and golden sword was transferred to representatives of the Indochinese Communist Party and the Vietnam Democratic Party. ${ }^{10}$ This would be the status quo for the following several years, until the conclusion of World War II.

\footnotetext{
${ }^{7}$ Indochina was divided into three colonial territories, Annam, Tonkin and Cochinchina, which were administered by the French.

${ }^{8}$ Gravel, ed., The Pentagon Papers, 1:16.

${ }^{9}$ David G. Marr, Vietnam 1945: The quest for power (University of California Press, 1997), 443-444.

${ }^{10}$ Arthur J. Dommen, The Indochina experience of the French and the Americans: nationalism and communism in Cambodia, Laos, and Vietnam (Indiana University Press, 2002), 107-110.
} 
On V-J Day, September 2, 1945, Ho Chi Minh declared the independence of the Democratic Republic of Vietnam. This was short-lived, as by September 23, French forces overthrew the Hanoi government. At this point, the United States foreign policy towards French occupation in Vietnam was neutral: they would not oppose the reestablishment of French control, but they also would not assist the French reestablish their control. ${ }^{11}$ By mid-December 1946, fighting erupted between Vietnamese troops and French forces in Hanoi. This sentiment spread across North Vietnam, increasing violence towards French occupiers. French emissaries approached Bao Dai with an offer to be reinstated as head of state of an independent Vietnam. An agreement between the French Government and Bao Dai was signed on December 7, 1947 aboard a French vessel in Ha Long Bay, which provided minor facets of independence for the Vietnamese. This was followed by another agreement on June 5, 1948, which was a stronger commitment to Vietnamese independence, albeit the French government would still be in control of infrastructure (including the military and foreign relations). ${ }^{12}$ This was confirmed on March 8, 1949 when French President Auriol signed the Elysee Agreement, which recognized Vietnam as an independent state within the French Union.

\section{Normative Differences}

The philosophical traditions between Vietnam and the United States are quite different, relying on different assumptions about human nature and the proper order of society. Confucianism places great emphasis on the maintenance of correct human relationships as a mechanism for achieving social order. In order to achieve such harmony, each individual has a particular place in the natural order and is expected to fulfill the duties required. These duties can

\footnotetext{
${ }^{11}$ Gravel, ed., The Pentagon Papers, 1:18.

12 Ellen Joy Hammer, The Struggle for Indochina, 1940-1955 (Stanford University Press, 1966), 224-228.
} 
take the form of four different organizations, the work unit, family, school and community. ${ }^{13}$ Most important are the Five Relations, which include: (1) father and son, (2) ruler and minister, (3) husband and wife, (4) old and young, and (5) friends. ${ }^{14}$

These relations are unequal, with the exception of the relationship between friends. That is to say that one party much show respect and reverence towards the other party. That is not to say that the other party may take license, but rather show mutual benevolence to one another. The epitome of harmony (Li) is filial piety or xiao (which includes one's parents, elders and ancestors), which is predicated on reverence (jing). ${ }^{15}$ As such, Confucian philosophy places great emphasis on the family unit as the most basic unit within society.

The Vietnamese civil religion is a dichotomous yin-yang of contradictions, in which both Confucian and Buddhist tenets are melded together. On the one hand, strict social organization and discipline is practiced, while also maintaining independence and individualism. ${ }^{16}$ For Westerners, these traits would be mutually exclusive, but not so in Eastern Philosophy. ${ }^{17}$ The way in which this manifests itself is through the multiple roles that a person performs as they carry out their duties. It is through the performance of duty (Li) that one self-cultivates, aspiring to be the "profound person" (Junzi). This is inextricably linked to the Confucian sense of morality, which is characterized as "the profound person understands" as opposed to "the small person understands what is profitable". ${ }^{18}$

\footnotetext{
${ }^{13}$ Lewis, When Cultures Collide, 488.

${ }^{14}$ Mencius The book of Mencius 3A:4.

${ }^{15}$ Analects 1.11, 2.7, 4.18.

${ }^{16}$ Richard D. Lewis, When Cultures Collide: Leading Across Cultures (Boston: Nicholas Brealey Publishing, 2006), 480-1.

${ }^{17}$ The Neo-Confucian Ch'eng I describes the relationship of yin-yang as "man's body and shadow... as they are simultaneous, it should not be said that a man has his body today and his shadow tomorrow. To have them is to have them at the same time" (I-shu 15:13b).

${ }^{18}$ Confucius Analects 4.16.
} 
Christian theologians have reached a much different conclusion about the human condition and proper ordering of society. Saint Paul was the first to acknowledge that "It is for freedom that Christ has set us free." ${ }^{19}$ Theologians such as St. Augustine and St. Thomas Aquinas extrapolated an early theory of utilitarianism, which postulates that human actions are directed toward a good, which is defined by his/her conception of happiness. This is reflected in the Catechism of the Catholic Church: "God created man a rational being, conferring on him the dignity of a person who can initiate and control his own actions. "God willed that man should be "left in the hand of his own counsel,' so that he might of his own accord seek his Creator and freely attain his full and blessed perfection by cleaving to him." ${ }^{20}$ Under the guise of Imago Dei ${ }^{21}$, Christian doctrine was predicated on the individual's consent and free will to control their own destiny. This was affirmed during the Gregorian reforms (1000-1300 AD), which attempted to supplant Germanic and Roman traditional social structures which centered around relationships of natural inequality. This transition was facilitated by the establishment of papal sovereignty, for which all individuals were equally subjected to the authority of the Pope. Traditional structures of natural inequality, which perpetuated the family as the primary unit of society, were challenged by canon law. ${ }^{22}$

The American civil religion, which places emphasis on individual liberty and selfactualization. The civil religion of the United States has deep roots in the Christian ontological tradition, which places emphasis on individualism and equal liberty. The tenets of liberalism, a cornerstone of United States civil religion "preserves the Christian ontology without the

\footnotetext{
${ }^{19}$ Galatians 5:1.

${ }^{20}$ Catechism of the Catholic Church, 2nd ed., 1730.

${ }^{21}$ Genesis 1:26-28, 5:1-3, 9:6.

${ }^{22}$ Siedentop, Inventing the Individual, 237-240.
} 
metaphysics of salvation". ${ }^{23}$ This is consistent with the development of classical liberalism, which emphasizes individual rights and freedom.

\section{Domestic Political Change}

The rapidly changing political situation within Vietnam, including the rise of Ho Chi Minh, coupled with the Communist rise in China, provoked fears from the United States. These fears of communism spreading throughout Asia - domino theory - resulted in military containment policies within Vietnam. After the French forces were defeated, the United States took a more active role in Vietnam, which was framed as the front line of communism. The tactics used during the war underscored the basal differences between the United States and Vietnam. These differences were manifest in the treatment of civilians and the environment. This section will discuss the events that led up to the conflict and provide in-depth analysis of United States tactics during the war.

The political landscape in Vietnam changed in 1949, after the Chinese National government collapsed and was replaced with a Communist government under Mao Zedong. The foreign policy of the United States in Asia became similar to that of Eastern Europe, including collective security, economic aid and military assistance. ${ }^{24}$ It was this arrangement that resulted in the Korean War, Southeast Asia Treaty Organization (SEATO) and early involvement in Vietnam. Due to these political changes in Asia, the State Department changed their tune on May 10, 1949: "[The] Bao Dai solution [is the] only means [of] safeguarding Vietnam from aggressive designs [of the] Commie Chinese". ${ }^{25}$ By late June 1949, Bao Dai was officially named the head of state within Vietnam, supported by an elected legislative assembly. While Vietnam was treated

\footnotetext{
${ }^{23}$ Larry Siedentop, Inventing the Individual: The Origins of Western Liberalism (Cambridge: Belknap Press, 2014), 338.

${ }^{24}$ Ibid., 1:6.

${ }^{25}$ Ibid.
} 
as an independent nation, the French were still de facto administrators of the government. Even Bao Dai himself described the situation: "What they call a Bao Dai solution turned out to be just a French solution". ${ }^{26}$

During the early months of 1950, the French relinquished control of all colonial control, transferring power to Bao Dai. Ho Chi Minh denounced the puppet government established by the French, claiming that the Democratic Republic of Vietnam (DRV) was the only legitimate government of the people. ${ }^{27}$ The Bao Dai regime was recognized as legitimate by most Western States. However, both Russia and China formally recognized the Ho Chi Minh regime. This demarcation of legitimacy was perceived by Secretary of State Acheson to "remove any illusions as to the "nationalist" nature of Ho Chi Minh's aims and reveals Ho in his true colors as the mortal enemy of native independence in Indochina". ${ }^{28}$

The first indication of Ho Chi Minh's communist leanings was discovered by the State Department in July 1948, which indicated that he had a history of affiliating with known Communists, including the socialist French newspaper L'Humanité, and was described as a 'communist' by Russian publications. ${ }^{29}$ The report also indicated that there was no direct evidence linking Ho Chi Minh to the Soviets. Nevertheless, concerns of Chinese Communism spreading to other parts of Asia prompted the United States foreign policy stance to be fueled by anticommunism. The Viet Minh were perceived as being part of a world-wide communist movement. The French acted as containment for the communist threat in Vietnam. Without a buttress against the spread of Communism, it would lead to other surrounding nations to become Communist.

\footnotetext{
${ }^{26}$ Ibid., 1:16.

${ }^{27}$ Ibid., 1:7.

28 Ibid.

${ }^{29}$ Bernard B. Fall, Ho Chi Minh on Revolution: Selected Writings, 1920-66 (New American Library of Canada, 1968), 8-10.
} 
This was known as domino theory, which predated the Korean War, formalized in National Security Council (NSC) 48/1 (June 1949), Secretary of Defense Louis Johnson declared that "the extension of communist authority in China represents a grievous political defeat for us...If Southeast Asia is also swept by communism, we shall have suffered a major political rout the repercussions of which will be felt throughout the rest of the world, especially in the Middle East and in a then critically exposed Australia". ${ }^{30}$ It goes on to recognize the vulnerability of former colonies, "the colonial-nationalist conflict provides a fertile field for subversive communist movements, and it is now clear that Southeast Asia is the target for a coordinated offensive directed by the Kremlin". 31

The logic of domino theory was further laid out in the following NSC report:

It is important to United States security interests that all practicable measures be taken to prevent further communist expansion in Southeast Asia. Indochina is a key area of Southeast Asia and is under immediate threat. The neighboring countries of Thailand and Burma could be expected to fall under Communist domination if Indochina were controlled by a Communist-dominated government. The balance of Southeast Asia would then be in grave hazard. ${ }^{32}$

After Korea, the threat of communism in Asia was not the Kremlin, but China. This was explained clearly in NSC 124/2, which superseded NSC 48 and NSC 64, describing "the danger of an overt military attack against Southeast Asia is inherent in the existence of a hostile and aggressive Communist China". ${ }^{33}$ The purpose of NSC 124/2 was clear that the primary threat in Indochina was China, and no direct involvement would take place in Indochina, insofar as it was not the result of "overt or covert Chinese Communist aggression". ${ }^{44}$ If overt Chinese aggression

\footnotetext{
${ }^{30}$ U.S. National Security Council, NSC 48/1: The Position of the United States with Respect to Asia. December 23, 1949.

${ }^{31}$ Ibid.

${ }^{32}$ U.S. National Security Council, Report by the National Security Council on the Position of the United States with Respect to Indochina. February 27, 1950.

${ }^{33}$ U.S. National Security Council, NSC 124/2: United States Objectives and Courses of Action with Respect to Southeast Asia. June 25, 1952.

${ }^{34}$ Ibid.
} 
did occur, it recommended: “(1) naval, air and logistical support of French Union forces; (2) naval blockade of Communist China; (3) attacks by land and carrier-based aircraft on military targets in Mainland China". ${ }^{35}$ This was echoed in the earliest NSC document of the Eisenhower administration (NSC 5405), stating that:

\begin{abstract}
Certain other countries, such as Indochina or Formosa, are of such strategic importance to the United States that an attack on them probably would compel the United States to react with military force either locally at the point of attack or generally against the military power of the aggressor. Moreover, the principle of collective security through the United Nations, if it is to continue to survive as a deterrent to continued piecemeal aggression and a promise of an eventual effective world security system, should be upheld even in areas not of vital strategic importance. ${ }^{36}$
\end{abstract}

This document clearly defined the United States position on Domino Theory ${ }^{37}$ and expressed firm concern over a coalition regime. ${ }^{38}$ Based on the NSC documentation, which held Indochina as a valuable strategic resource, it necessitated United States action if the French withdrew. Military intervention in Indochina was, as The Plans Division of the Army General Staff pointed out, "that under current programs the Army did not have the capability of providing divisional forces for operations in Indochina while maintaining its existing commitments in Europe and the Far East". ${ }^{39}$ Army also suggested a "reevaluation of the importance of Indochina and Southeast Asia in relation to the possible cost of saving it" ${ }^{40}$ Vice Admiral A.C. Davis wrote that "If it is determined desirable to introduce air and naval forces in combat in Indochina it is difficult to understand how involvement of ground forces could be avoided". ${ }^{41}$ There was also a divide

\footnotetext{
${ }^{35}$ Gravel, ed., The Pentagon Papers, 1:94.

${ }^{36}$ U.S. National Security Council, NSC 5405: United States Objectives and Courses of Action with Respect to Southeast Asia. January 16, 1954.

37 "such is the interrelation of the countries of the area that effective counteraction would be immediately necessary to prevent the loss of any single country from leading to submission to, or an alignment with, communism by the remaining countries of Southeast Asia and Indonesia." (Gravel, ed., The Pentagon Papers, 1:92)

${ }^{38}$ The document expressed concern that "a nominally non-Communist coalition regime would eventually turn the country over to Ho Chi Minh with no opportunity for the replacement of the French by the United States or the United Kingdom." (Gravel, ed., The Pentagon Papers, 1:87)

${ }^{39}$ Gravel, ed., The Pentagon Papers, 1:94

${ }^{40} \mathrm{Ibid}$.

${ }^{41}$ Ibid., 1:95.
} 
between the state and defense departments. At NSC's $179^{\text {th }}$ meeting on January 8, 1954 it was said that "The commitment of U.S. forces in a 'civil war' in Indochina will be an admission of the bankruptcy of our political policies re Southeast Asia and France and should be resorted to only in extremity". 42

A working group was formed, in the aftermath of the NSC 177 and NSC 5405 unable to determine a commitment to Indochina in the event that French forces were unsuccessful in regaining control of the situation. This was under the chairmanship of General G.B. Erskine, with representatives from all the major departments (State, Defense, Joint Chiefs and CIA). The first part of the report (February 6,1954) echoed previous sentiments of U.S. foreign policy towards Indochina. Namely, that military and economic aid should be used to support the French and reliant on Vietnamese support to turn the tide against the Viet Minh. ${ }^{43}$ The second part of the report (March 17, 1954) was the first clear indication of U.S. involvement if the French were defeated. This document recommended that the U.S. policy in Indochina should be uncompromising military victory. Furthermore, the U.S. should oppose any concessions made by France towards the Viet Minh at the Geneva negotiations. This was summarized by the Joint Chiefs of Staff (JCS), who prepared a memo for the Secretary of Defense:

If, despite all U.S. efforts to the contrary, the French Government elects to accept a negotiated settlement which fails to provide reasonably adequate assurance of the future political and territorial integrity of Indochina, the U.S. should decline to associate itself with such a settlement and should pursue, directly with the governments of the Associated States and with other Allies (notably the U.K.), ways and means of continuing the struggle against the Viet Minh in Indochina without participation of the French ${ }^{44}$

\footnotetext{
${ }^{42}$ Ibid., 1:95.

${ }^{43}$ Ibid., 1:97.

${ }^{44}$ U.S. Joint Chiefs of Staff, Preparation of Department of Defense Views Regarding Negotiations on Indochina for the Forthcoming Geneva Conference. March 12, 1954.
} 
The Eisenhower administration, who began taking seriously the prospects of the Viet Minh winning against the French, proposed a coalition effort in retaking Vietnam, which was coined the "United Action" proposal by Secretary of State Dulles (March 29, 1954). ${ }^{45}$ This plan proposed a ten-nation collective defense force that would operate to defeat the Viet Minh. While congress was not interested in intervention unless the plan was accepted, Eisenhower refused to act unilaterally without Congressional approval. Ultimately, Thailand and the Philippines were the only states to support the U.S. "United Action" plan.

The "United Action" plan was first proposed at the Berlin Conference of 1954, between the Big Four leaders. The U.K. was the most hesitant. Eden did not equate collective security in Asia with military action in Indochina. As Dulles correctly judged, behind Britain's push for a settlement was the "fear that if fighting continues, we will in one way or another become involved, thereby enhancing risk of Chinese intervention and possibility further expansion of war." ${ }^{26}$ The French also opposed any formation of a coalition because they feared it would create an internationalization of the war, which would remove their control. Prior to Dien Bien Phu, the focus was on decisive military victory. ${ }^{47}$

After Dien Bien Phu, U.S. policy towards Vietnam became disaggregated from the domino theory. On May 11 Dulles said that "Southeast Asia could be secured without Vietnam, Laos and Cambodia". ${ }^{48}$ The settlement at Geneva would divide the nation into a North and South Vietnam,

\footnotetext{
${ }^{45}$ The phrase "united action" stems from the following speech on March 29, 1954: "Under the conditions of today, the imposition on Southeast Asia of the political system of Communist Russia and its Chinese Communist ally, by whatever means, would be a grave threat to the whole free community. The United States feels that the possibility should not be passively accepted but should be met by united action. This might involve serious risks. But these risks are far less than those that will face us a few years from now if we dare not be resolute today." (IndochinaViews of the United States on the Eve of the Geneva Conference: Address by the Secretary of State. March 29, 1954. http://avalon.law.yale.edu/20th_century/inch019.asp\#1).

${ }^{46}$ Telegram from Secretary of State Dulles on Conversation with Eden and Bidault about Indochina. April 26, 1954.

${ }^{47}$ Gravel, ed., The Pentagon Papers, 1:110.

${ }^{48}$ Department of State Bulletin No. 24. May 1954, 782.
} 
with Ho Chi Minh governing the northern half. U.S. strategy at this point became aligned with U.K. sentiments of a defensive alliance in order to prevent future losses. ${ }^{49}$ NSC memorandum and French-American diplomatic dialogue illustrates that the end-goal of the U.S. was de-colonization in Indochina. The Geneva Accord ultimately achieved this goal, albeit not to the satisfaction of the United States.

The Geneva Conference (April 26-July 20, 1954) was convened by the major powers (The Soviet Union, The United States, France, the United Kingdom and China) to discuss the deteriorating situation in Korea and Indochina. The Geneva Accords marked the conclusion of the First Indochina War, and as a result, French imperialism in Indochina came to a halt. Vietnam, Cambodia and Laos were deemed to be independent states, who were afforded rights of selfdetermination through free elections. Vietnam was divided along the $17^{\text {th }}$ Parallel, with the intention of unification in the future via national elections. Neither North nor South Vietnam were content with the arbitrary separation of their country. The perception of the partition was viewed by the Viet Minh as "provisional and should not in any way be interpreted as constituting a political or territorial boundary". ${ }^{50}$ Nevertheless, the Geneva Accord provided a temporary solution of division until the time of national elections.

The U.S. attended the Conference with the intention of separating itself from the goals of the French delegation, which included a cease-fire and elections. This was a concern for the U.S., who feared that elections would be ineffective due to "factors as the prevalence of illiteracy, the lack of suitable educational media, and the absence of adequate communications in the outlying areas would render the holding of a truly representative plebiscite of doubtful feasibility". ${ }^{51}$ The

\footnotetext{
${ }^{49}$ Gravel, ed., The Pentagon Papers, 1:114.

${ }^{50}$ Gravel, ed., The Pentagon Papers, 1:172.

${ }^{51}$ U.S. Joint Chiefs of Staff, Preparation of Department of Defense Views Regarding Negotiations on Indochina for the Forthcoming Geneva Conference. March 12, 1954.
} 
Communists, by virtue of their superior capability in the field of propaganda, could readily pervert the issue as being a choice between national independence and French Colonial rule. Furthermore, it would be militarily infeasible to prevent widespread intimidation of voters by Communist partisans. While it is obviously impossible to make a dependable forecast as to the outcome of a free election, current intelligence leads the Joint Chiefs to believe that a settlement based upon free elections would "be attended by almost certain loss of the Associated States to Communist control". ${ }^{52}$ The resulting Geneva Accords were bittersweet for the U.S. The settlement included elements of American foreign policy interests (including independence for Laos and Cambodia), but they also meant that the free world lost another piece to the communist bloc. ${ }^{53}$ Eisenhower stated in a July 21 news conference that the Accords contained "features which we do not like, but a great deal depends on how they work in practice". 54

The United States, along with South and North Vietnam, were most interested in unification, rather than a division of the country. This was also a difficult position for the United States because they had supported an independent Vietnam prior to Ho Chi Minh. Since that time, they had adopted a more hardline approach that advocated for an independently non-communist united Vietnamese regime, which was almost assuredly not going to be the outcome if national elections occurred. The first die was cast in January 1955, when President Diem refused to act in accordance with the clauses pertaining to elections within the Geneva Agreement. ${ }^{55}$ Their justification in doing so was that they had not participated in the Settlement of 1954. It was the French who were the sole executor of the agreement, and they failed to maintain a presence in

\footnotetext{
${ }^{52}$ Ibid.

${ }^{53}$ This was a major defeat for NSC 5405, and cast the accords as a "serious loss for the free world, the psychological and political effects of which will be felt throughout the Far East and around the globe" (The Pentagon Papers, 192)

${ }^{54}$ Indochina - The Cease-Fire Agreements in Indochina: Statement by the President. July 21, 1954. http://avalon.law.yale.edu/20th_century/inch027.asp.

${ }^{55}$ Diem stated that "Southern Viet-Nam, since it protested the Geneva Agreement when it was made, does not consider itself a party to that Agreement, nor bound by it." (Gravel, ed., The Pentagon Papers, 1:343).
} 
Indochina after 1955. France granted South Vietnam independence in June 1954, handing control of infrastructure and governing functions to the South Vietnamese. The partition of Vietnam was different from the partitions in Korea or Germany because they lacked international enforcement. After the French Expeditionary Crops left in 1956, South Vietnam was largely defenseless.

From 1954 to 1961, North Vietnamese insurgents conducted operations in the South with the purpose of "political agitation". ${ }^{56}$ These operations utilized terrorist tactics, including civilian massacres and assassinations of prominent leaders. During the Kennedy administration, official U.S. foreign policy was to provide support and guidance to the Diem regime in their fight against the insurgency. By the time Johnson was inaugurated, the situation in Vietnam had deteriorated. It became clear that the South Vietnamese government was ineffective, leading to the U.S.sanctioned assassination of South Vietnamese President Diem. ${ }^{57}$ ARVN forces, supplied and trained by U.S. military advisors, were also unable to defend local populations or root out Viet Cong sympathizers. The turning point in the conflict was the Gulf of Tonkin incident, in which the USS Maddox was allegedly fired upon by North Vietnamese forces, leading to the Gulf of Tonkin Resolution on August 7, 1964.

\section{Ontological Threat}

The official foreign policy position of the U.S. emphasized the importance of Vietnam in the ideological battle against Communism. This was predicated on domino theory, which posits that Asian countries will continue to succumb to Communism one by one. While this was the official purpose of U.S. involvement in Vietnam, the indiscriminate conduct of U.S. forces indicates moral superiority to their inferior opponents. American decision-makers had a negative perception of the Vietnamese ideology (culture, language and history), which culminated in certain

\footnotetext{
${ }^{56}$ Gravel, ed., The Pentagon Papers, 1:314-316.

${ }^{57}$ Stanley Karnow, Vietnam: A History (New York: Penguin, 1997).
} 
practices of warfare that indiscriminately targeted civilian populations, via the use of chemical weapons and dehumanization of the Vietnamese people.

The uniqueness of the Vietnam War was the general consensus among policy-makers, military tacticians and the general public that the Vietnamese were culturally inferior to the U.S. These dehumanizing perceptions of elites were the catalyst for the tactics used during the Vietnam War. The following section will first deconstruct the negative perceptions of the Vietnamese by American elites, which was actualized in several unique tactics used by the Americans during the Vietnam War.

High-ranking military and political decision-makers approached the Vietnamese with a sense of moral superiority. President Johnson, who oversaw the buildup of troops and escalation of combat operations within Vietnam, referred to the Vietnamese as "yellow dwarfs" who lived in "young and unsophisticated" nations. ${ }^{58}$ General Westmoreland echoed this sentiment when he claimed that "The Oriental doesn't put the same high price on life as the Westerner. Life is plentiful, life is cheap in the Orient, and as the philosophy of the Orient expresses it, life is not important". 59

There are several implications with the way American elites cast the Vietnamese. First, dehumanization extended beyond the North Vietnamese Army (NVA) or Viet Cong. The conflict in Vietnam was fought against the communist forces in the North, yet policymakers tended to refer to all 'Vietnamese' with a negative connotation. The indiscriminate use of language may seem trivial, but would become problematic when facing an enemy that relied heavily upon civilian support. The perception of the Vietnamese people as a whole was not demarcated between North and South Vietnamese, Army of the Republic of Vietnam (ARVN) and NVA forces or civilians

\footnotetext{
${ }^{58}$ Beau Grosscup, Strategic terror: The politics and ethics of aerial bombardment (Zed Books, 2006), 92.

${ }^{59}$ Peter Davis, dir., Hearts and Minds (BBS, 1974))
} 
and Viet Cong. In other words, the entire culture was typecast by those who developed the strategy and conduct of the war. This was not limited to NVA or Viet Cong, but included ARVN and civilians, “A gook's a gook". ${ }^{60}$

Secondly, the prejudice that policymakers exhibited toward the Vietnamese became institutionalized in the training of military personnel. This was institutionalized in the "mere gook rule' or MGR, which de-emphasized the value of life of all Vietnamese, whether civilian or soldiers. The logic behind the MGR was "that it was no crime to kill or torture or rob or maim a Vietnamese because he was a mere gook...the trouble is no one sees the Vietnamese people. They're not people". ${ }^{61}$ Some American soldiers took this a step further, likening the Vietnamese to bugs or animals, rather than human beings. ${ }^{62}$ While there were varying degree of perception toward the Vietnamese, the military actively condoned the blatant disregard of human life. This is evidenced in the cadence used by the $1^{\text {st }}$ Cavalry division:

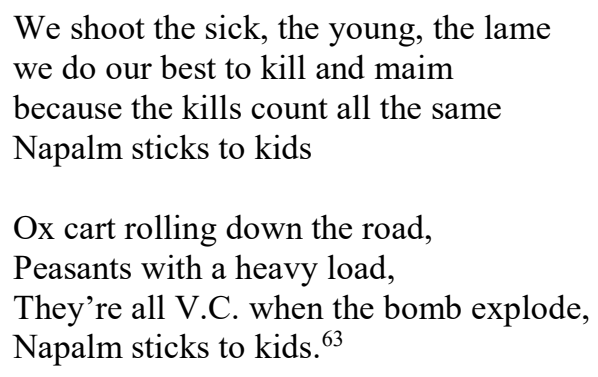

Within the institutionalized training of the soldier, inherent racism towards the Vietnamese was prevalent. Soldiers were trained not to treat civilians that were hurt "because they're not worth anything; they're just gooks", in addition "we were not allowed to waste [serum albumin] on a Vietnamese". ${ }^{64}$

\footnotetext{
${ }^{60}$ David H. Hackworth and Julie Sherman, About face: The odyssey of an American warrior (Simon and Schuster, 1990), 693.

${ }^{61}$ Gary D. Solis, Son Thang: an American war crime (Naval Inst Press, 1997), 103.

${ }^{62}$ Jinim Park, Narratives of the Vietnam War by Korean and American Writers (Peter Lang, 2007), 30.

${ }^{63}$ Jan Barry, ed., Peace Is Our Profession: Poems and Passages of War Protest (East River Anthology, 1981), 22.

${ }^{64}$ Geoff Simons, The Vietnam Syndrome: Impact on US Foreign Policy (Springer, 1997), 241.
} 
The dehumanization of an enemy force is not novel or unique during the Vietnam War. However, the combination of dehumanizing an entire culture, reliance on body counts and defoliation, resulted in widespread destruction and high volumes of civilian casualties. The institutionalized prejudice towards an inferior people in Vietnam laid the groundwork for the conduct of the war. It has been best summarized that "American military policy did not...make atrocities by individual soldiers inevitable, but it certainly made it inevitable that American forces as a whole would kill many civilians". ${ }^{65}$

The Gulf of Tonkin Resolution granted the power to conduct military operations in Vietnam without a congressional declaration of war. The first United States military personal was deployed in 1965, and would remain entrenched in the struggle until the Paris Peace Accords, signed on January 27, 1973. The war itself was the result of domino theory and communist containment, but the tactics used in Vietnam were much more disturbing. Of most important interest are attrition and body count, pacification and defoliation.

\section{Attrition and body count}

The experience in Vietnam was unique because it did not rely on clear cut battle lines and a distinguishable enemy force. Unlike previous conflicts that America had been involved, the enemy (NVA and VC) operated within the state and among the people whom the U.S. was containing against Communism. Because the goal of the Vietnam War was containment, rather than occupation of a territory or elimination of the enemy leadership, it was necessary to develop a new strategy of conducting warfare.

The Vietnam War was framed by U.S. decision-makers as a war of attrition against the Communist North. In January 1964, when Westmoreland became deputy commander of Military

\footnotetext{
${ }^{65}$ Christian G. Appy, Working-class war: American combat soldiers and Vietnam (University of North Carolina Press, 2000), 201.
} 
Assistance Command, Vietnam (or MACV), it was clear that the emphasis of American forces was on "search and destroy". American forces relied upon their superior firepower and mobility to seek out NVA/VC forces and prevent them from threatening rural populations. In conjunction with U.S. led "search and destroy" missions, ARVN forces were to focus their efforts on pacification. ${ }^{66}$ The logic behind search and destroy was rooted in attrition; aimed at eliminating threats in the South, without overextending operations in the North and risking higher casualties. Through the killing of NVA/VC forces, Westmoreland postulated that it would force Ho Chi Minh to respect the sovereignty of South Vietnam. From the beginning of the conflict, Westmoreland and McNamara were aware that attrition required a protracted conflict, as it would take time to break the will of the North. ${ }^{67}$ It was through this "victory strategy" that would provide an environment to negotiate with the North. ${ }^{68}$ An implication of an attrition-based strategy is that victory was conditional on your opponents will to fight; if the enemy continued to fight, it would deny victory. Westmoreland began to reconsider this strategy in January 1967, when he provided the Joint Chiefs with an assessment of long-term attrition. As a part of this briefing, Westmoreland demonstrated that the NVA/VC were able to replenish their forces at a rate of 12,000 per month. Even with sustained heavy losses, they managed to increase their total forces by 42,000 during 1966. ${ }^{69}$ This news was extremely disappointing, as the premise of an attrition strategy was reliant on upon wearing the enemy down.

The common way of measuring 'success' in a war of attrition is body count. If the number of enemy dead exceeds the number of friendly casualties, then it is considered a success. The American media focused on the body counts of soldiers, but rarely reported on the civilian death

\footnotetext{
${ }^{66}$ Gravel, ed., The Pentagon Papers, 3:395.

${ }^{67}$ Henry L. Trewhitt, McNamara (Harper \& Row, 1971).

${ }^{68}$ Gravel, ed., The Pentagon Papers, 3:456.

${ }^{69}$ Ibid., 3:348-354.
} 
toll. This was because collateral damage was politically irrelevant; resulting in methods (such as strategic bombing) that accentuated enemy casualties, while keeping friendly casualties low. ${ }^{70}$ With superior technology and training, it was expected that U.S. forces should have been able to inflict greater casualties than their opponents. The model developed under McNamara was likened to a balance sheet. ${ }^{71}$ The combination of Westmoreland's attrition-based strategy with a Secretary of Defense who quantified success using body count would create a difficult situation for soldiers in Vietnam, who were rewarded for meeting quotas.

The quota was one way in which commanders showed 'success' during the Vietnam War. Relying on body count as a measure of success meant that people were reduced to a balance sheet. Commanders had immense pressure to meet weekly quotas, and would either be rewarded for doing so, or punished for failing to be 'successful'. Soldiers who exceeded body count quotas were rewarded with prizes, including cans of beer and R\&R in Saigon. ${ }^{72}$ Mid-level officers were under constant pressure and competition for promotions within Vietnam increased the incentive of reaching arbitrary quotas. This even resulted in all $9^{\text {th }}$ infantry commanders being required to carry $3 \times 5$ cards with body count totals for their units organized by date, week and month. ${ }^{73}$

One of the unintended side-effects of using body count as a measure of success was the killing of civilians to satisfy the quota. Because of the pressure on unit commanders to produce enemy bodies, it led to the counting of civilians as Viet Cong. One of the mottos adopted was 'If it's dead and Vietnamese, it's VC'. ${ }^{74}$ In conjunction with quotas, the use of free fire zones was a

\footnotetext{
${ }^{70}$ Edward S. Herman and Noam Chomsky. Manufacturing consent: The political economy of the mass media (Random House, 2010), 132-3.

${ }^{71}$ This approach was familiar to McNamara, who had extensive experience working at Ford Motor Company as a financial analyst and strategist.

${ }^{72}$ Christopher Coker, The warrior ethos: military culture and the war on terror (Routledge, 2007), 22.

${ }^{73}$ Douglas Kinnard, Adventures in Two Worlds: Vietnam General and Vermont Professor (Xlibris Corporation), 2012.

${ }^{74}$ Philip Caputo, A Rumor of War. 1977 (New York: Henry Holt, 1996).
} 
common tactic for subduing an area of suspected enemy forces. Free-fire zones were used in previous wars, but the reliance upon them increased in an environment where body count was emphasized. Free-fire zones were defined by the U.S. Army as "A specific designated area into which any weapon system may fire without additional coordination with the establishing headquarters". ${ }^{75}$ Certain areas within the South were categorized in this way, allowing soldiers to eliminate targets indiscriminately. Through the use of free-fire zones, it was much easier to meet quotas while limiting the number of American casualties. The problem with this tactic was that it condoned the killing of civilians if they remained within the target area. The assumption made by U.S. military command was that innocent civilians would evacuate the area, thereby any remaining persons were assumed to be VC operatives. This disregarded the cultural importance of familial land, in which the Vietnamese felt a spiritual connection. ${ }^{76}$

Attrition as a strategy relies upon killing more enemies than sustained casualties. Through this strategy, it was expected to destroy the enemies' will to fight, which would result in a peaceful negotiation. In this particular case, the overarching goal in Vietnam was a two-state solution, in which the North recognized and respected the boundaries of South Vietnam. This strategy was undermined by the inability of decision-makers to clearly differentiate enemy combatants from civilians. This was by design, rather than an isolated incident (as happens in all conflicts), because of a perceived inferiority towards the Vietnamese as a whole. Villages that were determined to be

\footnotetext{
${ }^{75}$ U.S. Army, The Armored Division Brigade, FM 6-20 (Washington, DC, 1958).

${ }^{76}$ Vietnamese culture has been characterized as heavily influenced by Confucian values. As such, much emphasized is placed on duty and hierarchical relationships within society. The family is one of the most important units within society, and maintaining hierarchical roles is essential to order within society. The emphasis on tradition often takes the form of multiple generations living in the same house as well as being buried on the land. More on the cultural importance of the family in Vietnam can be read in the following: Charles Hirschman and Vu Manh Loi, "Family and household structure in Vietnam: Some glimpses from a recent survey," Pacific Affairs (1996): 229-249;, Stephen Cheng, "Understanding the culture and behaviour of East Asians-a Confucian perspective." Australian and New Zealand Journal of Psychiatry 24.4 (1990): 510-515; Mary W. Pye and Lucian W. Pye. Asian power and politics: The cultural dimensions of authority (Harvard University Press, 2009); Shaun Kingsley Malarney, Culture, ritual and revolution in Vietnam (University of Hawaii Press, 2002).
} 
hostile by South Vietnamese province chiefs were assumed to be Viet Cong base camps, which meant that they were reasonable targets, often subject to free-fire rules of engagement. ${ }^{77}$ That is not to say that efforts were not made to limit civilian casualties, but that the way in which pacification efforts were institutionalized only bolsters this premise.

\section{Pacification}

Pacification is a blanket term for efforts made by the South Vietnamese and American governments to reduce rural support and influence for the North Vietnam cause in the South. Since the inception of U.S. involvement in Vietnam, the U.S. had supported pacification programs, including the Strategic Hamlet Program and Hop Tac. Until 1967, pacification was conducted primarily by South Vietnamese forces (RVNAF), supported by the U.S. In May 1967, the United States developed CORDS (Civil Operations and Revolutionary Development Support) pacification plan, which served as an umbrella organization for all pacification efforts until the end of the war.

Several efforts were made by Ngo Dinh Diem, including the relocation of peasants to agricultural settlements that would allow for greater access to infrastructure. This program was first implemented in early 1955, in which ARVN forces were deployed in the Camau Peninsula. The process was replicated in other areas and followed a simple formula: ARVN troops would reclaim areas formally held by Viet Minh forces, followed by political indoctrination teams that would promote the message of Diem. Specialists would attack the tenets of communism and colonialism, promoting the reign of a free society under Diem. This was effective in certain operations, including within Quang Nai, Binh Dinh and Giai Phong. ${ }^{78}$

\footnotetext{
${ }^{77}$ Nick Turse, Kill Anything that Moves: The Real American War in Vietnam (Macmillan, 2013), 62.

${ }^{78}$ Gravel, ed., The Pentagon Papers, 1:408-410.
} 
This was followed by a program of Civic Action, which included social development, land reform and agricultural enhancements. Diem's Civil Action was modelled after the Groupes Administratifs Mobiles (GAMs), which was used by the French to bolster support of rural populations through the development of infrastructure and access to services. This included both the development of physical needs (i.e. the building of schools, hospitals and roads) as well as collective security through the forming of militias. In addition, civil servants were put into the field, working with villagers to assess their needs and develop services and community buildings to suit their needs. This may include a village hall, primary school and combination information hall (used for news and dispensary of medicine). Villagers were empowered to perform the maintenance of these services after the civil servant moved on to the next village. In part due to communist subversion, and fear from villagers, civil action was abandoned in $1957 .{ }^{79}$ While early efforts of pacification emphasized the development of services for rural communities, with the hope of currying favor for the South Vietnamese government, pacification efforts evolved to include other reforms as well.

Land reform was one of the most important issues facing rural Vietnamese farmers, who composed nearly $90 \%$ of the population. Ho Chi Minh was committed to distributing land equitably among the people, as evidenced in his actions during the First Indochina War. When the Viet Minh liberated an area from the French, they reallocated it to the poor and landless. ${ }^{80}$ In doing so, he became beloved by the rural populations within Vietnam. This provoked columnist Joseph Alsop, who witnessed these farms in action to declare that the Communist regime was genuinely "serving the people". ${ }^{81}$

\footnotetext{
${ }^{79}$ Ibid.

${ }^{80}$ Edward E. Moise, Land Reform in China and North Vietnam (Chapel Hill: University of North Carolina Press, 1983), 155-159.

${ }^{81}$ Joseph Alsop, “A Man in a Mirror,” The New Yorker, June 25, 1955.
} 
Diem had to offer a competitive offer in order to secure the loyalty of the peasants that composed ninety percent of South Vietnam. In order to maintain a balance with landowners, he proposed that wilderness lands be settled by villagers, which would be rent-controlled. Since they would be mandated to clear and irrigate previously unused land, peasants were outraged that they would also have to pay for their land holdings. The impact of these reforms actually consolidated landholdings in the hands of a few landowners, with $75 \%$ of all land owned by $15 \%$ of the population. A majority of these landowners hailed from the Northern part of South Vietnam and were Catholic. This created a cleavage between the 'privileged' group and peasant class, which only bolstered the Communist cause. ${ }^{82}$ While land reform and rural services had failed at gaining traction among rural populations, the goal of pacification turned to relocation.

Due to the failures of previous pacification attempts, it became clear that the South Vietnamese government was unable to convince rural populations to support their cause, an alternative strategy was necessary in order to bolster rural defenses against the Viet Cong. Relocation was a small part of the larger pacification program from 1957 to 1961, in which 210,000 people were relocated to new, more defensible positions. ${ }^{83}$

In 1959, more drastic relocation measures were taken. Diem hand-selected areas in lowland areas on the basis of strategic importance and defensibility. ${ }^{84}$ In some of these cases, these areas were unsuitable for farming. In other cases, it exacerbated ethnic tensions, such as the Montagnard people from the Central Vietnam Highlands. This group was targeted because of the historical tensions they had with the Vietnamese government. By relocating these tribes into larger groups, the Diem government thought they would be able to better defend them against Viet Cong

\footnotetext{
${ }^{82}$ Gravel, ed., The Pentagon Papers, 1:412.

${ }^{83}$ Ibid., 1:415.

${ }^{84}$ Ibid.
} 
infiltration. By 1961, over 35,000 Montagnard people (about 50\% of their total population) were relocated.

Another large scale relocation project took place in February 1959, with the objective to divide rural populations into two different groups: qui khu and qui ap. Qui Khu communities included individuals who were related to Viet Minh or harboring Viet Minh. Qui Ap communities were those with pro-GVN (Government of North Vietnam) families. After facing much resistance from farmers who did not want to separate from their ancestral land, this program was abandoned by March $1959 .{ }^{85}$

This program was supplanted by a "agrovilles" program, that would establish Khu Tru Mat (Prosperity and Density Centers). Over 80 settlements (and surrounding defensive structures) were built by the end of 1963, which included social services and infrastructure for the villagers. Villagers were expected to contribute to the construction of these agrovilles, and relied upon their existing house for the construction materials. ${ }^{86}$ For obvious reasons of peasant resistance, the agroville program was abandoned by February 1962, to be replaced by the Strategic Hamlet Program.

When this program was ineffective, the Strategic Hamlet Program was adopted in 1961. With the support of the American Ambassador to South Vietnam Frederick Bolting and William Colby, the Strategic Hamlet Program relied on moving rural villagers to fortified villages. This would allow for villagers to have a stake in their collective security and would allow ARVN forces to better defend hamlets. ${ }^{87}$ Rather than relying on relocation, the Strategic Hamlet Program

\footnotetext{
${ }^{85}$ Ibid.

${ }^{86}$ Joseph J. Zasloff, "Rural Resettlement in South Viet Nam: The Agroville Program." Pacific Affairs 35, no. 4 (1962): 327-340.

${ }^{87}$ Philip E. Catton, Diem 's final failure: prelude to America's War in Vietnam (University Press of Kansas, 2002).
} 
focused on bolstering the defense of existing villages. This included the construction of new defensive capabilities and training the local populace to defend the Hamlet.

In 1964, with assistance from the United States, Chien Thang (Struggle for Victory) was adopted. This program was less widespread than the Strategic Hamlet Program, with an emphasis on slowly expanding influence from Saigon spreading like an "oil spot" to the countryside. ${ }^{88}$ This was launched in conjunction with Hop Tac, which was a joint U.S.-South Vietnamese operation that attempted to purge Viet Cong forces from six provinces around Saigon (Gia Dinh, Bien Hoa, Binh Duong, Hau Nghia, Lorg An, and Phuoc Tuy). This was undertaken by ARVN $5^{\text {th }}$ Division and Airborne and Marine Brigades. ${ }^{89}$ Hop Tac was the conception of Henry Cabot Lodge, ambassador to Vietnam, but failed to gain support among his peers. ${ }^{90}$ Ambassador Maxwell Taylor and Westmoreland, among others, were convinced that "the U.S. military was doing so well now that we face a distinct possibility that $\mathrm{VC}$ main force units will be neutralized, and $\mathrm{VC}$ fortresses destroyed soon". ${ }^{91}$ Due to an overconfidence in military superiority, the United States didn't take pacification seriously until the spring of 1966. Through a March 28 memorandum, President Johnson appointed Robert W. Komer as Special Assistant and William Leonhart as Deputy of the Rural Construction/Pacification Program. ${ }^{92}$ Previous iterations of relocation had failed to achieve the goal of swaying rural public opinion away from the Viet Cong. It became clear that American frustrations with the rural Vietnamese had reached a breaking point.

The first American campaign of pacification, led by the 'pacification Czar' Robert Komer, took a different approach to dealing with civilian populations. Rather than attempting to coop

\footnotetext{
${ }^{88}$ Gravel, ed., The Pentagon Papers, 2:536.

${ }^{89}$ Vietnam Helicopter Pilots Association, “Operation Hop Tac Information,” October 3, 2015. https://www.vhpa.org/KIA/panel/battle/64090100.HTM

${ }^{90}$ Gravel, ed., The Pentagon Papers, 2:536.

${ }^{91}$ Ibid., 576.

92 U.S. White House, National Security Action Memorandum No. 343 (March 28, 1966).
} 
villagers into relocating from their ancestral homeland through economic incentives, an alternative of force was used. Inspired by the Japanese campaign in China, American elites opted to "drain the sea" of support for the Viet Cong. General Westmoreland bluntly describes the situation for the Vietnamese civilian: "Until now the peasant farmer has had three alternatives. He could stay put and follow his natural instinct to stay close to the land, living beside the grave of his ancestors. He could move into an area under government control, or he could join the VC. Our operations have been designed to make the first choice impossible". ${ }^{93}$ Westmoreland was not alone in these opinions, as Komer had also suggested that refugees would deprive the Viet Cong of a recruiting base. ${ }^{94}$ In essence, the intentional destruction of civilian homes, livestock and other property would force civilians to relocate to refugee camps. This would deny the Viet Cong access to their property, as well as removing the temptation to support them. This was not merely theoretical, as the groundwork was laid in Operation Sunshine (1962).

Operation Sunrise was launched in the Binh Duong Province, as a part of the Strategic Hamlet Program. Villages were often occupied by Viet Cong after resettlement, as a result, Operation Sunrise relocated hundreds of villages to camps, whilst destroying all of their property in the process to deny it to the Viet Cong. ${ }^{95}$ While this was the first operation, it was not the last of this kind. Civilians were supposed to be given warning 24 hours prior to resettlement ${ }^{96}$, before soldiers forcibly relocated the residents to refugee camps. Entire villages were torched with the mantra "burn the damn gooks out. Burn it. Burn it, and they can't ever come back" ${ }^{97}$ Even more problematic was the needless slaughter of livestock upon arriving to a village. Since property

\footnotetext{
${ }^{93}$ Nguyen Cao Ky, Twenty Years and Twenty Days (Stein and Day, 1976), 140-141.

${ }^{94}$ Gravel, ed., The Pentagon Papers, 4:441.

${ }^{95}$ Turse, Kill Anything that Moves, 65.

${ }^{96}$ In some cases, civilians were not given any warning prior to soldiers arriving (Human Sciences Research, A Study of Mass Population Displacement in the Republic of Viet-Nam, Part II: Case studies of Refugee Resettlement (McLean, Va., 1969)).

${ }^{97}$ Ibid., 96.
} 
would not be able to be transported to resettlement camps, it was necessary to destroy so that the Viet Cong would not benefit from it. This meant that all domesticated animals, such as chickens, ducks, pigs and water buffalo were killed prior to torching the villages. ${ }^{98}$ Civilians were escorted to refugee-type camps, that were not designed with the livelihood of the Vietnamese in mind, but rather a human storage container. Rural villagers, who often practiced sustenance farming, were provided with little or no arable land, water or jobs. ${ }^{99}$ By 1969 , an estimated 690,000 refugees were displaced inside I Corps (The northernmost part of South Vietnam (composed of Quang Tri, Thua Thien, Quang Nam, Quang Tin and Quang Ngai provinces). American forces were suspicious of Vietnamese civilians, who had been the support structure for the Viet Cong in the South. This suspicion coupled with prejudice towards the Vietnamese people, resulted in a utilitarian military policy. Rather than territory, the Vietnamese people were the principle battleground in Vietnam. By removing them from the equation (either through murder or relocation), the Viet Cong would be unable to thrive.

\section{Defoliation}

Defoliation began under the Kennedy Administration and continued into the Nixon Administration, with the purpose of creating defensible positions in key areas, reducing ambushes along major roads, and food denial for the Viet Cong. During the Kennedy Administration, defoliation was mulled as a potential option for clearing foliage. There were three strategic objectives of these operations identified: (1) food denial, (2) tactical and (3) border control. ${ }^{100}$ Food denial focused on eliminating the ability for Viet Cong agents to live off the land. By

\footnotetext{
98 James Ebert, A Life in a Year: The American Infantryman in Vietnam (Presidio Press, 2004).

${ }^{99}$ Betty Jean Lifton and Thomas C. Fox. Children of Vietnam (Atheneum, 1972), 17-21; Louis A. Wiesner, Victims and survivors: displaced persons and other war victims in Viet-Nam 1954-1975 (Greenwood Pub Group, 1988), 14:91.

${ }^{100}$ U.S. Department of Defense, Memorandum for the President: Defoliant Operations in Viet Nam, Roswell Gilpatric (November 21, 1961).
} 
eliminating sources of food, it forces "them onto the open plain where they can more easily be dealt with is a legitimate and necessary military objective". ${ }^{101}$ This tactical objective focused on clearing Zone D, which was a haven for Viet Cong forces located 25 miles northeast of Saigon. This would be achieved through the defoliation of brush along roads and "selected sections of Viet Cong base areas"102. Border Control would focus on clearing areas along the Cambodian and Laotian borders, reducing infiltration routes for the Viet Cong. ${ }^{103}$

The first mention of using food denial was in a memorandum to the Department of Defense by the Country Team, on November 21, 1961. "The subsistence available to the Viet Cong insurgents would be attacked by spraying their manioc, corn, sweet potato, rice and other crops with commercially produced agricultural weedkiller-type products (cacodylic acid and butyl 2, 4, 5-T)". ${ }^{104}$ The chemical compounds butyl 2, 4 and 5-T would be later be known as Agent Orange. Even though the scientific community was not fully aware of the risks associated with using these chemicals, the memo also provided collateral damage from their use. An incident on November 6, 1961 in Tay Ninh occurred, in which the South Vietnamese government used these chemicals, which resulted in the local population falling ill after defoliation. This was not a selective incident; the effects of defoliants were apparent to those on the ground almost immediately. Once the plants absorbed the herbicides, it resulted in the browning of leaves and decaying of the fruit. This effect could be seen occur less than 24 hours after spraying. ${ }^{105}$ In addition, economically important crops

\footnotetext{
${ }^{101}$ U.S. Information Agency, Memorandum for Mr. McGeorge Bundy: Defoliation, Edward R. Murrow (August 16, 1962).

${ }^{102}$ U.S. Department of Defense, Memorandum for the President: Defoliant Operations in Viet Nam, Roswell Gilpatric (November 21, 1961), 2.

${ }^{103}$ Ibid.

${ }^{104}$ Ibid., 1.

${ }^{105}$ Hoang Ngoc Lung, Indochina Monographs: Strategy and Tactics (Pickle Partners Publishing, 1978).
} 
for Vietnamese civilians ${ }^{106}$ were disproportionately targeted by defoliation, upwards of $42 \%$ of all defoliation in 1965 targeted food crops. ${ }^{107}$

Even with these potential side-effects, the memorandum stressed that "The agents have no harmful effects on humans, livestock or soil". ${ }^{108}$ Three days later, on November 24, 1961, Dean Rusk signed a memorandum to the president that assured him that "The use of defoliant does not violate any rule of international law concerning the conduct of chemical warfare". 109 This contradicts the previous memorandum, which warned that "any such program would be subject to charges of chemical/biological warfare". ${ }^{110}$ Even though there were some concerns for using these tactics, President Kennedy approved selective defoliant operations on Nov. 30, $1961^{111}$ and subsequent expansion of these programs ${ }^{112}$ on January $5,1962^{113}$ and August 9, 1962. ${ }^{114}$ In late 1962, Kennedy delegated his authority over defoliation missions to the ambassador and MVAC. ${ }^{115}$ President Johnson only continued to expand defoliation operations during his presidency, especially after the Gulf of Tonkin incident. These operations were expanded even though that “In 1963, President Johnson's Science Advisory Committee was worried enough about the longterm health effects of herbicides to provide the impetus for the National Cancer Institute study,

\footnotetext{
${ }^{106}$ Which include apples, rice, mango, rubber, jackfruit and pineapples.

${ }^{107}$ Marilyn Young, Vietnam Wars 1945-90 (Harper Collins, 1991).

${ }^{108}$ U.S. Department of Defense, Memorandum for the President: Defoliant Operations in Viet Nam, Roswell Gilpatric (November 21, 1961), 3.

${ }^{109}$ U.S. Secretary of State, Memorandum for the President: Defoliant Operations in Viet-Nam, Dean Rusk (November 21, 1961).

${ }^{110}$ U.S. Department of Defense, Memorandum for the President, 2.

${ }_{111}$ National Security Action Memorandum No. 115, McGeorge Bundy (November 30, 1961).

112 Memorandum for the President: Additional Defoliation Operations in Vietnam, Maxwell D. Taylor (February 3 , 1962); Memorandum for the President: Defoliant Operations in Vietnam, Robert S. McNamara (February 2, 1962).

113 U.S. National Security Council, Memorandum for the Secretary of Defense, Bromley Smith (February 5, 1962).

${ }^{114}$ Memorandum for the Secretary of State and Secretary of Defense: Destruction of the Mangrove Swamps in South Vietnam, Michael V. Forrestal (August 9, 1962).

${ }^{115}$ Message, Department of State to AMEMBASSY Saigon, Joint State-Defense Message No. 561 (30 November 1962).
} 
which established that dioxin caused birth defects in mice."116 The following graph illustrates the amount of defoliants sprayed from 1961 until 1971:

Figure 7-3: Defoliants Sprayed per Year ${ }^{117}$

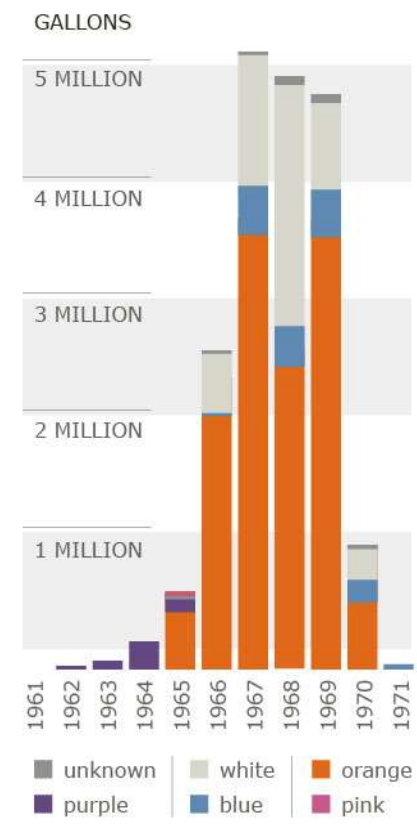

The RAND corporation published two different reports on the defoliation program in Vietnam in October 1967. ${ }^{118}$ These studies were based on interviews of 206 Vietnamese rural civilians, in which two important conclusions about defoliation were published. First, it concluded that defoliation had not resulted in any significant food shortages among the Viet Cong. ${ }^{119}$ They estimated that for every ton of rice denied to the Viet Cong, 500 civilians lost their primary food source. Secondly, defoliation had caused physical and emotional harm to residents, livestock and sustainable crops for civilian populations. Rural Vietnamese felt a deep connection to their

\footnotetext{
${ }^{116}$ David Burnham, "DOW Says U.S. Knew Dioxin Peril of Agent Orange," The New York Times, May 5, 1983.

117 Jason Grotto, Chris Groskopf, Ryan Mark, Joe Germuska and Brian Boyer, "U.S. troops, Vietnamese nationals exposed to dangerous chemicals," Chicago Tribune, December 4, 2009.

${ }^{118}$ Report, Anthony J. Russo, "A Statistical Analysis of the U.S. Crop Spraying Program in South Vietnam," (RM5450-1SA/ARPA) (October 1967); Report, Russell Betts and Frank Denton, "An Evaluation of Chemical Crop Destruction in Vietnam," (RM-5446-ISA/ARPA) (October 1967).

${ }^{119}$ William A. Buckingham Jr., "Operation Ranch Hand: Herbicides in Southeast Asia," Air University Review, July-August 1983, 133-134.
} 
ancestral land, and oftentimes generations of crop cultivation. This obviously had a demonstrable effect towards American involvement in Vietnam along with the South Vietnamese government itself. These findings, for the first time cast serious doubt on the effectiveness of the defoliation program, along with the potential side effects of the chemicals used on civilians. Even with these findings, Secretary of Defense McNamara and the Joint Chiefs, disputed these findings, opting to continue the defoliation program. ${ }^{120}$ The JCS believed that defoliation was successful in eliminating food sources, and downplayed the impact that it had on civilians. The JCS assumed that civilians affected by defoliation operations were $\mathrm{VC}$, or at the very least, already disgruntled with the U.S. presence in Vietnam. ${ }^{121}$ Other independent scientific studies were conducted, including one by the Midwest Research Institute, which failed to develop firm conclusions regarding the repeated exposure to Dioxin, a carcinogen that was present in Agent Orange. ${ }^{122}$ Additionally, President Nguyen Van Thieu expressed concerns about defoliation in rural populated areas, because of the backlash. ${ }^{123}$ A combination of these factors, in addition to the pending ratification of the Geneva Protocol on chemical and biological warfare, resulted in the eventual conclusion of operation ranch hand.

While the 'intent' was to kill brush and crops that Viet Cong were reliant upon, some 300,000 people per year were affected by agent orange. ${ }^{124}$ The decision to continue Operation Ranch Hand, knowing the damage it would cause to civilians' sustainable crops, as well as the potential health concerns, seems curious, considering the objective of winning the "hearts and minds" of the South Vietnamese.

\footnotetext{
${ }^{120}$ Letter, SECDEF to CJCS (November 21, 1967).

121 JCSM-719-67, Review of Crop Destruction Operations in South Vietnam, (December 29, 1967).

122 Report, “Assessment of Ecological Effects of Extensive or Repeated Use of Herbicides," Midwest Research Institute, ARPA Order No. 1086, AD824314 (December 1, 1967), 290-92.

${ }^{123}$ Report, “AMEMBASSY Saigon, Report of the Herbicide Policy Review Committee," (May 28 1968), i.

124 John Lewallen, Ecology of devastation: Indochina (Puffin, 1971).
} 


\section{Summary}

American interests in Vietnam span before World War II, because of its strategic economic importance. In the wake of the French occupation and subsequent defeat at Dien Bien Phu, U.S. interests in Vietnam were ideological. American elites were concerned that Communist involvement in Vietnam would trigger an outgrowth of Communism into Southeast Asia. The subsequent economic and military involvement in Vietnam was plagued with prejudice towards the Vietnamese people. This was not limited to rogue agents, but institutionalized in military and political life.

The enemy in Vietnam was communism, an ideology, which was not limited to territory or resource control. The conduct of war reflected this war against an idea, through the destruction of the Vietnamese and their way of life. The three different areas examined demonstrate this normative superiority towards Vietnamese culture and life. It has been said that "The resulting devastation, dislocation, and subordination was the price the Vietnamese paid for our self-assigned crusade to stop communism, save a people we regarded as backward, and revitalize an outmoded culture." ${ }^{25}$ Christian and Confucian traditions espouse very different perspectives on the proper ordering of society and human freedom. Among the cleavages between the civil religions of Vietnam and the United States include a fundamentally different pivot of society (individuals or groups) and freedom (individual free will or filial piety). These differences contributed to the mindset and behavior of United States foreign policy during the conflict in Vietnam.

\section{Sino-Vietnamese War (1979)}

The Sino-Vietnamese War was a limited military operation conducted by China against Vietnam from February 17 to March 16, 1979. While the invasion was limited in scope and lasted

${ }^{125}$ Michael H. Hunt, Ideology and US foreign policy (Yale University Press, 2009), 177. 
less than a month, casualty estimates range in the tens of thousands. ${ }^{126}$ While the fighting between Chinese and Vietnamese troops was intensely fierce, the conduct of Chinese troops towards noncombatants was restrained. The purpose of this case study is to analyze the Chinese decisionmaking to wage a limited war against Vietnam. I contend that the choice of limited warfare tactics, as opposed to total war, was due to shared cultural and historical beliefs.

China and Vietnam have a shared historical experience, including the Chinese occupation of modern-day Vietnam under the Han and Ming dynasties. The settlement of the new territory by ethnic Chinese also imported linguistic, cultural and moral beliefs. Even after gaining independence from China in $938 \mathrm{AD}$, foundational Vietnamese beliefs was forever influenced by Chinese value structures. After decades of colonialism and subsequent reunification of Vietnam, tensions with China began to mount over territorial issues.

The Sino-Vietnamese War was the result of years of hostile relations between China and Vietnam. China, who had previously supported Vietnam in their quest for independence, was displeased by the Vietnamese invasion of Cambodia, territorial infractions and the treatment of the Hoa. As a result of these transgressions, Chinese leadership had determined that the best course of action would be a limited military campaign against Vietnam. The goal of this campaign was punishing the Vietnamese government for their hostile policies toward China and their allies in Cambodia. This conflict can be differentiated from the previous conflicts in Vietnam (First and Second Indochina Wars) in the limited duration and goals of the conflict. This long-term strategic approach towards Vietnam was the defining factor that differentiated it from the previous Indochina Wars.

${ }^{126}$ Xiaoming Zhang, “China’s 1979 war with Vietnam: a reassessment,” The China Quarterly 184 (2005): 851-874. 
This is a unique crisis because of the limited duration and goals set established by China. Chinese military operations did not include naval or air forces and the goal was for ground forces to reach the gates of Hanoi. The decision to wage limited warfare also sidelined other actors, including the Soviet Union and United States. The use of war as a punitive action towards Vietnam speaks to the nature of the relationship between China and Vietnam. Chinese officials also placed great emphasis treatment of civilians during combat operations, which resulted in limited civilian casualties. This case study will demonstrate that the decision to engage in limited warfare with consideration toward civilians was the result of shared cultural and historical experience, which anthropomorphized the relationship between China and Vietnam as siblings. Chinese decisionmaking is consistent with this analogy, as the conflict was ultimately about punishing Vietnam for its behavior.

\section{Civil Religion}

The civil religion, or the secular national beliefs, dogmas and rituals, are similar between China and Vietnam. The modern-day territory of Vietnam was occupied and settled by ethnic Chinese, who brought their language, culture and customs. Confucian norms were integrated with Vietnamese traditions to form their national identity and civil religion. These normative similarities provided a similar foundation that characterized their relations. This section will develop these concepts further, explaining the shared historical experience and the implications on normative similarities.

\section{Historical Context}

The history of international relations between Vietnam and China extend over two millennia. In ancient times, the territory of modern day Vietnam ${ }^{127}$ was ruled by the Hong Bang

\footnotetext{
${ }^{127}$ Known as Van Lang
} 
dynasty. This dynasty was overthrown by Thuc Phan in 257 B.C., which was consolidated into the Au Lac territory (consisting of Northern Vietnam and Southern China). In 207 B.C., Chinese general Zhao Tuo defeated the Au Lac peoples, incorporating them into territories of the Han Dynasty. ${ }^{128}$ In 206 B.C., members of the deposed Qin Dynasty settled in the Tonkin Delta region, bringing their technology, culture and religion. By 111 B.C., Vietnam territories were absorbed into the Han empire. For the next century, Vietnam was subjected to Chinese domination, while also adopting their culture.

Even though the Vietnamese were subjected to Chinese domination for nearly a century, insurrections (albeit unsuccessful) were common during this time. From 39-43 AD, Trung Tac and Trung Nhi (known as the Trung sisters) led a Vietnamese independence movement against the Han Dynasty. Originating from military victory at Lien Lau, the Trung sisters forced the Chinese on their heels. For the next four years, they liberated areas of modern day southern China to Hue. They were eventually routed by the armies of General Ma Vien at Lang Bac (near Hanoi). Rather than surrender, they opted to commit suicide at the juncture of the Day and Red rivers. To this day, this date is celebrated as a modern holiday within Vietnam (Hai-Ba Trung Day). ${ }^{129}$

This was hardly the last attempt at independence. Major revolutionary movements had taken place in $248 \mathrm{AD}$ (Treu Au), 542-546 (Ly Bon), 687 (Ly Tu Tien and Dinh Kien), 722 (Mai Thuc Loan), 767-791 (Phung Hung) and 819-820 (Duong Thanh). Eventually in 938, there was a breakthrough, when the forces of Ngo Quyen defeated the forces of Southern Han at the Battle of Bach Dang River. Ngo Quyen established the first Vietnamese dynasty and ceased Chinese colonial rule. However, the Ming Dynasty invaded Vietnam in 1407, with aims of territorial

\footnotetext{
128 This was officially done in 111 B.C.

${ }^{129}$ Bruce Burton, "Contending Explanations of the 1979 Sino-Vietnamese War, International Journal Vol. 34 No. 4 (Autumn 1979): 701.
} 
expansion. Vietnam was occupied until the Lam Son Uprising (by Le Loi), and were eventually expelled by 1428 . Even after gaining independence in 938 and regaining independence in 1428 , Chinese culture had taken root within Vietnamese society.

\section{Normative Similarities}

Modern-day Vietnamese culture is an amalgamation of traditional Vietnamese and Chinese sources, rooted in localized ancient and Confucian philosophies. The most influential component of the civil religion of Vietnam is Confucianism, which was introduced during the Chinese occupation. Chinese customs, language, system of organizing government and philosophical traditions were welcomed by the Vietnamese, as they perceived it to give them an advantage over their neighbors. ${ }^{130}$ Much of the Vietnamese vocabulary, upwards of $60 \%$ are borrowed from Chinese characters (nearly $80 \%$ for legal vocabulary). ${ }^{131}$ Of all the Chinese influences, the Confucian philosophy had a lasting impact on bringing Vietnamese culture closer to China.

Confucianism introduced the concepts of structured relationships within society, established through the Analects, a collection of sayings by Confucius and his pupils. Confucian morality is focused on the development of one's character to the ideal of junzi. ${ }^{132}$ This is achieved through $\mathrm{Li}$ or principle. ${ }^{133} \mathrm{Li}$ has taken on multiple meanings (propriety, correctness and rites) and is difficult to translate into English. The best representation that Confucians interpret $L i$ is through the hierarchy that organizes society by delegating duties and responsibility to its members. This results in highly-structured unequal relationships between members within society. One such

\footnotetext{
${ }^{130}$ Lucian W. Pye. Asian Power and Politics: the Cultural Dimensions of Authority (Harvard University Press, 1988).

${ }^{131}$ Brantly Womack, China and Vietnam: The Politics of Asymmetry (New York: Cambridge University Press, 2006), 61.

${ }^{132}$ Henry Rosemont and Roger T. Ames. The Analects of Confucius: A Philosophical Translation (New York: Ballantine, 1998).

${ }^{133} \mathrm{Li}$ is an important character (禮) for Confucian thought, consisting of an altar character and a vase full of flowers representing a sacrifice to the gods.
} 
unequal relationship is between husband and wife, which challenged the traditional Vietnamese norms which placed the woman at the center of the family.

During the Chinese occupation of Vietnam, these traditional values towards females were supplanted by Confucian hierarchical relationships. Women were unable to separate from her husband, as they were considered to be bound until death, after which the wife had no legal entitlement to inheritance or property rights. ${ }^{134}$ This was eventually changed by Emperior Le Thanh Ton (1459-1497) to provide equal rights to women, including inheritance and the right to own private property. North Vietnam did likewise (1960), which included providing equal pay, paid maternity leave and other social services geared towards women. ${ }^{135}$

Even in modern-day Vietnam, the cultural identity of womenhood is complicated. Women in Vietnam are empowered and capable of self-actualization, afforded additional rights and privileges when compared to women in China. That being said, there are still remnants of Confucian "roles" within Vietnamese society. The way in which a woman behaves is dependent on the relationship, grounded in Confucian inequality. These roles are clearly defined, in which a woman can perform the role of daughter, subject to traditional family expectations. Additionally, the role of wife, which includes "formal respect to her husband, to his family and ancestors as well as her own, to continue her virtuous way or life so that she brings no shame to either family, and to produce children, especially sons". ${ }^{136}$ As a wife, Vietnamese women show respect and deference towards her husband, while also performing other roles as equals (including owning a business or handling money).

\footnotetext{
${ }^{134}$ Marilyn W. Hoskins, "Vietnamese women: Their roles and their opinions", in David J. Banks (ed.) Changing Identities in modern Southeast Asia (Chicago: Aldine, 1976), 128-134.

${ }^{135}$ Ibid.

${ }^{136}$ Ibid., 134.
} 
Another shared component between China and Vietnam is the importance of the family as the center of societal life. The South Vietnamese Constitution (1967) even recognized "the family as the foundation of society". While there are similarities, there are subtle differences between the interpretations of the way in which the family is best served. One such expression within Vietnam is phuc duc, which refers to individual accomplishments being a benefit for the whole society (or family). ${ }^{137}$ The filial piety which is a common theme within Confucianism and Chinese culture is interpreted as being more reciprocal, than unequal obligations. ${ }^{138}$

In addition to filial piety, Confucian philosophy was the underpinning of the civil religion of Vietnam, enshrined in the civil service examination system. From 1075 (under Ly Nhan Tong) until 1913, civil service examinations were the standard for selecting candidates for bureaucratic positions. Despite a deep hatred for the Chinese occupiers, they were the closest of all states to emulate the system of Chinese authority, including a bureaucracy well-versed in the Confucian classics. ${ }^{139}$ This is in part because "Vietnam considered itself equal to China only in its right to autonomy, never in the relationship itself." 140

Vietnamese culture remains a mix of Chinese Confucianism (which is more structured and communal) and Vietnamese Nationalism (which is more liberal and individualistic). Chinese culture permeated the lives of the Vietnamese, which challenged their own values and cultural identity. While there are subtle differences in the interpretation of Confucian values, including filial piety, the role of women and bureaucracy, the relative differences between the Vietnamese and Chinese ontological positions are minor, when compared to others.

\footnotetext{
${ }^{137}$ Stephen B. Young, "Unpopular Socialism in United Vietnam,” Orbis (Summer 1977): 238.

${ }^{138}$ Ibid., 229.

${ }_{139}$ Pye. Asian Power and Politics, 215.

${ }^{140}$ Womack, China and Vietnam, 61.
} 


\section{Domestic Political Change}

The relationship between Ho Chi Minh and Mao Zedong was strong during their struggle for independence. China had supported the North Vietnamese in their resistance against the United States during the Vietnam War. This included Chinese engineering units for the purpose of building and fortifying infrastructure as well as military and civilian aid. ${ }^{141}$ Upon the end of the War and subsequent reunification of Vietnam, this relationship of convenience had ended. A united Vietnam under Ton Duc Thang began acting autonomously and independently of Chinese influence, even threatening their interests in Cambodia.

While it may seem like ancient history, the tension between Vietnam and China was rekindled in recent decades. In the mid-1970s, this rivalry was acknowledged by both parties; the Vietnamese perceived China as oppressors and China perceived the Vietnamese as subservient. ${ }^{142}$ Amid the historical tensions, three specific catalysts provoked the Sino-Vietnamese War: (1) the Vietnamese invasion of Cambodia, (2) territorial disputes and (3) treatment of the Hoa. ${ }^{143}$

\section{Invasion of Cambodia}

The first justification for the Chinese invasion of Vietnam was based on the relations between Vietnam and Cambodia. During a period of the Second Indochina War (1967-1975), Cambodia was experiencing their own civil war between the North Vietnamese-supported Khmer Rouge and U.S.-supported Khmer Republic. North Vietnamese forces relied on access to Cambodia in order to transport supplies along the Ho Chi Minh Trail. However, the makeshift alliance between Pol Pot (Prime Minister of Kampuchea) and Vietnamese leadership (Ton Duc

\footnotetext{
${ }^{141}$ Chen Jian, “China’s Involvement in the Vietnam War, 1964-69,” The China Quarterly 142 (1995): 371.

142 Ezra F. Vogel, Deng Xiaoping and the Transformation of China (Cambridge, MA: Belknap Press, 2011), 274275.

${ }^{143}$ Steven J. Hood, Dragons Entangled: Indochina and the China-Vietnam War (Armonk: An East Gate Book, 1992), 55-56.
} 
Thang and Pham Van Dong) only lasted until the conclusion of the war. In the aftermath of the Vietnam War, philosophical differences between Cambodia and Vietnam became apparent. ${ }^{144}$ Pham Van Dong, prime minister of the Democratic Republic of Vietnam, noted that the Khmer Rouge government "turned the whole of Kampuchea into a hell on earth, a gigantic concentration camp, in which all elementary human rights, all ordinary activities of society, all activities of family life, and all cultural and religious activities, are abolished." ${ }^{145}$ These philosophical differences had devolved into aggression by the Cambodian government.

Beginning in 1975, relations between Vietnam and Cambodia had soured to the point of violence. The first aggression was the Cambodian invasion of two Vietnamese islands Phu Quoc and Tho Chu. In May, the Vietnamese retaliated by occupying the Cambodian island of Poulo Wai. The relationship remained strained for the next several years, but it was not until 1977 that violence erupted. In April 1977, Cambodian forces attacked Ha Tien and Chau Doc, pushing upwards of $10 \mathrm{~km}$ into Vietnam. By September, they began assaulting towns in the Tay Ninh Province. ${ }^{146}$ The Vietnamese response included air strikes and limited troop deployments along the Cambodian border. In addition to border skirmishes, the Cambodian genocide also created a refugee problem for Vietnam. This problem was twofold: first, the Khmer Rouge regime specifically targeted ethnic Vietnamese as a part of their genocide program; secondly, Vietnam was being flooded by Cambodian civilians who wanted to escape. ${ }^{147}$

The relationship between Vietnam and Cambodian had been strained in the aftermath of the Vietnam War and the rise of the Khmer Rouge to power. Vietnamese leadership was

\footnotetext{
${ }^{144}$ Tai Sung An, "Turmoil in Indochina: The Vietnam-Cambodia Conflict," Asian Affairs Vol. 5 No.4 (March-April 1978): 245 .

${ }^{145}$ United Nations Archives and Records Management Section, "Speech made by Pham Van Dong," (September 5, 1978), 4.

146 Tai Sung An, "Turmoil in Indochina: The Vietnam-Cambodia Conflict," Asian Affairs Vol. 5 No.4 (March-April 1978): 250-251.

${ }^{147}$ Huynh Kim Khahn, "Vietnam: Neither Peace Nor War,” Southeast Asian Affairs (1979):341.
} 
dissatisfied with the treatment of civilians in Cambodia and the border clashes. On December 25, 1978, Vietnam invaded Cambodia with the intention of removing the Khmer Rouge from power. They launched a Blitzkrieg style of assault, using 14 divisions along three fronts. ${ }^{148}$ In the first few weeks, nearly half of the Cambodian forces were destroyed. By January 7, 1979, Phnom Penh was occupied by the Vietnamese Army and the Kampuchean United Front for National Salvation (KUFNS), which was a revolutionary movement consisting of defected Khmer. ${ }^{149}$ Upon victory, the Khmer Rouge was deposed from power, installing the People's Republic of Kampuchea with Heng Samrin as their leader.

The Chinese perception of the Cambodian invasion was hegemonic. China believed that Vietnam was attempting to gain regional hegemony by conquering Cambodian territory, challenging their own claim for hegemony. ${ }^{150}$ Mao Zedong had supported the Khmer Rouge government in order to balance the expectations of Vietnamese hegemony. Chinese authorities were concerned that Vietnam had provoked Cambodia, in order to justify its military expansion. However, once the Khmer Rouge was deposed from power, Vietnam removed military forces, rather than occupying or conquering territory gained.

\section{Territorial Disputes}

The second justification for the Chinese invasion of Vietnam was territorial disputes between the states. Both China and Vietnam accused one another of not respecting the international boundaries set forth in the 1887 and 1895 agreements. It is unclear who was at fault for these skirmishes, but nonetheless the number had surged from 121 in 1974 to 1108 in 1978.

\footnotetext{
${ }^{148}$ Chen Min, The Strategic Triangle: Lessons from the Indochina War (London: Lynne Rienner, 1992), 148-149.

${ }_{149}$ Morris, Stephen J. Why Vietnam invaded Cambodia: political culture and causes of war. Chicago: Stanford University Press, (1999).

${ }^{150}$ United Nations Archives and Records Management Section, "Letter, Chen Chu to H.E. Baron Rudiger von Wechmar," (December 11, 1978).
} 
The boundaries between Indochina and China were defined in two agreements between the French and Chinese. In 1887, it was agreed upon that the boundary would be demarcated along the Black River (Heijiang). ${ }^{151}$ The 1895 agreement extended the boundary westward to the Mekong. ${ }^{152}$ An additional agreement was forged in 1957-1958, which allowed for the maintenance of status quo of the frontier border areas, for which any disputes would be settled via negotiation. ${ }^{153}$

The first issue concerning border areas occurred when the Vietnam-China railway connection was restored from Huu Nhi Quan to Yen Vien, more than 300 meters inside Vietnamese territory, which was considered by China to be rightful Chinese territory. On December 22, 1974, China proposed that the border line be readjusted to include this railway connection, which was refused by the Vietnamese delegation. Because the connection was located inside of Vietnamese territory, China refused to maintain and repair the rail connection. On December 22, 1978, China unilaterally suspended of all train traffic, including passengers and goods, along the international railway to and from Vietnam. ${ }^{154}$ In addition to the dispute over the railway connection, countless number of border skirmishes took place during the 1970s.

Chinese officials were quite adamant that Vietnamese hostilities and mobilization were aggressive acts challenging China. ${ }^{155}$ China accused Vietnam of dispatching troops to border areas, as well as utilizing special forces to perform espionage and sabotage in Chinese border areas. This included the use of landmines in ten different villages, including in Hekou, Maguan and

\footnotetext{
${ }^{151}$ Ibid.

${ }^{152}$ Ibid.

${ }^{153}$ United Nations Archives and Records Management Section, "Memorandum of the Ministry of Foreign Affairs of the Socialist Republic of Viet Nam on the Chinese Authorities' Intensified Armed Activities on the Viet Nam Border and their Frantic War Preparations against Viet Nam," (February 16, 1979).

${ }^{154}$ United Nations Archives and Records Management Section, "Note of the Foreign Ministry of the Socialist Republic of Viet Nam Sent to the Chinese Embassy in Ha Noi on the Viet Nam - China Railway Service," (January 25,1979 ).

${ }^{155}$ United Nations Archives and Records Management, “Letter, Chen Chu to Ambassador A.Y. Bishara," (February $15,1979)$.
} 
Longzhou counties. China documented a number of attacks on January 11 through 17, involving four villages Longbang commune, and January 28 within Hekou Country. ${ }^{156}$ From Feb 9-12, 1979, Vietnamese armed forces attacked several border areas on 30 different occasions (within Fangcheng, Ningming, Longzhou, Jingxi and Napo Counties). China issued an ultimatum suggesting they cease provocations or "bear full responsibility for all the consequences arising therefrom". ${ }^{157}$

On February 10, 1979, the Vietnamese Deputy Prime Minister appealed to the United Nations regarding the influx of Chinese military mobilization along the border. Over 20 divisions, aircraft and tanks were deployed on the border of Vietnam. In conjunction with the previous aggression to the Hoang Sa Islands, and countless border skirmishes, the Vietnamese perceived that an attack is imminent. ${ }^{158}$

\section{Treatment of Hoa}

The last justification for the Chinese invasion of Vietnam was predicated on the treatment of Hoa people living in Vietnam. Hoa is a blanket phrase with refers to ethnic Chinese peoples who reside within Vietnam. Nearly 1.2 million Hoa lived in Vietnam at the conclusion of the Vietnam War. ${ }^{159}$ The government of South Vietnam welcomed ethnic Chinese, affording them all of the rights of Vietnamese citizens. This was formalized into an Agreement signed in 1955 between China and South Vietnam with the purpose was to respect rights of Hoa people and allow them to adopted Vietnamese nationality voluntarily. The same year, the Diem regime reneged on these commitments and passed a law which classified those with mixed Vietnamese-Chinese

\footnotetext{
${ }^{156}$ United Nations Archives and Records Management Section, “Chinese Foreign Ministry's Note to the Vietnamese Embassy in China Protesting against Viet Nam's Military Provocations," (February 12, 1979).

${ }^{157}$ United Nations Archives and Records Management Section, "Chinese Foreign Ministry's Note of Protest against Vietnamese Encroachment upon Chinese Territory and Creation of Bloodshed," (February 16, 1979), 2.

${ }^{158}$ United Nations Archives and Records Management Section, "Message from the Deputy Prime Minister and Minister of Foreign Affairs of Viet Nam addressed to the Secretary-General,” (February 10, 1979).

159 Ibid.
} 
parentage as South Vietnamese citizens. This was bolstered by Decree 48 and 52 (on August 21 and $29^{\text {th }} 1956$, respectively), which afforded all ethnic Chinese born in Vietnam citizenship and required all Vietnamese citizens to adopt a Vietnamese name. ${ }^{160}$

After unification, the united Vietnamese government honored the Diem guidelines. This culminated in restrictions on those who refused to do so. They were denied access to education and employment, and were harassed by law enforcement. Government policies specifically targeted the Hoa, including laws regarding ownership of private property. This eventually culminated in the forcible expulsion of Hoa from Vietnam. One such incident, on August 25, 1978, resulted in nearly two thousand Chinese nationals being removed from their shelters at $\mathrm{Yu}$ Yi Kuan in a "premeditated and meticulously planned operation" by Vietnamese forces. ${ }^{161}$

The accusations of these incidents were denied by the Government of Vietnam on several occasions for several reasons. First, Vietnamese officials did not recognize the 1955 agreement between Diem and China, because the regime of North Vietnam was not included in this agreement. ${ }^{162}$ Secondly, Vietnamese officials differentiated Chinese nationals from Hoa, claiming that all Hoa people are actually Vietnamese citizens. Alternatively, Chinese nationals living in Vietnam are treated as foreigners, the same as refugees from Kampuchea. This was perceived as a premediated plan by China, who was attempting to force Vietnam "to give up its correct line of independence, sovereignty and international solidarity". ${ }^{163}$ Many Hoa fled to China, creating a refugee crisis which culminated in China closing the border. China accused Vietnam of

\footnotetext{
${ }^{160}$ Khanh Tran, The ethnic Chinese and economic development in Vietnam (Institute of Southeast Asian, 1993), 2829.

${ }^{161}$ United Nations Archives and Records Management Section, "Chinese Protests against Vietnam," (September 07, 1978), 3.

${ }^{162}$ United Nations Archives and Records Management Section, "Chinese Government Delegation Leader's Statement at 8th Session of Sino-Vietnamese Negotiations," (October 05, 1978).

${ }^{163}$ United Nations Archives and Records Management Section, "Statement by Vietnamese Chief Delegate Hoang Bich Son at the 8th Meeting in the Negotiations between the Socialist Republic of Viet Nam and the People's Republic of China," (October 09, 1978).
} 
deliberately expelling Hoa people that lived on the border, including Hoand Lien Son, Lai Chau and Son La provinces. By the year 1978, China claimed that over 160,000 refugees have been forced out by the Vietnamese government. ${ }^{164}$

\section{Ontological Threat}

The ontological threat of Vietnam after unification was met with resistance from Chinese leadership. The foreign policy decision-making of Vietnam in the region had upended the status quo relationship with China. As a result, Chinese leadership formulated a plan of correcting this behavior through the use of a limited war. This reinforced the historical relationship between the states, with China filling the role of 'big brother', needing to punish Vietnam for its insurrection. While punitive action was inevitable, the shared military culture which was codified in the political work structure, provided limits to Chinese aggression towards civilians. This section will develop these discuss each of these concepts further, explaining how these similarities contributed to limited military action with an emphasis on limiting collateral damage.

On February 17, 1979, China launched artillery attacks, followed by at least 30 divisions of ground troops and mobilized approximately 450,000 infantry on the Vietnamese border. Vietnamese forces only numbered 50,000, but they had defensive advantages of prepared defensive fortresses. ${ }^{165}$ The initial infantry advance surged across 26 different points using all 450,000 troops. The majority of forces were concentrated on advancing towards the three provincial capitals. The Vietnamese forces relied upon high-ground, defensive fortifications, ambushing Chinese forces that opted for direct assaults. The tactics used by the Chinese forces were outdated and the use of massed infantry attacks failed against a dug-in fortified enemy. ${ }^{166}$

\footnotetext{
${ }^{164}$ United Nations Archives and Records Management Section, “Chinese Government Delegation Leader’s Statement at 8th Session of Sino-Vietnamese Negotiations," (October 05, 1978).

${ }^{165}$ Edward C. O’Dowd, Chinese Military Strategy in the Third Indochina War (Routledge: New York, 2007$), 53$.

${ }^{166}$ Li Man Kin, Sino-Vietnamese War (Hong Kong: Kingsway International Publications, Ltd., 1981 ), 189.
} 
The Vietnamese were able to inflict proportionately higher casualties because of this approach. The Chinese, who lacked experience, coordination and familiarity with the territory, slowly advanced towards the provincial capitals.

\section{Figure 7-1: Chinese Assault on Vietnamese Provincial Capitals ${ }^{167}$}

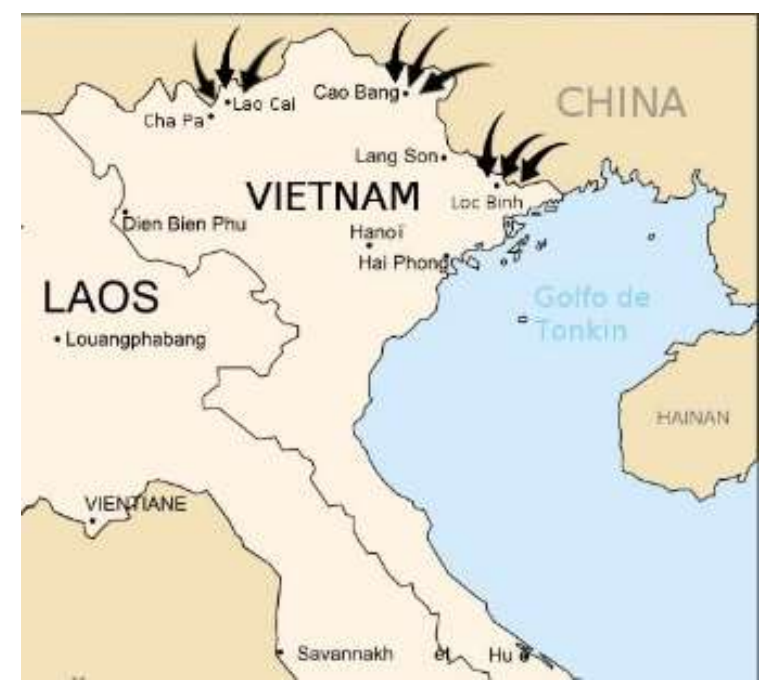

On February 26, the capitals were captured, but faced heavy resistance in Lang Son. ${ }^{168}$

Lang Son was of most strategic importance for the Vietnamese, as it was the closest provincial capital to Hanoi, as well as the primary road and rail route to Hanoi. Once retaking Long Son on March 4, a full withdrawal was announced. Leaders believed that they achieved their operational goals. In marching back to the Chinese border, they practiced scorched earth tactics. In sum, an estimated 26,000 Chinese and 30,000 Vietnamese were killed as a result of this conflict. ${ }^{169}$

\section{Limited War}

From the onset of the conflict, the goals of the Chinese were crystal clear. This was intended to be a limited military operation, with the goal of 'punishing' the Vietnamese for their

\footnotetext{
${ }^{167}$ Map by Ceresnet, distributed under a CC BY-SA 2.5 Generic License.

${ }^{168}$ Ted Wang, trans. 2009. "Main Experiences Gained by the No.XXX Division During the Counterattack in SelfDefense Against Vietnam," Chinese Law and Government, 42, no. 5 (September-October 2009): 55-62. ${ }^{169}$ King C. Chen. China's War with Vietnam, 1979: Issues, Decisions and Implications (Stanford CA: Hoover Institution Press, 1987), 114.
} 
behavior. ${ }^{170}$ In a similar fashion to the Chinese-Indian conflict of 1962 and the Chinese-Soviet clashes of 1969, no Vietnamese territory would be ceded or occupied by the Chinese. ${ }^{171}$ Rather than engage in a full-scale war against Vietnam, they opted to not use Navy or Air Forces during the conflict. The conflict was framed by Deng Xiaoping as 'teaching Vietnam a lesson', because "we cannot allow Vietnam to run wild everywhere". ${ }^{172}$ China's clearly stated desire to "teach Vietnam a lesson" conveyed its foremost war objective to be "an act of revenge." 173 One of the points of emphasis was a short conflict with Vietnam. It was recognized that Vietnam had experience fighting wars of attrition (with France and the United States), as well as a better understanding of the terrain, which made it extremely important to quickly annihilate the enemy with superior forces. The analogy used by Central Military Commission was "killing the chicken with an ox cleaver". ${ }^{174}$ In order to achieve swift victory in battle, the Chinese relied on encirclement strategies, which would limit the ability to retreat, while pushing on both flanks.

Political education of the troops reflected this sentiment, with the purpose of demonstrating that Vietnam was no longer "comrades and brothers" of the past. They framed the war as a defensive counter-attack against the "Cuba of the east" that infringed on their borders. ${ }^{175}$ The outcome of this limited war was to persuade the Vietnamese to cease border hostilities and improve treatment towards the Hoa. ${ }^{176}$ The use of the People's Liberation Army (PLA) in order to achieve

\footnotetext{
${ }^{170}$ This was first documented in the People's Daily on December 25, "We wish to warn the Vietnamese authorities that if they, emboldened by Moscow's support, try to seek a foot after gaining an inch and continue to act in this unbridled fashion, they will decidedly meet with the punishment they deserve."

${ }^{171}$ Xiaoming Zhang, "Deng Xiaoping and China's Decision to go to War with Vietnam," Journal of Cold War Studies 12:3 (Summer 2010): 26.

172 "Chinese Deputy Premier Teng Hsiao-Ping Visits U.S.; Signs Agreements with Carter." Facts On File, February 2, 1979. (Accessed August 10, 2016).

${ }^{173}$ Robert Ross, The Indochina Tangle: China's Vietnam Policy, 1975-1979 (Columbia University Press, 1988), 224.

${ }^{174}$ Ted Wang, trans. 2009. "Main Experiences Gained by the XX Army During the Counterattack in Self-Defense Against Vietnam, Part 2," Chinese Law and Government. 42:5 (September-October 2009): 36.

${ }^{175}$ Ibid., 42.

${ }^{176}$ U.S. Central Intelligence Agency, “The Sino-Vietnamese Border Dispute.” No. 0000789482, (February 4, 1979, 11).
} 
political goals reflects a different mentality towards foreign policy, one which has been summarized as the following:

China, unlike the United States, is accustomed to high casualties in war, as borne out by the millions of dead Chinese soldiers and civilians often forgotten in the west's memory of the last century's wars. China under the CCP does not appear to shy away from casualties in order to achieve its strategic objectives through war, and that is an important cultural point to appreciate. ${ }^{177}$

In order to accomplish this goal, the objective of the operation was to control three of the six provincial capitals, namely Lao Cai, Cao Bang and Lang Son. ${ }^{178}$ The decision to undertake military action against Vietnam was the result of a series of meetings of the Chinese Communist Party elites.

Several meetings were held within Chinese leadership to determine the course of action that should be taken against Vietnam. In September 1978, the PLA General Staff Department discussed small-scale operations against Trung Khanh. ${ }^{179}$ This was viewed as too limited a response, opting for action that would result in a more demonstrable impact on Hanoi's behavior. ${ }^{180}$ Deng Xiaoping visited Thailand, Malaysia and Singapore in November in order to gauge the regional sentiment towards an invasion of Vietnam. November 23, the General Staff met to discuss a revised course of action, broadened to include all cities in Guangxi and Yunnan border provinces. ${ }^{181}$ On December 7, the Central Military Commission formalized plans to launch a limited war, limited to $50 \mathrm{~km}$ inside the border and only lasting two weeks. On December 31 , Deng Xiaoping announced this plan to the Chinese Communist Party (CCP), with a caveat that

\footnotetext{
${ }^{177}$ Christopher M. Gin, "How China Wins: A Case Study of the 1979 Sino-Vietnamese War," (master's thesis, United States Army Command and General Staff College, 2015), 8.

${ }^{178}$ O'Dowd, Chinese Military Strategy in the Third Indochina War, 55.

${ }^{179}$ Luo Yuansheng, Baizhan jiangxing Wang Shangrong (The Biography of General Wang Shangrong) (Beijing: PLA Art Press, 1999), 375-77.

${ }^{180}$ Zhou Deli, Yi ge gaoji canmouzhang de zishu (Personal Recollections of a High-ranking Chief of Staff) (Nanjing: Nanjing Press, 1992), 239-243.

${ }^{181}$ Ibid., 244-45.
} 
actions will be delayed until he had a chance to meet with United States and Japan to "Test the waters". 182

\section{Political Work System}

During a speech by Mao Zedong at the Gutian Conference of 1929, he argued for a politicized military, such that the Party should always control the military. ${ }^{183}$ The relationship between the party/state and the military in China was more intertwined than professional armies ${ }^{184}$ and praetorian armies. ${ }^{185}$ This interconnectedness between civil-military relations has meant that active and former military officials have served in leadership roles ${ }^{186}$ and serve an active role in policy making.

The Vietnamese relied heavily upon Chinese institutions, language and culture, while proclaiming their own independence. During periods of conflict, they actively sought help from China, but once unified, they wanted to maintain distance. ${ }^{187}$ Both China and Vietnam had utilized a political work system (zhengzhi gongzuo xitong). ${ }^{188}$ This included three components, the party committee (dangwei), political commissar (zhengwei) and administrative and functional (jiguan). ${ }^{189}$ Figure 1 illustrates the organization of the political work system in China:

\footnotetext{
182 Gerald Segal, Defending China (Oxford University Press: 1985), 214.

${ }^{183}$ David Shambaugh, "The Soldier and the State in China: The Political Work System in the People's Liberation Army," The China Quarterly, no. 127 (September 1991): 531.

${ }^{184}$ Such as those in the United States, Japan and Western Europe.

185 Those militaries in post-colonial states that seized power from civilians.

${ }^{186}$ Directly administering from 1949-1952 and 1967-1973.

${ }^{187}$ Qiang Zhai, China and The Vietnam Wars, 1950-1975 (Chapel Hill, NC: The University of North Carolina Press, 2000), 219.

188 The Vietnamese political work system was influenced greatly by Maoism, but eventually developed into their own brand. More information is available in D.M. Fitzgerald, The Vietnam People's Army: Regularization of Command, 1975-1988 (Canberra: Australian National University, 1989).

${ }^{189}$ Kenneth W. Allen, Morgan Clemens, Steven Gilnert and Daniel Yoon, “China’s Military Political Commissar System in Comparative Perspective,” China Brief XIII:5 (March 4, 2013).
} 


\section{Figure 7-2: Structure of the Political Work System ${ }^{190}$}

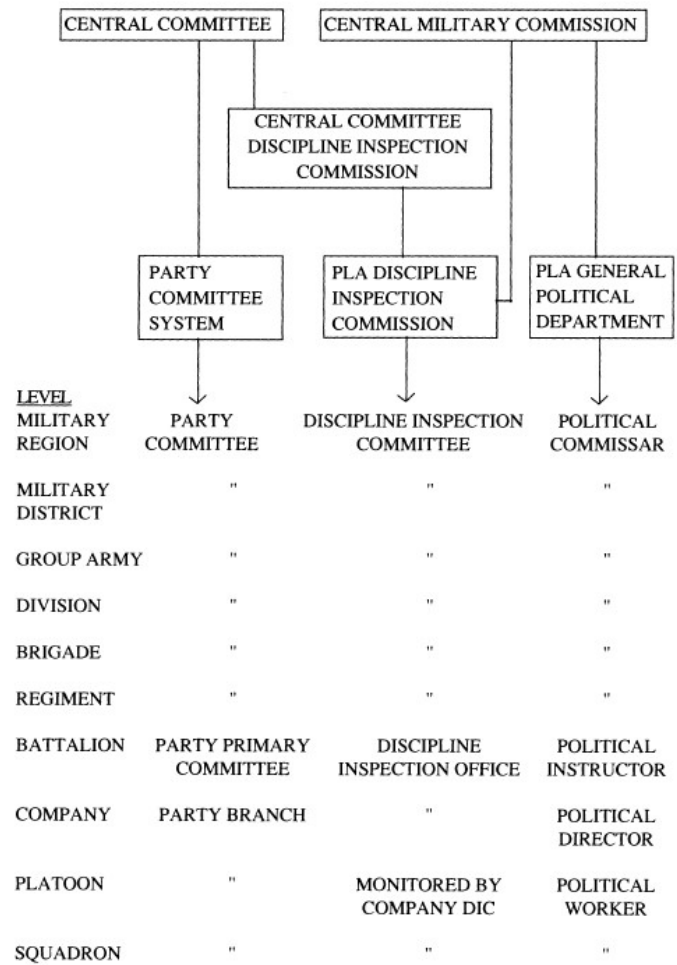

The party committee provided guidance for lower-level party committees and collected information that would be passed on to higher-level party committees. It was also the arbiter for all military and political questions. They also were the evaluators for soldiers, they determined who was worthy of promotional recognition. ${ }^{191}$ The political commissar was the liaison between the committee and the individual soldier. He operated outside of the chain of command, which allowed them to act impartially and without interference. ${ }^{192}$ The third facet of the system, the administrative and functional, was embodied through cadres, who served in technical, political and leadership roles. It was the purpose of the cadres to motivate troops and instill the values of the political commissars. ${ }^{193}$

\footnotetext{
${ }^{190}$ Shambaugh, "The Soldier and the State in China: The Political Work System in the People's Liberation Army," 547.

${ }^{191}$ O’Dowd. Chinese Military Strategy, 14.

192 Ibid.

${ }^{193}$ Ibid.
} 
In contrast to Western armies, the political work system served to provide troops with a set of ideals to follow. These ideals were rooted in Maoist doctrine, which included a litany of structured concepts, including "the three major tasks", "the three major principles of political work", "the three democracies" and the "three rules of discipline and the eight points of attention". ${ }^{194}$ These interlocking concepts provide the foundation for political work and structure for the army.

There are two of these core concepts that are of utmost importance for the handling of the war. First, the "three major principles of political work" are defined as "unity of the officers and soldiers", "unity of the army and the people" and "disintegrate the enemy". ${ }^{195} \mathrm{He}$ expounded on these principles in an interview with James Bertram on October 25, 1937:

\begin{abstract}
Another highly significant and distinctive feature of the Eighth Route Army is its political work, which is guided by three basic principles. First, the principle of unity between officers and men, which means eradicating feudal practices in the army, prohibiting beating and abuse, building up a conscious discipline and sharing weal and woe - as a result of which the entire army is closely united. Second, the principle of unity between the army and the people, which means maintaining a discipline that forbids the slightest violation of the people's interests, conducting propaganda among the masses, organizing and arming them, lightening their financial burdens, and suppressing the traitors and collaborators who do harm to the army and the people - as a result of which the army is closely united with the people and welcomed everywhere. Third is the principle of disintegrating the enemy troops and giving lenient treatment to prisoners of war. Our victory depends not only upon our military operations but also upon the disintegration of the enemy troops. 196
\end{abstract}

The second set of principles included the "three main rules of discipline and the eight points of attention" provided guidance to troops as to how to interact with civilian populations (whether friendly or enemy). These tenets were developed by Mao Zedong during the Second Revolutionary War, and were modified by the General Headquarters of the Chinese People's

\footnotetext{
${ }^{194}$ Ibid., 16.

${ }^{195}$ Mao Zedong, "Interview with the British Journalist James Bertram," in Selected Works of Mao Tse-tung, Vol. 2 (Beijing: Foreign Languages Press, 1975), 53.

196 Ibid.
} 
Liberation Army in 1947. The three main rules of discipline are: (1) obey orders in all your actions;

(2) do not take a single needle or piece of thread from the masses; and (3) turn in everything captured. The eight points for attention are: (1) speak politely; (2) pay fairly for what you buy; (3) return everything you borrow; (4) pay for anything you damage; (5) do not hit or swear at people; (6) do not damage crops; (7) do not take liberties with women; and (8) do not ill-treat captives. ${ }^{197}$ The expectation was that treating civilians with respect and civility could convert enemies into friends. ${ }^{198}$ These were not empty words, but were reinforced prior to the Sino-Vietnamese War.

Prior to the War, the GPD issued regulations to all political officers, offering the explanation of the conflict as to "strike the reactionary Vietnamese authorities". ${ }^{199}$ It continued by noting the emphasis on winning over the Vietnamese people. Additional regulations were issued by the GPD to all troops that were focused on winning over the Vietnamese civilian populations. ${ }^{200}$ This included the importance of showing respect for the Vietnamese civilians and reinforcement of the "three main rules of discipline and eight points of attention". ${ }^{201}$ Cadres of Unit 56041 were assigned a deputy political commissar for the purpose of educating troops in handling civilian populations. This training included lecturing on civil-military relations, Vietnamese customs and problems that they may encounter. ${ }^{202}$ Upon entering Vietnam, additional regulations were imposed by unit commanders, (1) they do not damage homes or crops, (2) do not take property of civilians, (3) do not kill or injure livestock, (4) sending of an advanced guard to

\footnotetext{
${ }^{197}$ Mao Zedong, Selected Military Writings of Mao Tse-tung (Beijing: Foreign Languages Press, 1972), 343.

${ }_{198}$ O’Dowd. Chinese Military Strategy, 18.

${ }^{199}$ General Office of the General Political Department, Zhong Yue Bianjing Ziwei Huanji Zuozhan Zhengzhi Gongzuo Jingyan Xuanbian (Compilation of Experiences of Political Work in the Counterattack in Self-Defense on the Sino-Vietnamese Border) (Beijing: Zongzhengzhibu, 1980), 1:16.

${ }^{200}$ O’Dowd. Chinese Military Strategy, 134.

${ }^{201}$ General Office of the General Political Department, Zhong Yue Bianjing Ziwei Huanji Zuozhan Zhengzhi Gongzuo Jingyan Xuanbian, 1:16.

${ }^{202}$ Ibid., 1:278-9.
} 
warn civilians and (5) respecting of customs. ${ }^{203}$ The implementation of these regulations were surprisingly effective.

There were numerous documented examples of Chinese soldiers interacting with Vietnamese civilians. Chinese Unit 56041 was successful in avoiding conflict with the Vietnamese civilian populace, and the interactions included Chinese medical teams assisting sick and injured Vietnamese civilians. Because of their respectful treatment of civilians, Unit 56041 faced little resistance from the local populace. In fact, they managed to gain the cooperation of the locals, which included gaining intelligence against the Vietnamese Army. ${ }^{204}$

Yunnan Provincial Military District provided financial support for civilians along with 200,000 kilograms of rice. Chinese work teams were deployed, including the $2^{\text {nd }}$ Battalion of Unit 35548 to Lao Cai, who helped dig wells, cultivated food and supplied firewood. By building the trust of the local populace, they were able to convince militants to return home and surrender their weapons. ${ }^{205}$ During Unit 33762 withdrawal from Vietnam in March 1979, civilians cast the soldiers as "an army of Buddhas" because they treated the civilians with such respect. ${ }^{206}$ Respect and compassion towards civilians is an important Maoist ideal. ${ }^{207}$ The logic is that through the unity of army and the people, it can increase the chance of operational success.

There were always exceptions to the norm, three incidents had occurred whereby the Chinese army had taken advantage of the Vietnamese. A pamphlet distributed by Vietnamese authorities that documented these incidents. First, Chinese troops used axes and knives to kill 43

\footnotetext{
${ }^{203}$ O’Dowd. Chinese Military Strategy, 135.

${ }^{204}$ General Office of the General Political Department, Zhong Yue Bianjing Ziwei Huanji Zuozhan Zhengzhi Gongzuo Jingyan Xuanbian, 1:281-2.

${ }^{205}$ O'Dowd. Chinese Military Strategy, 136.

${ }^{206}$ General Office of the General Political Department, Zhong Yue Bianjing Ziwei Huanji Zuozhan Zhengzhi Gongzuo Jingyan Xuanbian, .2:228.

${ }^{207}$ Song Shilun, Mao Zedong Junshi Sixiangde Xingcheng Jiqi Fazhan (The Formulation and Development of Mao Zedong's Military Thought) (Beijing: Military Science Publishers, 1984), 81.
} 
women and children at Tong Chup. Second, withdrawing Chinese troops stole everything of value, including furniture and bicycles. Third, several buildings were destroyed by Chinese troops in the town of Cam Duong. ${ }^{208}$

\section{Summary}

The Third Indochina War was the result of centuries of historical friction and decades of specific issue cleavages. The Chinese invasion of Vietnam was calculated with particular goals in mind, along with a specific timetable in order to accomplish said goals. The ensuing conflict was inherently limited, in terms of both resources utilized and the strategic goals. As a result, the conflict was confined to certain areas and differentiated between civilian and military targets. I contend that in part this was due to the historical similarities between these states. Rather than for conquest or morality sake, the incursion into Vietnam was simply a show of force, with the purpose of behavior modification.

\section{Conclusion}

These cases have illustrated the historical circumstances, military objectives and strategies undertaken towards civilians during the Second and Third Indochina Wars. There are several important themes that can be extrapolated from these conflicts. The purpose of the incursion into Vietnam was different for the United States and China. In the case of the United States, the war was ideological against the Communist threat. For China, it war was conducted to discipline Vietnam for their transgressions. These are fundamentally different casus belli, and the ends of achieving these goals reflected the reason for war.

The United States fought to ensure a 'free' Vietnam, one that could be a buffer against Communist China. In order to accomplish this goal, total annihilation of the Vietnamese people,

\footnotetext{
${ }^{208}$ Editorial Board of the Vietnam Courier, Chinese War Crimes in Vietnam (Hanoi: Vietnam Courier, 1979).
} 
culture, resources and environment was a tactic for United States forces. Pacification efforts failed because of the ontological cleavages, in which American policymakers made little attempt to understand or empathize with the Vietnamese people. Rather than cooperating with civilian populations, it became much easier to dehumanize all Vietnamese in order to achieve their objectives.

This was in stark contrast with the Third Indochina War, in which China demarcated the goals of war prior to invasion. It was clear from the Central Committee Party meetings that a sufficient show of force was necessary for behavioral correction, while limiting the goals to capturing (and not holding) the provincial capitals in the north. This conflict was defined by the aggressor, and as such, they relied upon civilian support to achieve their goals in an expedited manner. The training and subsequent reinforcement of differentiating civilian and soldier was not necessary for their war goals.

Given the purpose of each conflict, it begs the question why China placed such emphasis on limiting collateral damage and why the United States did not. From a realist perspective, the treatment of civilians seems counterintuitive to the goals of China and the United States. Chinese commanders were willing to dedicate resources to ensure troops were respectful towards civilian populations, even though there was no intention of maintaining a presence afterwards. Since the intention was only to engage in a limited war from the onset, why was such emphasis placed on limiting collateral damage? In contrast, the United States, who was fighting an ideological war, needed to win the 'hearts and minds' of Vietnamese civilians, but demonized the entire Vietnamese population. The theory proposed herein provides insights to better understand this behavior, through the examination of differences in ontology and civil religion. 


\section{Chapter 8: Analysis and Conclusion}

This research project has been dedicated to the development of a novel approach to a timeless question within international relations: why are some dyads more likely to experience hostilities or the escalation of crisis? Previous scholarship has primary focused on regime-level variables, whether under the guise of ideology, political psychology or regime type. While this scholarship was integral to the study of dyadic relations, it fails to explain the variation in state behavior during crises. In particular, these theories fall short in explaining how fundamental differences in civil religion impact threat perception vis-a-vis ontological threat. Furthermore, these theories fail to explain the variation in state behavior towards particular opponents that share ideological or regime characteristics. In some cases, such as the Iran-Syria and Iraq-Iran, both states were ruled by similar regime types (autocratic) and ideologies (revisionist). Even though the regime characteristics between both dyads were similar, the Baathist crisis between Iraq and Syria was resolved prior to escalation. This can be contrasted with the Iran-Iraq War, which featured some of the most brutal tactics of warfare, including the deployment of chemical weapons and indiscriminate civilian targeting. Previous scholarship has also failed to account for variation in types of dyadic conflict (total or limited war). The conduct of war of China during the SinoVietnamese War can be contrasted with American conduct during the Vietnam War. The Chinese government was effective in educating their soldiers in proper conduct towards Vietnamese civilians. This can be contrasted with American racism towards the Vietnamese, which was actualized through body counts, pacification and chemical warfare. War of any kind between similar regimes and ideology runs counter to the expectations of the literature, even if the scope was limited, as was the Sino-Vietnamese War. The theory developed and tested herein transcends 
previous explanations of conflict through the examination of cultural values and historical experience.

Cultural values and moral belief structures are individualistic in nature, passed from generation to generation at an impressionable age. These individual values can differ from person to person, but aggregate on the societal level. These values are instrumental in developing the social contract between individuals and government, who enshrines these aggregate values in positive laws and norms. This results in the codification of a states' civil religion - or national dogmas, rites and rituals, which are specific to a particular area. Civil religion acts as a proxy for understanding the worldview or ontology of a particular people. As an image, these value structures filter information according to that which is familiar. In the event of a rapid regime or political change, normalized relations between states was supplanted by fear and mistrust. In this period of uncertainty, states rely on known quantities, which include the differences in moral belief structures. If the content of these belief structures was vastly different between dyads in crisis, it can pose an ontological threat, or threats directed towards another's identity. When in crisis, the variation in state behavior (restraint/belligerence and/or limited/total war) was based on the similarities and differences in civil religion.

This theory has been tested using both quantitative and qualitative methodologies. The quantitative analysis has been included to demonstrate generalizability across time, region and dyad. Through the use of MID and ICB data, the results highlight the particular importance of certain types of cultural values - the state and society variables (individualism and power distance). Both of these tests validate the inclusion of cultural difference in the study of dyadic conflict, whether hostility or escalation of crisis. Qualitative analysis was conducted through the use of three different case studies involving Argentina, Iraq and Vietnam. Each of these cases included 
a pair of cases that involve the same regime entangled in crisis with two states, with wildly different outcomes. These cases demonstrate how difference in cultural values impacted the resolution or escalation of crisis. Returning to the original questions posited in the introduction: The theory developed herein has attempted to provide answers to these three pivotal questions, with the empirical sections dedicated to testing the validity of the theoretical expectations.

What role does societal norms and cultural values have in threat perception? The theoretical expectations of this research is that societal norms and cultural values provide a better explanation for understanding ontological threats. Societal norms and cultural values are used as an information prism, for which threats are deciphered. When normalized relations between a dyad are disrupted by rapid regime change, differences in these values act as a catalyst for ontological threat. This can be differentiated from material threats, as ontological threats are related to threats towards the identity of a state - otherwise known as the civil religion.

The quantitative results provide limited support for this proposition, with particular attention to the state and society variables. Individualism was significant when examining the effect of these values on hostilities. Both individualism and power distance were found to be statistically significant in crisis escalation. It can be extrapolated from these results that differences in beliefs related to the state and society have an impact on the perception of threat, which ultimately results in hostility and crisis escalation. The qualitative analysis does a better job of refining this process. Each of the case studies features two pairs of dyadic relations that involved one state under the same regime.

Why do states practice restraint in some crises and escalation of belligerence in others? The theoretical expectations of this research is that societal norms and cultural values provide a framework for negations that facilitates peaceful resolution. Differences in societal norms and 
cultural values facilitate the breakdown of communication during crises. On the other hand, similarities can assist in the resolution of crises prior to escalation. These dynamics have been explored in both quantitative and qualitative analyses.

The qualitative analysis specifically dedicated a section to the escalation of crisis through the inclusion of the ICB data. The qualitative section was more effective in isolating the mechanisms for conflict resolution. For two of these dyads - Iraq-Syria and Argentina-Chile, the states with shared historical and/or cultural values tended to resolve crisis prior to the escalation of conflict. This was achieved by appealing to the commonalities between theses dyads. In the case of Iraq and Syria, both states had a common history that generated common linkages to the Baathist ideology and the Arab League. In the case of Argentina and Chile, both states had a common colonial history that allowed the papacy to intervene prior to escalation. On the other hand, the other dyadic conflict featured less linkages and common negotiating ground, resulting in an escalation of conflict.

Why do some conflicts result in total war and others in limited wars? The theoretical expectations of this research is that shared societal norms and cultural values promote more 'humane' warfare practices. Differences in societal norms and cultural values can be used as justification for dehumanizing the enemy. As a result, certain tactics of warfare may be condoned against opponents that are perceived to be lesser beings. This can include intentional civilian targeting, the use of chemical and biological weapons.

The case studies illustrate the effect of societal norms and cultural values on the deliberation to unleash total war on an opponent. During the planning stages for many of these conflicts, decision-makers discussed possible options for war. Notably in the Iran-Iraq, ArgentineGreat Britain, United States-Vietnam and China-Vietnam cases, these differences were 
instrumental in deciding the course of action. It was from these cultural differences of Arab and Persian that Saddam Hussein authorized the use of chemical agents and intentional civilian targeting with the explicit goal of murdering Persians. Likewise, the American perception of Vietnamese culture was a catalyst in relying on quotas, spraying carcinogenic herbicides and pacification efforts. This can be contrasted with the Chinese decision-making, which went to great lengths to prevent collateral damage to civilian populations.

While this research project has accomplished its intended goals, future research should be dedicated to bolstering these findings. Future research would benefit from the applying these theories to a larger-N of cases. This could be in the form of an expanded dataset, which measures conflict escalation and battle fatalities pre-1816 would allow the theory to be tested across several centuries. Additionally, more precise measurements of civil religion would be welcome, as the six cultural dimensions are mere proxies for the moral and normative structure of the state. While it would be a labor intense endeavor, the classification of states according to a standardized rubric based on their enshrined values, would provide a more precise measurement of civil religion. Lastly, this theory could be applied to additional case studies, further increasing the generalizability. The other direction for further research is on the specific significant cultural findings from the quantitative analysis. The consistent significance of state and society variables, such as individualism and power distance allude to a possible underlying connection with dyadic conflict. Future research should investigate this relationship further, in order to determine how differences can alter the perceptions of states. 


\section{Bibliography}

“1958 Interim Constitution” Article 8; Article 9

(http://confinder.richmond.edu/admin/docs/1958_Interim_Constitution_English_.PDF)

“Agreement on Disengagement.” Geneva. June 5, 1974. UN Document S/11302/Add. $1-3$.

“Anglo-Iraq Treaty of 1930.” June 30, 1930. 132 LNTS 363.

"Boundary dispute between Argentina and Chile concerning the frontier line between boundary post 62 and Mount Fitzroy," October 21, 1994.

"Boundary Treaty and Protocol Concerning the Shatt-al-Arab Waterway.". July 3, 1937. International Legal Materials 8, no. 3 (May 1969):478-492.

"Boundary Treaty of 1881," July 23, 1881.

"Chemical Warfare in the Iraq-Iran War." Fact Sheet. Stockholm International Peace Research Institute.

"Chinese Deputy Premier Teng Hsiao-Ping Visits U.S.; Signs Agreements with Carter." Facts On File, February 2, 1979. (Accessed August 10, 2016).

"General Military Intelligence Directorate (GMID) Studies on the Foundation of the Da'wah Party and the Supreme Council of the Islamic Revolution Party," March-December 1995. SH-GMID-D-000-622, cited in Murray and Woods, The Iran-Iraq War, 132.

"General Military Intelligence Directorate Memos on Iran's Chemical Weapons Capability and Alleged Use," October, 1987, History and Public Policy Program Digital Archive, Conflict Records Research Center, National Defense University, SH-GMID-D-000-898.

"Letter Dated 11 April 1985 From The Permanent Representative of the Islamic Republic of Iran to The United Nations Addressed to The Secretary General," 21 March 1985. S/17096.

"Letter Dated 14 March 1985 From The Permanent Representative of the Islamic Republic of Iran to The United Nations Addressed to The Secretary General," 14 March 1985. S/17031.

"Letter Dated 20 March 1985 From The Permanent Representative of the Islamic Republic of Iran to The United Nations Addressed to The Secretary General," 21 March 1985. S/17046.

"Meeting between Saddam Hussein, the National Command, and the Revolutionary Command Council Discussing the Iran-Iraq War," September 16, 1980.

“Our Lady of Guadalupe.” New Catholic Encyclopedia. New York: McGraw Hill, 1967. 
"Protocol limits between Chile and Argentina 1893," May 1, 1893.

"Saddam and High-Ranking Officials Discussing Khomeini, the Ethiopian-Eritrean conflict, the Potential for Kurdish Unrest, and the Iranian Economy," February 20, 1979, History and Public Policy Program Digital Archive, Conflict Records Research Center, National Defense University, SH-SHTPA-000-851

"Saddam and His Advisers Discussing the Importance of Morale, Mobilizing Popular Support, and Targeting Iranian Cities," March 01, 1987, History and Public Policy Program Digital Archive, Conflict Records Research Center, National Defense University, SH-SHTP-A001-023.

“San Remo Resolution” April 25, 1920 (b)

"Sykes-Picot Agreement." https://wwi.lib.byu.edu/index.php/Sykes-Picot_Agreement (accessed 15 February, 2017)

“The Myth of the Bi-Oceanic Principle." El-Mercurio, as translanted by Chilean Embassy. Washington, D.C.

"Transcripts of Iraqi Leadership Meetings Discussing Responses to Iranian Missile Strikes,” 12-24 September 1986. SH-SHTP-D-000-411.

"Treaty Concerning the State Frontier and Neighbourly Relations between Iran and Iraq." June 13, 1975. UNTS 136.

“Treaty of Versailles.” June 28, 1919. Article 171.

"Various GMID Reports and Correspondence with the General Command of the Armed Forces and Air \& Air Defense Force Regarding Suitable Iranian Targets, Economic and Military," SH-GMID-D-001-366.

Abrahamian, Ervand. Iran between two revolutions. Princeton University Press, 1982.

Acosta-Alzuru, C. and E. Roushanzamir. "A war by any other name: A textual analysis of Falklands/Malvinas War." in The global dynamics of news: studies in international news coverage and news agendas, edited by A. Malek and P. A. Kavoori. Ablex: Connecticut, 2000. 2009.

Afkhami, Gholam Reza. The life and times of the Shah. University of California Press,

Aflaq, Michel. Fi Sabil al-Ba'ath, Edited by Sa'dun Hamadi. Beirut: Dar al-Taliy'a, 1959.

Alam, Mahboob. Iraqi foreign policy since revolution. Mittal Publications, 1995.

al-Banna, Hasan. Mudhakkirat al-da'wa wa I-da'iya. 
Ali, Javed. "Chemical weapons and the Iran-Iraq war: A case study in noncompliance." The Nonproliferation Review 8, no. 1 (2001): 43-58.

Allen, Kenneth W. Morgan Clemens, Steven Gilnert and Daniel Yoon. "China's Military Political Commissar System in Comparative Perspective." China Brief XIII:5 (March 4, 2013).

Alsop, Joseph. The New Yorker (June 25, 1955).

Appy, Christian G. Working-class war: American combat soldiers and Vietnam. University of North Carolina Press, 2000.

Arceneaux, Craig L. Bounded Missions: Military Regimes and Democratization in the Southern Cone and Brazil. Penn State Press, 2001.

Armstrong, Patrick Hamilton and Vivian Forbes. The Falkland Islands and their Adjacent Maritime Area, 1999.

Arquilla, John and Maria Moyano Rasmussen, "The Origins of the South Atlantic War," Journal of Latin American Studies 34, no. 4 (November 2001): 739-775. 1982.

Associated Press, "Iraq Vows to Quit Iran, Fight Israel," The New York Times, June 10,

Axelrod, Robert. The Evolution of Cooperation. New York: Basic Books, 1984.

Axworthy, Michael. Revolutionary Iran: a history of the Islamic Republic. Oxford University Press, 2013.

Ayalon, Ami. "The Iraqi-Iranian War" in Middle East Contemporary Survey. Vol. 1. Edited by Colin Legum. New York: Holmes \& Meier Publishers, 1981.

Barry, Jan, ed. Peace Is Our Profession: Poems and Passages of War Protest. East River Anthology, 1981.

Beach, D., \& Pedersen, R. B. Process-tracing methods: Foundations and guidelines. Ann Arbor: University of Michigan Press, 2013.

Beiner, Ronald. Civil religion: A dialogue in the history of political philosophy. Cambridge University Press, 2010.

Bellah, Robert N. "Civil religion in America." Daedalus (1967): 1-21.

Bercovitch, Jacob, and Judith Fretter. Regional guide to international conflict and management from 1945 to 2003. CQ Press, 2004.

Bercovitch, Jacob, and Richard Jackson. International conflict: A chronological encyclopedia of conflicts and their management, 1945-1995. CQ Press, 1997. 
Bermudez, H.R. "La libertad religiosa en la Constitucion Nacional." in La libertad religiosa en el Derencho argentine. Edited by R. Bosca and J.G. Navarro Floria. Buenos Aires: Konrad Adenuer Stiftung, 2007.

Booth, Ken. "The concept of strategic culture affirmed." In Strategic Power: USA/Ussr, 121-128. Palgrave Macmillan UK, 1990.

Booth, Ken. Strategy and Ethnocentrism. New York: Holmes \& Meier, 1979.

Boulding, Kenneth Ewart. The image: Knowledge in life and society. University of Michigan Press, 1956.

Boyce, D. George. The Falklands War. Palgrave Macmillan, 2005. 1997.

Brecher, Michael and Jonathan Wilkenfeld. A Study of Crisis. University of Michigan,

Brecher, Michael, and Jonathan Wilkenfeld. "International Crisis Behavior Project, 19182001." (2004).

Brumberg, Daniel. Reinventing Khomeini: The struggle for reform in Iran. University of Chicago Press, 2001.

Buckingham Jr., William A. "Operation Ranch Hand: Herbicides in Southeast Asia." Air University Review 34, no. 5 (July-August 1983): 42-53.

Bulloch, John, and Harvey Morris. The Gulf War: Its Origins, History and Consequences. London: Methuen, 1989.

Bukovansky, Mlada. Legitimacy and power politics: the American and French Revolutions in international political culture. Princeton University Press, 2010.

Burnham, David. "DOW Says U.S. Knew Dioxin Peril of Agent Orange." The New York Times. May 5, 1983.

Burton, Bruce. "Contending Explanations of the 1979 Sino-Vietnamese War." International Journal 34, no. 4 (Autumn 1979): 699-722.

Caputo, Philip. A Rumor of War. 1977. New York: Henry Holt, 1996.

Cardoso, Oscar Raúl, et al. Falklands: The Secret Plot. Translated by Bernard Ethell. Preston Editions, 1987.

Carleton, Gregory. Russia: The Story of War. Harvard University Press, 2017.

Carnevale, Peter J. and Dong-Won Choi. "Culture in the mediation of international disputes." International Journal of Psychology 35, no. 2 (2000): 105-110. 
Catton, Philip E. Diem 's final failure: prelude to America's War in Vietnam. University Press of Kansas, 2002.

Chen, King C. China's War with Vietnam, 1979: Issues, Decisions and Implications. Stanford CA: Hoover Institution Press, 1987.

Choueiri, Youssef M. Arab Nationalism: A History. Oxford: Blackwell, 2016.

Chubin, Shahram, and Sepehr Zabih. The foreign relations of Iran: A developing state in a zone of great-power conflict. University of California Press, 1974.

Clodfelter, Michael. "Warfare and armed conflicts." A Statistical Reference to Casualty and Other Figures 1618-1991. McFarland and Company. 1992. 2007.

Coker, Christopher. The warrior ethos: military culture and the war on terror. Routledge,

Coleman, John A. “Civil religion.” Sociological Analysis 30 (1969): 67-77.

Collier, David. "Understanding process tracing." PS Political science and politics 44, no. 4 (2011): 823-30.

Collier, Simon, and William F. Sater. A history of Chile, 1808-1994. Cambridge University Press, 1996.

Cristi, Marcela. From civil to political religion: The intersection of culture, religion and politics. Wilfrid Laurier University Press, 2006.

Cusimano, Joseph J. “An Analysis of Iran-Iraq Bilateral Border Treaties.” Case W. Res. J. Int'l L. 24 (1992): 89-113.

Cussen, James G. “'Tordesillas' - or how soft power works sometimes.” Paper presented at the International Symposium on Cultural Diplomacy. Berlin, 2011.

Daniels, R. Prisoners Without Trial: Japanese Americans in World War II. New York: Hill and Wang, 1993.

Dann, Uriel and Ofra Bengio. "Iraq," in Middle East Contemporary Survey. Vol. 1 Edited by Colin Legum. New York: Holmes \& Meier Publishers, 1978. 1969.

Dann, Uriel. Iraq under Qassem: a political history, 1958-1963. New York: Praeger,

Low, David B. "Prospects for Use of Chemical Weapons by Iraq against Iran over the next six months," February 24, 1984.

Mares, David R. Violent Peace: militarized interstate bargaining in Latin America. Columbia University Press, 2001. 
Davis, Peter, dir., Hearts and Minds (BBS, 1974))

De Mesquita, Bruce Bueno, and Randolph M. Siverson. "War and the survival of political leaders: A comparative study of regime types and political accountability." American Political Science Review 89, no. 4 (1995): 841-855.

De Mesquita, Bruce Bueno, James D. Morrow, Randolph M. Siverson, and Alastair Smith. "An institutional explanation of the democratic peace." American Political Science Review 93, no. 4 (1999): 791-807.

Deli, Zhou. Yi ge gaoji canmouzhang de zishu (Personal Recollections of a High-ranking Chief of Staff). Nanjing: Nanjing Press, 1992.

Delue, Steven M. Political Thinking, Political Theory and Civil Society. Boston: Allyn and Bacon, 1997.

Department of State Bulletin No. 24. May 1954.

Devlin, John F. The Ba'th party: a history from the origins to 1966. Hoover Institution Press, 1976.

Dishon, Daniel and Varda Ben-Zvi. "Inter-Arab Relations." in Middle East Contemporary Survey. Vol. 1. Edited by Colin Legum. New York: Holmes \& Meier Publishers, 1978 .

Dixon, William J. "Democracy and the management of international conflict." Journal of Conflict Resolution 37, no. 1 (1993): 42-68.

Dommen, Arthur J. The Indochinese experience of the French and the Americans: nationalism and communism in Cambodia, Laos, and Vietnam. Indiana University Press, 2002.

Doran, Susan, and Christopher Durston. Princes, Pastors and People: The Church and Religion in England, 1500-1689. Routledge, 2002.

Doyle, Michael W. "Liberalism and world politics." American Political Science Review 80, no. 4 (1986): 1151-1169.

Ebert, James. A life in a year: The American Infantryman in Vietnam. Presidio Press, 1993.

Eddy, Paul et al. War in The Falklands: The Full Story. Time Warner Paperbacks, 1982.

Editorial Board of the Vietnam Courier. Chinese War Crimes in Vietnam. Hanoi: Vietnam Courier, 1979.

Entessar, Nader. "The Kurds in post-revolutionary Iran and Iraq." Third World Quarterly 6, no. 4 (1984): 911-933. 
Eytan, Edwin. "Syria will Continue Intervention in Lebanon, Assad says.” Jewish Telegraphic Agency. June 18, 1976.

Fall, Bernard B. Ho Chi Minh on Revolution: Selected Writings, 1920-66. New American Library of Canada, 1968.

Fearon, James D. "Domestic Political Audiences and the Escalation of International Disputes.” American Political Science Review. 88, no. 3 (1994): 577-92.

Femenia, Nora. National identity in times of crises: The scripts of the Falklands-Malvinas War. Nova Publishers, 1996.

Firro, Kais. Inventing Lebanon: Nationalism and the State under the Mandate. London: IB Tauris, 2002.

Fisher, George E. “The Beagle Channel: Chile and Argentina's Gulf of Agaba.” PhD diss., U.S. Naval War College, 1970.

Fox, Jonathan. "Ethnic minorities and the clash of civilizations: A quantitative analysis of Huntington's thesis.” British journal of political science 32, no. 3 (2002): 415-434.

Freedman, Lawrence and Virginia Gamba-Stonehouse. Signals of War: The Falklands Conflict of 1982. Princeton University Press, 1991.

Freedman, Lawrence. The official history of the Falklands: The Origins of the Falklands conflict. London: Routledge, 2005.

Fremantle, Anne. The Social Teaching of the Church. New York: Mentor-Omega, 1963.

Garrett, James L. "The Beagle Channel Dispute: Confrontation and Negotiation in the Southern Cone.” Journal of International American Studies 27, no. 3 (Autumn 1985): 81-110.

Gartzke, Erik. "The capitalist peace.” American journal of political science 51, no. 1 (2007): 166-191.

General Assembly Resolution 1514, Declaration on the Granting of Independence to Colonial Countries and Peoples. (14 December 1960).

General Assembly Resolution 2065, Question of the Falkland Islands (Malvinas). (16 December 1965).

General Assembly Resolution 3160, Question of the Falkland Islands (Malvinas). (14 December 1973).

General Office of the General Political Department. Zhong Yue Bianjing Ziwei Huanji Zuozhan Zhengzhi Gongzuo Jingyan Xuanbian (Compilation of Experiences of Political Work in the Counterattack in Self-Defense on the Sino-Vietnamese Border). Beijing: Zongzhengzhibu, 1980 . 
Giardinelli, Mempo. El país de las maravillas: los argentinos en el fin del milenio. Buenos Aires: Planeta, 1998.

Gibran, Daniel K. The Falklands War: Britain Versus the Past in the South Atlantic. McFarland, 1997.

Giddens, Anthony. Modernity and self-identity: Self and society in the late modern age. Stanford University Press, 1991.

Gilpin, Robert. War and change in world politics. Cambridge University Press, 1983.

Gin, Christopher M. "How China Wins: A Case Study of the 1979 Sino-Vietnamese War." master's thesis, United States Army Command and General Staff College, 2015.

Gorman, Stephen. "Peruvian Foreign Policy Since 1975: External Political and Economic Initiatives." Inter-American Economic Affairs 33 (1978): 51-71.

Grayson, George W. "Chile's Christian Democratic Party: Power, Factions, and Ideology." The Review of Politics 31, no. 02 (1969): 147-171.

Graziano, Frank. Divine Violence: Spectacle, Psychosexuality, and Radical Christianity in the Argentine "Dirty War." Boulder, CO: Westview, 1992. Books, 2006.

Grosscup, Beau. Strategic terror: The politics and ethics of aerial bombardment. Zed

Grossling, Bernardo. Petroleum Prospects in the Energy Crisis. Geological Survey Bulletin 1411.

Grossman, D., with Christensen, L. "The Psychology and Physiology of Deadly Conflict in War and in Peace." WSG Research Publications, 2004.

Grotto, Jason, Chris Groskopf, Ryan Mark, Joe Germuska and Brian Boyer. "U.S. troops, Vietnamese nationals exposed to dangerous chemicals." Chicago Tribune. December 4, 2009.

Gustafson, Lowell S. The Sovereignty Dispute over the Falkland (Malvinas) Islands. Oxford University Press, 1988.

Gutierrez, Gustavo, and Caridad Inda. A theology of liberation: History, politics, and salvation. Edited by Caridad Inda and John Eagleson. New York: Orbis Books, 1988.

Haas, Mark L. The ideological origins of great power politics, 1789-1989. Cornell University Press, 2005.

Hackworth, David H., and Julie Sherman. About face: The odyssey of an American warrior. Simon and Schuster, 1990.

Haig, Alexander. Caveat: Realism, Reagan, and foreign policy. MacMillan Publishing Company, 1984. 

1966.

Hammer, Ellen Joy. The struggle for Indochina, 1940-1955. Stanford University Press,

Hasim, Ahmed. "Iran's military Situation." In Iran's strategic intentions and capabilities, Edited by Patrick Clawson. Washington D.C.: Institute for National Strategic Studies, 1994.

Hastings, Max, and Simon Jenkins. The Battle for the Falklands. New York: Norton, 1983.

Her Majesty's Stationary Office, Falkland Islands Review (1983).

Herman, Edward S., and Noam Chomsky. Manufacturing consent: The political economy of the mass media. Random House, 2010.

Herrmann, R. K., Voss, J. F., Schooler, T. Y. E., \& Ciarrochi, J. "Images in international relations: An experimental test of cognitive schemata." International Studies Quarterly, 41 (1997): 403-433.

Herrmann, R.K. "Perceptions and image theory in international relations." in Handbook of Political Psychology 334-363, Edited by D. Sears, L. Huddy and J. Levy. New York: Oxford University Press, 2013.

Higham, John. Strangers in the Land: Patterns of American Nativism, 1860-1925. New Brunswick: Rutgers University Press, 1955.

Hinnebusch, Raymond A. "State and civil society in Syria." Middle East Journal 47, no. 2 (1993): 243-257.

Hinnebusch, Raymond. "Syria-Iraq Relations: State Construction and Deconstruction and the Mena States System." LSE Middle East Centre Paper Series, 4 (October 2014).

Hinnebusch, Raymond. Syria: Revolution from above. Routledge, 2004.

Hiro, Dilip. The longest war: The Iran-Iraq military conflict. Psychology Press, 1989.

Hofstede, Geert, Gert Jan Hofstede, and Michael Minkov. Cultures and organizations: Software of the mind. Vol. 2. London: McGraw-Hill, 2010.

Hofstede, Geert. "Culture and organizations." International Studies of Management \& Organization 10, no. 4 (1980): 15-41.

Holian, Timothy J. The German-Americans and World War II: An Ethnic Experience. New York: Peter Lang, 1996.

Holsti, Ole R. "Cognitive dynamics and images of the enemy." Journal of International Affairs 21, no. 1 (1967): 16-39.

Honeywell, Martin and Jenny Pearce. Falklands/Malvinas; whose crisis? Latin American Bureau, 1982. 
Hood, Steven J. Dragons Entangled: Indochina and the China-Vietnam War. Armonk: An East Gate Book, 1992.

Horgan, John. "No, War is not inevitable." Discover (June 2012).

http://discovermagazine.com/2012/jun/02-no-war-is-not-inevitable (accessed July 1, 2017).

Hoskins, Marilyn W. "Vietnamese women: Their roles and their opinions", in David J. Banks. Changing Identities in modern Southeast Asia. Chicago: Aldine, 1976.

House, R. J., Hanges, P. J., Javidan, M, Dorfman, P. W., \& Gupta, V. 2004. Culture, Leadership and Organizations: The Globe Study of 62 Societies. Thousand Oaks, CA: Sage Publications.

Human Sciences Research. A Study of Mass Population Displacement in the Republic of Viet-Nam, Part II: Case studies of Refugee Resettlement. McLean, Va., 1969.

Hunt, Michael H. Ideology and US foreign policy. Yale University Press, 2009, 177.

Huntington, Samuel P. "The clash of civilizations?.” Foreign affairs (1993): 22-49.

Hutchison, Elizabeth Quay, Thomas Miller Klubock, Nara B. Milanich, and Peter Winn. “The Chile Reader: History, Culture." Politics (2014).

Ibranhim Anvari Tehrani. "Iraqi Attitudes and Interpretation of the 1975 Agreement." In The Iran-Iraq War: The Politics of Aggression, Rajaee, Farhang, ed. Gainesville: University Press of Florida Press, 1993.

Ikenberry, G. John. "The West: Precious, not Unique: Civilizations Make for a Poor Paradigm Just Like the Rest." Foreign Affairs (1997).

Indochina - The Cease-Fire Agreements in Indochina: Statement by the President. July 21, 1954. http://avalon.law.yale.edu/20th_century/inch027.asp.

Inglehart, Ronald, and Pippa Norris. "The true clash of civilizations." Foreign policy (2003): 63-70.

Ivereigh, Austen. Catholicism and politics in Argentina, 1810-1960. Springer, 2016.

Malamud-Goti, Jaime E. Game without end: State terror and the politics of justice. University of Oklahoma Press, 1996.

Javidan, M., House, R. J., Dorfman, P. W., Hanges, P. J., \& Sully de Luque, M. 2006. "Conceptualizing and measuring cultures and their consequences: a comparative review of GLOBE's and Hofstede's approaches." Journal of International Business Studies, 37 (6): 897914. 1967.

JCSM-719-67, Review of Crop Destruction Operations in South Vietnam, December 29 
Jepperson, Ronald L., Alexander Wendt, and Peter J. Katzenstein. "Norms, identity, and culture in national security." In Culture and National Security, Edited by Peter J. Katzenstein, 33-75. New York: Columbia University Press, 1996.

Jervis, Robert. Perception and Misperception in International Politics. Princeton: Princeton University Press, 1976.

Jones, Daniel M., Stuart A. Bremer, and J. David Singer. "Militarized interstate disputes, 1816-1992: Rationale, coding rules, and empirical patterns." Conflict Management and Peace Science 15, no. 2 (1996): 163-213. 1994.

Kacowicz, Arie Marcelo. Peaceful territorial change. University of South Carolina Press,

Kamrava, Mehran. The modern Middle East: a political history since the First World War. Berkeley: University of California Press, 2005.

Karsh, Efraim. The Iran-Iraq War 1980-1988. London: Osprey 2002.

Keohane, Robert O., and Joseph S. Nye. Power and interdependence. Boston: Longman, 1977.

Keohane, Robert. After Hegemony: Cooperation and Discord in the World Political Economy. Princeton: Princeton University Press, 1984.

Khadduri, Majid. Socialist Iraq: A study in Iraqi politics since 1968. Middle East Institute, 1978.

Khoury, Philip Shukry. Syria and the French Mandate: The Politics of Arab Nationalism, 1930-1945. Princeton University Press, 2014.

Kienle, Eberhard. Ba'th v. Ba'th: The conflict between Syria and Iraq, 1968-1989. London: IB Tauris, 1990.

Kim Khahn, Huynh. "Vietnam: Neither Peace Nor War." Southeast Asian Affairs (1979).

King, Philip Parker. Narrative of the Surveying Voyages of His Majesty's Ships Adventure and Beagle. London: Colburn, 1839.

Kinnard, Douglas. Adventures in Two Worlds: Vietnam General and Vermont Professor. Xlibris Corporation, 2012. 2003.

Kumar, Krishan. The making of English national identity. Cambridge University Press,

Ky, Nguyen Cao. Twenty years and twenty days. Scarborough House, 1976.

Lacina, Bethany, and Nils Petter Gleditsch. "Monitoring trends in global combat: A new dataset of battle deaths." European Journal of Population 21, no. 2 (2005): 145-166. 
Laing, Ronald D. The Divided Self. An Existential Study in Sanity and Madness. Harmondsworth: Penguin, 1959.

Laucirica, Jorge O. "Lessons from Failure: The Falklands/Malvinas Conflict.” Seton Hall J. Dipl. \& Int’l Rel. 1 (2000): 79-95.

Laudy, Mark. "The Vatican Mediation of the Beagle Channel Dispute: Crisis Intervention and Forum Building." In Words Over War: Mediation and Arbitration to Prevent Deadly Conflict, Edited by Melanie C. Greenberg, John H. Barton, and Margaret E. McGuinnes, 293-320. New York: Rowman \& Littlefield, 2000.

Laurie, Clayton D. "The Ultimate Dilemma of Psychological Warfare in the Pacific: Enemies who don't Surrender, and GIs who don't Take Prisoners." War \& Society 14.1 (1996): $99-120$.

Laver Roberto C. The Falklands/Malvinas Case: Breaking the Deadlock in the AngloArgentine Sovereignty Dispute. Martinus Nijhoff: The Hague, 2001.

Layne, Christopher. "Kant or cant: The myth of the democratic peace." International security 19, no. 2 (1994): 5-49.

Lebow, Richard Ned. "Miscalculation in the South Atlantic: The Origins of the Falklands War." In Psychology and Deterrence, Edited by Robert Jervis, 89-125. Johns Hopkins University Press, 1985.

Leonard Binder, trans. "The Constitution of the Arab Resurrection Socialist Party." Middle East Journal 13 (Spring 1959): 195-200.

Letter, SECDEF to CJCS, 21 November 1967.

Levy, Jack and Lily I. Vakili. "Diversionary Action by Authoritarian Regimes: Argentina in the Falklands/Malvinas Case." in The Internationalization of Communal Strife, ed. Manus I. Midlarsky, 118-146, New York: Routledge, 1992.

Lewallen, John. Ecology of devastation: Indochina. Puffin, 1971.

Lewis George G., and John Mehwa. History of Prisoner of War Utilization by the United States Army 1776-1945. Department of the Army, 1955.

Lewis, Richard D. When Cultures Collide: Leading Across Cultures. Boston: Nicholas Brealey Publishing, 2006.

Lifton, Betty Jean, and Thomas C. Fox. Children of Vietnam. Atheneum, 1972.

Lindsley, Lisa. "The Beagle Channel settlement: Vatican mediation resolves a century-old dispute." Journal of Church and State 29, no. 3 (1987): 435-454. 
Lipset, Seymour Martin. American exceptionalism: A double-edged sword. WW Norton \& Company, 1997.

Lung, Hoang Ngoc. "Indochina Monographs: Strategy and Tactics." 1978.

Mackey, Sandra. The Iranians: Persia, Islam, and the soul of a nation. Plume, 1998.

Mackey, Sandra. The reckoning: Iraq and the legacy of Saddam Hussein. WW Norton \& Company, 2003. Ltd., 1981.

Man Kin, Li. Sino-Vietnamese War. Hong Kong: Kingsway International Publications,

Maoz, Zeev, and Bruce Russett. "Normative and structural causes of democratic peace, 1946-1986." American Political Science Review 87, no. 3 (1993): 624-638.

Maoz, Zeev. Domestic sources of global change. University of Michigan Press, 1996.

Mares, David R. Violent Peace: militarized interstate bargaining in Latin America. Columbia University Press, 2001.

Markus, Hazel R., and Shinobu Kitayama. "Culture and the self: Implications for cognition, emotion, and motivation." Psychological review 98, no. 2 (1991): 224-253.

Marr, David G. Vietnam 1945: The quest for power. University of California Press, 1997.

Martin, P. "Iran Forces on Full Alert in Dispute with Iraq." The Times. April 21, 1969.

Masalha, Nur. "Faisal's Pan-Arabism, 1921-33." Middle Eastern Studies 27, no. 4 (October 1991): 679-693.

Maseland, Robbert, and André Van Hoorn. "Explaining the negative correlation between values and practices: A note on the Hofstede-GLOBE debate." Journal of International Business Studies 40, no. 3 (2009): 527-532.

Maseland, Robbert, and André Van Hoorn. "Values and marginal preferences in international business." Journal of International Business Studies 41, no. 8 (2010): 1325-1329.

Masters, Bruce. "The treaties of Erzurum (1823 and 1848) and the changing status of Iranians in the Ottoman Empire.” Iranian Studies 24, no. 1-4 (1991): 3-15.

McDowall, David. Modern History of the Kurds. London: IB Tauris, 2003.

McKeown, Elizabeth. "Civil Religion: Prophetic Freedom or Cultural Captivity." Proceedings of the Catholic Theological Society of America 31 (2012).

McManis, David Y. “Monthly warning meetings for February 1984.” March 13, 1984. 
McSweeney, Bill. Security, identity and interests: a sociology of international relations. Cambridge University Press, 1999.

Mearsheimer, John. The Tragedy of Great Power Politics. New York: Norton Publishers, 2001.

Memorandum for the President: Additional Defoliation Operations in Vietnam. By Maxwell D. Taylor. February 3, 1962;

Memorandum for the President: Defoliant Operations in Vietnam. By Robert S. McNamara. February 2, 1962.

Memorandum for the Secretary of State and Secretary of Defense: Destruction of the Mangrove Swamps in South Vietnam. By Michael V. Forrestal. August 9, 1962.

Message, Department of State to AMEMBASSY Saigon, Join State-Defense Message No. 561, 30 November 1962.

Alfaq, Michel. "Thawriyat al-Wihdah al-Arabiyah," in Ma'rakat al-Masir al-Wahid. Beirut: Dar al-IIm li al-Malayin, 1958.

Middlebrook, Martin. Operation CORPORATE: The Story of the Falklands War. London: Viking, 1987.

Mill, John Stuart. Utilitarianism. Broadview Press, 2010.

Min, Chen. The Strategic Triangle: Lessons from the Indochina War. London: Lynne Rienner, 1992.

Mirow, Matthew C. "International Law and Religion in Latin America: The Beagle Channel Dispute." Suffolk Transnat'l L. Rev. 29 (2004): 1-29.

Mitzen, Jennifer. "Ontological security in world politics: State identity and the security dilemma.” European Journal of international relations 12, no. 3 (2006): 341-370.

Moise, Edward E. Land Reform in China and North Vietnam. Chapel Hill: University of North Carolina Press, 1983.

Moorman, John. History of the Church in England. Church Publishing, Inc., 1980.

Morony, Michael G. "Conquerors and Conquered: Iran." Studies on the First Century of Islamic Society. Cardale: Southern Illinois University Press, 1982: 110-75.

Morris, Stephen J. Why Vietnam invaded Cambodia: political culture and causes of war. Chicago: Stanford University Press, 1999.

Müller, Harald, and Jonas Wolff. "Dyadic democratic peace strikes back." In 5th PanEuropean International Relations Conference, The Hague. 2004. 
Murray, Williamson, and Kevin M. Woods. The Iran-Iraq War: A Military and Strategic History. Cambridge University Press, 2014.

National Security Action Memorandum No. 115. By McGeorge Bundy. November 30, 1961.

Newhaus, Richard John. Time Toward Home-the American Experiment as Revelation. Seabury Press, 1975.

Ngoc Lung, Hoang. Strategy and Tactics. Pickle Partners Publishing, 2015.

al-Bath, Nidal. Beirut. Beirut: Dar al-Taliah, 1963.

Nisan, Mordechai. "The Syrian Occupation of Lebanon.” In Peace with Syria: No Margin for Error, 51-107. ACPR, 2000.

Nouzeilles, Gabriela, and Graciela Montaldo. The Argentina reader: History, culture, politics. Duke University Press, 2002.

Nyrop, Richard F. Brazil: A Country Study. Washington, D.C., 1982.

O'Ballance, Edgar. The Gulf War: Nineteen Eighty to Nineteen Eighty-Seven. London: Brassey's Defense Publishers, 1988.

O'Dowd, Edward C. Chinese Military Strategy in the Third Indochina War. Routledge: New York, 2007.

Oakes, Amy. Diversionary war: Domestic unrest and international conflict. Stanford University Press, 2012.

Oren, Ido. "The subjectivity of the" democratic" peace: changing US perceptions of imperial Germany." International Security 20, no. 2 (1995): 147-184.

Oren, Ido. Our enemies and US: America's rivalries and the making of political science. Cornell University Press, 2003.

Owen, John M. "How liberalism produces democratic peace." International security 19, no. 2 (1994): 87-125.

Owen, John M. The Clash of Ideas in World Politics: Transnational Networks, States, and Regime Change, 1510-2010: Transnational Networks, States, and Regime Change, 15102010. Princeton University Press, 2010.

Papayoanou, Paul A. "Interdependence, institutions, and the balance of power: Britain, Germany, and World War I." International Security 20, no. 4 (1996): 42-76.

Park, Jinim. Narratives of the Vietnam War by Korean and American Writers. Peter Lang, 2007. 
Parveen, Talat. Iran's Policy Towards the Gulf. Concept Publishing Company, 2006.

Passarelli, Bruno. El Delirio Armado: Argentina-Chile, La Guerra que Evito el Papa. Editorial Sudamericana 1998.

Peceny, Mark, Caroline C. Beer, and Shannon Sanchez-Terry. "Dictatorial peace?." American Political Science Review 96, no. 1 (2002): 15-26.

Pelletiere, Stephen C. "Iraq's Decision to Go to War." In The Iran-Iraq War: The IranIraq Conflict. New York: Praeger Publishers, 1992.

Perkins, Roger. Operation Paraquat: The Battle for South Georgia. Chippenham: Picton Publishing, 1986.

Perry, William. Contemporary Brazilian Foreign Policy: The International Strategy of an Emerging Power. Philadelphia, PA: Sage Publications, 1976.

Phillips, Andrew. War, Religion, and Empire. Cambridge University Press, 2010.

Pipes, Daniel. Greater Syria: the history of an ambition. Oxford University Press, 1992.

Platteau, Jean-Philippe. Institutions, social norms, and economic development. Vol. 1. Psychology Press, 2000.

Pope Paul VI. Gaudium et Spes. December 7, 1965. Papal Archive. The Holy See. $<$ http://www.vatican.va/archive/hist_councils/ii_vatican_council/documents/vatii_cons_19651207_gaudium-et-spes_en.html>.

Potter, Lawrence, and Gary Sick, eds. Iran, Iraq, and the legacies of war. Springer, 2004.

Princen, Thomas E. Intermediary intervention: A model of intervention and a study of the Beagle Channel case. Cambridge: Harvard University Press, 1988.

Princen, Thomas. "International Mediation-The View from the Vatican." Negotiation Journal 3, no. 4 (1987): 347-366.

Princen, Thomas. Intermediaries in international conflict. Princeton University Press, 2014.

Puchala, Donald J. "International encounters of another kind." Global Society: Journal of Interdisciplinary International Relations 11, no. 1 (1997): 5-29.

Pye, Lucian W. Asian Power and Politics: The Cultural Dimensions of Authority. Harvard University Press, 1988.

Qutb, Sayyid. Ma'alim fi-l-Tariq. Cairo: Dar al-Shuruq, 1964.

Rabinovich, Itamar. The war for Lebanon, 1970-1985. Cornell University Press, 1985. 
Records Research Center, National Defense University, SH-SHTP-A-001-023.

Reisman, W. Michael. "The struggle for the Falklands." The Yale Law Journal 93, no. 2 (1983): 287-317.

Reiter, Dan, and Allan C. Stam. "Democracy, war initiation, and victory." American Political Science Review 92, no. 2 (1998): 377-389.

Report, "Assessment of Ecological Effects of Extensive or Repeated Use of Herbicides," Midwest Research Institute, ARPA Order No. 1086, AD824314, 1 December 1967. May 1968.

Report, AMEMBASSY Saigon, Report of the Herbicide Policy Review Committee, 28

Report, Anthony J. Russo, A Statistical Analysis of the U.S. Crop Spraying Program in South Vietnam (RM-5450-1SA/ARPA), October 1967; Report, Russell Betts and Frank Denton, An Evaluation of Chemical Crop Destruction in Vietnam (RM-5446-ISA/ARPA), October 1967.

Rezamand, Ardalan. "Use of Religious Doctrine and Symbolism in the Iran-Iraq War." Illumine: Journal of the Centre for Studies in Religion and Society Graduate Students Association 9, no. 1 (2011): 83-107.

Rippley, La Vern J. The German-Americans. Boston: Twayne Publishers, 1976.

Risse-Kappen, Thomas. "Democratic peace-warlike democracies? A social constructivist interpretation of the liberal argument." European Journal of International Relations 1, no. 4 (1995): 491-517.

Rock, David. Argentina, 1516-1982: from Spanish colonization to the Falklands War. Berkeley: University of California Press, 1985.

Rosemont, Henry and Roger T. Ames. The Analects of Confucius: A Philosophical Translation. New York: Ballantine, 1998.

Ross, Robert. The Indochina Tangle: China's Vietnam Policy, 1975-1979. Columbia University Press, 1988.

Rousseau, Jean-Jacques. The social contract, or, Principles of political right. No. 83. George Allen \& Unwin, 1895.

Russett, Bruce M., John R. Oneal, and Michaelene Cox. "Clash of civilizations, or realism and liberalism déjà vu? Some evidence." Journal of Peace Research 37, no. 5 (2000): 583-608.

Russett, Bruce, and John Oneal. Triangulating peace: Democracy, Interdependence, and International Organizations. New York, 2001. 
Russett, Bruce. "The Fact of Democratic Peace." In Debating the democratic peace (1996): 58-81.

Russett, Bruce. Grasping the democratic peace: Principles for a post-Cold War world. Princeton University Press, 1994.

Salem, Paul. Bitter legacy: ideology and politics in the Arab world. Syracuse University Press, 1994.

Samir Khalil. Republic of Fear: The Inside Story of Saddam's Iraq. New York: Pantheon, 1989.

Schwartz, Shalom H. "Are there universal aspects in the structure and contents of human values?.” Journal of social issues 50, no. 4 (1994): 19-45.

Schwartz, Shalom H. "Universals in the content and structure of values: Theoretical advances and empirical tests in 20 countries." Advances in experimental social psychology 25 (1992): 1-65.

Schweller, Randall L. "Neorealism's status-quo bias: What security dilemma?." Security Studies 5, no. 3 (1996): 90-121.

Segal, Gerald. Defending China. Oxford University Press: 1985.

Shambaugh, David. "The Soldier and the State in China: The Political Work System in the People's Liberation Army." The China Quarterly, no. 127 (September 1991): 527-568.

Shilun, Song. Mao Zedong Junshi Sixiangde Xingcheng Jiqi Fazhan (The Formulation and Development of Mao Zedong's Military Thought). Beijing: Military Science Publishers, 1984.

Siedentop, Larry. Inventing the Individual: The Origins of Western Liberalism. Cambridge: Belknap Press, 2014.

Sigmund, Paul E. "Revolution, counterrevolution, and the catholic church in Chile." The ANNALS of the American Academy of Political and Social Science (1986): 25-35.

Simons, Geoff. The Vietnam Syndrome: Impact on US Foreign Policy. Springer, 1997.

Singer, Joel David, and Melvin Small. Wages of War, 1816-1980: Augmented with Disputes and Civil War Data. Inter-university Consortium for Political and Social Research, 1984.

Small, Melvin, and Joel David Singer. Resort to arms: International and civil wars, 1816-1980. Sage Publications, 1982.

Solis, Gary D. Son Thang: An American war crime. Naval Institute Press, 1997. 
Stewart, Nora K. Mates and Muchachos: Unit Cohesion in the Falklands-Malvinas War. Potomac Books Incorporated, 1991.

Stockholm International Peace Research Institute (SIPRI). World Armaments and Disarmament. Cambridge, MA: Oelgeschlager, Gunn and Hain, Inc., 1982.

Stransky, Steven G. "Re-examining the Falkland Islands War: The Necessity for MultiLevel Deterrence in Preventing Wars of Aggression." Georgia Journal of International \& Comparative Law 473, (2011-2012): 473-525.

Sung An, Tai. "Turmoil in Indochina: The Vietnam-Cambodia Conflict." Asian Affairs Vol. 5 No.4 (March-April 1978): 245-256.

Tanner, Henry. "Syria and Iraq Reach an Accord to Pull Back Troops on Border." The New York Times. November 27, 1976.

Tapia, Luis Alfonso. Esta Noche: La Guerra. Editorial Grijalbo, 1997.

“Targeting Iranian Cities,” March 01, 1987, History and Public Policy Program Digital Archive, Conflict

Telegram from Secretary of State Dulles on Conversation with Eden and Bidault about Indochina. April 26, 1954.

The Centers for Disease Control and Prevention. "Facts about Sulfur Mustard." https://emergency.cdc.gov/agent/sulfurmustard/basics/facts.asp (accessed January 22, 2017).

The Pentagon Papers. Vol. 1. Senator Mike Gravel, editor. Boston: Beacon Press, 1972.

The Pentagon Papers. Vol. 2. Senator Mike Gravel, editor. Boston: Beacon Press, 1972.

The Pentagon Papers. Vol. 3. Senator Mike Gravel, editor. Boston: Beacon Press, 1972.

The Pentagon Papers. Vol. 4. Senator Mike Gravel, editor. Boston: Beacon Press, 1972.

Tiano, Susan. "Authoritarianism and Political Culture in Argentina and Chile in the Mid1960's." Latin American Research Review 21, no. 1 (1986): 73-98.

Tran, Khanh. The ethnic Chinese and economic development in Vietnam. Institute of Southeast Asian, 1993. Row, 1971.

Trewhitt, Henry L. McNamara: His Ordeal in the Pentagon. New York: Harper and

Triandis, Harry C. Individualism and Collectivism: New Directions in Social Psychology. Boulder, CO: Westview Press, 1995. 
Tulchin, Joseph S. "Authoritarian Regimes and Foreign Policy: The Case of Argentina." in Latin American Nations in World Politics, Edited by Heraldo Muñoz and Joseph S. Tulchin. Boulder: Westview Press, 1984. 2013.

Turse, Nick. Kill Anything that Moves: The real American war in Vietnam. Macmillan,

U.S. Army, The Armored Division Brigade, FM 6-20 (Washington, D.C.: Government Printing Office, 1958).

U.S. Central Intelligence Agency. "Iran's likely reaction to the Iraqi use of Chemical Weapons." November 4, 1983. 1982.

U.S. Central Intelligence Agency. "Iran-Iraq: Situation Report Number 27." July 29,

U.S. Central Intelligence Agency. “Iraq: Use of Nerve Agent.” March 23, 1984.

U.S. Central Intelligence Agency. "The Sino-Vietnamese Border Dispute.” No. 0000789482. (February 4, 1979, 11).

U.S. Central Intelligence Agency. The President's Daily Brief. CIARDP79T00936A013400010029-7. June 15, 1976.

U.S. Central Intelligence Agency. The President's Daily Brief. CIARDP79T00936A013400010027-9. June 12, 1976.

U.S. Central Intelligence Agency. The President's Daily Brief. CIARDP79T00024A000300060005-1. November 27, 1976.

U.S. Department of State, ARGENTINA REJECTS BEAGLE AWARD. January 25, 1978.

U.S. Department of State, ARGENTINA TO REJECT BEAGLE CHANNEL RULING; NAVY BEGINS MANEUVERS. January 10, 1978.

U.S. Department of State, ARGENTINE LEGAL ARGUMENTS IN BEAGLE DISPUTE. September 11, 1978.

U.S. Department of State, CHILEANS REQUEST USG GOOD OFFICES ON BEAGLE DISPUTE January 7, 1978

U.S. Department of State. ARGENTINE-CHILEAN COMMISSION ISSUES REPORT ON BEAGLE CHANNEL DISCUSSIONS. April 7, 1978.

U.S. Department of State. BEAGLE CHANNEL TALKS. June 1, 1978.

U.S. Department of State. BEAGLE CHANNEL TALKS: PHASE TWO RESTARTED. September 15, 1978. 
U.S. Department of State. BEAGLE CHANNEL; PRESIDENTS TO SIGN AGREEMENT FEBRUARY 20. February 17, 1978.

U.S. Department of State. BEAGLE CHANNEL; PRESIDENTS TO SIGN AGREEMENT FEBRUARY 20. February 17, 1978.

U.S. Secretary of State. ALLEGED ALERT ORDER REGARDING INITIATION OF MILITARY OPERATIONS. December 14, 1978.

U.S. Secretary of State. ARGENTINA AMENABLE TO MEDIATION IN BEAGLE DISPUTE. November 9, 1978.

U.S. Secretary of State. ARGENTINA GLOOMY ON BEAGLE SOLUTION PROSPECTS. October 31, 1978.

U.S. Secretary of State. ARGENTINE MOVES IN BEAGLE CHANNEL DISPUTE. October 26, 1978.

U.S. Secretary of State. BEAGLE CHANNEL AFFAIR AND POSSIBLE POPE'S PARTICIPATION. October 27, 1978.

U.S. Secretary of State. BEAGLE CHANNEL DISPUTE. December 16, 1978.

U.S. Secretary of State. BEAGLE CHANNEL DISPUTE. December 5, 1978.

U.S. Secretary of State. BEAGLE CHANNEL DISPUTE. December 9, 1978.

U.S. Secretary of State. BEAGLE CHANNEL SIDPUTE: CHILE CONSIDERS REPEATING ICJ INVITATION. December 19, 1978.

U.S. Secretary of State. BEAGLE CHANNEL TENSIONS SUBSIDE; SOLUTION AT HAND?. September 20, 1978.

U.S. Secretary of State. BEAGLE CHANNEL UPDATE. November 1, 1978.

U.S. Secretary of State. BEAGLE CHANNEL UPDATE. November 1, 1978; U.S. Secretary of State. ARGENTINA GLOOMY ON BEAGLE SOLUTION PROSPECTS. October 31, 1978.

U.S. Secretary of State. BEAGLE CHANNEL: CHILE ACCEPTS EMISSARY BUT PLANS TO INVOKE RIO TREATY TONIGHT OR TOMORROW. December 22, 1978.

U.S. Secretary of State. BEAGLE CHANNEL: POPE'S REMARKS ON SPECIAL ENVOY. December 22, 1978.

U.S. Secretary of State. BEAGLE CHANNEL: PRESS COMMENTS AND TALK WITH AMBASSADOR BARROS. November 8, 1978.

U.S. Secretary of State. BEAGLE CHANNEL: VATICAN VIEWS. December 16, 1978. 
U.S. Secretary of State. CHILEAN EMBASSY VIEWS ON BEAGLE DISPUTE. November 15, 1978.

U.S. Secretary of State. REPORT OF ARGENTIEN TROOP MOVEMENTS ON CHILEAN BORDER. September 12, 1978.

UN Treaty Series. Act of Montevideo (Montevideo 1979). MLXXXVIII.

United Nations Archives and Records Management Section. "Chinese Foreign Ministry's Note to the Vietnamese Embassy in China Protesting against Viet Nam's Military Provocations." (February 12, 1979).

United Nations Archives and Records Management Section. “Chinese Foreign Ministry's Note of Protest against Vietnamese Encroachment upon Chinese Territory and Creation of Bloodshed." (February 16, 1979).

United Nations Archives and Records Management Section. "Chinese Protests against Vietnam.” (September 07, 1978).

United Nations Archives and Records Management Section. "Chinese Government Delegation Leader's Statement at 8th Session of Sino-Vietnamese Negotiations." (October 05, 1978).

United Nations Archives and Records Management Section. "Chinese Government Delegation Leader's Statement at 8th Session of Sino-Vietnamese Negotiations." (October 05, 1978).

United Nations Archives and Records Management Section. "Letter, Chen Chu to H.E. Baron Rudiger von Wechmar.” (December 11, 1978).

United Nations Archives and Records Management Section. "Memorandum of the Ministry of Foreign Affairs of the Socialist Republic of Viet Nam on the Chinese Authorities' Intensified Armed Activities on the Viet Nam Border and their Frantic War Preparations against Viet Nam.” (February 16, 1979).

United Nations Archives and Records Management Section. "Message from the Deputy Prime Minister and Minister of Foreign Affairs of Viet Nam addressed to the SecretaryGeneral." (February 10, 1979).

United Nations Archives and Records Management Section. "Note of the Foreign Ministry of the Socialist Republic of Viet Nam Sent to the Chinese Embassy in Ha Noi on the Viet Nam - China Railway Service.” (January 25, 1979).

United Nations Archives and Records Management Section. "Speech made by Pham Van Dong." (September 5, 1978). 
United Nations Archives and Records Management Section. "Statement by Vietnamese Chief Delegate Hoang Bich Son at the 8th Meeting in the Negotiations between the Socialist Republic of Viet Nam and the People's Republic of China." (October 09, 1978).

United Nations Archives and Records Management. "Letter, Chen Chu to Ambassador A.Y. Bishara." (February 15, 1979).

United Nations Disengagement Observer Force (1974) "Map of the Area of Separation (AOS)." UNDOF, http://www.undof.unmissions.org/Default.aspx?tabid=9229\&language=enUS, retrieved on 04/05/2013. abbr.: United Nations 1974.

United Nations Reports of International Arbitral Awards, Boundary dispute between Argentina and Chile concerning the frontier line between boundary post 62 and Mount Fitzroy (1994), XXII.

United States Department of Defense. Memorandum for the President: Defoliant Operations in Viet Nam. By Roswell Gilpatric. November 21, 1961.

United States Information Agency. Memorandum for Mr. McGeorge Bundy: Defoliation. By Edward R. Murrow. August 16, 1962.

United States Joint Chiefs of Staff. Preparation of Department of Defense Views Regarding Negotiations on Indochina for the Forthcoming Geneva Conference. March 12, 1954.

United States National Security Council. Memorandum for the Secretary of Defense. By Bromley Smith. February 5, 1962.

United States Secretary of State. Memorandum for the President: Defoliant Operations in Viet-Nam. By Dean Rusk. November 21, 1961.

United States White House. National Security Action Memorandum No. 343. By Lyndon Johnson. March 28, 1966.

http://www.lbjlib.utexas.edu/johnson/archives.hom/NSAMs/nsam343.asp

US Central Intelligence Agency, Falkland Islands Situation Report \#1.

US National Security Council. NSC 124/2: United States Objectives and Courses of Action with Respect to Southeast Asia. June 25, 1952.

US National Security Council. NSC 5405: United States Objectives and Courses of Action with Respect to Southeast Asia. January 16, 1954.

US National Security Council. Report by the National Security Council on the Position of the United States with Respect to Indochina. February 27, 1950.

van der Bijl, Nick. Nine Battles to Stanley. London: Leo Cooper, 1999.

Vasquez, John A. The war puzzle revisited. Vol. 110. Cambridge University Press, 2009. 
Vietnam Helicopter Pilots Association, "Operation Hop Tac Information," October 3, 2015. https://www.vhpa.org/KIA/panel/battle/64090100.HTM

Vogel, Ezra F. Deng Xiaoping and the Transformation of China. Cambridge, MA: Belknap Press, 2011.

Voll, John Obert. Islam: Continuity and change in the modern world. Syracuse University Press, 1994.

Walt, Stephen M. "Alliance formation and the balance of world power." International security (1985): 3-43. 176-89.

Walt, Stephen M. "Building Up New Bogeymen,” Foreign Policy 106 (Spring 1997):

Waltz, Kenneth. Theory of International Politics. Reading, MA: Addison-Wesley, 1979.

Wang, Ted trans. 2009. "Main Experiences Gained by the XX Army During the Counterattack in Self-Defense Against Vietnam, Part 2." Chinese Law and Government. 42, no. 5 (September-October 2009).

Watson, Bruce W. and Peter M. Dunn. Military Lessons of the Falkland Islands War. Boulder: Westview Press, 1984.

Weart, Spencer R. Never at war: Why democracies will not fight one another. Yale University Press, 1998. 1999.

Wendt, Alexander. Social theory of international politics. Cambridge University Press,

Wiesner, Louis A. Victims and survivors: displaced persons and other war victims in Viet-Nam, 1954-1975. Vol. 14. Greenwood Pub Group, 1988.

Womack, Brantly. China and Vietnam: The Politics of Asymmetry. New York: Cambridge University Press, 2006.

Woodward, Sandy, and Patrick Robinson. One hundred days: the memoirs of the Falklands Battle Group Commander. Naval Institute Press, 1997.

Worldology, LLC. "Iran-Iraq War (1980-1988)."

http://www.worldology.com/Iraq/iran_iraq_war.htm (accessed August 8, 2017).

Wynia, Gary W. Argentina: Illusions and Realities. New York: Holmes \& Meier, 1986.

Young, Marilyn. Vietnam Wars 1945-90. Harper Collins, 1991.

Young, Stephen B. "Unpopular Socialism in United Vietnam.” Orbis 21, no. 2 (Summer 1977): 227-239. 
Yuansheng, Luo. Baizhan jiangxing Wang Shangrong (The Biography of General Wang Shangrong). Beijing: PLA Art Press, 1999.

Zasloff, Joseph J. "Rural Resettlement in South Viet Nam: The Agroville Program." Pacific Affairs 35, no. 4 (1962): 327-340.

Zedong Mao. Selected Military Writings of Mao Tse-tung. Beijing: Foreign Languages Press, 1972.

Zedong, Mao. "Interview with the British Journalist James Bertram." in Selected Works of Mao Tse-tung, Vol. 2. Beijing: Foreign Languages Press, 1975.

Zhai, Qiang. China and The Vietnam Wars, 1950-1975. Chapel Hill, NC: The University of North Carolina Press, 2000.

Zhang, Xiaoming. "China's 1979 war with Vietnam: a reassessment." The China Quarterly 184 (2005): 851-874.

Zhang, Xiaoming. "Deng Xiaoping and China's Decision to go to War with Vietnam." Journal of Cold War Studies 12, no. 3 (Summer 2010): 3-29. 


\section{Appendix 1: Global Deaths in Conflicts since 1400}

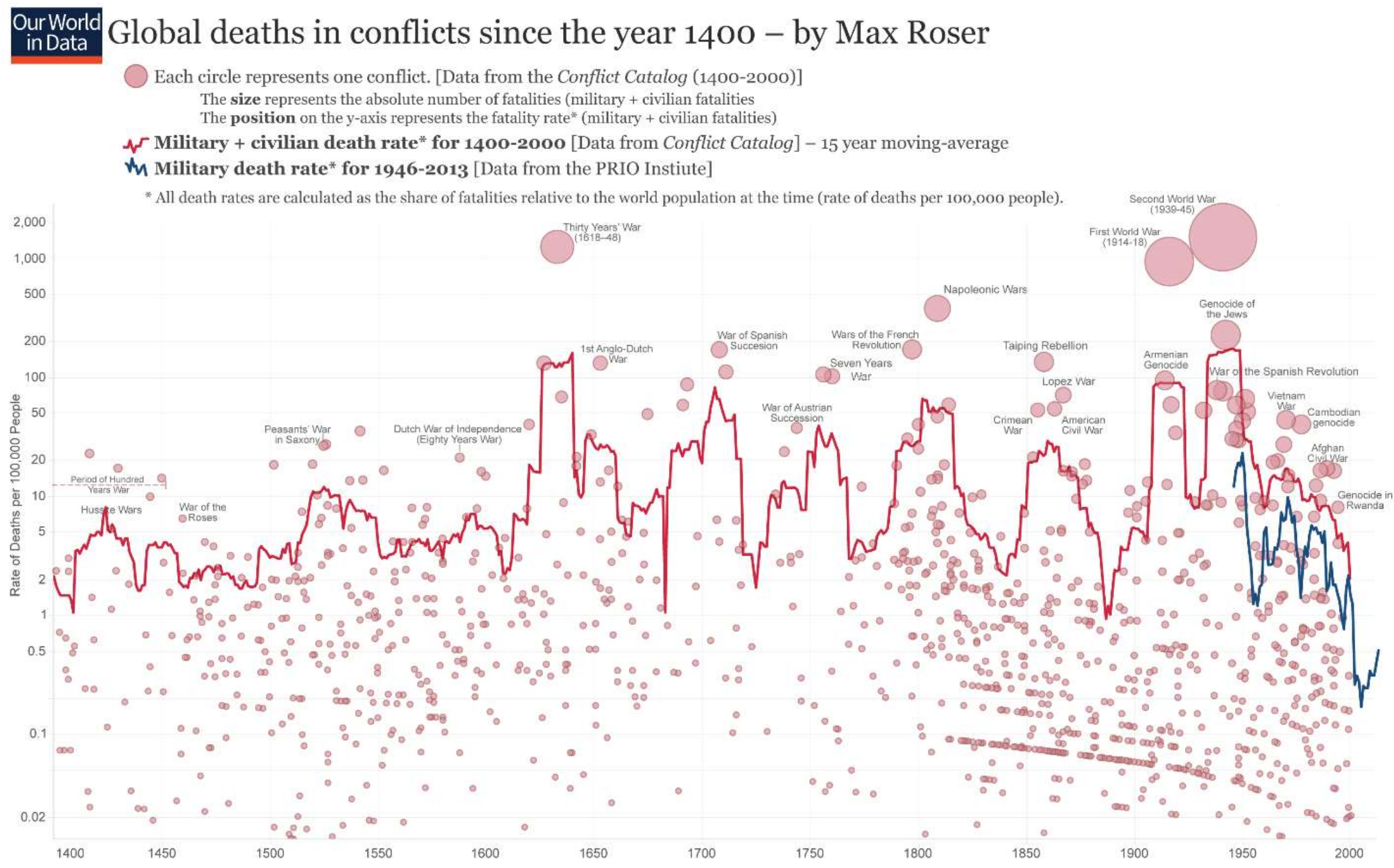

Data sources: Battle Deaths Dataset v.3.0. published by the PRIO Institute and Conflict Catalog by Peter Brecke for data on battle deaths. And world population data from HYDE and UN.

This is a data visualisation from OurWorldinData.org. There you find more visualisations on this topic.

Licensed under CC-BY-NC-SA by the author Max Roser 


\section{Appendix 2: VSM 2013 Survey}

Please think of an ideal job, disregarding your present job, if you have one. In choosing an ideal job, how important would it be to you to ... (please circle one answer in each line across):

$1=$ of utmost importance

$2=$ very important

$3=$ of moderate importance

$4=$ of little importance

$5=$ of very little or no importance

01. have sufficient time for your personal or home life

\section{$\begin{array}{lllll}1 & 2 & 3 & 4 & 5\end{array}$}

02. have a boss (direct superior) you can respect

$\begin{array}{lllll}1 & 2 & 3 & 4 & 5\end{array}$

03. get recognition for good performance

$\begin{array}{lllll}1 & 2 & 3 & 4 & 5\end{array}$

04. have security of employment

\section{$\begin{array}{lllll}1 & 2 & 3 & 4 & 5\end{array}$}

05. have pleasant people to work with

\section{$\begin{array}{lllll}1 & 2 & 3 & 4 & 5\end{array}$}

06. do work that is interesting

$$
\begin{array}{lllll}
1 & 2 & 3 & 4 & 5
\end{array}
$$

07. be consulted by your boss in decisions involving your work

\section{$\begin{array}{lllll}1 & 2 & 3 & 4 & 5\end{array}$}

08. live in a desirable area

\section{$\begin{array}{lllll}1 & 2 & 3 & 4 & 5\end{array}$}

09. have a job respected by your family and friends

$\begin{array}{lllll}1 & 2 & 3 & 4 & 5\end{array}$


10. have chances for promotion

$\begin{array}{lllll}1 & 2 & 3 & 4 & 5\end{array}$

In your private life, how important is each of the following to you: (please circle one answer in each line across):

11. keeping time free for fun

$\begin{array}{lllll}1 & 2 & 3 & 4 & 5\end{array}$

12. moderation: having few desires

$\begin{array}{lllll}1 & 2 & 3 & 4 & 5\end{array}$

13. doing a service to a friend

$\begin{array}{lllll}1 & 2 & 3 & 4 & 5\end{array}$

14. thrift (not spending more than needed)

$\begin{array}{lllll}1 & 2 & 3 & 4 & 5\end{array}$

15. How often do you feel nervous or tense?

1 always 2 usually 3 sometimes 4 seldom 5 never

16. Are you a happy person?

1 always 2 usually $\quad 3$ sometimes $\quad 4$ seldom 5 never

17. Do other people or circumstances ever prevent you from doing what you really want to?

1 yes, always 2 yes, usually 3 sometimes 4 no, seldom 5 no, never

18. All in all, how would you describe your state of health these days?

1. very good $\quad$ 2. good $\quad 3$. fair $\quad 4$. poor $\quad$ 5ery poor

19. How proud are you to be a citizen of your country?
1. very proud
2. fairly proud
3. somewhat proud
4. not very proud 5 . not proud at all

20. How often, in your experience, are subordinates afraid to contradict their boss (or students their teacher?)
1. never
2. seldom
3. sometimes
4. usually
5. always 
To what extent do you agree or disagree with each of the following statements? (please circle one answer in each line across):

$1=$ strongly agree

$2=$ agree

$3=$ undecided

$4=$ disagree

$5=$ strongly disagree

21. One can be a good manager without having a precise answer to every question that a subordinate may raise about his or her work

\section{$\begin{array}{lllll}1 & 2 & 3 & 4 & 5\end{array}$}

22. Persistent efforts are the surest way to results

$\begin{array}{lllll}1 & 2 & 3 & 4 & 5\end{array}$

23. An organization structure in which certain subordinates have two bosses should be avoided at all cost

\section{$\begin{array}{lllll}1 & 2 & 3 & 4 & 5\end{array}$}

24. A company's or organization's rules should not be broken not even when the employee thinks breaking the rule would be in the organization's best interest

\section{$\begin{array}{lllll}1 & 2 & 3 & 4 & 5\end{array}$}

Some information about yourself (for statistical purposes):

25. Are you:

1. male 2. female

26. How old are you?
1. Under 20
2. $20-24$
3. $25-29$
4. $30-34$
5. $35-39$
6. 40-49 7. 50-59
8. 60 or over

27. How many years of formal school education (or their equivalent) did you complete (starting with primary school)?
1. 10 years or less
2. 11 years
3. 12 years
4. 13 years
5. 14 years 

6. 15 years
7. 16 years
8. 17 years
9. 18 years or over

28. If you have or have had a paid job, what kind of job is it / was it?

1. No paid job (includes full-time students)

2. Unskilled or semi-skilled manual worker

3. Generally trained office worker or secretary

4. Vocationally trained craftsperson, technician, IT-specialist, nurse, artist or equivalent

5. Academically trained professional or equivalent (but not a manager of people)

6. Manager of one or more subordinates (non-managers)

7. Manager of one or more managers

29. What is your nationality?

30. What was your nationality at birth (if different)?

Thank you very much for your cooperation! 